\title{
Investigation of Protein-protein Interactions within the Human Spliceosomal U4/U6.U5 tri-snRNP Particle
}

\author{
Dissertation \\ zur Erlangung des Doktorgrades \\ der Mathematisch-Naturwissenschaftlichen Fakultäten \\ der Georg-August-Universität zu Göttingen
}

vorgelegt von

Sunbin Liu

aus Fujian, V.R. China

Göttingen 2005 
D7

Referent: Prof. Dr. Ralf Ficner

Korreferent: Prof. Dr. Hans-Joachim Fritz

Tag der mündlichen Prüfung: 28. April 2005 
In the beginning God created the heavens and the earth.

[Genesis 1:1] 


\section{CONTENTS}

\section{Summary}

2.1 Pre-mRNA Splicing 4

2.2 The Chemistry of the Splicing Reaction 4

2.2.1 The two-step splicing reactions 4

2.2.2 The consensus sequence of the introns 5

2.3 The Splicing Machinery 6

2.3.1 The spliceosome 6

2.3.2 Spliceosomal snRNAs $\quad 7$

2.3.3 The spliceosomal snRNP proteins 9

2.3.3.1 The common proteins 9

2.3.3.2 The snRNP-specific proteins 11

2.3.4 U4/U6.U5 tri-snRNP proteins and retinitis pigmentosa 16

2.4 The Dynamic Nature of the Spliceosome 17

$\begin{array}{ll}\text { 2.4.1 The spliceosome cycle } & 17\end{array}$

2.4.2 Dynamics of RNA-RNA interactions in the spliceosome 18

2.4.3 Dynamic changes of protein components of U4/U6.U5 tri-snRNP during the spliceosome cycle 20

2.4.4 The roles of tri-snRNP proteins in the activation of spliceosome 21 


\section{Materials and Methods}

3.1 Materials 27

3.1.1 Chemicals $\quad 27$

3.1.2 Media 28

3.1.3 Nucleotides, radionucleotides and amino acids 28

3.1.4 Antibodies 28

3.1.5 Enzymes and inhibitors $\quad 28$

3.1.6 Oligonucleotide primers for PCR 29

3.1.7 Vectors and plasmids $\quad 32$

3.1.8 Bacterial strains $\quad 37$

3.1.9 Yeast strains

3.1.10 Reaction sets (Kits) 37

3.1.11 Equipments $\quad 37$

3.1.12 Special materials 38

$\begin{array}{ll}3.2 \text { Methods } & 39\end{array}$

3.2.1 Molecular Cloning $\quad 39$

3.2.1.1 PCR amplification $\quad 39$

3.2.1.2 Agarose gel electrophoresis and DNA fragment isolation 40

3.2.1.3 Enzyme digestion and ligation $\quad 41$

3.2.1.4 Bacterial transformation $\quad 41$

3.2.1.4.1 Transformation of $E$. coli cells by electroporation 41

3.2.1.4.2 Transformation of E. coli cells by heat shock 42

3.2.1.5 Mini-preparation of plasmid DNA 43

3.2.1.6 DNA sequencing 43

3.2.1.7 PCR-based site directed mutagenesis $\quad 44$

3.2.1.8 cDNA cloning from library $\quad 45$

3.2.1.9 Plasmid construction for two-hybrid analysis $\quad 47$

3.2.2 Yeast Two-hybrid System $\quad \mathbf{4 8}$

3.2.2.1 Yeast two-hybrid analysis of known proteins for interaction studies $\quad 50$

3.2.2.2 Colony-lift filter assay 50 
3.2.2.3 Chemiluminescence $\beta$-galactosidase assay 51

3.2.2.4 X- $\alpha$-Gal assay 52

3.2.2.5 LiAc-mediated yeast co-transformation 52

3.2.2.6 Yeast two-hybrid screen with the N-terminal region of U5-200K 53

3.2.2.7 Quick preparation of plasmid DNA from yeast 54

3.2.2.8 Preparation of yeast protein extract 55

3.2.2.9 Western blotting $\quad 56$

3.2.3 In vitro Biochemical Methods

3.2.3.1 Transcription and translation in vitro $\quad 57$

3.2.3.2 GST-102K pull-down assays $\quad 58$

3.2.3.3 GST-61K pull-down assays $\quad 59$

3.2.3.4 His pull-down assays $\quad 59$

3.2.3.5 Co-immunoprecipitations $\quad 59$

\section{Results $\quad 62$}

4.1 cDNA cloning $\quad 62$

4.2 Protein-protein interactions within U4/U6-snRNP particle $\quad 68$

4.2.1 The interactions of proteins in the $20 \mathrm{~K} \cdot 60 \mathrm{~K} \cdot 90 \mathrm{~K}$

RNA-free heterotrimer 68

4.3 Protein-protein interactions within the U5-snRNP particle 72

4.3.1 Interactions between U5 snRNP proteins in the RNA-free

$220 \mathrm{~K} \cdot 200 \mathrm{~K} \cdot 116 \mathrm{~K} \cdot 40 \mathrm{~K}$ heterotetramer 72

4.3.1.1 Overexpression of the protein fragments from 220K and 200K $\quad 76$

4.3.2 Multiple interactions of $102 \mathrm{~K}$ with other U5 snRNP proteins within the tri-snRNP particle $\quad 77$

4.4 Protein-protein interactions between U4/U6 and U5 snRNP particles $\quad \mathbf{8 0}$

4.4.1 U5-102K binds specifically to U4/U6-61K in the yeast two-hybrid system and in vitro 
4.4.2 U5-102K binds specifically to the C-terminal region of U4/U6-90K in the in vitro binding assay

4.5 The interactions of the tri-snRNP-specific protein $110 \mathrm{~K}$

4.6 The interaction domains of U5-102K protein

4.7 Specific binding of the U5-52K protein to the U5 snRNP $102 \mathrm{~K}$ and $15 \mathrm{~K}$ proteins

4.7.1 Overexpression of U5-52K proteins and X-ray crystallography study of 52K GYF domain in complex with U5-15K protein

4.8 The interaction of the U4/U6-90K with U6-p110

4.9 The $\mathrm{N}$-terminal region of the $\mathrm{U} 4 / \mathrm{U} 6-90 \mathrm{~K}$ is required for binding of U2-associated protein SPF30/SMNrp

4.10 Analysis of point mutations related to the retinitis pigmentosa

4.10.1 Analysis of U4/U6-61K mutations identified in retinitis pigmentosa

4.10.2 Analysis of U4/U6-90K mutations identified in retinitis pigmentosa 100

4.10.3 Analysis of U5-220K mutations found in retinitis pigmentosa

4.11 Yeast two-hybrid screen with the $\mathrm{N}$-terminal 434 amino acids of protein U5-200K

\section{Discussion}

5.1 Protein associations within the U4/U6-snRNP particle

5.2 Protein associations within the U5-snRNP particle

5.2.1 Interactions of the RNA-free $220 \mathrm{~K} \cdot 200 \mathrm{~K} \cdot 116 \mathrm{~K} \cdot 40 \mathrm{~K}$ heterotetramer

5.2.2 Poly-TPR protein $102 \mathrm{~K}$ is stably bound to U5-snRNP particle via multiple protein-protein interactions

5.2.3 The U5-52K protein interacts with the U5-specific proteins $102 \mathrm{~K}$ and $15 \mathrm{~K}$, but dissociates upon tri-snRNP formation 
5.3 The interaction between U5-102K and U4/U6-61K is critical for the formation of U4/U6.U5 tri-snRNP

5.4 The recruitment of tri-snRNP to the pre-spliceosome

5.4.1 The C-terminal region of tri-snRNP-110K is required for anchoring protein $110 \mathrm{~K}$ to the tri-snRNP while the $\mathrm{N}$-terminal RS domain potentially mediates the association with the pre-spliceosome

5.4.2 The N-terminal region of U4/U6-90K is essential for the binding of U2-SPF30/SMNrp required for the formation of the mature spliceosome

5.5 The link between the C-terminal region of U4/U6-90K and the TPR domain of U6-p110 is necessary for the recycling of U4/U6 snRNPs

5.6 The role of tri-snRNP splicing factors in retinitis pigmentosa 


\section{Summary}

The removal of introns from nuclear pre-messenger RNA (pre-mRNA) is catalysed by the spliceosome. One of the major building blocks of the human spliceosome is the 25S U4/U6.U5 tri-snRNP. The purified tri-snRNP from HeLa cells contains in addition to the U4, U5 and U6 snRNAs at least 29 distinct proteins. One set of seven Sm proteins is associated with both U4 and U5 snRNAs, while one set of LSm 2-8 proteins is bound to the 3' end of U6 snRNA. Proteins $15.5 \mathrm{~K}, 20 \mathrm{~K}, 60 \mathrm{~K}, 61 \mathrm{~K}$, and $90 \mathrm{~K}$ interact specifically with the U4/U6 snRNPs. U5 snRNA, in contrast, is associated with the $220 \mathrm{~K}, 200 \mathrm{~K}, 116 \mathrm{~K}$, $102 \mathrm{~K}, 100 \mathrm{~K}, 40 \mathrm{~K}$, and $15 \mathrm{~K}$ U5-specific proteins. Three proteins, namely $110 \mathrm{~K}$, $65 \mathrm{~K}$, and $27 \mathrm{~K}$, more stably associated with the tri-snRNP than with free U4/U6or U5-particle, represent the tri-snRNP specific group.

The tri-snRNP particle has to be assembled from U4, U6 and U5 snRNPs prior to association with the pre-spliceosome. First, U4 and U6 snRNPs interact through extensive base-pairing of their respective snRNAs to form the U4/U6 snRNPs. Subsequently, the U4/U6 snRNPs interacts with U5 snRNP to form the U4/U6.U5 tri-snRNP. The recruitment of tri-snRNP to the pre-spliceosome initiates the activation of the spliceosome, which undergoes a series of rearrangements to form the catalytic core. The proteins of the tri-snRNP play a central part in the tri-snRNP assembly and the activation of the spliceosome, and thus in the splicing of pre-mRNA. In this work, yeast two-hybrid techniques and in vitro binding assays were established to investigate the protein-protein interactions in these particles.

Two-hybrid data allowed me to define the regions through which proteins $220 \mathrm{~K}$, $200 \mathrm{~K}$, and $116 \mathrm{~K}$ interact with each other. These regions include the $\mathrm{N}$-terminal and C-terminal domains of protein $220 \mathrm{~K}$, the second helicase domain of $200 \mathrm{~K}$, and the C-terminal domain of $116 \mathrm{~K}$. Strikingly, most of the binding domains are also identified in the interactions of the yeast orthologue proteins Prp8p, Brr2p, and Snu114p. 
Protein $102 \mathrm{~K}$ interacts with several particle-specific proteins of both the U5 and the U4/U6 snRNP, and thus very probably acts as a bridging or scaffolding protein in the formation or structural stabilisation of the tri-snRNP. The interactions with $\mathrm{U} 5-220 \mathrm{~K}, 200 \mathrm{~K}$ and $116 \mathrm{~K}$ allow the $102 \mathrm{~K}$ protein to bind stably to the U5-snRNP particle. The $102 \mathrm{~K}$ protein is the only U5-specific protein identified in this work that interacts with U4/U6-specific proteins $61 \mathrm{~K}$ and $90 \mathrm{~K}$. The former interaction has been proved to be critical for the formation of the trisnRNP. One of the missense mutations (A194E) in the $61 \mathrm{~K}$ protein responsible for the disorder retinitis pigmentosa has been shown a reduced interaction with the $102 \mathrm{~K}$ in this study. The possible mechanisms of this are discussed. Mutational analysis showed that the TPR repeats of $102 \mathrm{~K}$ protein are each dedicated to the interactions with specific partners. All repeats participate in the interaction with the U4/U6-61K, whereas only the first nine repeats interact with $110 \mathrm{~K}, 200-4$ fragment of $200 \mathrm{~K}$, and the $220-1$ fragment of $220 \mathrm{~K}$.

The U4/U6-90K protein interacts with $60 \mathrm{~K}$ within the $20 \mathrm{~K} \cdot 60 \mathrm{~K} \cdot 90 \mathrm{~K}$ heterotrimer and contacts the U6 snRNA in the stem II region in the U4/U6-snRNP particle. In this study, it was shown that this protein interacts with human recycling factor U6-p110 and thus functions in the recycling of U4/U6 snRNPs. Mutational analysis showed that the C-terminal domain of $90 \mathrm{~K}$, comprising amino acids 417-683, is responsible for this binding. During the formation of tri-snRNP, the U5-102K protein interacts with $90 \mathrm{~K}$ protein in the same domain, suggesting that U5-102K might function in the release of U6-p110. Protein 90K also interacts with U2-associated protein SPF30/SMNrp through its $\mathrm{N}$-terminal region, and therefore functions in the recruitment of tri-snRNP into pre-spliceosome.

The tri-snRNP-specific $110 \mathrm{~K}$ protein interacts with U4/U6-90K, U5-102K and U5-200K through the C-terminal region lacking an RS domain. Since the absence of $110 \mathrm{~K}$ protein does not compromise the stability of the tri-snRNP, it appears reasonable that anchoring $110 \mathrm{~K}$ to these proteins may be required to properly position $110 \mathrm{~K}$ for its contribution in connecting the tri-snRNP to the prespliceosome. 
The U5-52K protein interacts with the U5-102K and $15 \mathrm{~K}$ proteins, suggesting that these interactions contribute to its integration into the U5 particle. Binding studies performed with $52 \mathrm{~K}$ deletion mutants revealed that the $\mathrm{N}$-terminal twothirds of $52 \mathrm{~K}$ interact with the $102 \mathrm{~K}$ protein, whereas its C-terminal GYF-domain binds the $15 \mathrm{~K}$ protein. The GYF domain has been characterised previously as a polyproline-targeting molecule. As the $15 \mathrm{~K}$ protein lacks a proline-rich tract, these data indicate for the first time that a GYF-domain can also engage in specific protein-protein interactions in a polyproline-independent manner. The crystallography study of the $52 \mathrm{~K}$ GYF domain in complex with $15 \mathrm{~K}$, a cooperative work with the laboratory of Prof. R. Ficner at the University of Göttingen, showed that the $15 \mathrm{~K}$ protein makes contact with the distinctive surface of GYF domain, as does the proline-rich target. The data from this study and others demonstrated that the $52 \mathrm{~K}$ protein is the only $20 \mathrm{~S}$ U5-specific protein that is not integrated into the tri-snRNP.

On the basis of the data obtained in this work, I propose a model of the assembly of the U4/U6.U5 tri-snRNP. 


\section{Introduction}

\subsection{Pre-mRNA Splicing}

Eukaryotic pre-mRNAs must undergo several posttranscriptional modifications before their export to the cytoplasm as functional mRNAs. Most pre-mRNAs contain intervening sequences (introns) that must be removed in order to place the coding sequences (exons) in a protein-reading frame. The mechanism of this critical processing event, known as pre-mRNA splicing, has been extensively studied (reviewed in Brow, 2002). It has long been known that intron removal and the ligation of exons occurs through two sequential transesterification reactions that are carried out by a multicomponent complex that is known as the spliceosome. Most introns have common consensus sequences near their $5^{\prime}$ and $3^{\prime}$ ends that are recognized by spliceosomal components and are required for spliceosome formation. The assembly of a spliceosome onto a pre-mRNA is an ordered process that involves five small nuclear ribonucleoprotein particles (snRNPs; U1, U2, U4, U5 and U6), as well as a large number of non-snRNP proteins. The spliceosome acts through a multitude of RNA-RNA, RNA-protein and protein-protein interactions to precisely excise each intron and join the exons in the correct order. However, the regulation of splicing is still not well understood, particularly in the context of the structure of the spliceosome.

\subsection{The Chemistry of the Splicing Reaction}

\subsubsection{The two-step splicing reactions}

Splicing comprises two transesterification reactions (figure 2.1; Ruby and Abelson, 1991; Sharp et al., 1987). In the first step, the phosphodiester bond at the 5' splice site (SS) is cleaved by a nucleophilic attack by the 2'-hydroxyl group of the conserved adenosine (A) located at the intron branch point. This generates a 2'-5' phosphodiester bond between the branch site and the 5' end of the intron as well as a free 3' hydroxyl group on the 5' exon. The cleavage also results in two RNA molecules, i.e., a free exon 1 and a "lariat" intron-exon 2. In the second step, the free 3' hydroxyl on the end of the 5' exon attacks the 
phosphodiester bond at the 3 ' splice site, resulting in the joining of the exons and release of the lariat intron. The basic chemistry of pre-mRNA splicing is similar to that of the group II introns, also called self-splicing introns, that are found in organelles. This group of introns catalyze their own removal and require no protein cofactors (Cech, 1990a, b; Michel and Jacquier, 1987). In contrast to these self-splicing introns, nuclear pre-mRNA splicing requires an input of energy and protein cofactors that are organized into a large ribonucleoprotein particle called the spliceosome.

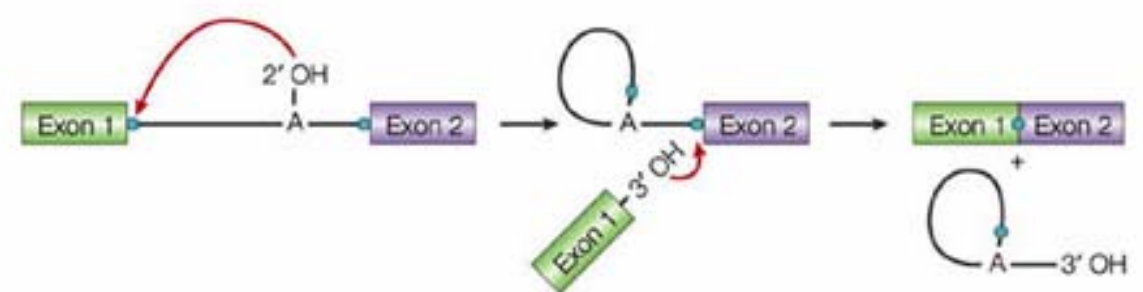

Figure 2.1. Pre-mRNA splicing occurs by two sequential transesterification reactions. A schematic pre-messenger RNA is shown on the left as a single intron (solid line) flanked by two exons. The first and second steps of splicing involve nucleophilic attacks (red arrows) on the terminal phosphodiester bonds (blue dots) by the 2' hydroxyl of the branch-point adenosine (A) and by the 3' hydroxyl of the upstream exon, respectively. The ligated exons and the lariat intron products are shown on the right (from Patel and Steitz, 2003).

\subsubsection{The consensus sequence of the introns}

Intron removal occurs in a process called nuclear pre-mRNA splicing after the gene has been transcribed. Conserved sequence elements within the primary RNA transcript provide the signals required for precise intron removal. These sequences include 5' and '3' splice sites (SS), a branch point sequence containing a strictly conserved adenosine residue, and a stretch of pyrimidines that is located between the branch point and the 3' splice site (figure 2.2).

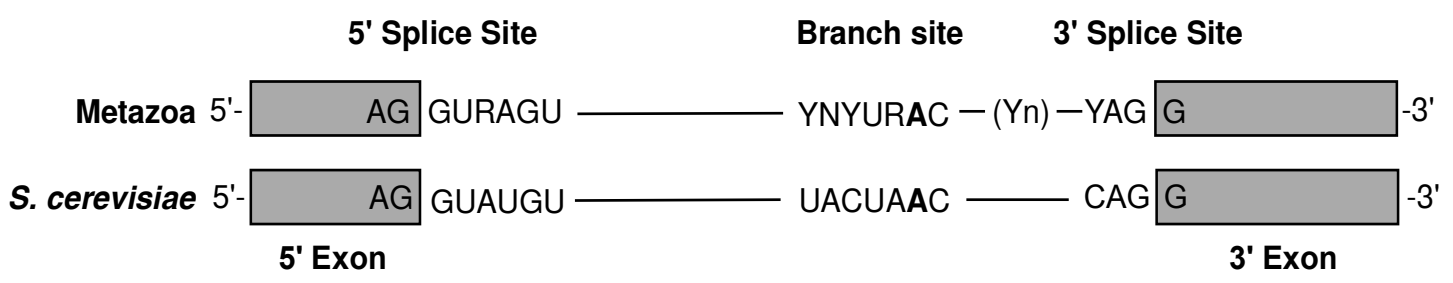

Figure 2.2. Conserved sequences of the introns in a typical metazoan or yeast premRNA. The intron consensus sequences direct spliceosome assembly and define the splice sites and branch site ( $\mathrm{Y}$ denotes pyrimidine; $\mathrm{R}$ denotes purine). 
Interestingly, although the conserved sequence at the 5' and 3' splice sites and branch point are similar in all organisms, these signals are much more conserved in the yeast Saccharomyces cerevisiae than in mammals. The 5' SS sequence signal in yeast is almost always GUAUGU while in humans only the first two positions (i.e., GU) are very highly conserved. Similarly, the branch point sequence found in yeast introns is almost always UACUAAC, but the sequence is very degenerate in mammalian introns. In both yeast and mammals, the 3' SS signal is rather short, consisting of a pyrimidine ( $U$ or $C$ ) followed by AG. The differences in signal sequence conservation probably reflect the relative complexity of the systems. As a simple, single-celled eukaryote, yeast has few introns and no alternative splicing. Their introns can therefore have very strong, clear-cut signals. Higher organisms that utilize alternative splicing, however, have a number of weaker signals that allow a choice between their usages under various conditions.

\subsection{The Splicing Machinery}

\subsubsection{The spliceosome}

Splicing is accomplished in a complex cellular machine called the spliceosome, which co-ordinates the removal of introns from pre-mRNAs. Since the discovery that a large complex was responsible for splicing, the list of spliceosome components has grown to include five small nuclear RNAs (snRNAs) and more than 180 proteins (Burge et al., 1999; Brow, 2002; Jurica and Moore, 2003). Each of the five snRNAs (U1, U2, U4, U5 and U6) is found in a complex with a number of proteins to form small nuclear ribonucleoprotein particles or snRNPs. Non-snRNP proteins are also required for splicing and are likely to interact with other splicing components only transiently. One particular class of proteins found in metazoans that are not present in yeast is the SR family of proteins. All SR proteins have a similar bipartite structure composed of two functional domains: an N-terminal RNA binding domain, comprising multiple RNArecognition-motifs (RRMs), and a C-terminal arginine-serine-rich (RS) domain. Whereas the RRMs are sufficient for sequence-specific RNA binding, the RS domain is required for enhancement of splicing activities. 
Until now, two distinct spliceosomes have been identified (reviewed by Padgett et al., 2002). The large majority of introns are called U2-dependent introns and are spliced by the major spliceosomal snRNPs U1, U2, U4, U5 and U6. Interestingly, a minor class of introns have been identified in some more advanced organisms including Arabadopsis, Drosophila, Xenopus, mice and humans. This rare class of introns are called U12-dependent and are spliced by a group of less abundant snRNPs including U11, U12, U4atac and U6atac in coordination with the standard U5 snRNP. This class of introns was first identified by their unusual intron termini, which contained an AT-AC sequence instead of the otherwise highly conserved GT-AG sequence (Burge et al., 1999). It was later found that the 5' splice site and branchpoint sequences in this class of introns were complementary to stretches of the U11 and U12 snRNAs, two low-abundance snRNAs with previously unknown function. The involvement of these two snRNAs in splicing was supported by evidence of interactions between U11, U12, and U5 (Hall and Padgett, 1996; Tarn and Steitz, 1996a). Two additional novel snRNA components, U4atac and U6atac, which appear functionally analogous to $U 4$ and $U 6$ in the standard U2-type spliceosome, were also identified (Tarn and Steitz, 1996b).

\subsubsection{Spliceosomal snRNAs}

The major spliceosome contains five snRNAs, U1, U2, U4, U5, and U6, which are packaged as ribonucleoprotein particles (snRNPs). The primary and secondary structure of the snRNAs is shown in figure 2.3. Spliceosomal snRNAs are uridine-rich RNA molecules. These snRNAs associate dynamically with each other and with pre-mRNA substrates in the spliceosome assembly and splicing catalysis. Among the five snRNAs and the snRNP particles they form, U1, U2, U4 and U5 are similar. The U1-U5 snRNAs are transcribed by RNA polymerase II and modified by a unique trimethylguanosine cap structure that is not found in the U6 snRNA. Similarly, only U1, U2, U4, and U5 snRNAs contain a conserved Sm site, a structural domain that allows binding to Sm core proteins, B/B', D1, D2, D3, E, F and G (Branlant et al., 1982; Mattaj et al., 1986). In contrast, U6 snRNA has no Sm site and consequently does not associate with the Sm proteins. Moreover, its biogenesis pathway differs in many respects from that of the other snRNAs, as it is transcribed by RNA polymerase III 
(Dahlberg and Lund, 1991) and capped with y-monomethyl triphosphate (Singh and Reddy, 1989). Finally, U6 does not leave the nucleus during snRNP biogenesis (Vankan et al., 1990; Terns et al., 1993; Boelens et al., 1995).

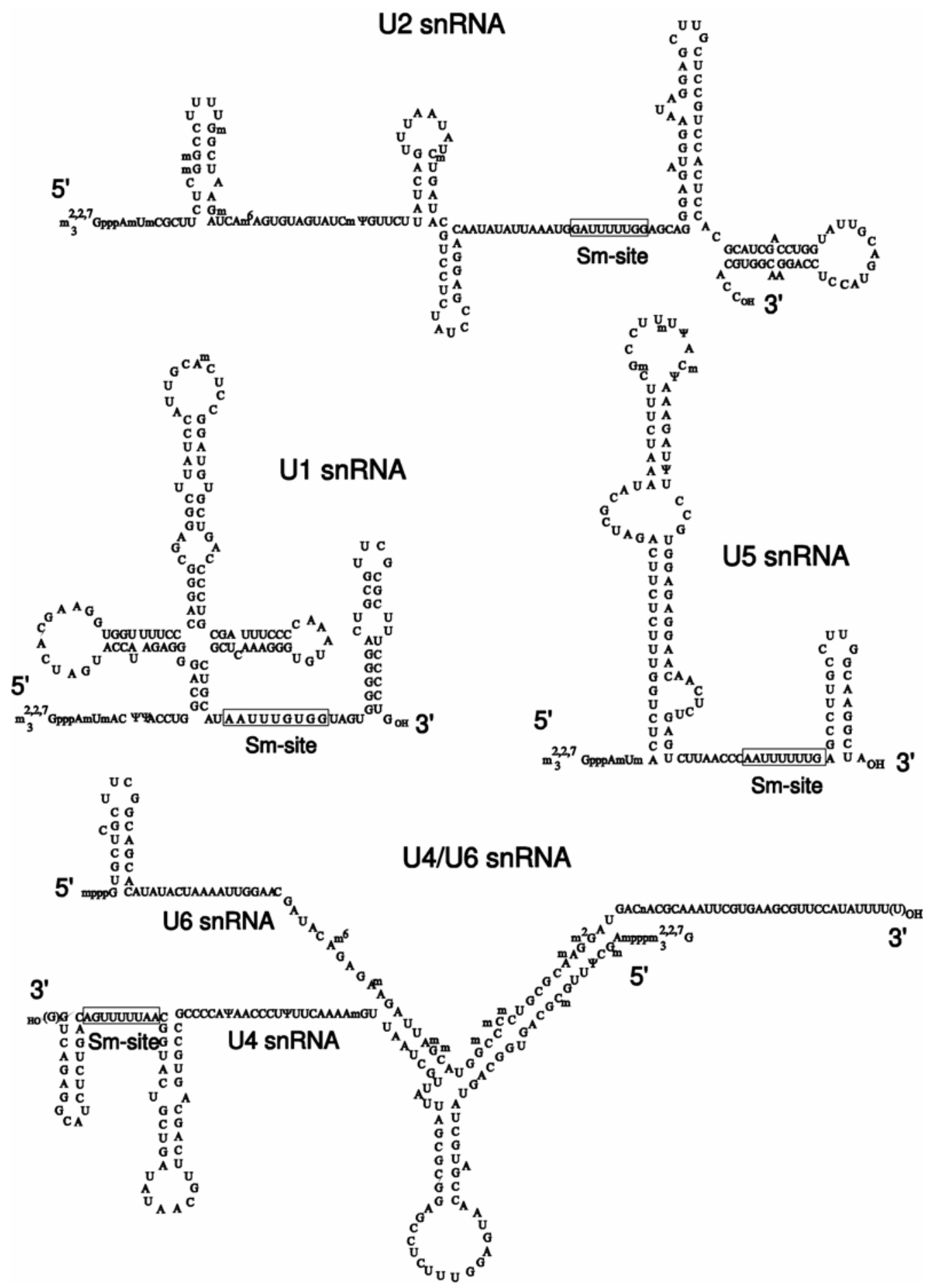

Figure 2.3. The primary and secondary structure of human U snRNAs U1, U2, U4, U5 and U6. The Sm site which binds Sm core proteins is indicated (provided by Dr. C. Will in the laboratory of Prof. Lührmann). 


\subsubsection{The spliceosomal snRNP proteins}

The protein composition of the major spliceosomal snRNPs has been best characterized in HeLa cells and yeast (Saccharomyces cerevisiae) and is summarized in table 2.1. Proteins associated with the U1, U2, U5, and U4/U6 snRNPs fall into two classes. The first class consists of the so-called common or Sm proteins, which are tightly associated with all snRNP particles. The second class is comprised of the particle-specific proteins, which associate with a particular snRNP particle or complex. These proteins exhibit a wide range of binding affinities, and their association with an snRNP particle is thus dependent on the ionic strength of the particle's environment.

\subsubsection{The common proteins}

The U1, U2, U4, and U5 snRNPs contain seven common Sm core proteins. The human Sm proteins were initially identified by their ability to cross-react with antisera from patients with the autoimmune disorder systemic lupus erythematosus and were named B/B', D1, D2, D3, E, F and G based on their relative mobilities during gel electrophoresis (Lerner and Steitz, 1979; van Venrooij, 1987). B and B' are encoded by alternatively spliced transcripts of the same gene. The homologues of the Sm proteins have been identified in Saccharomyces cerevisiae and named after their respective human counterparts. These proteins are known to initiate snRNP assembly in the cytoplasm by associating with the conserved Sm site in the U1, U2, U4, and U5 snRNAs upon their export from the nucleus (Branlant et al., 1982; Mattaj and De Robertis, 1985). The association of the $\mathrm{Sm}$ proteins then allows hypermethylation of the $5^{\prime}-\mathrm{m}^{7} \mathrm{G}$ cap of these snRNAs to convert it to a 2,2,7-trimethylguanosine $\left(\mathrm{m}_{3} \mathrm{G}\right)$ which together with the Sm proteins provides a signal for import into the nucleus (Fischer and Lührmann, 1990; Hamm et al., 1990). After returning to the nucleus, the remainder of the snRNP specific proteins associate with the particle to complete the maturation process (Zieve and Sauterer, 1990). In contrast, U6 snRNP contains seven Sm-like (LSm) proteins, LSm2-8. LSm proteins bind directly to the 3'-end of U6 snRNA. All Sm and LSm proteins share a conserved Sm sequence motif consisting of two segments, $\mathrm{Sm} 1$ and Sm2, interrupted by a spacer region of variable length (Cooper et al., 1995; Hermann et al., 1995; Seraphin, 1995). 


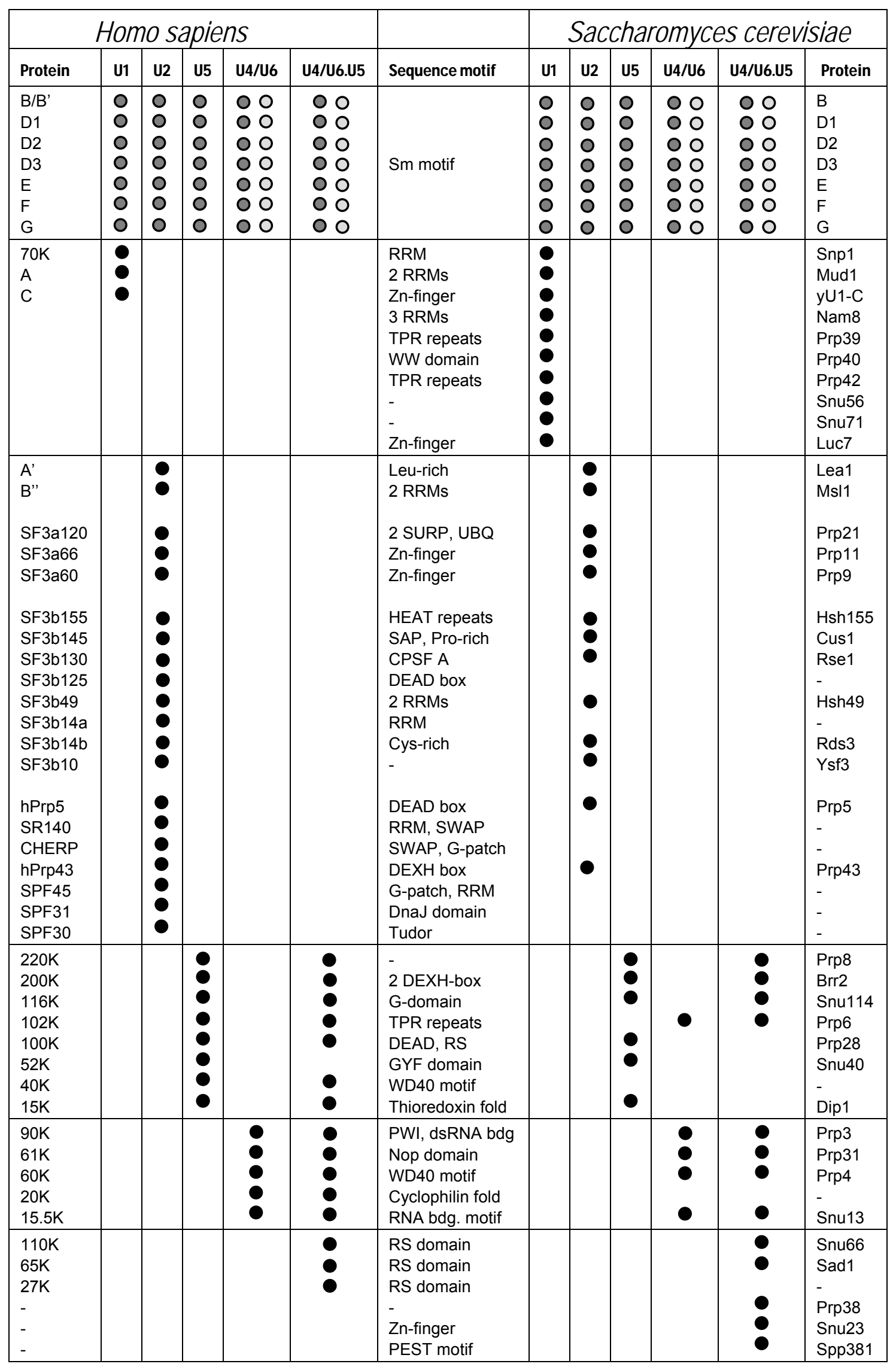

Table 2.1. Protein composition of the U snRNPs in human and yeast. The snRNP proteins consist of the so called common Sm (grey spots) or LSm (light grey spots) proteins, and particle-specific proteins (black spots). 


\subsubsection{The snRNP-specific proteins}

The mammalian 12S U1 snRNP consists of three particle-specific proteins, U1$70 \mathrm{~K}, \mathrm{~A}$ and $\mathrm{C}$, in addition to the common Sm proteins. The two largest proteins, U1-70K and U1-A, bind directly to U1 snRNA stem/loop I and II, respectively (Nagai et al., 1994). The structure of the amino-terminal fragment of U1-A in complex with the loop of stem II has been solved by X-ray crystallography (Oubridge et al., 1994). The smaller U1-C protein is probably attached by protein-protein interactions with Sm proteins and U1-70K protein (Nelissen et al., 1994).

The 17S U2 snRNP is a large particle containing two stably associated proteins: U2-A' and U2-B" (Lea1p and Msl1p/Yib9p in yeast) (Lührmann et al., 1990; Tang et al., 1996; Caspary and Séraphin, 1998), and two multisubunit complexes: SF3a and SF3b (Brosi et al., 1993). SF3a is composed of three polypeptides (SF3a120, SF3a66, SF3a60, in human; Prp21p, Prp11p and Prp9p in yeast; Krämer, 1995), while human SF3b was reported to contain seven proteins (SF3b155, SF3b145, SF3b130, SF3b49, SF3b14a/p14, SF3b14b and SF3b10) (Gozani et al., 1996; Das et al., 1999; Will et al., 2002). Yeast homologues of six of these factors have been characterized (Wells et al., 1996; Igel et al., 1998; Caspary et al., 1999; Wang and Rymond, 2003; Dziembowski et al., 2004). Interestingly, human SF3a acts exclusively during the splicing of major introns (Will et al., 1999), while SF3b is required for splicing of both types of introns by associating with U2 and U12 snRNPs, respectively (Das et al., 1999; Will et al., 1999). Thus, both factors are essential for splicing. Furthermore, many SF3b subunits can be crosslinked to the branchpoint region of the pre-mRNA (Staknis and Reed, 1994; Gozani et al., 1996; Query et al., 1996; McPheeters and Muhlenkamp, 2003). Several additional human $\mathrm{U} 2$ associated proteins including SPF30/SMNrp, hPrp5p and hPrp43p have been identified recently (Meister et al., 2001; Will et al., 2002).

U4 and U6 snRNAs contain extensive complementary sequence and interact to form U4/U6 snRNP. In addition to the seven Sm proteins that bind the Sm site of the U4 snRNA, and the seven LSm proteins that are associated with U6 snRNA, 13S U4/U6 snRNP contains five particle-specific proteins, 90K, 60K, 
$20 \mathrm{~K}, 61 \mathrm{~K}$, and $15.5 \mathrm{~K}$ (the terminology is derived from their apparent molecular weights in electrophoresis; reviewed in Will and Lührmann, 2001). The proteins $20 \mathrm{~K}, 60 \mathrm{~K}$, and $90 \mathrm{~K}$ form a biochemically stable, heteromeric complex (Horowitz et al., 1997; Teigelkamp et al., 1998). Protein $20 \mathrm{~K}$ belongs to the cyclophilin family of peptidyl-prolyl isomerases, termed cyclophilin $\mathrm{H}(\mathrm{CypH})$ or SnuCyp-20 or USA-Cyp (Horowitz et al., 1997; Teigelkamp et al., 1998). The crystal structure of $\mathrm{CypH}$ shows a typical cyclophilin fold (Reidt et al., 2000). Protein $61 \mathrm{~K}$ shares a homologous central domain with the proteins Nop56 and Nop58, which are integral constituents of the box C/D snoRNPs (Gautier et al., 1997; Makarova et al., 2002). The smallest protein $15.5 \mathrm{~K}$ possesses a novel RNAbinding domain and binds directly to U4 snRNA (Nottrott et al., 1999). This is the first U4/U6-specific protein identified as interacting directly with U4 snRNA, and the structure of protein $15.5 \mathrm{~K}$ in complex with the $5^{\prime}$ stem-loop of U4 snRNA has been determined by X-ray crystallography (Vidovic et al., 2000). Moreover, the binding of protein $15.5 \mathrm{~K}$ to the U4 5' stem-loop is required for subsequent interaction of both $61 \mathrm{~K}$ protein and the $20 \mathrm{~K} \cdot 60 \mathrm{~K} \cdot 90 \mathrm{~K}$ protein complex with U4/U6 snRNA duplex (Nottrott et al., 2002). In this respect, protein $15.5 \mathrm{~K}$ functions as a nucleation factor. Interestingly, $15.5 \mathrm{~K}$ protein is also present in box C/D snoRNPs, providing a link between the pre-mRNA and prerRNA processing machineries (Walkins et al., 2000). Except for the 20K protein, orthologous proteins termed Snu13p (15.5K in human), Prp4p (60K), Prp3p (90K) and Prp31p $(61 \mathrm{~K})$ are also associated with the yeast U4/U6 snRNP particle (Banroques and Abelson, 1989; Peterson-Bjørn et al., 1989; Anthony et al., 1997; Weidenhammer et al., 1997; Gottschalk et al., 1999; Stevens and Abelson, 1999). Like their human counterparts, Prp4p and Prp3p interact directly with each other (Wang et al., 1997; Gonzalez-Santos et al., 2002; Ayadi et al., 1998). Genetic and biochemical studies in yeast and HeLa cells have shown that all conserved U4/U6-specific proteins are essential for cell viability and required for pre-mRNA splicing (Lustig et al., 1986; Banroques and Abenlson, 1989; Peterson-Bjørn et al., 1989; Weidenhammer et al., 1997; Nottrott et al., 1999).

After each spliceosome cycle, the U4 and U6 snRNAs are released separately and are recycled to the functional U4/U6 snRNP. The p110 (SART3) protein, 
the homologue of yeast Prp24p, has been identified in the mammalian system which is required for recycling of the U4/U6 snRNP from singular U4 and U6 snRNPs (Bell et al., 2002). Protein p110 associates only transiently with U6 and U4/U6 snRNPs during the recycling phase of the spliceosome cycle.

Interestingly, recent biochemical evidence indicated that these U4/U6 snRNPspecific proteins are also associated with the HeLa U4atac/U6atac snRNP (Schneider et al., 2002).

U5 snRNP possesses a complex protein composition, with a sedimentation coefficient of $20 \mathrm{~S}$ (Bach et al., 1989). In addition to the seven common Sm proteins and the U5 snRNA, 20S U5 snRNP consists of a total of eight particlespecific proteins, referred to as $15 \mathrm{~K}, 40 \mathrm{~K}, 52 \mathrm{~K}, 100 \mathrm{~K}, 102 \mathrm{~K}, 116 \mathrm{~K}, 200 \mathrm{~K}$ and 220K proteins (Bach et al., 1989; reviewed in Will et al., 1993). Of these, all except the $40 \mathrm{~K}$ protein have identifiable homologues in yeast (Stevens et al., 2001). Proteins common to the U5 snRNPs from human and yeast (in parentheses) include 220K (Prp8p), 200K (Brr2p), 116K (Snu114p), 100K (Prp28p), 52K (Snu40p/Lin1p), and 15K (Dib1p). While protein 102K is stably associated with U5 snRNP in human, the yeast homologue Prp6p is present in the U4/U6 snRNP particle (Makarov et al., 2000; Abovich et al., 1990).

Most of the U5-specific proteins display significant domain features, and play central roles in the splicing machinery (reviewed in Will and Lührmann, 1997). For example, protein 200K (Brr2p) and 100K (Prp28p) contain the RNA helicase domain (Lauber et al., 1996; Teigelkamp et al., 1997). Protein 116K (Snu114p) is the sole GTPase identified in the spliceosome to date and is related to translation elongation factor EF-2 (Fabrizio et al., 1997; Stevens et al., 2001; Jurica and Moore, 2003). Protein $220 \mathrm{~K}$ is the most highly conserved splicing factor among species, displaying $62 \%$ identity between the human and yeast proteins throughout the entire amino acid sequence. However, it contains little in the way of recognizable sequence motifs, so that its domain structure is unclear and it is difficult to make testable predictions about the biochemical activities of the protein. The functions of these proteins are discussed in sections 2.4.2 and 2.4.4 in detail. The structural study using X-ray 
crystallography has indicated that the small protein $15 \mathrm{~K}$ adopts a thioredoxin fold, and may thus be involved in the extensive protein-protein interactions in the spliceosome (Reuter et al., 1999). Protein 102K (Prp6p) contains multiple 34-amino-acid TPR motifs. TPR domains provide a structural unit of two antiparallel $\alpha$ helices that assemble to a platform for specific protein-protein interactions (reviewed in Blatch and Lässle, 1999). The $52 \mathrm{~K}$ protein had not been characterised when I started this work.

Although the composition of U5 snRNP is well defined, our knowledge of structural organization of the particle is still limited. Interestingly, several studies attempting to elucidate the protein-snRNA interactions in the U5 snRNP have indicated that the protein-protein interactions may contribute to the formation of U5-snRNP (Bach and Lührmann, 1991; Dix et al., 1998; Black and Pinto, 1989). First, the interaction of the U5-specific proteins with U5 snRNA was investigated by comparison of the differential accessibility towards nuclease and dimethylsulfate of defined regions of U5 snRNA in purified 20 S and 10 S U5 snRNPs (Bach and Lührmann, 1991). The results indicated that only the central part of stem/loop I of U5 snRNA contains binding sites for U5-specific proteins, suggesting that most of the U5-specific proteins may be bound to U5 snRNP via protein-protein interactions. These data support and extend the previous investigation of Black and Pinto, who performed comparative structural probing of naked U5 snRNA and U5 snRNP in HeLa nuclear extracts with chemical reagents. Consistently with this, photo-crosslinking demonstrated that only limiting proteins are in contact with U5 snRNA in the reconstituted yeast U5 snRNP (Dix et al., 1998). Among them, the Prp8p and Snu114p are significant candidates. Some additional data further support the observation that proteinprotein interactions are the main building force in the U5 snRNP. For example, U5 protein $40 \mathrm{~K}$ and three large proteins $116 \mathrm{~K}, 200 \mathrm{~K}$ and $220 \mathrm{~K}$ can form a stable heteromeric complex in the absence of U5 snRNA (Achsel et al., 1998). Co-immunoprecipitation experiments showed that the U5-102K protein does not bind to either U5 snRNA or U5 core snRNP when this contains only U5 snRNA and Sm proteins; instead, it binds stably to the 20 S U5 snRNP. This result suggested that one or more of the U5-specific proteins are required for the association of the protein 102K (Makarov et al., 2000). 
The U4/U6 and U5 snRNPs must be pre-assembled in vivo as a U4/U6.U5 trisnRNP particle in order to join the spliceosome. Within the tri-snRNP particle there is extensive base pairing between the U4 and U6 snRNAs, leading to the formation of two stem structures, and the U5 snRNP appears to be associated with the U4/U6 snRNP through protein-protein interactions. The tri-snRNP particle can be purified in vitro from HeLa nuclear extract and yeast cellular extract at low salt concentration $(150 \mathrm{mM} \mathrm{NaCl})$ and sediments at $25 \mathrm{~S}$ in glycerol gradients (Behrens and Lührmann, 1991; Fabrizio et al., 1994; Gottschalk et al., 1999; Stevens and Abelson, 1999). The protein composition of the tri-snRNP is well established. In human cells, the tri-snRNP contains at least 15 specific proteins, and many of these are essential for splicing (reviewed in Will and Lührmann, 1997, 2001). The U4/U6-snRNP proteins $15.5 \mathrm{~K}, 61 \mathrm{~K}$, the $20 \mathrm{~K} \cdot 60 \mathrm{~K} \cdot 90 \mathrm{~K}$ complex and the U5-snRNP proteins including $220 \mathrm{~K}, 200 \mathrm{~K}, 116 \mathrm{~K}$, $102 \mathrm{~K}, 100 \mathrm{~K}, 40 \mathrm{~K}$ and $15 \mathrm{~K}$ are present in this particle. In addition, three other proteins $(110 \mathrm{~K}, 65 \mathrm{~K}$ and $27 \mathrm{~K})$ are more stably associated with the $25 \mathrm{~S}$ trisnRNP particle, and are thus referred to as tri-snRNP-specific proteins. Interestingly, all three tri-snRNP-specific proteins contain an $\mathrm{N}$-terminal arginine-serine-rich (RS) domain (Fetzer et al., 1997; Makarova et al., 2001). Of these, the two largest proteins are shown to be required for the recruitment of tri-snRNP to the pre-spliceosome (Makarova et al., 2001).

While some information has been accumulated on protein-protein and proteinRNA interactions within the individual U4/U6 or U5 snRNP, little is known about the interactions that bridge the U4/U6 and U5 snRNPs. There is no indication of RNA-RNA interactions between the two particles (Black and Pinto, 1989). Consistently with this, the tri-snRNP dissociates into U4/U6 and U5 snRNPs at monovalent salt concentrations between 300 and $400 \mathrm{mM}$, suggesting that trisnRNP formation is mediated by protein-protein and/or protein-RNA interactions. However, apart from a crosslink observed between the yeast U5 protein Prp8p and U6 snRNA (Vidal et al., 1999), there is a paucity of information about interactions that potentially mediate the association of the U5 and U4/U6 snRNPs. In yeast, Prp6p appears to be important for the interaction of the U4/U6 and U5 snRNPs. Mutation of the PRP6 gene inhibits tri-snRNP accumulation, while accumulation of the individual U4/U6 and U5 snRNPs is not 
affected (Galisson and Legrain, 1993). This suggests that the Prp6p protein is not needed for the integrity and hence stability of the U4/U6 or U5 snRNPs, but only for tri-snRNP formation. Consistently with this, recent data from a mammalian system showed that $\mathrm{U} 5-102 \mathrm{~K}$ protein prepared by translation in vitro binds to purified 13S U4/U6 snRNP (Makarov et al., 2000). To substantiate the hypothesis that $102 \mathrm{~K}$ protein bridges the U4/U6 and U5 snRNPs, it will be important in future experiments to elucidate in detail the interaction partners of $102 \mathrm{~K}$ in the tri-snRNP particle.

\subsubsection{U4/U6.U5 tri-snRNP proteins and retinitis pigmentosa}

The importance of tri-snRNP in human disease was realised recently as a result of several studies (Vithana et al., 2001; McKie et al., 2001; Chakarova et al., 2002). In the year 2001, McKie et al. showed that mutations of several highly conserved residues in the C-terminal part of $220 \mathrm{~K} / \mathrm{hPrp} 8 \mathrm{p}$ correlated with autosomal dominant retinitis pigmentosa (RP13), while Vithana et al. found that mutations in another splicing factor, $61 \mathrm{~K} / \mathrm{hPrp} 31 \mathrm{p}$, are linked to the autosomal dominant gene RP11. In the following year, mutations of the third gene encoding 90K/hPrp3p were implicated in RP18 (Chakarova et al., 2002). It was recently found that two missense mutations (A194E, A216P) in the $61 \mathrm{~K}$ gene (PRPF31) may affect splicing by impeding the translocation of $61 \mathrm{~K}$ protein into the nucleus. The splicing defect of A216P was further demonstrated by the finding that $61 \mathrm{~K}$ with $\mathrm{A} 216 \mathrm{P}$ failed to complement fully the functional deficiency in a temperature-sensitive, Prp31p-deficient yeast strain at the high restrictive temperature (higher growth rate, high demand for splicing) (Deery et al., 2002). It was argued that rod photoreceptors may have a high demand for splicing of important molecules such as opsin mRNA, and subtle defects in splicing due to loss of function of protein $61 \mathrm{~K}$ may lead to a disease in this system (RP). However, the molecular mechanism of retinitis pigmentosa caused by mutations in these three tri-snRNP proteins is unclear at present. 


\subsection{The Dynamic Nature of the Spliceosome}

\subsubsection{The spliceosome cycle}

Studies in both the yeast and mammalian systems have revealed a cycle of spliceosome assembly and disassembly on a pre-mRNA (figure 2.4) (Cheng and Abelson, 1987; Konarska and Sharp, 1986; Konarska and Sharp, 1987). The first step that commits a pre-mRNA to the splicing pathway is recognition of the 5 ' SS by the U1 snRNP, initiating the early (E) complex in mammals. This initial step does not require energy (ATP) for formation. U1 is the only component that can bind in the absence of ATP, and its interaction with the premRNA is in general required for the other snRNPs to bind. After the association of the U1 snRNP with the 5' SS, the U2 snRNP recognizes and binds to the branchpoint to form complex A. Addition of the U2 snRNP is the first energydependent step in the splicing pathway, and binding of the U2 snRNP is mediated in part by the U1 snRNP as well as additional non-snRNP factors that bridge the two components. After U2 snRNP binding, the U4/U6.U5 tri-snRNP particle joins the A complex to form complex B. Complex B is structurally rearranged to form the catalytically activated spliceosome $\left(B^{*}\right)$, which subsequently catalyses the first transesterification reaction, generating complex C. After the second step of splicing, the mRNA is released, the postspliceosomal complex dissociates, and the snRNPs are recycled for new rounds of splicing.

Thus, spliceosome assembly goes through many intermediate stages, the most stable of which (e.g., the A, B, C complexes) can be detected biochemically, for example, by native gel electrophoresis. Some additional stable intermediates, such as the immunoaffinity-purified activated spliceosome $B^{*}$ and pre-catalytic complex, which contains intact U4/U6.U5 tri-snRNP but lacks U1 snRNP (designated $\mathrm{B} \Delta \mathrm{U} 1$ ) have been also reported recently (Makarov et al., 2002; Makarova et al., 2004). 


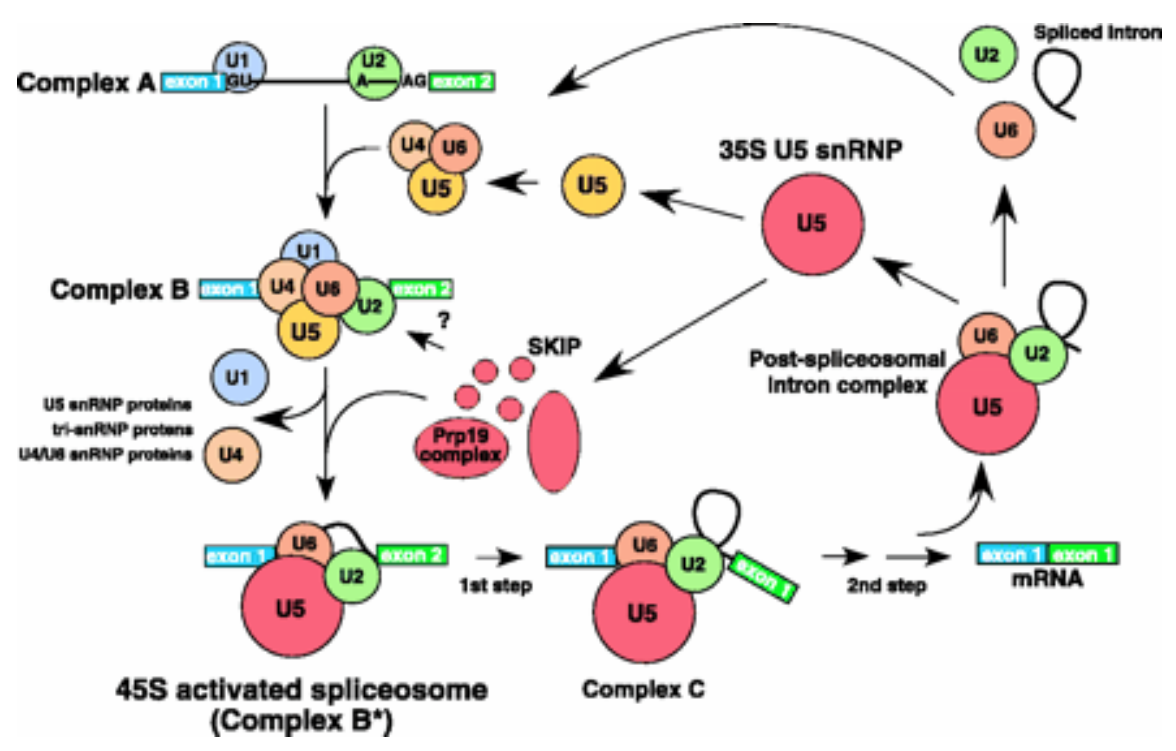

Figure 2.4. Schematic diagram of spliceosomal and snRNP remodelling events. In the early phase of spliceosome formation, U1 snRNA base pairs with the 5' splice site, and U2 snRNA interacts with the branch site to form the pre-spliceosomal A complexes. Spliceosome assembly is completed by the addition of the 25S U4/U6.U5 tri-snRNP particle, forming spliceosomal complexes B and C. Complexes with a red U5 snRNP contain the SKIP protein (from Makarov et al., 2002).

\subsubsection{Dynamics of RNA-RNA interactions in the spliceosome}

The most decisive step during the spliceosome maturation process is the conversion of complex $B$ into the catalytically activated spliceosome $B^{*}$. This occurs after the recruitment of U4/U6.U5 tri-snRNP into pre-spliceosome.

Once all five snRNPs are present, the complex undergoes a series of rearrangements. The interaction between the U1 snRNA and the $5^{\prime} \mathrm{SS}$ is disrupted, and the U1 snRNP particle is released from the complex. Similarly, the base pairing between the U4 and U6 snRNAs is also disrupted, allowing the release of the U4 snRNP and new base-pairing to form between the U2 and U6 snRNAs (Villa et al., 2002). The resulting RNA network forms the catalytic core of the spliceosome (figure 2.5). U2 and U6 snRNAs interact with the branch point and 5' splicing site respectively, and provide a structural basis for juxtaposing the branch site and 5' splicing site for the first catalytic step. U5 snRNA bears a highly conserved stem-loop that is implicated in aligning the exons for the second catalytic step (O'Keefe et al., 1996). The U6 snRNA is proposed to be the actual catalytic entity, indicating that the spliceosome may 
be a true ribozyme. Most RNA enzymes require metal ions as cofactors for catalysis, and it was recently determined that specific bases in the U6 snRNA bind $\mathrm{Mg}^{2+}$ ions, a strong indication that this molecule may indeed be the catalytic agent (Collins and Guthrie, 2000; Yean et al., 2000). A protein-free complex of the U2 and U6 snRNAs is able to bind a small RNA and activate the attack of a branch point adenosine on a catalytically important region of U6. This reaction is similar to the first step of splicing, further supporting the potential catalytic activity of the U2 and U6 snRNAs (Valadkhan and Manley, 2001).

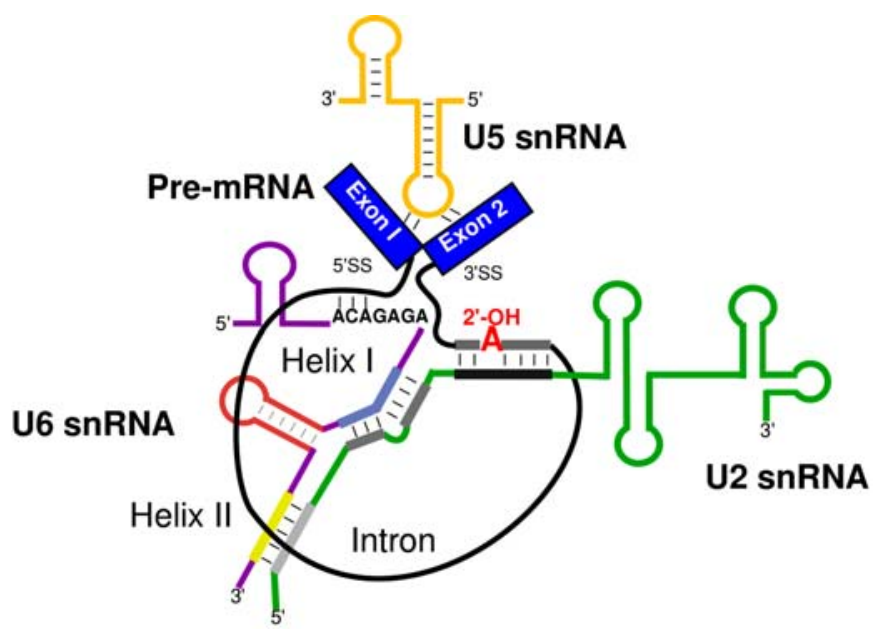

Figure 2.5. Model of the catalytic RNA core of the spliceosome. The U2 and U6 snRNAs are extensively base-paired with one another and with the branch site sequence and 5' splice site respectively. An invariant loop sequence in the U5 snRNA interacts initially with Exon 1, and then also with Exon 2 after the first catalytic step (modified from Dr. P. Fabrizio in the laboratory of Prof. Lührmann).

In addition to the U6 and U2 snRNA molecules, Prp8p (220K in human) has also been proposed to play a critical role at the catalytic core of the spliceosome. Prp8p is a component of the U5 snRNP in both mammalian and yeast systems and is the most highly conserved splicing factor among species. Prp8p is unique in making extensive contacts with U5 and U6 snRNAs and with the pre-mRNA substrate at the splice sites and intron branch site (Wyatt et al., 1992; Teigelkamp et al., 1995; Dix et al., 1998; Vidal et al., 1999). Prp8p probably plays a role in stabilizing the interactions between the U5 snRNA loop sequence and the exons (Teigelkamp et al., 1995) and may also be responsible for juxtaposing the U5 loop with the rest of the catalytic core. Mutational studies 
of Prp8p (Kuhn et al., 2002; Collins and Guthrie, 1999; Siatecka et al., 1999; Kuhn and Brow, 2000; Query and Konarska, 2004) also support the view that this protein is intimately involved in the functions of the catalytic core of the spliceosome.

\subsubsection{Dynamic changes of protein components of U4/U6.U5 tri-snRNP during the spliceosome cycle}

The restructuring that the U4/U6.U5 tri-snRNP undergoes during the spliceosomal cycle affects not only its RNA components but its proteins as well. This has become evident from proteomic analysis of purified spliceosomal complexes at defined functional stages. Mass spectrometry of a purified precatalytic spliceosomal B complex containing U2, U4/U6 (still base-paired) and U5 snRNAs but lacking U1 snRNA (therefore termed $\mathrm{B} \Delta \mathrm{U} 1$ ) revealed that all of the U4/U6- and U5-specific proteins (with the single exception of U5-100K) are stably bound at this spliceosomal assembly stage (Makarov et al., 2004). In striking contrast, all of the U4/U6-specific proteins as well as the U5-15K protein are significantly destabilized upon transformation of complex $B$ into the catalytically active spliceosome (complex $B^{*}$ ) such that these proteins are no longer retained in complex $\mathrm{B}^{*}$ when this is isolated under the same stringent conditions as complex $\mathrm{B} \Delta \mathrm{U} 1$ (Makarova et al., 2002). Of the tri-snRNP-specific proteins, only $110 \mathrm{~K}$ remains stably bound in complex $\mathrm{B}^{*}$. Recently, a novel $35 \mathrm{~S}$ RNP particle containing U5 snRNA was identified in nuclear extracts from HeLa cells, and its protein composition was characterized by mass spectrometry. This particle contained - in addition to the established U5-specific proteins (220K, $200 \mathrm{~K}, 116 \mathrm{~K}$ and $40 \mathrm{~K}$ ) - a group of splicing factors (such as the human Prp19 protein complex) that are stably integrated into the spliceosome during the transformation of complex $B$ into the catalytically activated $B^{*}$ spliceosome, indicating that the 35S U5 snRNP complex represents a post-spliceosomal disassembly intermediate of the splicing machinery (Makarov et al., 2002; Makarova et al., 2004). Interestingly, several proteins which are stoichiometrically present in $20 \mathrm{~S}$ U5 snRNPs - namely, the U5-specific 102K, $100 \mathrm{~K}$ and $15 \mathrm{~K}$ proteins - are completely absent in the 35S U5 RNP particle (Makarov et al., 2002). Thus, the protein composition of the U5 snRNP changes within the framework of the spliceosome, and the resulting U5 particle has to be 
extensively reformed before it can build a U4/U6.U5 tri-snRNP and then reenter the spliceosome. Very little is known about these remodelling steps or the proteins possibly involved.

\begin{tabular}{|c|c|c|c|}
\hline $\begin{array}{l}\text { U4/U6.U5 } \\
\text { tri-snRNP }\end{array}$ & $\begin{array}{l}\text { B } \Delta U 1 \\
\text { (Makarova et al., } \\
\text { 2004) }\end{array}$ & $\begin{array}{l}\text { 45S activated } \\
\text { spliceosome }\left(\mathrm{B}^{*}\right) \\
\text { (Makarov et al., } \\
2002) * *\end{array}$ & $\begin{array}{l}\text { 35S U5 snRNP } \\
\text { (Makarov et al., } \\
2002) * *\end{array}$ \\
\hline Sm Proteins & Sm Proteins & Sm Proteins & $\underline{\text { Sm Proteins }}$ \\
\hline B,D1,D2,D3,E,F,G & B,D1,D2,D3,E,F,G & B,D1,D2,D3,E,F,G & $\mathrm{B}, \mathrm{D} 1, \mathrm{D} 2, \mathrm{D} 3, \mathrm{E}, \mathrm{F}, \mathrm{G}$ \\
\hline LSm proteins & LSm proteins & LSm proteins & LSm proteins \\
\hline$\overline{\operatorname{LSm} 2,3,4,5,6,7,8}$ & $\overline{\operatorname{LSm} 3,4,7,8}$ & $\overline{\operatorname{LSm} 2,3}$ & \\
\hline U5 snRNP & U5 snRNP & U5 snRNP & U5 snRNP \\
\hline $220 \mathrm{~K}$ & $220 \mathrm{~K}$ & $220 \mathrm{~K}$ & $220 \mathrm{~K}$ \\
\hline $200 \mathrm{~K}$ & $200 \mathrm{~K}$ & $200 \mathrm{~K}$ & $200 \mathrm{~K}$ \\
\hline $116 \mathrm{~K}$ & $116 \mathrm{~K}$ & $116 \mathrm{~K}$ & $116 \mathrm{~K}$ \\
\hline $40 \mathrm{~K}$ & $40 \mathrm{~K}$ & $40 \mathrm{~K}$ & $40 \mathrm{~K}$ \\
\hline $102 \mathrm{~K}$ & $102 \mathrm{~K}$ & $102 \mathrm{~K}$ & - \\
\hline $15 \mathrm{~K}$ & $15 \mathrm{~K}$ & - & - \\
\hline $100 \mathrm{~K}$ & - & - & - \\
\hline tri-snRNP & tri-snRNP & tri-snRNP & tri-snRNP \\
\hline $110 \mathrm{~K}$ & $110 \mathrm{~K}$ & $110 \mathrm{~K}$ & - \\
\hline $65 \mathrm{~K}$ & - & - & - \\
\hline $27 \mathrm{~K}$ & - & - & - \\
\hline U4/U6 snRNP & U4/U6 snRNP & U4/U6 snRNP & $\underline{\mathrm{U} 4 / \mathrm{U} 6}$ snRNP \\
\hline $90 \mathrm{~K}$ & $90 \mathrm{~K}$ & - & - \\
\hline $60 \mathrm{~K}$ & $60 \mathrm{~K}$ & - & - \\
\hline $20 \mathrm{~K}$ & $20 \mathrm{~K}$ & - & - \\
\hline $61 \mathrm{~K}$ & $61 \mathrm{~K}$ & - & - \\
\hline $15.5 \mathrm{~K}$ & $15.5 \mathrm{~K}$ & - & - \\
\hline
\end{tabular}

Table 2.2. The protein composition of the U4/U6.U5 tri-snRNP in the complex B $\Delta U 1$, the $45 \mathrm{~S}$ activated spliceosome $\left(\mathrm{B}^{*}\right)$, and $35 \mathrm{~S}$ U5 snRNP. $* *$ A number of proteins (including CDC5/Prp19 complex) recruited in $\mathrm{B}^{*}$ and associated with $35 \mathrm{~S}$ U5 snRNP are not showed in this table.

\subsubsection{The roles of tri-snRNP proteins in the activation of spliceosome}

Although the splicing reactions themselves do not directly require energy input, remodelling of a network of RNA-RNA and RNA-protein interactions in the spliceosome consumes a number of ATP molecules. These rearrangements are catalysed by several ATP-dependent RNA helicases and may also involve the activity of a GTPase related to the translation elongation factor EF-2. The largest class of energy-requiring proteins involved in splicing belongs to the DEXD/H box family: these proteins are commonly known as RNA helicases but 
in some cases may act as RNPases (ribonucleoproteinases), which disrupt RNA-protein complexes in the spliceosome (Schwer, 2001).

While the U4/U6 snRNP part of the tri-snRNP contributes a substantial component of the catalytic RNA network (described in section 2.4.2), the driving force of catalytic activation and the rearrangements of the spliceosome all appear to be U5 snRNP residents. U5 snRNP contains three NTPases: 100K (Prp28p in yeast), 200K (Brr2p) and 116K (Snu114p). The NTPases of the U5 snRNP are involved in the critical switch in which $U 1$ is replaced by $U 6$ at the $5^{\prime}$ splice site (figure 2.6). This is an important stage in spliceosome activation, which contributes to the fidelity of $5^{\prime}$ splice site recognition. The two unwinding events that disrupt base-pairing between U1 snRNA and the $5^{\prime}$ splice site, and between U4 and U6 snRNAs, allow the $5^{\prime}$ splice site, U6 and U2 catalytic core structure to form (described in section 2.4.2; Brow, 2002). It has been shown that Prp28p in yeast has a role in destabilizing the U1 snRNA interaction with the $5^{\prime}$ splice site. This DEXD/H box protein may unwind the helix formed between the $5^{\prime}$ splice site and U1 snRNA (Staley and Guthrie, 1999). Alternatively, it is a prime candidate to act as an RNPase. Under normal conditions, Prp28p is an essential protein in yeast, but if the U1C protein (a factor that stabilizes the interaction between $U 1$ and the $5^{\prime}$ splice site) is mutated, then Prp28p becomes dispensable (Chen et al., 2001). This suggests that Prp28p participates in disrupting the U1C interaction, either by acting directly against the protein or by disrupting the double helix between the $U 1$ snRNA and the $5^{\prime}$ splice site that forms its site of interaction. 


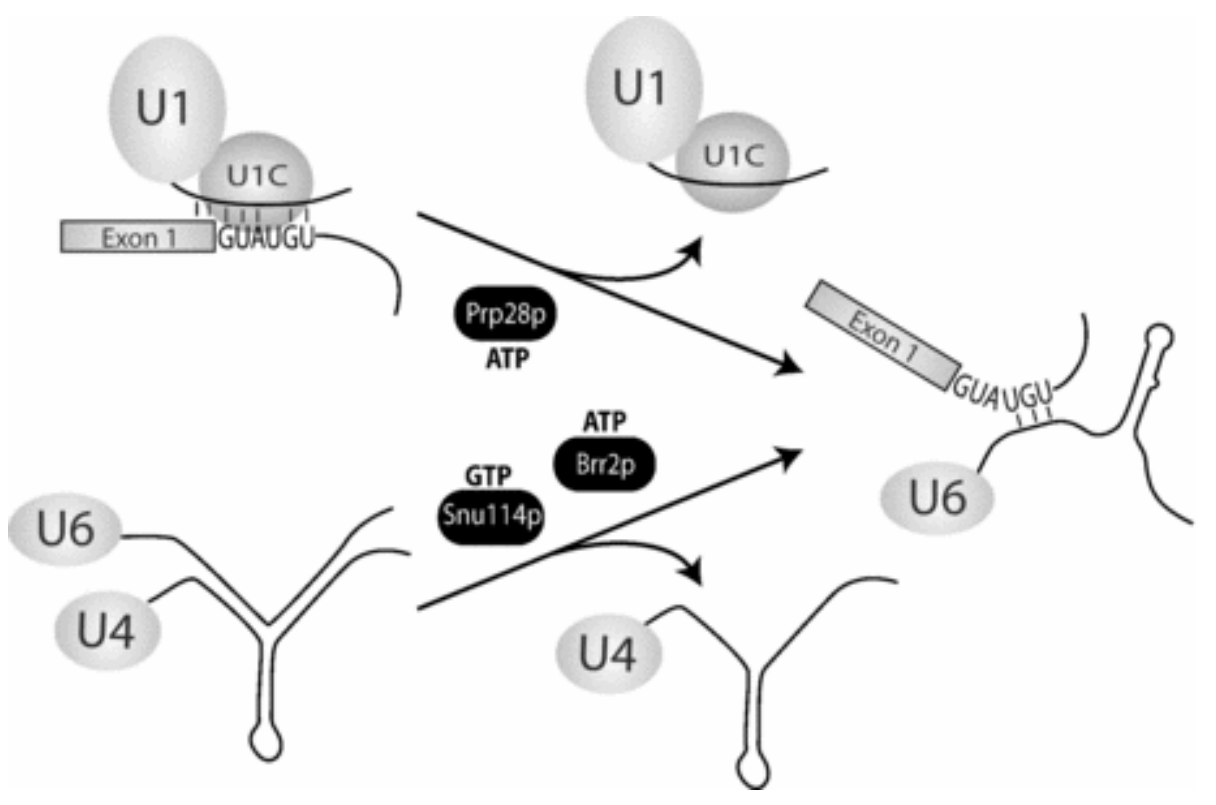

Figure 2.6. Model of the 5' splice site switch. During spliceosome assembly, the 5' splice site is initially recognized by the U1 snRNP. This interaction is later replaced by U6, which must base-pair with the 5' splice site before the first catalytic step. The unwinding of U4:U6 is also required for the spliceosome to become active. These events occur concurrently and allow the release of U1 and U4 snRNPs from the spliceosome. The roles that the U5 snRNP components, Prp28p, Brr2p and Snu114p, are hypothesized to perform during activation of the spliceosome are indicated: Prp28p displaces U1 (and the U1C protein, see text) from the 5' splice site presumably utilizing ATP, whereas Brr2p and Snu1 14p are involved in the unwinding of U4 and U6 snRNAs, a process requiring ATP and GTP. This results in free U6 paired with the 5' splice site. U6 is also capable of forming an intramolecular stem loop, a structure important for catalysis, after release from U4. The 5' splice site consensus from Saccharomyces cerevisiae is used with base-pairing to U1 and U6 snRNAs indicated. Adapted from Turner et al., 2004.

Disruption of the interaction between $\mathrm{U} 1$ snRNA and the $5^{\prime}$ splice site is accompanied by the release of U6 from U4 (figure 2.6). The U4/U6.U5 trisnRNP contains the base-paired U4:U6 structure that prevents the formation of catalytic core structures until the correct time. In vitro work has shown that the $200 \mathrm{~K} / \mathrm{hBr} 2 \mathrm{p}$ protein is capable of unwinding RNA helices including a basepaired U4:U6 complex (Laggerbauer et al., 1998). Furthermore, it has been shown that a mutation in the ATPase domain of the yeast homologue Brr2p (brr2-1) inhibits the ATP-dependent disruption of U4/U6.U5 tri-snRNPs in yeast cell extracts (Raghunathan and Guthrie, 1998). These studies suggest that $200 \mathrm{~K}$ protein is the motor that drives the release of U6 before formation of the U6:5'-splice-site and U6:U2 structures. Both Snu114p and Prp8p (a large U5 snRNP protein) are supposed to control the action of Brr2p (Bartels et al., 2002, 
2003; Kuhn et al., 1999, 2002). Elegant studies using an Snu114p mutant that switched specificity from GTP to XTP allowed dissection of this regulatory role of Snu114p (Bartels et al., 2003). It was shown that stalled complexes would only unwind the U4:U6 helices when supplied with hydrolysable XTP, implying that Snu114p has a role either in unwinding U4:U6 or, more probably, in controlling the action of Brr2p. Prp8p has been implicated in several aspects of spliceosome remodelling and activation, in addition to putative cofactor activity in catalysis (described in section 2.4.2). These aspects include a central role in governing the activities of the Brr2p and Prp28 $p$ RNA-dependent ATPases (Kuhn et al., 1999, 2002). A mutation in PRP8, prp8-201, was identified as a suppressor of the U4-cs1 mutation. U4-cs1 extends the base pairing between the U4 and U6 snRNAs into the ACAGA box of the U6 snRNA, preventing its interaction with the $5^{\prime} \mathrm{SS}$. This led to the proposal that Prp8p may trigger the unwinding of the U4 and U6 snRNAs only after correct recognition of the 5' SS by the ACAGA box of U6. Like many other PRP8 mutations, this alteration in Prp8p maps to the C-terminal domain of the protein (Kuhn et al., 1999). Additional genetic interactions indicate that Prp8p may regulate Brr2p, the putative U4/U6 helicase, and Prp28p, the putative U1/5'-SS helicase, in order to control the rearrangements that they promote and thus to allow spliceosome activation (Kuhn and Brow, 2000; Kuhn et al., 2002).

Interestingly, experimental evidence also indicated a role for the $15.5 \mathrm{~K} / \mathrm{Snu} 13 \mathrm{p}$ and Prp4p proteins in the transition of fully assembled spliceosome toward an active form (Ayadi et al., 1997; Nottrott et al., 1999).

\subsection{The Aims of the Current Studies}

The 25S U4/U6.U5 tri-snRNP, pre-assembled from U4/U6 and U5 snRNPs, is one of the major building blocks of the spliceosome. As mentioned in section 2.3.3, this particle contains - in addition to the U4, U6 and U5 snRNAs - ca. 30 distinct proteins which make up approximately $80 \%$ of the tri-snRNP's total mass. Most of the tri-snRNP proteins exhibit significant domain features, possibly providing hints of the potential functions of these proteins. For instance, the TPR repeats of U5-102K, the WD40 domain of U4/U6-60K and U5-40K, the 
cyclophilin fold of U4/U6-20K, and the thioredoxin fold of U5-15K all predict a rich diversity of protein-protein interactions and protein modifications within the tri-snRNP particle (see section 2.3.3 for detailed description). The following evidence also suggests that the protein-protein interactions might be the major building force of the tri-snRNP. First, the stable heteromeric complexes $20 \mathrm{~K} \cdot 60 \mathrm{~K} \cdot 90 \mathrm{~K}$ and $220 \mathrm{~K} \cdot 200 \mathrm{~K} \cdot 116 \mathrm{~K} \cdot 40 \mathrm{~K}$ could be isolated separately in vitro in the absence of snRNAs (see section 2.3.3.2). Second, protein U5-102K binds in vitro directly to the latter heterotetrameric complex (Makarov et al., 2000). However, this is probably only part of protein-protein interaction map in such a large complex. For example, little is known about the interactions that bridge the U4/U6 and U5 snRNPs although it has been suggested that the protein-protein interactions may dominate this connection (see section 2.3.3.2).

There is evidence that the DExH-box RNA helicase U5-200K and the GTPase U5-116K are driving forces behind the disruption of the U4/U6 snRNA helices (see section 2.4.4). However, the mechanism - that is, how these U5-specific proteins actually disrupt the U4/U6 RNA helices, i.e. by directly contacting the RNAs or more indirectly, by modulating the activity of U4/U6 snRNA binding proteins via a network of protein-protein interactions - is still not understood.

Therefore, the knowledge of protein-protein interactions appears to be important for understanding the mechanisms of the tri-snRNP assembly and its role in the activation of spliceosome and catalysis of splicing. A major part of my PhD work has been to identify the protein-protein interactions within the individual U4/U6 and U5 snRNPs, as well as protein contacts between these two snRNPs in the tri-snRNP particle, and protein domains involved. The combination of all the interaction data will allow me to draw up a comprehensive protein-protein interaction map, and thus aid in the understanding of the structure and functional mechanisms of the tri-snRNP complex and the dynamic nature of the spliceosome. In addition, the knowledge of protein-protein interaction will provide a basis for protein co-expression for the structure study by X-ray crystallography. 
For this purpose, the yeast two-hybrid $(\mathrm{Y} 2 \mathrm{H})$ system and in vitro biochemical methods were first established. The $\mathrm{Y} 2 \mathrm{H}$ system was developed by Fields and Song (1989) and is a sensitive method for identifying protein-protein interactions in vivo. Briefly, the two-hybrid system takes advantage of the properties of the GAL4 transcription factor, which has separable domains for DNA binding (amino acids 1-147) and transcriptional activation (amino acids 768-881). The proteins being studied are expressed as hybrid constructs with a DNA binding domain or activation domain. If the two proteins interact with each other, both domains of GAL4 transcription factor are brought into close physical proximity and allow trans-activation of the reporter genes, e.g. HIS3 and ADE2. GST pulldown assays and co-immunoprecipitation assays are the two methods used for in vitro binding studies in this work. In the most case, one of the tested protein pair has to be expressed in $E$. coli and purified as a functional recombinant protein. Mutational analysis was used for identified the interacting domains.

The same methods are also applied in the following other studies. The interactions between tri-snRNP proteins and the U6-associated protein p110 and the U2-associated splicing factor SPF30/SMNrp are investigated in order to elucidate the functions of tri-snRNP proteins in the recycling of U4/U6 and the recruitment of tri-snRNP to the pre-spliceosome. Furthermore, I am interested in the role of tri-snRNP proteins $220 \mathrm{~K}, 90 \mathrm{~K}$ and $61 \mathrm{~K}$ in retinitis pigmentosa, in the context of protein-protein interactions. To understand the function of protein $200 \mathrm{~K}$, the N-terminal 434-amino-acid fragment of $200 \mathrm{~K}$ was used as a prey in a yeast two-hybrid screen to identify the interaction partners of $200 \mathrm{~K}$. 


\section{Materials and Methods}

\subsection{Materials}

\subsubsection{Chemicals}

Acrylamide solution

Adenine sulfate

Agarose

Ammonium persulfate (APS)

Ampicillin

Amplify $^{\text {TM }}$

Bovine serum albumin (BSA), acetyliert

Bradford solution

Bromophenol blue

B-Per ${ }^{\mathrm{TM}}$ Bacterial Protein Extraction Reagent

Carrier DNA

Chloramphenicol

Coomassie Brillant Blau R250

Dimethyl sulfate (DMS)

Dimethyl sulfoxide (DMSO)

Dithioerythrol (DTE)

Dithiothreitol (DTT)

Sodium dodecyl sulfate (SDS)

Acetic acid

Ethanol

Ethylendiamine tetra-acetic acid (EDTA)

Ethidium bromide solution

Glutathion (reduced)

Glycin

Glycerol

Guanidinium hydrochloride

Heparin

HEPES

Imidazole

Isopropyl- $\beta$-D-thiogalactoside (IPTG)

Kanamycin

Lysozyme

Milk powder, instant

Magnesium chloride

Methanol

NDSB-256[3-(1-Pyridino)-1-propan sulfate]

$1 \mathrm{~kb}$ DNA ladder

Phenylmethylsulfonylfluoride (PMSF)

p-Nitrophenyl $\alpha$-D-Galactopyranoside (PNP- $\alpha-G a l)$

Polyethylenglycol 3350 (PEG3350)

Ponceau S

Potassium chloride

Precision protein standard marker

Roti-Phenol/Chloroform

Silver nitrate

Sodium chloride

Sodium thiosulfate

$\mathrm{N}, \mathrm{N}, \mathrm{N}$ ', N'-Tetramethylethylendiamin (TEMED)

3-Amino-1,2,4-Triazole (3-AT)

tRNA, E. coli

Tris-(hydroxymethylen)aminomethan (TRIS)

Triton X-100

Roth, Karlsruhe

QBiogene, Heidelberg

Invitrogen, USA

Merck, Darmstadt

Sigma, Deisenhofen

Amersham Biosciences, Freiburg

Sigma, Deisenhofen

Biorad, München

Merck, Darmstadt

Pierce, UK

Clontech, Heidelberg

Boehringer, Mannheim

Serva, Heidelberg

Fluka, Schweiz

Sigma, Deisenhofen

Sigma, Deisenhofen

Roth, Karlsruhe

Merck, Darmstadt

Merck, Darmstadt

Merck, Darmstadt

Roth, Karlsruhe

Roth, Karlsruhe

Sigma, Deisenhofen

Merck, Darmstadt

Merck, Darmstadt

Fluka, Schweiz

Sigma, Deisenhofen

Calbiochem, USA

Merck, Darmstadt

Sigma, Deisenhofen

Boehringer, Mannheim

Boehringer, Mannheim

Cenovis $\mathrm{GmbH}$, Radolfzell

Merck, Darmstadt

Merck, Darmstadt

Calbiochem, USA

Invitrogen, USA

Boehringer, Mannheim

Sigma, Deisenhofen

Sigma, Deisenhofen

Serva, Heidelberg

Merck, Darmstadt

Biorad, München

Roth, Karlsruhe

Merck, Darmstadt

Merck, Darmstadt

Merck, Darmstadt

Sigma, Deisenhofen

Sigma, Deisenhofen

Boehringer, Mannheim

Roth, Karlsruhe

Sigma, Deisenhofen 
Tween 20

X-a-Gal

(5-Bromo-4-Chloro-3-indolyl a -D-galactopyranoside) X-Gal

(5-Bromo-4-Chloro-3-indolyl $\beta$-D-galactopyranoside) Xylene cyanol FF Urea
Sigma, Deisenhofen

Clontech, Heidelberg

Clontech, Heidelberg

Fluka, Schweiz

Merck, Darmstadt

\subsubsection{Media (Qbiogene, Eschwege, Germany)}

CSM-Leu, CSM-Trp, CSM-His, CSM-Ade, CSM-Ura, CSM-Leu-Trp, CSM-Leu-Trp-His, CSM-Leu-Trp-His-Ade, DOB, DOBA, NYZ Broth, SOC Broth, SOB Broth, LB Broth, LB Agar, YPD Broth, YPD Agar

\subsubsection{Nucleotides, radionucleotides and amino acids}

\section{Nucleotide}

Deoxynucleoside-5'-Triphosphate, 100 mM (dATP, dCTP, dGTP, dTTP)

Nucleoside-5'-Triphosphate, $100 \mathrm{mM} \quad$ (ATP, CTP, GTP, UTP)

Radionucleotide (Amersham Biosciences,
$\begin{array}{ll}{\left[\alpha^{32} \mathrm{P}\right]-\mathrm{dATP}} & 3000 \mathrm{Ci} / \mathrm{mmol} ; 10 \mathrm{Ci} / \mathrm{l} \\ {\left[\gamma^{32} \mathrm{P}\right]-\mathrm{ATP}} & 6000 \mathrm{Ci} / \mathrm{mmol} ; 10 \mathrm{Ci} / \mathrm{l} \\ {\left[\mathrm{\alpha}^{32} \mathrm{P}\right]-\mathrm{UTP}} & 3000 \mathrm{Ci} / \mathrm{mmol} ; 10 \mathrm{Ci} / \mathrm{l} \\ {\left[\gamma^{32}\right]-\mathrm{pCp}} & 3000 \mathrm{Ci} / \mathrm{mmol} ; 10 \mathrm{Ci} / \mathrm{l}\end{array}$

Amino acid (Amersham Biosciences, Freiburg)

L- $\left[{ }^{35} \mathrm{~S}\right]$ Methionine $1000 \mathrm{Ci} / \mathrm{mmol}$

\subsubsection{Antibodies}

Anti-c-myc-peroxidase

Penta.His Antibody

Monoclonal antibody, HA.11

c-Myc monoclonal antibody

HA-tag polyclonal antibody

Polyclonal anti-110K rabbit antibody

Polyclonal anti-60K rabbit antibody

\subsubsection{Enzymes and inhibitors}

AMV Reverse Transcriptase (15 U/ $\mu \mathrm{l})$

DNase I

Pfu DNA Polymerase $(2,5 \mathrm{U} / \mu \mathrm{l})$

Proteinase Inhibitor Cocktail Complete ${ }^{\mathrm{TM}}$, EDTA-free
Boehringer, Mannheim

Qiagen, Hilden

Covance, USA

Clontech, USA

Clontech, USA

Lührmann lab, a-pep 110

Lührmann lab
Amersham Biosciences, Freiburg

Roche, Mannheim

Stratagene, Heidelberg

Roche, Mannheim 
Proteinase K $(10 \mathrm{mg} / \mathrm{ml})$

Ready-To-Go T4 DNA ligase

Restriction Endonucleases

RNAsin $\quad(40 \mathrm{U} / \mu \mathrm{l})$

SP6 RNA Polymerase (20 U/ $\mu \mathrm{l})$

Taq DNA Polymerase (5000 U/ul)

T4 DNA Ligase (400 U/ $\mu \mathrm{l}$ )

T4 Polynucleotide Kinase (20 U/ $/ \mathrm{l})$

T3 RNA Polymerase (17 $\mathrm{U} / \mu \mathrm{l})$

T7 RNA Polymerase (50 U/ul)

Thrombin Protease
Sigma, Deisenhofen

Amersham Biosciences, Freiburg

New England Biolabs, France

Promega, USA

Promega, USA

Promega, USA

New England Biolabs, Frankfurt

New England Biolabs, Frankfurt

Promega, USA

Promega, USA

Amersham Biosciences, Freiburg

\subsubsection{Oligonucleotide primers for PCR (Table 3.1)}

\begin{tabular}{|c|c|c|c|}
\hline Protein & Oligo & Description & Sequence $\left(5^{\prime} \rightarrow 3^{\prime}\right)$ \\
\hline \multirow{2}{*}{$15.5 \mathrm{~K}$} & HPV-140 & \multirow{2}{*}{ full-length } & CCTTCGAACATATGACTGAGGCTGATGTGAAT \\
\hline & HPV-141 & & CCTTCGAACTCGAGTTAGACTAAGAGCCTTTCAAT \\
\hline \multirow{2}{*}{$20 \mathrm{~K}$} & HPV-142 & \multirow{2}{*}{ full-length } & CCTTCGAACATATGGCGGTGGCAAATTCAAGT \\
\hline & HPV-143 & & ССTTCGAACTCGAGCTACATCTCCCCACACTGCGA \\
\hline \multirow{2}{*}{$27 \mathrm{~K}$} & HPV-148 & \multirow{2}{*}{ full-length } & CCTTCGAACATATGGGTCGCAGTCGCAGCCGC \\
\hline & HPV-149 & & CCTTCGAACTCGAGTCATGCAATGAAATCCAAAGG \\
\hline \multirow{2}{*}{$40 \mathrm{~K}$} & HPV-82 & \multirow{2}{*}{ full-length } & CCCGGATCCCATATGATAGATCAGCAGAAGCGT \\
\hline & HPV-83 & & CCCСTCGAGTCACTGAATCTCTCCCATATAC \\
\hline \multirow{2}{*}{$\begin{array}{l}52 \mathrm{~K} \\
(128 / 129)\end{array}$} & HPV-128 & \multirow{2}{*}{ full-length } & CCTTCGAACATATGCCAAAGAGGAAAGTGACC \\
\hline & HPV-129 & & СCTTCGAACTCGAGTCAGGTGTAGAGGTCAAAGTC \\
\hline $52 \mathrm{~N}(128 / 243)$ & HPV-243 & \multirow{2}{*}{ truncation } & CCCCTCGAGTCACAACTCCTCAGCGAACATGTC \\
\hline $52 \mathrm{C}(242 / 129)$ & HPV-242 & & CCCCATATGGCGGAGGAGGAACTGGAGACC \\
\hline \multirow{2}{*}{$60 \mathrm{Kmut}$} & HPV-144 & \multirow{2}{*}{ full-length } & СCTTCGAACATATGGCTTCCTCGCGAGCCTCT \\
\hline & HPV-145 & & CCTTCGAACTCGAGCTATTCCAGCATCCAC AGC TT \\
\hline \multirow[t]{2}{*}{$60 \mathrm{Kwt}$} & HPV-324 & \multirow{2}{*}{ full-length } & CCCGGATCCATATGGCTTCCTCGCGAGCCTCTTCC \\
\hline & HPV-325 & & CCCCTCGAGCTATTCAGCCATCCACAGCTTGAA \\
\hline \multirow{2}{*}{$61 \mathrm{~K}$} & HPV-345 & \multirow{2}{*}{ full-length } & CCCCATATGTCTCTGGCAGATGAGCTC \\
\hline & HPV-346 & & CCCCTCGAGTCAGGTGGACATAAGGCCACTC \\
\hline \multirow{2}{*}{ A194E } & HPV-384 & \multirow{2}{*}{ mutagenesis } & GAGGCCTGCGACATGGAGCTGGAGCTGAACGCCTCC \\
\hline & HPV-385 & & GCTTGGAGGCGTTCAGCTCCAGCTCCATGTCGCAGGCC \\
\hline \multirow{2}{*}{ A216P } & HPV-386 & \multirow{2}{*}{ mutagenesis } & GTGGAGTCCCGGATGTCCTTCATCCCACCCAACCTGTCC \\
\hline & HPV-387 & & GATGGACAGGTGGGTGGGATGAAGGACATCCGGGACTCC \\
\hline \multirow{2}{*}{$90 \mathrm{~K}$} & HPV-146 & \multirow{2}{*}{ full-length } & CCATCGATCATATGGCACTGTCAAAGAGGGAG \\
\hline & HPV-147 & & CCATCGATCTCGAGTCAATCAGTGGACTCTAACAC \\
\hline 90K_N194 & LSB-1 & truncation & GGTCTCCCATGGAATTCATGGCACTGTCAAAGAGGGAG \\
\hline
\end{tabular}




\begin{tabular}{|c|c|c|c|}
\hline 90K_N194 & LSB-2 & truncation & AAACTCGAGGTACCTTAAGTGGCAGCCTGGGAGGGCTG \\
\hline $90 \mathrm{~K} \_N 309(1 / 8)$ & LSB-8 & \multirow{2}{*}{ truncation } & AAACTCGAGGTACCTTAGGTATTGGATTCCATGTCTTC \\
\hline $90 \mathrm{~K} \_N 442(1 / 6)$ & LSB-6 & & AAACTCGAGGTACCTTACTTGGTAAGATATACTCC \\
\hline \multirow{2}{*}{ 90K_C267 } & LSB-5 & \multirow{2}{*}{ truncation } & GGTCTCCCATGGAATTCCTTGTTGAACATCCAGCCCAGC \\
\hline & LSB-4 & & AAACTCGAGGTACCTCAATCAGTGGACTCTAACAC \\
\hline 90K_C381(7/4) & LSB-7 & \multirow{2}{*}{ truncation } & GGTCTCCCATGGAATTCGAAGACATGGAATCCAATACC \\
\hline $90 \mathrm{~K} \_489(3 / 4)$ & LSB-3 & & GGTCTCCCATGGAATTCATGAATGATGCCATTGAG \\
\hline \multirow{2}{*}{ P493S } & HPV-359 & \multirow{2}{*}{ mutagenesis } & AAGCTGTTCAAGACCTCACGAAGGTAGAAGCCC \\
\hline & HPV-360 & & GTGGGCTTCTACCTTCGTGAGGTCTTGAACAGC \\
\hline \multirow{2}{*}{ T494M } & HPV-347 & \multirow{2}{*}{ mutagenesis } & AAGCTGTTCAAGACCCCATGAAGGTAGAAGCCC \\
\hline & HPV-348 & & GTGGGCTTCTACCTTCATGGGGTCTTGAACAGC \\
\hline \multirow{2}{*}{$102 \mathrm{~K}$} & HPV-235 & \multirow{2}{*}{ full-length } & CCCCCGCGGCATATGAACAAGAAGAAGAAACCGTTC \\
\hline & HPV-237 & & CCCGTCGACTCAGAAGGTGTTCTTGATGCGGCCGGC \\
\hline $\begin{array}{l}\text { 102K-NTD } \\
(235 / 272)\end{array}$ & HPV-272 & truncation & CCCGTCGACTCACTTCTTGATATCATTGATGTC \\
\hline \multirow{2}{*}{$\begin{array}{l}\text { 102K-TPR_M } \\
(273 / 278)\end{array}$} & HPV-273 & \multirow{2}{*}{ truncation } & AAACCCCATATGGCGCGACTGCTCCTCAAGTC \\
\hline & HPV-278 & & CCCGTCGACTTAGGACTCCCGAGTGCCATGG \\
\hline $\begin{array}{l}\text { 102K-TPR_C } \\
(279 / 237)\end{array}$ & HPV-279 & truncation & AAACCCCATATGCTGGAAGCACTCCTGCAG \\
\hline \multirow{2}{*}{$110 \mathrm{~K}-\mathrm{RS}$} & HPV-318 & \multirow{2}{*}{ truncation } & CCCGAATTCCATATGGGGTCGTCCAAGAAG CAT \\
\hline & HPV-319 & & CCCCTCGAGTCAGCTAGTTTTGGAGCTGGCAGC \\
\hline \multirow{2}{*}{$110 \mathrm{~K}-\Delta \mathrm{RS}$} & HPV-320 & \multirow{2}{*}{ truncation } & CCCGAATTCCATATGTCAGGCGATGCCTCCTCACTC \\
\hline & HPV-321 & & CCCCTCGAGTCACTTGGTGATGGTGTTCGC \\
\hline \multirow{2}{*}{$\begin{array}{l}116 \mathrm{~K} \\
(73 / 74)\end{array}$} & HPV-73 & \multirow{2}{*}{ full-length } & CCCGGATCCCATATGGATACTGACTTGTATGATG \\
\hline & HPV-74 & & CCCCTCGAGTCACATGGGATAATTGAGCAC \\
\hline $116-1(73 / 88)$ & HPV-88 & truncation & CCCCTCGAGTCAGCCAAGCTCGTCTAGGGTCCG \\
\hline \multirow[t]{2}{*}{$116-2$} & HPV-76 & \multirow{2}{*}{ truncation } & CCCCATATGCGACACATTGTGGATGAGGTC \\
\hline & HPV-89 & & CCCCTCGAGTCAAGGCTCAGCAATCATGGTGAT \\
\hline $116-3(78 / 74)$ & HPV-78 & truncation & CCCCATATGCTTGATGGCCTGCGCAAG \\
\hline \multirow{7}{*}{$200 \mathrm{~K}$} & HPV-29 & \multirow{7}{*}{$\begin{array}{l}\text { cDNA cloning } \\
\text { from library }\end{array}$} & CAGAGGTCCTGTCTTAGAAGCTTT \\
\hline & $\mathrm{HPV}-30$ & & GTGCACTGACAACTCCAACTTGGG \\
\hline & HPV-31 & & ATGTGTCCTCTGCGCCAGTTCCGG \\
\hline & HPV-32 & & ATTGGGGTTCTGTGTCATGCGGCG \\
\hline & HPV-33 & & GCCAAGCCTGTGTACCATGCTATC \\
\hline & HPV-34 & & CCCСTCGAGTCAATCTGAATCACTGTCTGTCTC \\
\hline & HPV-52 & & AGGGTCAACACGTAGAAAGGTGGC \\
\hline \multirow{2}{*}{$200-1$} & HPV-63 & \multirow{2}{*}{ truncation } & CCGCGGCCGCATATGGCGGATGTAACCGCCCGTAGTC \\
\hline & $\mathrm{HPV}-50$ & & CCCTCATGCCTGGGCATACTTTGGCAGCTT \\
\hline \multirow{2}{*}{$200-2$} & HPV-59 & \multirow{2}{*}{ truncation } & CCСАTATGGATCTCGACCAGGGTGGA \\
\hline & HPV-56 & & CCCTCACACTTGGGTGCCTTTGATGATGAC \\
\hline \multirow{2}{*}{$200-3$} & HPV-36 & truncation & CCCATATGCAGGTTTTAGTTTCCACCGCAACT \\
\hline & HPV-46 & truncation & AAATCAGTTGAAGTTCTGCACGTTCTTGCG \\
\hline
\end{tabular}




\begin{tabular}{|c|c|c|c|}
\hline \multirow{2}{*}{$200-4$} & HPV-38 & \multirow{2}{*}{ truncation } & CCCATATGGACCTGCAGCCCTTGCCCGTGT \\
\hline & HPV-44 & & AGCTCACATGCCTAGGTTCAGAGGCGCCAC \\
\hline \multirow{2}{*}{$200-5$} & HPV-40 & \multirow{2}{*}{ truncation } & CCCATATGTGTCAGGGCTCCAAGAAGGAT \\
\hline & HPV-34 & & CCCСTCGAGTCAATCTGAATCACTGTCTGTCTC \\
\hline \multirow{6}{*}{$220 \mathrm{~K}$} & HPV-3 & \multirow{6}{*}{$\begin{array}{l}\text { cDNA cloning } \\
\text { from library }\end{array}$} & СCCTTCGAAGCATATGGCCGGAGTGTTTCCTTATC \\
\hline & HPV-4 & & ССCCTGAGACTGGTTCAACCGAGAC \\
\hline & HPV-5 & & СССАСTAGTTATAAGCATGACACCAAGTTGCTC \\
\hline & HPV-6 & & CСССTCGAGACATTCCACTTATAGGAGGC \\
\hline & HPV-7 & & ATATAAGATGAACTCTTCCTGTG \\
\hline & HPV-8 & & CCCCTCGAGTTCGAAAGGCTTCGGCCTCGGGAGGCTG \\
\hline \multirow{2}{*}{$220-1$} & HPV-3 & \multirow{2}{*}{ truncation } & CCCTTCGAAGCATATGGCCGGAGTGTTTCCTTATC \\
\hline & HPV-66 & & CCCCTCGAGTCAGAAGGGCTCCACAAACTCCGG \\
\hline \multirow{2}{*}{$220-2$} & HPV-25 & \multirow{2}{*}{ truncation } & ССССАTATGCTGAAGGACACACCCCTCTA \\
\hline & HPV-26 & & CCCCTCGAGTCAGAATGGGATGGGTGAAAACC \\
\hline \multirow{2}{*}{$220-3$} & HPV-67 & \multirow{2}{*}{ truncation } & CCCGGATCCCATATGCCCCCACTCTCCTATAAGCAT \\
\hline & HPV-68 & & CCCCTCGAGTCAGTTGAGTCCAATCTTGATACG \\
\hline \multirow{2}{*}{$220-4$} & HPV-27 & \multirow{2}{*}{ truncation } & CCCCATATGTCCAAGATGCCAAGTCGGTT \\
\hline & HPV-28 & & CCCCTCGAGTCATGACTTTCGGGGATGGATTG \\
\hline \multirow{2}{*}{$220-5$} & HPV-69 & \multirow{2}{*}{ truncation } & CCCGAATTCCATATGTATAAGATGAACTCTTCCTGT \\
\hline & HPV-70 & & CСССTCGAGTCAATCCTTGAGCTGCACCTCGAC \\
\hline \multirow{2}{*}{$220-6$} & HPV-71 & \multirow{2}{*}{ truncation } & CCCGAATTCCATATGCTGATCTTGGCTGACTACGGC \\
\hline & HPV-72 & & CCCCTCGAGTCAGGCATACAGGTCCTCCCG \\
\hline \multirow{2}{*}{$220-6-\Delta C$} & HPV-71 & \multirow{2}{*}{ truncation } & CCCGAATTCCATATGCTGATCTTGGCTGACTACGG \\
\hline & HPV-326 & & CCCCTCGAGTCAGTTCGCCAGCTGTAGCTCATA \\
\hline \multirow{2}{*}{$220-6-\Delta \mathrm{N}$} & HPV-327 & \multirow{2}{*}{ truncation } & AAACCCCATATGCGCCAGAACACAGACAAGGGCAAC \\
\hline & HPV-72 & & CCCCTCGAGTCAGGCATACAGGTCCTCCCG \\
\hline \multirow{2}{*}{$220-6-\Delta \mathrm{N}$ P2301T } & HPV-331 & \multirow{2}{*}{ mutagenesis } & GAGCTACAGCTGGCGAACACCAAAGAGTTCTACC \\
\hline & HPV-332 & & CCTCGTGGTAGAACTCTTTGGTGTTCGCCAGCTGTAGC \\
\hline \multirow{2}{*}{ 220-6- $\Delta$ N F2304L } & HPV-333 & \multirow{2}{*}{ mutagenesis } & GCGAACCCCAAAGAGTTGTACCACGAGGTGCACAGG \\
\hline & HPV-334 & & GCCTGTGCACCTCGTGGTACAACTCTTTGGGGTTCG \\
\hline \multirow{2}{*}{ 220-6- $\triangle \mathrm{N}$ H2309P } & HPV-335 & mutarenecic & GAGTTCTACCACGAGGTGCCCAGGCCCTCTCACTTCC \\
\hline & HPV-336 & mutagenesis & TTGAGGAAGTGAGAGGGCCTGGGCACCTCGTGGTAGAAC \\
\hline $220-6-\Delta N$ & HPV-337 & mutorenecic & GAGTTCTACCACGAGGTGCGCAGGCCCTCTCACTTCC \\
\hline H2309R & HPV-338 & mutagenesis & TTGAGGAAGTGAGAGGGCCTGCGCACCTCGTGGTAGAAC \\
\hline $220-6-\Delta \mathrm{N}$ & HPV-339 & muttoneci & GAGTTCTACCACGAGGTGCACGGGCCCTCTCACTTCC \\
\hline R2310G & HPV-340 & mutagenesis & TTGAGGAAGTGAGAGGGCCCGTGCACCTCGTGGTAGAAC \\
\hline $220-6-\Delta N$ & HPV-341 & myta & GAGTTCTACCACGAGGTGCACAAGCCCTCTCACTTCC \\
\hline R2310K & HPV-342 & ilutagensis & TTGAGGAAGTGAGAGGGCTTGTGCACCTCGTGGTAGAAC \\
\hline $220-6-\Delta \mathrm{N}$ & HPV-343 & myta & TGCACAGGCCCTCTCACTTACTCAACTTTGCTCTCCTGC \\
\hline F2314L & HPV-344 & Allutagentis & AGGAGAGCAAAGTTGAGTAAGTGAGAGGGCCTGTGC \\
\hline
\end{tabular}




\begin{tabular}{|l|l|l|l|}
\hline \multirow{2}{*}{ SPF30/SMNrp } & LSB-17 & \multirow{2}{*}{ full-length } & CGCCGCCATATGTCAGAGGATTTAGCAAAGCAGC \\
\cline { 2 - 2 } & LSB-18, & & GGAACTCGAGGTACCTTATTGAGGCATCAAATGCC \\
\hline \multirow{2}{*}{ U6-p110 } & HPV-361 & \multirow{2}{*}{ full-length } & AAACCCGAATTCATGGCGACTGCGGCCGAAACC \\
\cline { 2 - 2 } pGEX-6P-1 & HPV-362 & & CCCCTCGAGTCACTTTCTCAGAAACAGCTTGG \\
\hline \multirow{2}{*}{ pGEX-5' } & \multirow{2}{*}{ modification } & GGGCTGGCAAGCCACGTTTGGTG \\
\cline { 2 - 2 } & pGEX-3' & & CCGGGAGCTGCATGTGTCAGAGG \\
\hline
\end{tabular}

\subsubsection{Vectors and plasmids (Table 3.2)}

\begin{tabular}{|c|c|c|}
\hline Plasmid & Description & Source \\
\hline pBluescript II KS & Cloning vector, $\mathrm{T} 7$ promoter, $\mathrm{Amp}^{\mathrm{r}}$ & Stratagene \\
\hline pGADT7 & $\begin{array}{l}\text { Y2H vector expresses proteins fused to GAL4 } \\
\text { activation domain, LEU2 marker, Amp }{ }^{\text {r }}\end{array}$ & Clontech \\
\hline pGBKT7 & $\begin{array}{l}\text { Y2H vector expresses proteins fused to GAL4 DNA } \\
\text { binding domain, TRP1 marker, } \operatorname{Kan}^{\mathrm{r}}\end{array}$ & Clontech \\
\hline pGEX-6P-1 & GST expression vector, $A m p^{r}$ & AP Biotech \\
\hline pET-28a-c & Expression vector, His-tag, T7 promoter, $\mathrm{Kan}^{\mathrm{r}}$ & Novagen \\
\hline pNoTA/T7 & Cloning vector, $\mathrm{T} 7$ promoter, $\mathrm{Amp}^{\mathrm{r}}$ & $5^{\prime} \rightarrow 3^{\prime}$ Inc. \\
\hline pGADT7-15K & Cloning sites $N d e \mathrm{I} \rightarrow$ SalI & $\begin{array}{l}\text { HP Vornlocher } \\
\text { (Lührmann lab) }\end{array}$ \\
\hline pGBKT7-15K & Cloning sites $N d e \mathrm{I} \rightarrow$ SalI & $\begin{array}{l}\text { HP Vornlocher } \\
\text { (Lührmann lab) }\end{array}$ \\
\hline pNoT-15.5K & Introduce cloning sites $N d e \mathrm{I} \rightarrow X h o \mathrm{I}$ by PCR, $\mathrm{Amp}^{\mathrm{r}}$ & This study \\
\hline pGADT7-15.5K & Cloning sites $N d e \mathrm{I} \rightarrow X h o \mathrm{I}$ & This study \\
\hline pGBKT7-15.5K & Cloning sites $N d e \mathrm{I} \rightarrow X h o \mathrm{I}$ & This study \\
\hline pNoT-20K & Introduce cloning sites $N d e \mathrm{I} \rightarrow X h o \mathrm{I}$ by PCR & This study \\
\hline pGADT7-20K & Cloning sites $N d e \mathrm{I} \rightarrow X h o \mathrm{I}$ & This study \\
\hline pGBKT7-20K & Cloning sites $N d e \mathrm{I} \rightarrow X h o \mathrm{I}$ & This study \\
\hline pNoT-27K & Introduce cloning sites NdeI $\rightarrow$ XhoI by PCR & This study \\
\hline pGADT7-27K & Cloning sites $N d e \mathrm{I} \rightarrow X$ hoI & This study \\
\hline pGBKT7-27K & Cloning sites $N d e \mathrm{I} \rightarrow X h o \mathrm{I}$ & This study \\
\hline pNoT-40K & Introduce cloning sites $\mathrm{NdeI} \rightarrow \mathrm{XhoI}$ by PCR & This study \\
\hline pGADT7-40K & Cloning sites $N d e \mathrm{I} \rightarrow X h o \mathrm{I}$ & This study \\
\hline pGBKT7-40K & Cloning sites $N d e \mathrm{I} \rightarrow X h o \mathrm{I}$ & This study \\
\hline pNoT-52K & Introduce cloning sites $N d e \mathrm{I} \rightarrow X h o \mathrm{I}$ by PCR & This study \\
\hline pGADT7-52K & Cloning sites $N d e \mathrm{I} \rightarrow X h o \mathrm{I}$ & This study \\
\hline pGBKT7-52K & Cloning sites $N d e \mathrm{I} \rightarrow X h o \mathrm{I}$ & This study \\
\hline pET28a-52K & Cloning sites $N d e \mathrm{I} \rightarrow X h o \mathrm{I}$ & This study \\
\hline pGADT7-52N & Cloning sites $N d e \mathrm{I} \rightarrow X h o I$, insert $: 1-255 \mathrm{aa}$ & This study \\
\hline pGBKT7-52N & Cloning sites $N d e I \rightarrow X h o I$, insert $: 1-255$ aa & This study \\
\hline pET28a-52N & Cloning sites $N d e \mathrm{I} \rightarrow X h o I$, insert $: 1-255$ aa & This study \\
\hline pGADT7-52C & Cloning sites $N d e I \rightarrow X h o I$, insert $: 256-341$ aa & This study \\
\hline pGBKT7-52C & Cloning sites $N d e \mathrm{I} \rightarrow X$ hoI, insert $: 256-341$ aa & This study \\
\hline pET28a-52C & Cloning sites $N d e \mathrm{I} \rightarrow X$ hoI, insert $: 256-341$ aa & This study \\
\hline pNoT-60K(mut) & Introduce cloning sites $N d e \mathrm{I} \rightarrow X h o I$ by PCR & This study \\
\hline pGADT7-60K(mut) & Cloning sites $N d e \mathrm{I} \rightarrow X h o \mathrm{I}$ & This study \\
\hline pGBKT7-60K(mut) & Cloning sites $N d e \mathrm{I} \rightarrow X h o \mathrm{I}$ & This study \\
\hline pNoT-60K(wt) & Introduce cloning sites $N d e \mathrm{I} \rightarrow X h o \mathrm{I}$ by PCR & This study \\
\hline
\end{tabular}




\begin{tabular}{|c|c|c|}
\hline pGADT7-60K(wt) & Cloning sites $N d e I \rightarrow X h o I$ & This study \\
\hline pGBKT7-60K(wt) & Cloning sites $N d e \mathrm{I} \rightarrow X h o \mathrm{I}$ & This study \\
\hline pGEX6P-60K(wt) & Cloning sites $N d e \mathrm{I} \rightarrow X h o \mathrm{I}$ & This study \\
\hline pGADT7-61K & Cloning sites $N d e \mathrm{I} \rightarrow X h o \mathrm{I}$ & $\begin{array}{l}\text { OV Makarova } \\
\text { (Lührmann lab) }\end{array}$ \\
\hline pGBKT7-61K & Cloning sites $N d e I \rightarrow X h o I$ & $\begin{array}{l}\text { OV Makarova } \\
\text { (Lührmann lab) }\end{array}$ \\
\hline pGEX6P-61K & Cloning sites $\mathrm{BamHI} \rightarrow$ XhoI & $\begin{array}{l}\text { S. Nottrott } \\
\text { (Lührmann lab) }\end{array}$ \\
\hline pNoT-61K-A194E & Introduce cloning sites $N d e \mathrm{I} \rightarrow X$ XhoI by PCR & This study \\
\hline pGBKT7-61K-A194E & Cloning sites $N d e \mathrm{I} \rightarrow X h o \mathrm{I}$ & This study \\
\hline pNoT-61K-A216P & Introduce cloning sites $N d e \mathrm{I} \rightarrow X h o \mathrm{I}$ by PCR & This study \\
\hline pGADT7-61K-A216P & Cloning sites $\mathrm{NdeI} \rightarrow X$ XhoI & This study \\
\hline pGBKT7-61K-A216P & Cloning sites NdeI $\rightarrow$ XhoI & This study \\
\hline pGADT7-65K & Cloning sites $E c o R I \rightarrow X h o I$ & $\begin{array}{l}\text { OV Makarova } \\
\text { (Lührmann lab) }\end{array}$ \\
\hline pGBKT7-65K & Cloning sites $E c o R I \rightarrow X h o I$ & $\begin{array}{l}\text { OV Makarova } \\
\text { (Lührmann lab) }\end{array}$ \\
\hline pNoT-90K & Introduce cloning sites $N d e \mathrm{I} \rightarrow X$ hoI by PCR & This study \\
\hline pGADT7-90K & Cloning sites $N d e \mathrm{I} \rightarrow X$ hoI & This study \\
\hline pGBKT7-90K & Cloning sites $N d e \mathrm{I} \rightarrow X h o \mathrm{I}$ & This study \\
\hline pNoT-90K-P493S & Introduce cloning sites $N d e \mathrm{I} \rightarrow X h o I$ by PCR & This study \\
\hline pGADT7-90K-P493S & Cloning sites $N d e \mathrm{I} \rightarrow X h o \mathrm{I}$ & This study \\
\hline pGBKT7-90K-P493S & Cloning sites $N d e \mathrm{I} \rightarrow X h o \mathrm{I}$ & This study \\
\hline pNoT-90K-T494M & Introduce cloning sites $N d e \mathrm{I} \rightarrow X h o I$ by PCR & This study \\
\hline pGADT7-90K-T494M & Clonign sites $N d e \mathrm{I} \rightarrow X$ XhoI & This study \\
\hline pGBKT7-90K-T494M & Cloning sites $N d e \mathrm{I} \rightarrow X h o \mathrm{I}$ & This study \\
\hline pGADT7-90K-N194 & Cloning sites NdeI $\rightarrow$ XhoI & This study \\
\hline pGBKT7-90K-N194 & Cloning sites $N d e \mathrm{I} \rightarrow X h o \mathrm{I}$ & This study \\
\hline pGADT7-90K-N309 & Cloning sites $E c o R I \rightarrow X h o I$ & This study \\
\hline pGBKT7-90K-N309 & Cloning sites EcoRI $\rightarrow X$ hoI & This study \\
\hline pGADT7-90K-N442 & Cloning sites EcoRI $\rightarrow X h o I$ & This study \\
\hline pGBKT7-90K-N442 & Cloning sites EcoRI $\rightarrow X$ hoI & This study \\
\hline pGADT7-90K-C267 & Cloning sites EcoRI $\rightarrow X h o I$ & This study \\
\hline pGBKT7-90K-C267 & Cloning sites EcoRI $\rightarrow X$ hoI & This study \\
\hline pGADT7-90K-C381 & Cloning sites EcoRI $\rightarrow X h o I$ & This study \\
\hline pGBKT7-90K-C381 & Cloning sites EcoRI $\rightarrow X h o I$ & This study \\
\hline pGADT7-90K-C489 & Cloning sites EcoRI $\rightarrow X h o I$ & This study \\
\hline pGBKT7-90K-C489 & Cloning sites EcoRI $\rightarrow$ XhoI & This study \\
\hline pGADT7-100K & Cloning sites $N d e \mathrm{I} \rightarrow$ SalI & $\begin{array}{l}\text { D. Ortlepp } \\
\text { (Lührmann lab) }\end{array}$ \\
\hline pGBKT7-100K & Cloning sites $N d e I \rightarrow$ SalI & $\begin{array}{l}\text { D. Ortlepp } \\
\text { (Lührmann lab) }\end{array}$ \\
\hline pNoT-102K & Cloning sites $N d e \mathrm{I} \rightarrow$ SalI & This study \\
\hline pGADT7-102K & Cloning sites $N d e \mathrm{I} \rightarrow$ SalI & This study \\
\hline pGBKT7-102K & Cloning sites $N d e \mathrm{I} \rightarrow$ SalI & This study \\
\hline pGEX6P-102K & Cloning sites $N d e \mathrm{I} \rightarrow$ SalI & This study \\
\hline pET28a-102K & Cloning sites $N d e \mathrm{I} \rightarrow$ SalI & This study \\
\hline pGADT7-102K-NTD & Cloning sites $N d e \mathrm{I} \rightarrow$ SalI & This study \\
\hline pGBKT7-102K-NTD & Cloning sites $N d e \mathrm{I} \rightarrow$ SalI & This study \\
\hline pET28a-102K-NTD & Cloning sites $N d e \mathrm{I} \rightarrow$ SalI & This study \\
\hline
\end{tabular}




\begin{tabular}{|c|c|c|}
\hline $\begin{array}{l}\text { pGADT7-102K- } \\
\text { TPR_M }\end{array}$ & Cloning sites $N d e \mathrm{I} \rightarrow$ SalI & This study \\
\hline $\begin{array}{l}\text { pGBKT7-102K- } \\
\text { TPR M }\end{array}$ & Cloning sites $N d e \mathrm{I} \rightarrow$ SalI & This study \\
\hline pET28a-102K-TPR_M & Cloning sites $N d e \mathrm{I} \rightarrow$ SalI & This study \\
\hline $\begin{array}{l}\text { pGADT7-102K- } \\
\text { TPR C }\end{array}$ & Cloning sites $N d e \mathrm{I} \rightarrow$ SalI & This study \\
\hline $\begin{array}{l}\text { pGBKT7-102K- } \\
\text { TPR_C }\end{array}$ & Cloning sites $N d e \mathrm{I} \rightarrow$ SalI & This study \\
\hline pGADT7-110K & Cloning sites $N d e \mathrm{I} \rightarrow X h o \mathrm{I}$ & $\begin{array}{l}\text { EM Makarov } \\
\text { (Lührmann lab) }\end{array}$ \\
\hline pGBKT7-110K & Cloning sites $N d e \mathrm{I} \rightarrow X h o I$ & $\begin{array}{l}\text { EM Makarov } \\
\text { (Lührmann lab) }\end{array}$ \\
\hline pET28a-110K & Makarov et al., 2001 & $\begin{array}{l}\text { EM Makarov } \\
\text { (Lührmann lab) }\end{array}$ \\
\hline pGADT7-110K_RS & Cloning sites $N d e \mathrm{I} \rightarrow X h o I, 1-111$ aa (insert) & This study \\
\hline pGBKT7-110K_RS & Cloning sites $N d e \mathrm{I} \rightarrow X h o \mathrm{I}, 1-111$ aa & This study \\
\hline pGADT7-110K_ $\Delta \mathrm{RS}$ & Cloning sites $N d e \mathrm{I} \rightarrow X h o \mathrm{I}, 112-800$ aa & This study \\
\hline pGBKT7-110K_ARS & Cloning sites $N d e \mathrm{I} \rightarrow X$ hoI, $112-800$ aa & This study \\
\hline pNoT-116K & Introduce cloning sites $N d e \mathrm{I} \rightarrow X h o I$ by PCR & This study \\
\hline pGADT7-116K & Cloning sites NdeI $\rightarrow$ XhoI, full-length 972 aa & This study \\
\hline pGBKT7-116K & Cloning sites $N d e \mathrm{I} \rightarrow$ XhoI, full-length 972 aa & This study \\
\hline pNoT-116-1 & Introduce cloning sites $N d e \mathrm{I} \rightarrow X$ hoI by PCR & This study \\
\hline pGADT7-116-1 & Cloning sites $N d e \mathrm{I} \rightarrow X h o \mathrm{I}, 1-400$ aa (insert) & This study \\
\hline pGBKT7-116-1 & Cloning sites $N d e \mathrm{I} \rightarrow X h o I, 1-400$ aa (insert) & This study \\
\hline pNoT-116-2 & Introduce cloning sites $N d e \mathrm{I} \rightarrow X h o \mathrm{I}$ by PCR & This study \\
\hline pGADT7-116-2 & Cloning sites $N d e \mathrm{I} \rightarrow X h o \mathrm{I}, 279-691$ aa (insert) & This study \\
\hline pGBKT7-116-2 & Cloning sites $N d e \mathrm{I} \rightarrow X$ hoI, $279-691$ aa (insert) & This study \\
\hline pNoT-116-3 & Introduce cloning sites $N d e \mathrm{I} \rightarrow X h o \mathrm{I}$ by PCR & This study \\
\hline pGADT7-116-3 & Cloning sites $N d e I \rightarrow X h o I, 603-972$ aa (insert) & This study \\
\hline pGBKT7-116-3 & Cloning sites $N d e \mathrm{I} \rightarrow X$ hoI, 603-972 aa (insert) & This study \\
\hline pBlue(KS)-200K & Cloning sites NotI $\rightarrow$ XhoI, full-length 2136 aa & $\begin{array}{l}\text { HP Vornlocher } \\
\text { (Lührmann lab) }\end{array}$ \\
\hline pGADT7-200K & Cloning sites $N d e I \rightarrow X h o I$, full-length 2136 aa & This study \\
\hline pGBKT7-200K & Cloning sites $N d e \mathrm{I} \rightarrow X h o \mathrm{I}$, full-length 2136 aa & This study \\
\hline pNoT-200-1 & Introduce cloning sites $N d e \mathrm{I}$ at $5^{\prime}$ end by PCR & This study \\
\hline pGADT7-200-1 & Cloning sites $N d e \mathrm{I} \rightarrow B a m H I, 1-434$ aa (insert) & This study \\
\hline pGBKT7-200-1 & Cloning sites $N d e \mathrm{I} \rightarrow B a m H I, 1-434$ aa & This study \\
\hline pET28c-200-1 & Cloning sites $N d e \mathrm{I} \rightarrow \mathrm{BamHI}, 1-434$ aa & This study \\
\hline pNoT-200-2 & Introduce cloning site $\mathrm{NdeI}$ at $5^{\prime}$ end by PCR & This study \\
\hline pGADT7-200-2 & Cloning sites $N d e \mathrm{I} \rightarrow E c o R I, 393-832$ aa (insert) & This study \\
\hline pGBKT7-200-2 & Cloning sites $N d e \mathrm{I} \rightarrow E c o R \mathrm{I}, 393-832$ aa & This study \\
\hline pET28c-200-2 & Cloning sites $N d e \mathrm{I} \rightarrow E c o R \mathrm{I}, 689-832$ aa & This study \\
\hline pNoT-200-3 & Introduce cloning site $N d e \mathrm{I}$ at $5^{\prime}$ end by PCR & This study \\
\hline pGADT7-200-3 & Cloning sites $N d e \mathrm{I} \rightarrow E c o R I, 807-1449$ aa (insert) & This study \\
\hline pGBKT7-200-3 & Cloning sites $N d e \mathrm{I} \rightarrow E c o R I, 807-1449$ aa & This study \\
\hline pET28c-200-3 & Cloning sites $N d e \mathrm{I} \rightarrow E c o R I, 807-1449$ aa & This study \\
\hline pNoT-200-4 & Introduce cloning site $\mathrm{NdeI}$ at 5 ' end by PCR & This study \\
\hline pGADT7-200-4 & Cloning sites $N d e \mathrm{I} \rightarrow E c o R I, 1301-1816$ aa (insert) & This study \\
\hline pGBKT7-200-4 & Cloning sites $N d e \mathrm{I} \rightarrow E c o R \mathrm{I}, 1301-1816$ aa & This study \\
\hline pET28c-200-4 & Cloning sites $N d e \mathrm{I} \rightarrow E c o R \mathrm{I}, 1301-1816$ aa & This study \\
\hline
\end{tabular}




\begin{tabular}{|c|c|c|}
\hline pNoT-200-5 & Introduce cloning sites $N d e \mathrm{I} \rightarrow X h o \mathrm{I}$ by PCR & This study \\
\hline pGADT7-200-5 & Cloning sites $N d e \mathrm{I} \rightarrow E c o R \mathrm{I}, 1705-2136$ aa (insert) & This study \\
\hline pGBKT7-200-5 & Cloning sites $N d e \mathrm{I} \rightarrow E c o R \mathrm{I}, 1705-2136$ aa & This study \\
\hline pET28c-200-5 & Cloning sites $N d e \mathrm{I} \rightarrow E c o R \mathrm{I}, 1705-2136$ aa & This study \\
\hline pNoT-220K-5, & Introduce cloning sites BstBI/NdeI at $5^{\prime}$ end by PCR & $\begin{array}{l}\text { HP Vornlocher } \\
\text { (Lührmann lab) }\end{array}$ \\
\hline pNoT-220K-Mi & Introduce cloning sites $S p e I \rightarrow X h o I$ by PCR & $\begin{array}{l}\text { HP Vornlocher } \\
\text { (Lührmann lab) }\end{array}$ \\
\hline pNoT-220K-Mi & Introduce cloning sites $X h o \mathrm{I} / \mathrm{Bst} B \mathrm{I}$ at 3' end by PCR & $\begin{array}{l}\text { HP Vornlocher } \\
\text { (Lührmann lab) }\end{array}$ \\
\hline pBlue(KS)-220K & Cloning sites $N d e I \rightarrow X h o I$, full-length 2335 aa & This study \\
\hline pGADT7-220K & Cloning sites NdeI $\rightarrow X h o I$, full-length 2335 aa & This study \\
\hline pGBKT7-220K & Cloning sites $N d e \mathrm{I} \rightarrow X h o I$, full-length 2335 aa & This study \\
\hline pNoT-220-1 & Introduce cloning sites $N d e \mathrm{I} \rightarrow X h o \mathrm{I}$ by PCR & This study \\
\hline pGADT7-220-1 & Cloning sites $N d e \mathrm{I} \rightarrow X h o \mathrm{I}, 1-387$ aa insert & This study \\
\hline pGBKT7-220-1 & Cloning sites $N d e \mathrm{I} \rightarrow X$ hoI, $1-387$ aa & This study \\
\hline pET28c-220-1 & Cloning sites $N d e \mathrm{I} \rightarrow$ SstI, $1-370$ aa & $\begin{array}{l}\text { HP Vornlocher } \\
\text { (Lührmann lab) }\end{array}$ \\
\hline pNoT-220-2 & Introduce cloning sites $N d e \mathrm{I} \rightarrow X h o \mathrm{I}$ by PCR & $\begin{array}{l}\text { HP Vornlocher } \\
\text { (Lührmann lab) }\end{array}$ \\
\hline pGADT7-220-2 & Cloning sites $N d e \mathrm{I} \rightarrow X$ hoI, $388-827$ aa insert & This study \\
\hline pGBKT7-220-2 & Cloning sites $N d e \mathrm{I} \rightarrow X$ hoI, $388-827$ aa & This study \\
\hline pET28c-220-2 & Cloning sites $N d e \mathrm{I} \rightarrow X h o I, 388-827$ aa & $\begin{array}{l}\text { HP Vornlocher } \\
\text { (Lührmann lab) }\end{array}$ \\
\hline pNoT-220-3 & Introduce cloning sites $N d e \mathrm{I} \rightarrow X$ hoI by PCR & This study \\
\hline pGADT7-220-3 & Cloning sites NdeI $\rightarrow X h o I, 828-1304$ aa insert & This study \\
\hline pGBKT7-220-3 & Cloning sites NdeI $\rightarrow X h o \mathrm{I}, 828-1304$ aa & This study \\
\hline pET28b-220-3 & Cloning sites NdeI $\rightarrow$ SstI, $1015-1274$ aa & $\begin{array}{l}\text { HP Vornlocher } \\
\text { (Lührmann lab) }\end{array}$ \\
\hline pNoT-220-4 & Introduce cloning sites $N d e \mathrm{I} \rightarrow X h o \mathrm{I}$ by PCR & $\begin{array}{l}\text { HP Vornlocher } \\
\text { (Lührmann lab) }\end{array}$ \\
\hline pGADT7-220-4 & Cloning sites NdeI $\rightarrow$ XhoI, $1305-1619$ aa insert & This study \\
\hline pGBKT7-220-4 & Cloning sites $N d e \mathrm{I} \rightarrow$ XhoI, $1305-1619$ aa & This study \\
\hline pET28c-220-4 & Cloning sites $N d e I \rightarrow X h o I, 1305-1619$ aa & $\begin{array}{l}\text { HP Vornlocher } \\
\text { (Lührmann lab) }\end{array}$ \\
\hline pNoT-220-5 & Introduce cloning sites $N d e \mathrm{I} \rightarrow X h o \mathrm{I}$ by PCR & This study \\
\hline pGADT7-220-5 & Cloning sites NdeI $\rightarrow$ XhoI, $1620-1985$ aa insert & This study \\
\hline pGBKT7-220-5 & Cloning sites NdeI $\rightarrow$ XhoI, $1620-1985$ aa & This study \\
\hline pET28c-220-5 & Cloning sites BamHI $\rightarrow$ BglII, 1736-2006 aa & $\begin{array}{l}\text { HP Vornlocher } \\
\text { (Lührmann lab) }\end{array}$ \\
\hline pNoT-220-6 & Introduce cloning sites $N d e \mathrm{I} \rightarrow X h o \mathrm{I}$ by PCR & This study \\
\hline pGADT7-220-6 & Cloning sites NdeI $\rightarrow$ XhoI, $1986-2335$ aa insert & This study \\
\hline pGBKT7-220-6 & Cloning sites NdeI $\rightarrow$ XhoI, $1986-2335$ aa & This study \\
\hline pET28c-220-6 & Cloning sites $N d e I \rightarrow X h o I, 1986-2335$ aa (?) & $\begin{array}{l}\text { HP Vornlocher } \\
\text { (Lührmann lab) }\end{array}$ \\
\hline pNoT-220-6- $\Delta \mathrm{C}$ & Introduce cloning sites $N d e \mathrm{I} \rightarrow X h o \mathrm{I}$ by PCR & This study \\
\hline pGADT7-220-6- $\Delta \mathrm{C}$ & Cloning sites $N d e \mathrm{I} \rightarrow X$ hoI, $1986-2300$ aa insert & This study \\
\hline pGBKT7-220-6- $\Delta \mathrm{C}$ & Cloning sites $N d e \mathrm{I} \rightarrow$ XhoI, $1986-2300$ aa & This study \\
\hline pET28a-220-6- $\Delta$ C & Cloning sites $N d e \mathrm{I} \rightarrow X h o \mathrm{I}, 1986-2300$ aa & This study \\
\hline pNoT-220-6- $\Delta \mathrm{N}$ & Introduce cloning sites $N d e \mathrm{I} \rightarrow X h o I$ by PCR & This study \\
\hline pGADT7-220-6- $\Delta \mathrm{N}$ & Cloning sites NdeI $\rightarrow$ XhoI, $2239-2335$ aa insert & This study \\
\hline pGBKT7-220-6- $\Delta \mathrm{N}$ & Cloning sites $N d e \mathrm{I} \rightarrow$ XhoI, $2239-2335$ aa & This study \\
\hline
\end{tabular}




\begin{tabular}{|c|c|c|}
\hline pET28a-220-6- $\Delta N$ & Cloning sites $N d e \mathrm{I} \rightarrow$ XhoI, $2239-2335$ aa & This study \\
\hline $\begin{array}{l}\text { pNoT-220-6- } \Delta \mathrm{N}- \\
\text { P2301T }\end{array}$ & Introduce a point mutation by PCR & This study \\
\hline $\begin{array}{l}\text { pGADT7-220-6- } \Delta \mathrm{N}- \\
\text { P2301T }\end{array}$ & Cloning sites $N d e I \rightarrow X h o I, 2239-2335$ aa insert & This study \\
\hline $\begin{array}{l}\text { pGBKT7-220-6- } \Delta \mathrm{N}- \\
\mathrm{P} 2301 \mathrm{~T}\end{array}$ & Cloning sites NdeI $\rightarrow$ XhoI, 2239-2335 aa & This study \\
\hline $\begin{array}{l}\text { pNoT-220-6- } \Delta \text { N- } \\
\text { F2304L }\end{array}$ & Introduce a point mutation by $\mathrm{PCR}$ & This study \\
\hline $\begin{array}{l}\text { pGADT7-220-6- } \Delta \mathrm{N}- \\
\text { F2304L }\end{array}$ & Cloning sites $N d e I \rightarrow X h o I, 2239-2335$ aa insert & This study \\
\hline $\begin{array}{l}\text { pGBKT7-220-6- } \Delta \mathrm{N}- \\
\text { F2304L }\end{array}$ & Cloning sites $N d e \mathrm{I} \rightarrow X h o I, 2239-2335$ aa & This study \\
\hline $\begin{array}{l}\text { pNoT-220-6- } \Delta \mathrm{N}- \\
\mathrm{H} 2309 \mathrm{P}\end{array}$ & Introduce a point mutation by PCR & This study \\
\hline $\begin{array}{l}\text { pGADT7-220-6- } \Delta \mathrm{N}- \\
\mathrm{H} 2309 \mathrm{P}\end{array}$ & Cloning sites $N d e I \rightarrow X h o I, 2239-2335$ aa insert & This study \\
\hline $\begin{array}{l}\text { pGBKT7-220-6- } \Delta \text { N- } \\
\text { H2309P }\end{array}$ & Cloning sites $N d e \mathrm{I} \rightarrow$ XhoI, $2239-2335$ aa & This study \\
\hline $\begin{array}{l}\text { pNoT-220-6- } \Delta \text { N- } \\
\text { H2309R }\end{array}$ & Introduce a point mutation by $\mathrm{PCR}$ & This study \\
\hline $\begin{array}{l}\text { pGADT7-220-6- } \Delta \text { N- } \\
\text { H2309R }\end{array}$ & Cloning sites $N d e \mathrm{I} \rightarrow X h o I, 2239-2335$ aa insert & This study \\
\hline $\begin{array}{l}\text { pGBKT7-220-6- } \Delta \text { N- } \\
\text { H2309R }\end{array}$ & Cloning sites $N d e \mathrm{I} \rightarrow$ XhoI, $2239-2335$ aa & This study \\
\hline $\begin{array}{l}\text { pNoT-220-6- } \Delta \text { N- } \\
\text { R2310G }\end{array}$ & Introduce a point mutation by PCR & This study \\
\hline $\begin{array}{l}\text { pGADT7-220-6- } \Delta \mathrm{N}- \\
\text { R2310G }\end{array}$ & Cloning sites $N d e I \rightarrow X h o I, 2239-2335$ aa insert & This study \\
\hline $\begin{array}{l}\text { pGBKT7-220-6- } \Delta N- \\
\text { R2310G }\end{array}$ & Cloning sites $N d e \mathrm{I} \rightarrow X h o I, 2239-2335$ aa & This study \\
\hline $\begin{array}{l}\text { pNoT-220-6- } \Delta \text { N- } \\
\text { R2310K }\end{array}$ & Introduce a point mutation by PCR & This study \\
\hline $\begin{array}{l}\text { pGADT7-220-6- } \Delta \mathrm{N}- \\
\text { R2310K }\end{array}$ & Cloning sites $N d e I \rightarrow X h o I, 2239-2335$ aa insert & This study \\
\hline $\begin{array}{l}\text { pGBKT7-220-6- } \Delta \mathrm{N}- \\
\text { R2310K }\end{array}$ & Cloning sites $N d e \mathrm{I} \rightarrow X h o I, 2239-2335$ aa & This study \\
\hline $\begin{array}{l}\text { pNoT-220-6- } \Delta \mathrm{N}- \\
\text { F2314L }\end{array}$ & Introduce a point mutation by PCR & This study \\
\hline $\begin{array}{l}\text { pGADT7-220-6- } \Delta \mathrm{N}- \\
\text { F2314L }\end{array}$ & Cloning sites $N d e \mathrm{I} \rightarrow X h o I, 2239-2335$ aa insert & This study \\
\hline $\begin{array}{l}\text { pGBKT7-220-6- } \Delta \mathrm{N}- \\
\text { F2314L }\end{array}$ & Cloning sites $N d e \mathrm{I} \rightarrow$ XhoI, 2239-2335 aa & This study \\
\hline $\begin{array}{l}\text { pGADT7- } \\
\text { SPF30/SMNrp }\end{array}$ & Cloning sites $N d e I \rightarrow X h o I$, full-length 239 aa & This study \\
\hline $\begin{array}{l}\text { pGBKT7- } \\
\text { SPF30/SMNrp }\end{array}$ & Cloning sites $N d e I \rightarrow X h o I$, full-length 239 aa & This study \\
\hline $\begin{array}{l}\text { pGEX6P- } \\
\text { SPF30/SMNrp }\end{array}$ & Cloning sites $N d e \mathrm{I} \rightarrow X h o I$, full-length 239 aa & This study \\
\hline pNoT-U6-p110 & Introduce cloning sites $E c o R I \rightarrow X h o I$ by PCR & This study \\
\hline pGADT7-U6-p110 & Cloning sites $E c o R I \rightarrow X h o I, 2-963$ aa (insert) & This study \\
\hline pGBKT7-U6-p110 & Cloning sites EcoRI $\rightarrow$ XhoI, 2-963 aa & This study \\
\hline pGADT7-p110- $\Delta \mathrm{N}$ & 537-963 aa insert; Medenbach et al., 2004 & Bindereif lab \\
\hline pGADT7-p110- $\Delta \mathrm{C}$ & 2-688 aa insert; Medenbach et al., 2004 & Bindereif lab \\
\hline pGADT7-p110-AF & 2-350 aa insert; Medenbach et al., 2004 & Bindereif lab \\
\hline
\end{tabular}




\subsubsection{Bacterial strains}

E. coli BL21(DE3)

Novagen, Darmstadt

E. coli $\mathrm{DH} 5 \alpha$

Invitrogen, USA

E. coli HMS174(DE3)

Novagen, Darmstadt

E. coli $\mathrm{XL}-1$ blue

Stratagene, Heidelberg

\subsubsection{Yeast strains (Clontech, USA)}

\section{AH109, Y187}

\subsubsection{Reaction sets (Kits)}

ABI PRISM ${ }^{\text {TM }}$ Dye Deoxy Cycle Sequencing Kit

Amicon Centriplus Concentrator

ECL Western Blot Detection Kit

GFX Purification Kit

Human Hela Marathon-Ready ${ }^{\mathrm{TM}}$ cDNA Library

Luminescent ß-galactosidase Detection Kit II

Matchmaker Yeast Two-hybrid System 3

Pretransformed Human HeLa cDNA Library

Prime-It ${ }^{\circledR}$ || Random Primer Labelling Kit

Primer PCR Cloner ${ }^{\mathrm{TM}}$ Cloning System

pSTBlue-1 Perfertly Blunt ${ }^{\text {TM }}$ Cloning Kit

QIAprep Spin Miniprep Kit

QIAquick Gel Extraction Kit

QIAquick PCR Purification Kit

$\mathrm{TNT}^{\circledR}$ T7 Coupled Reticulocyte Lysate System
Applied Biosystems, Weiterstadt

Millipore, France

Amersham Biosciences, Freiburg

Amersham Biosciences, Freiburg

Clontech, Heidelberg

Clontech, Heidelberg

Clontech, Heidelberg

Clontech, Heidelberg

Stratagene, Heidelberg

5' $\rightarrow$ 3' Inc., USA

Novagen, Darmstadt

Qiagen, Hilden

Qiagen, Hilden

Qiagen, Hilden

Promega, USA

\subsubsection{Equipments}

ABI PRISM ${ }^{\mathrm{TM}} 310$ Genetic Analyzer

Biofuge (pico/fresco)

Electrophorese apparaturen

Gel documentation system

Gradient Master Modell 106

Heating block

Head over tail Rotor 7637-01

Hybridisation oven

Incubator BK-600

Incubation shaker Multitron

Petrischalen 92/16 mit Nocken

$\mathrm{pH}$ Meter

Phosphorimager Typhoon 8600

Applied Biosystems, Weiterstadt

Heraeus, Hanau

BiorRad, München

Biorad, München

BioComp Instruments, Canada

Hybaid Biometra, UK

Cole-Parmer, USA

Hybaid, Biometra

Heraeus, Hanau

Infors, Switzerland

Sarstedt, Nümbrecht

MettlerToledo,Switzerland

Molecular Dynamics 
Replica plater

SMART System

Sonifier

Sorvall Rotor

Speed Vac Concentrator 5301

Spectrophotometer Ultropsec 300 pro

SW60 Rotor

Scintillation counter LS 1701/TRI-CARB 2100TR

Ultra centrifuge

UV Lamp 254nm

Thermal Cycler

Vortex

X-ray film developer X-Omat 2000

\subsubsection{Special materials}

Amylose Resin

Cuvettes for Monolight 3010

Collodium Bags

Dialysis cassettes

Falcon tubes $(5,15,50 \mathrm{ml})$

Glass Beads (425-600 microns)

Glutathione Sepharose 4B

Nylon membrane Hybond-(N+)

Pipettes

Protein A Sepharose

Protein G Sepharose

Protran Nitrocellulose Membrane

Reaction tubes $(0.5 ; 1.5 ; 2 \mathrm{ml})$

Sterile filter $(0.2 ; 0.45 \mu \mathrm{m})$

Talon metal affinity resin

Vivaspin concentrators

X-ray film BioMax MR
Qbiogene, Eschwege

Pharmacia Biotech

Heinemann Labortechnik

Kendro, USA

Eppendorf, Hamburg

Amersham Biosciences, Freiburg

Beckman, USA

Beckman/Packard, USA

Sorvall/Beckman, USA

Bachofer, Reutlingen

Hybaid Omni Gene, UK

Janke \& Kunkel, Staufen i. Br.

Kodak, USA

New England Biolabs, France

Pharmingen, USA

Sartorius $\mathrm{GmbH}$, Göttingen

Pierce, USA

Greiner, Kremsmünster

Sigma, Deisenhofen

Amersham Biosciences, Freiburg

Qiagen, Hilden

Eppendorf, Hamburg

Amersham Biosciences, Freiburg

Amersham Biosciences, Freiburg

Schleicher \& Schuell, Dassel

Eppendorf, Hamburg

Millipore, France

Clontech, Heidelberg

Vivascience, Sartorius

Kodak, USA 


\subsection{Methods}

\subsubsection{Molecular Cloning}

Two strategies were used for the plasmid construction and the cDNA cloning in this work. In one strategy, DNA was amplified and the desired restriction enzyme sites were introduced at the 5' end by PCR (section 3.2.1.1). The PCR products were subcloned into a shuttle cloning vector pNoTA/T7 which is provided in the PRIMER PCR CLONER cloning system ( $5 \rightarrow 3$ ' Inc., Boulder, Colorado, USA). The correct insert in the pNoTA/T7 was subsequently transferred into the target vectors such as pGADT7 and pGBKT7. In the other strategy, PCR products were purified from agarose gel (section 3.2.1.2); the purified DNA was digested with appropriate enzymes and ligated with target vectors after purification (section 3.2.1.3). 1-2 $\mu$ ligation reaction was used for transformation (section 3.2.1.4). The positive colony was inoculated in LB medium and the plasmid DNA was prepared (section 3.2.1.5). $2 \mu \mathrm{I}$ DNA sample from mini-preparation was digested with appropriate enzymes and checked on the agarose gel. The insert with the right size was verified by sequencing (3.2.1.6).

\subsubsection{PCR amplification}

Polymerase chain reaction (PCR) was mostly used as a tool for CDNA cloning and plasmid construction in this work. For this purpose, forward and reverse primers were designed to introduce compatible restriction enzyme sites and 3-6 additional bases were added at the 5 ' ends to allow efficient digestion by restriction enzymes (table 3.1). The following text describes a typical PCR reaction and a PCR cycling programme. The annealing temperature can be chosen on the basis of the melting temperature of the primers. This may work, but sometimes the results may not match up to expectations. Therefore, a simple procedure used many times in this work was to use an initial annealing temperature of $53^{\circ} \mathrm{C}$ (usually good for most primers with a length around $20 \mathrm{bp}$ or more). If non-specific products resulted, this temperature was increased. If there were no products, the temperature was decreased. 
PCR reaction mixture $(50 \mu \mathrm{l})$

\begin{tabular}{ll}
\hline $1.0 \mu \mathrm{l}$ & DNA sample ( 20ng) \\
$5.0 \mu \mathrm{l}$ & 5' oligo (10 pmol/ $\mu \mathrm{l})$ \\
$5.0 \mu \mathrm{l}$ & 3' oligo $(10 \mathrm{pmol} / \mu \mathrm{l})$ \\
$5.0 \mu \mathrm{l}$ & 10x cloned Pfu buffer \\
$5.0 \mu \mathrm{l}$ & DMSO \\
$1.0 \mu \mathrm{l}$ & dNTP $(25 \mathrm{mM}$ each $)$ \\
$2.0 \mu \mathrm{l}$ & $P f u$ polymerase \\
$26.0 \mu \mathrm{l}$ & $\mathrm{H}_{2} \mathrm{O}$
\end{tabular}

\section{PCR cycling programme}

\begin{tabular}{ll}
\hline $\mathrm{x}$ & $95^{\circ} \mathrm{C} 1^{\prime}$ \\
$30 \mathrm{x}$ & $95^{\circ} \mathrm{C} 30^{\prime \prime}, 53^{\circ} \mathrm{C} 1^{\prime}, 72^{\circ} \mathrm{C} 2^{\prime} / \mathrm{kb}$ \\
$1 \mathrm{x}$ & $72^{\circ} \mathrm{C} 6^{\prime}$
\end{tabular}

hold temperature at $4^{\circ} \mathrm{C}$

\subsubsection{Agarose gel electrophoresis and DNA fragment isolation}

For analysis of plasmid DNA, $0.8 \%$ agarose gel was usually used in this study. A 1-kb DNA ladder at a concentration of $0.05 \mathrm{mg} / \mathrm{ml}$ was loaded in one lane as a marker. Gel was run in 1 x TBE buffer and stained in $0.5 \mu \mathrm{g} / \mathrm{ml}$ ethidium bromide (EtBr). DNA was visualized under UV light.

\begin{tabular}{ll} 
10x TBE buffer $(\mathrm{pH} 8.3)$ \\
\hline $1 \mathrm{M}$ & Tris base \\
$0.83 \mathrm{M}$ & Boric acid \\
$10 \mathrm{mM}$ & EDTA \\
& \\
$5 x$ DNA loading buffer \\
\hline $30 \%$ & glycerol $(\mathrm{v} / \mathrm{v})$ \\
$0.25 \%$ & bromophenol blue $(\mathrm{w} / \mathrm{v})$ \\
$025 \%$ & xylene cyanol FF $(\mathrm{w} / \mathrm{v})$
\end{tabular}

QIAquick gel exaction kit (Qiagen, Hilden, Germany) was used for isolation of DNA fragments from agarose gel. The samples (PCR products or enzymedigested DNA samples) were electrophoresed through $0.8 \%$ agarose gel and stained with EtBr. The band of interest was identified using a UV-illuminator and cut out of the gel. The gel slice containing the DNA fragment was placed in the prepared tube and weighed. Every $100 \mathrm{mg}$ of gel was dissolved in $300 \mu \mathrm{l}$ buffer QG at $50^{\circ} \mathrm{C}$ for 10 minutes. After the gel slice has dissolved completely, it was applied to the QIAquick column and spun down for 1 minute. The column was washed once with $0.75 \mathrm{ml}$ wash buffer PE and the DNA sample was eluted with $30 \mu$ l elution buffer EB (10 mM Tris- $\mathrm{HCl}, \mathrm{pH} 8.5)$. 


\subsubsection{Enzyme digestion and ligation}

For the ligation reaction, the vector DNA and the insert DNA have to be prepared by digesting with appropriate restriction enzymes and then purifying with either GFX purification kit (Amersham Biosciences) or QIAquick PCR Purification Kit (Qiagen) according to the manufacture's protocol. The ligation reaction was established as follows. For the optimal ligation efficiency, two DNA molecules were added in the reaction in the range of $3: 1$ to $5: 1$ molar ratio of insert to vector. The reaction mixture was incubated at $16^{\circ} \mathrm{C}$ for 3 hours or more and was then incubated at $65^{\circ} \mathrm{C}$ for 15 minutes to inactivate the enzyme. The sample was spun down briefly and $2 \mu$ was used for transformation.

$\underline{20} \mu \mathrm{l}$ ligation reaction mixture

$2.0 \mu \mathrm{l} \quad 10 \mathrm{x}$ buffer for T4 DNA ligase

$2.0 \mu \mathrm{l} \quad$ linearised vector DNA

$8.0 \mu \mathrm{l} \quad$ insert DNA

$7.5 \mu \mathrm{l} \quad \mathrm{H}_{2} \mathrm{O}$

$0.5 \mu \mathrm{l} \quad$ T4 DNA ligase $(400 \mathrm{U} / \mu \mathrm{l})$

\subsubsection{Bacterial transformation}

Two methods were used for the bacterial transformation in this work.

\subsection{Transformation of $E$. coli cells by electroporation}

\section{- Preparation of competent cells}

One litre of culture was incubated until an OD600 of 0.4-0.6 was reached. The culture was centrifuged at $4000 \times \mathrm{g}$ for 15 minutes. The pellet was washed twice with $500 \mathrm{ml}$ ice-cooled, sterile water, once with $200 \mathrm{ml}$ ice-cooled, sterile $10 \%$ glycerol and once with $50 \mathrm{ml}$ ice-cooled, sterile $10 \%$ glycerol. The last pellet was resuspended in $4 \mathrm{ml}$ of ice-cooled, sterile $10 \%$ glycerol. $50 \mu$ laliquots were prepared and were shock-frozen in liquid nitrogen and placed in the $-70^{\circ} \mathrm{C}$ freezer for storage.

\section{- Transformation}

Before transformation, a $50 \mu$ aliquot of competent cells was thawed on ice. The DNA to be transformed was then added to competent cells and the cell mixture was transferred to a pre-chilled electroporation cuvette (BioRad). After a brief incubation on ice, the cells were exposed to a voltage of $1.8 \mathrm{kV}$ (for 
cuvettes with $0.1 \mathrm{~mm}$ width) using the E. coli Pulser (BioRad). $950 \mu \mathrm{l}$ of LB medium was added to the cuvette after electroporation. The cells were transferred to a $1.5-\mathrm{ml}$ microcentrifuge tube, incubated at $37^{\circ} \mathrm{C}$ for $40-60$ minutes, spread on LB plates containing appropriate antibiotics and incubated at $37^{\circ} \mathrm{C}$ overnight.

\subsection{Transformation of $E$. coli cells by heat shock}

\section{- Preparation of competent cells (rubidium chloride method)}

$250 \mathrm{ml}$ culture was incubated until an OD600 of $0.4-0.6$ was reached. The culture was centrifuged at $4000 \times \mathrm{g}$ for 15 minutes at $4^{\circ} \mathrm{C}$. The cell pellet was resuspended in $100 \mathrm{ml}$ ice-cooled TFBI buffer and incubated on ice for 10 minutes. The resuspension was centrifuged at $4000 \mathrm{xg}$ for 5 minutes at $4^{\circ} \mathrm{C}$. The pellet was resuspended in $10 \mathrm{ml}$ ice-cooled TFBll buffer and incubated on ice for at least 15 minutes. $100 \mu \mathrm{l}$ aliquots were prepared and were shockfrozen in liquid nitrogen and placed in the $-70^{\circ} \mathrm{C}$ freezer for storage.

TFBI

30 mM potassium acetate

$100 \mathrm{mM}$ rubidium chloride

$10 \mathrm{mM} \quad$ calcium chloride

$50 \mathrm{mM} \quad$ manganese chloride

$15 \% \mathrm{v} / \mathrm{v} \quad$ glycerol

Adjust to $\mathrm{pH} 5.8$ with acetic acid and filter $(0.20 \mu \mathrm{m}$, Millipore $)$ to sterilize.

$\underline{\text { TFBII }}$

$\overline{10 \mathrm{mM}} \quad$ MOPS

$75 \mathrm{mM} \quad$ calcium chloride

$10 \mathrm{mM} \quad$ rubidium chloride

$15 \% \mathrm{v} / \mathrm{v} \quad$ glycerol

Adjust $\mathrm{pH}$ to 6.5 with $\mathrm{KOH}$ and filter to sterilize.

\section{- Transformation}

Before transformation, a $100 \mu$ l aliquot of competent cells was thawed on ice. The DNA or ligation reaction to be transformed was then added to the competent cells and the cell mixture was incubated on ice for 20-30 minutes and then at $42^{\circ} \mathrm{C}$ for 90 seconds for heat shock. $900 \mu$ of LB medium was added and incubated at $37^{\circ} \mathrm{C}$ for 45 minutes and then spread on the LB plates containing appropriate antibiotic and incubated at $37^{\circ} \mathrm{C}$ overnight. 


\subsubsection{Mini-preparation of plasmid DNA}

QIAprep spin miniprep kit (Qiagen, Hilden, Germany) was used for this purpose. The purification of plasmid DNA was performed following the methods described by manufacturer. A single colony was inoculated into $5 \mathrm{ml}$ LB liquid medium containing appropriate antibiotic and grown overnight at $37^{\circ} \mathrm{C}$ with shaking. $2 \mathrm{ml}$ of overnight culture was transferred to a 2-ml microcentrifuge tube and centrifuged at $13,000 \mathrm{rpm}$ at $4^{\circ} \mathrm{C}$ for 10 minutes. The cell pellet was resuspended in $250 \mu \mathrm{l}$ buffer $\mathrm{P} 1$ and then $250 \mu \mathrm{l}$ buffer P2 was added and mixed gently by inverting the tube 4-6 times. After 5 minutes incubation at room temperature, $350 \mu$ l buffer P3 was added and mixed immediately but gently by inverting the tube 4-6 times. The tube was centrifuged at 13,000 rpm for 10 minutes. The supernatant was applied to a QIAprep spin column by decanting. The column was spun down for 1 minute to remove the liquid and washed once with $0.75 \mathrm{ml}$ buffer PB and subsequently with $0.75 \mathrm{ml}$ buffer PE. The residual wash buffer was removed by additional centrifugation for 1 minute and air-dried for 1 minute. To elute DNA, $50 \mu$ l elution buffer EB was added to the centre of each column and the column was allowed to stand for 1 minute and centrifuged for 1 minute to collect the DNA sample. For checking the insert, $2 \mu$ LNA sample was used for enzyme digestion and run on $0.8 \%$ agarose gel.

\subsubsection{DNA sequencing}

To minimize potential misincorporation during PCR, I used high-fidelity Pfu DNA polymerase. In addition, the sequence accuracy of PCR products for each construct and cDNA was confirmed by sequencing. The sequencing reaction and PCR cycling programme were established as follows.

$20 \mu \mathrm{l}$ sequencing reaction

$10.0 \mu \mathrm{l} \quad \mathrm{H}_{2} \mathrm{O}$

$6.0 \mu \mathrm{l} \quad$ BigDye (Applied Biosystems, Weiterstadt, Germany)

$3.0 \mu \mathrm{l} \quad$ DNA sample ( 250 ng)

$1.0 \mu \mathrm{l} \quad$ sequencing oligo $(10 \mathrm{pmol} / \mu \mathrm{l})$

$\frac{\text { PCR cycling programme }}{1 \times \quad 96^{\circ} \mathrm{C} 1^{\prime}}$
$25 x \quad 96^{\circ} \mathrm{C} 30^{\prime \prime}, 55^{\circ} \mathrm{C} 30^{\prime \prime}, 60^{\circ} \mathrm{C} 4^{\prime}$
hold temperature at $4^{\circ} \mathrm{C}$

Following the temperature cycling, the reaction was spun down briefly. To precipitate the sample, $15 \mu \mathrm{l} 3 \mathrm{M} \mathrm{NaAc} \mathrm{pH} 5.3,65 \mu \mathrm{l} \mathrm{H}_{2} \mathrm{O}$ and $300 \mu \mathrm{l} 100 \%$ ethanol were added and mixed. The tube was centrifuged at $13,000 \mathrm{rpm}$ at 
$15^{\circ} \mathrm{C}$ for 20 minutes. The pellet was washed once with $750 \mu \mathrm{l} 70 \%$ ethanol, dried in air and resuspended in $25 \mu$ of template suppression reagent (Applied Biosystems, Weiterstadt, Germany). The DNA sample was sequenced by ABI PRISM $^{\text {TM }} 310$ Genetic Analyzer (Applied Biosystems).

\subsubsection{PCR-based site directed mutagenesis}

In vitro site-directed mutagenesis is an invaluable technique for studying protein structure-function relationships, gene expression and vector modification. Several methods have appeared in the literature, but many of these methods require single-stranded DNA as the template. The reason for this, historically, has been the need for separating the complementary strands to prevent reannealing. The use of $\mathrm{PCR}$ in site-directed mutagenesis accomplishes strand separation by using a denaturing step to separate the complementary strands and allowing efficient polymerization of the PCR primers. PCR-based sitedirected methods thus allow site-specific mutations to be incorporated in virtually any double-stranded plasmid, eliminating the need for M13-based vectors or single-stranded DNA rescue.

In this study, this method was used to introduce single-point mutations into human genes PRPF3 (U4/U6-90K) and PRPF8 (U5-220K). PfuTurbo DNA polymerase from Stratagene (Heidelberg, Germany) was used in the PCR reaction. I followed basically the protocol provided by Stratagene. The mutagenic oligonucleotide primers were ordered from MWG Biotech (Ebersberg, Germany) and are listed in table 3.1. Primers HPV-331-344 were synthesised for U5-220K; HPV-347, 348, 359 and 360 for U4/U6-90K. The PCR reaction and cycling programme were established as follows.

$35 \mu \mathrm{l} \mathrm{PCR}$ reaction

$\begin{array}{ll}1.0 \mu \mathrm{l} & \text { DNA template }(\sim 16 \mathrm{ng}) \\ 3.5 \mu \mathrm{l} & \text { 10x cloned Pfu buffer } \\ 2.0 \mu \mathrm{l} & \text { 5' oligo }(10 \mathrm{pmol} / \mu \mathrm{l}) \\ 2.0 \mu \mathrm{l} & \text { 3' oligo }(10 \mathrm{pmol} / \mu \mathrm{l}) \\ 1.0 \mu \mathrm{l} & \text { 25 mM dNTP } \\ 24.5 \mu \mathrm{l} & \mathrm{H}_{2} \mathrm{O} \\ 1.0 \mu \mathrm{l} & \text { PfuTurbo DNA polymerase }(2.5 \mathrm{U} / \mu \mathrm{l})\end{array}$

$\frac{\text { PCR cycling programme }}{1 \mathrm{x} \quad 95^{\circ} \mathrm{C} 30^{\prime \prime}}$

$12 \mathrm{x} \quad 95^{\circ} \mathrm{C} 30^{\prime \prime}, 55^{\circ} \mathrm{C} 1^{\prime}, 68^{\circ} \mathrm{C} 2^{\prime} / \mathrm{kb}$ 
Following the temperature cycling, the reaction mixture was cooled on ice for 2 minutes. To digest the methylated parental DNA template, $1 \mu$ restriction endonuclease $D p n l$ was added to the reaction and incubated at $37^{\circ} \mathrm{C}$ for one hour. $1 \mu \mathrm{l}$ of Dpnl-treated DNA was transformed into $50 \mu \mathrm{l} \mathrm{XL}-1$ blue competent cells by electroporation as described in section 3.2.1.4.1. The cells were spread on the LB plates containing appropriate antibiotic and grown at $37^{\circ} \mathrm{C}$ overnight. Several single colonies were inoculated into $5 \mathrm{ml} \mathrm{LB}$ medium at $37^{\circ} \mathrm{C}$ overnight respectively. The protocol described in section 3.2.1.5 was used for preparing plasmid DNA. The mutation was confirmed by DNA sequencing (section 3.2.1.6).

\subsubsection{8 cDNA cloning from library}

To clone U4/U6-60K, two oligonucleotides HPV-324 and HPV-325 (see table 3.1) corresponding respectively to the $5^{\prime}$ and $3^{\prime}$ ends of the ORF (gi|2708304) were synthesized and used in PCR with human Marathon-Ready cDNA as template. The amplified cDNA was cloned into the PCR cloning vector pNoTA/T7 (5' $\rightarrow$ 3' Inc.) to generate pNoT-60K. To construct pGADT7-60K and pGBKT7-60K, the Ndel-Xhol fragment of 60K was subcloned between the Ndel and Xhol sites of pGADT7 and the Ndel and Sall sites of pGBKT7, respectively. Since Ndel cleaves in the 3'-terminal region of 60K, Xhol-digested pNoT-60K was partially digested with Ndel to isolate the intact ORF DNA.

To clone the U5-220K protein, three overlapping fragments comprising the 5', central and 3 ' regions of full-length $220 \mathrm{~K}$ were amplified from Marathon-Ready cDNA by PCR using three pairs of oligonucleotides: HPV-3/HPV-4, HPV-5/HPV-6, and HPV-7/HPV-8 (see table 3.1). These were designed according to the sequence deposited in the GenBank data base (gi|3661609). The PCR products were cloned into the pNoTA/T7 vector. The three fragments were then released from pNoTA/T7 and jointly cloned into pBluescript-II-KS to generate the pBlue(KS)-220K full-length cDNA. To construct pGADT7-220K and pGBKT7-220K, 3.0-kb Ndel-Ndel and 3.9-kb Ndel-Xhol fragments of pBlue(KS)-220K were jointly cloned between the Ndel and Xhol sites of pGADT7 and the Ndel and Sall sites of pGBKT7, respectively. 
To clone the U5-200K gene, three overlapping fragments were PCR-amplified from Marathon-Ready cDNA by using three pairs of oligonucleotides: HPV-29/HPV-30, HPV-31/HPV-32 and HPV-33/HPV-34 (see table 3.1). These are complementary to the partial cDNA sequence of 200K (gi|20521659; Nagase et al., 1998). The three PCR products were cloned into pNoTA/T7 and subsequently cloned jointly into pBluescript-II-KS, resulting in a 4.8-kb 3'-region of the 200K cDNA. To obtain the 5'-end sequence, 5'-RACE PCR was performed using Marathon-Ready cDNA and the gene-specific primer HPV-52 (see table 3.1). The resulting 2.0-kb 5' RACE product was sequenced (it shows a 92-bp overlap with the sequence of the $3^{\prime}$ region) and fused with the $3^{\prime}$ sequence to yield full-length pBlue(KS)-200K cDNA. To construct pGADT7200K and pGBKT7-200K, 1.0-kb Ndel-Dralll and 5.4-kb Drall-Xhol fragments were jointly cloned between the Ndel and Xhol sites of pGADT7 and the Ndel and Sall sites of pGBKT7, respectively. To clone various truncated forms of the $200 \mathrm{~K}$ protein in pGADT7 and pGBKT7, fragments were generated and amplified by PCR by using pBlue(KS)-200K as a template. An Ndel site is at the same time introduced at the 5 ' ends. PCR products were cloned into pNoTA/T7 to generate the pNoT-200-(1 to 5) series. The Ndel-BamHI fragment of pNoT200-1 was cloned between the corresponding sites of pGADT7 and pGBKT7. The Ndel-Ndel and Ndel-EcoRl fragments of pNoT-200-2 were jointly subcloned between the Ndel-EcoRl sites of pGADT7 and pGBKT7, respectively. The Ndel-EcoRl fragments of pNoT-200-(3 to 5) were subcloned between the Ndel-EcoRI sites of pGADT7 and pGBKT7, respectively.

To clone U2-SPF30/SMNrp, two oligonucleotides LSB-17 and LSB-18' (see table 3.1) corresponding respectively to the $5^{\prime}$ and $3^{\prime}$ ends of the ORF (gi|54126076) were synthesized by introducing Ndel at 5' end and Xhol at 3' end and used in PCR with human Marathon-Ready cDNA as template. The PCR products were purified and digested with Ndel/Xhol and were subcloned between the Ndel and Xhol sites of pGADT7 and the Ndel and Sall sites of pGBKT7, respectively. 


\subsubsection{Plasmid construction for two-hybrid analysis}

To construct two-hybrid plasmids for the U4/U6-15.5K, U4/U6-20K, U4/U6.U5-27K, U5-40K, U5-52K， U4/U6-61K-A194E， U4/U6-61K-A216P, U4/U6-90K, and U5-116K proteins, the corresponding ORFs were amplified by PCR, at the same time including terminal Ndel and Xhol sites. PCR products were cloned into pNoTA/T7, and Ndel-Xhol fragments were transferred into pGADT7 linearised with Ndel/Xhol or into pGBKT7 linearised with Ndel/Sall. Fragments of the $52 \mathrm{~K}, 116 \mathrm{~K}$ and $220 \mathrm{~K}$ proteins were constructed in a similar manner. The cDNAs encoding full-length $100 \mathrm{~K}$ and $102 \mathrm{~K}$ were PCR-amplified, introducing terminal Ndel and Sall sites, respectively. PCR products were cloned into pNoTA/T7 to generate pNoT-100K and pNoT-102K respectively. Ndel-Sall fragments were transferred to pGADT7 cut with Ndel/Xhol or pGBKT7 cut with Ndel/Sall. To construct pGADT7-15K and pGBKT7-15K, the Ndel-Sall fragment from pXC35-15K (Reuter et al., 1999) was subcloned between the Ndel and Xhol sites of pGADT7 or between the Ndel and Sall sites of pGBKT7. The EcoRI-Xhol fragment of pSK-65K and the Ndel-Xhol fragments of pET28a-61K and pSK-110K (Makarova et al., 2001, 2002) were processed in the same way to obtain pGADT7-65K and pGBKT-65K, pGADT7$61 \mathrm{~K}$ and pGBKT-61K or pGADT7-110K and pGBKT-110K, respectively. To generate $\mathrm{Y} 2 \mathrm{H}$ vectors expressing truncated forms of $102 \mathrm{~K}$, the fragments indicated in figure 4.13 were PCR-amplified, again introducing terminal Ndel and Sall sites. PCR products were restriction-digested with Ndel and Sall and introduced into pGADT7 or pGBKT7 linearised with Ndel and Xhol or Ndel and Sall, respectively. The original constructs used for PCR cloning are showed in the table 3.3. 
Table 3.3. List of the original constructs used in this study

\begin{tabular}{|c|c|c|c|c|}
\hline $\begin{array}{l}\text { Human } \\
\text { protein }\end{array}$ & $\begin{array}{l}\text { Original } \\
\text { construct }\end{array}$ & $\begin{array}{l}\text { mRNA } \\
\text { Accession }\end{array}$ & Source* & Reference \\
\hline U4/U6-90K & $\begin{array}{l}\text { EST-90K } \\
(\text { aa205466) }\end{array}$ & gi|2708306 & S. Schieborr & $\begin{array}{l}\text { Lauber et al.1997 } \\
\text { Horowitz et al., } \\
1997\end{array}$ \\
\hline U4/U6-61K & $\begin{array}{l}\mathrm{pBISK}(-) / \mathrm{zm} 27- \\
61 \mathrm{~K}\end{array}$ & gi|18249846 & $\begin{array}{l}\text { Dr. O.V. } \\
\text { Makarova }\end{array}$ & $\begin{array}{l}\text { Makarova et al., } \\
2002\end{array}$ \\
\hline U4/U6-61K mut & $\begin{array}{l}\text { pTriEX-61K- } \\
\text { A194E }\end{array}$ & & \multirow{2}{*}{$\begin{array}{l}\text { Dr. S. S. } \\
\text { Bhattacharya }\end{array}$} & \multirow{2}{*}{$\begin{array}{l}\text { Vithana et al., } \\
2001 \\
\text { Deery et al., } 2002\end{array}$} \\
\hline U4/U6-61K mut & $\begin{array}{l}\text { pTriEX-61K- } \\
\text { A216P }\end{array}$ & & & \\
\hline U4/U6-60K & pNoT-60K & gi|2708304 & this study & $\begin{array}{l}\text { Horowitz et al., } \\
1997\end{array}$ \\
\hline U4/U6-20K & pKS-20K & gi|3647229 & Dr. D. Ingelfinger & $\begin{array}{l}\text { Teigelkamp et al. } \\
1998\end{array}$ \\
\hline U4/U6-15.5K & pKS-15.5K & gi|6318598 & Dr. S. Nottrott & $\begin{array}{l}\text { Nottrott et al., } \\
1999\end{array}$ \\
\hline U5-220K & pKS-220K & gi|3661609 & this study & Luo et al., 1999 \\
\hline U5-200K & pKS-200K & gi|45861371 & $\begin{array}{l}\text { Dr. H.-P. } \\
\text { Vornlocher }\end{array}$ & $\begin{array}{l}\text { Lauber et al., } \\
1996\end{array}$ \\
\hline U5-116K & НА01047 & gi| 434758 & Dr. P. Fabrizio & $\begin{array}{l}\text { Fabrizio et al., } \\
1997 \text { Nomura et } \\
\text { al., } 1994\end{array}$ \\
\hline U5-102K & $\begin{array}{l}\text { pKS-102K, } \\
\text { pET21a-102K }\end{array}$ & gi|7658290 & $\begin{array}{l}\text { Dr. E.M. } \\
\text { Makarov }\end{array}$ & $\begin{array}{l}\text { Makarov et al., } \\
2000 \\
\text { Nishikimi et al., } \\
1999\end{array}$ \\
\hline U5-52K & EST262201 & gi| 33875510 & $\begin{array}{l}\text { Dr. O.V. } \\
\text { Makarova }\end{array}$ & $\begin{array}{l}\text { Laggerbauer et } \\
\text { al., } 2005 \\
\text { Bialkowska et al., } \\
2002\end{array}$ \\
\hline U5-40K & pKS-40K & gi|3820593 & Dr. T. Achsel & $\begin{array}{l}\text { Achsel et al., } \\
1998\end{array}$ \\
\hline U5-15K & $\mathrm{pXC} 35-15 \mathrm{~K}$ & gi| 6572635 & Dr. K. Reuter & $\begin{array}{l}\text { Reuter et al., } \\
1999\end{array}$ \\
\hline U4/U6.U5-110K & $\mathrm{pSK}(-) / 110 \mathrm{~K}$ & gi|13926067 & $\begin{array}{l}\text { Dr. O.V. } \\
\text { Makarova } \\
\end{array}$ & $\begin{array}{l}\text { Makarova et al., } \\
2001\end{array}$ \\
\hline U4/U6.U5-65K & pSK-65K & gi||13926070 & $\begin{array}{l}\text { Dr. O.V. } \\
\text { Makarova }\end{array}$ & $\begin{array}{l}\text { Makarova et al., } \\
2001\end{array}$ \\
\hline U4/U6.U5-27K & RY-1 & gi|431952 & Dr. P. Fabrizio & Fetzer et al., 1997 \\
\hline U6-p110 & $\begin{array}{l}\text { pFastBacHT- } \\
\text { p110 }\end{array}$ & gi|21327689 & Dr. A. Bindereif & $\begin{array}{l}\text { Medenbach et al., } \\
2004\end{array}$ \\
\hline $\begin{array}{l}\text { U2- } \\
\text { SPF30/SMNrp }\end{array}$ & $\begin{array}{l}\text { pGADT7- } \\
\text { SPF30/SMNrp }\end{array}$ & gi|54126076 & this study & $\begin{array}{l}\text { Meister et al., } \\
2001 \\
\text { Reppsilber et al., } \\
2001\end{array}$ \\
\hline
\end{tabular}

* All these persons have been worked or are still working in the laboratory of Prof. Lührmann except Dr. Bindereif and Dr. Bhattacharya.

\subsubsection{Yeast Two-hybrid System}

The Matchmaker Two-Hybrid System 3 (Clontech, Palo Alto, USA) was used in this study. Two vectors pGADT7 and pGBKT7, two yeast strains AH109 and 
Y187, and two plasmids pGADT7-T and pGBKT7-53 were provided in this system. pGADT7-T encodes a Gal4 activation domain/SV40 large T-antigen fusion protein, while pGBKT7-p53 encodes a Gal4 DNA binding domain/murine p53 fusion protein. Murine p53 and SV40 large T-antigen are known to interact in a yeast two-hybrid assay and therefore provide a positive control for interacting proteins. The map of the vectors pGADT7 and pGBKT7 is shown in the Appendix; the genotypes of the yeast strains are shown in table 3.4. AH109 utilizes two nutritional markers HIS3 and ADE2 to control the stringency of selection: the $A D E 2$ gene, under the control of the GAL2 promoter, reduces the number of false positives, while the HIS3 gene, under the control of the GAL1 promoter, provides sensitive growth selection that helps to identify weak positive signals (section 3.2.2.1). $\beta$-galactosidase encoded by lacZ reporter can be detected using a variety of assays that differ in their relative levels of sensitivity (sections 3.2.2.2 and 3.2.2.3). I used yeast strain Y187 instead of AH109 for $\beta$-galactosidase assays, because $\mathrm{Y} 187$ exhibits a higher level of induced $\beta$-galactosidase activity than does AH109. X- $\alpha-G a l$ assay was used to detect inherent yeast MEL1 gene expression level (section 3.2.2.4). The phenotypes of the yeast strains $\mathrm{AH} 109$ and $\mathrm{Y} 187$ were verified before they were used in a transformation or mating experiment.

The yeast co-transformation method is described in section 3.2.2.5. To check protein expression after transformation into yeast cells, I followed the methods given in sections 3.2.2.8 and 3.2.2.9.

Table 3.4 Yeast host strain genotype used in this study

\begin{tabular}{|c|c|c|}
\hline Strain & Genotype & Reporters \\
\hline AH109 & $\begin{array}{l}\text { MATa, trp1-901, leu2-3, 112, ura3-52, } \\
\text { his3-200, gal4A, gal80A, } \\
\text { LYS2: : GAL1 UAS-GAL1 TATA -HIS3, } \\
\text { GAL2 UAS-GAL2 TATA-ADE2 } \\
\text { URA3 : : MEL1 UAS-MEL1 TATA-lacZ } \\
\text { MEL1 }\end{array}$ & $\begin{array}{l}\text { HIS3, ADE2, } \\
\text { MEL1, lacZ }\end{array}$ \\
\hline Y187 & $\begin{array}{l}\text { MATa, ura3-52, his3-200, trp1, leu2, } \\
\text { ade2-101, trp1-901, leu2-3, 112, } \\
\text { gal4A, gal80A, met }{ }^{-} \\
\text {URA3 : : GAL1 } \text { UAS }^{-G A L 1} \text { TATA-lacZ } \\
\text { MEL1 }\end{array}$ & MEL1, lacZ \\
\hline
\end{tabular}




\subsubsection{Yeast two-hybrid analysis of known proteins for interaction studies}

All cDNAs encoding full-length or truncated proteins were cloned into pGBKT7 (a Gal4 DNA-binding domain "bait" vector) and pGADT7 (a Gal4 activation domain "prey" vector) as described in sections 3.2.1.8 and 3.2.1.9. Two-hybrid assays were carried out according to procedures described in the manufacturer's manual. To screen for protein-protein interactions, the bait and prey plasmids were co-transformed into the yeast strain $\mathrm{AH} 109$ by using the lithium acetate method (section 3.2.2.5). Co-transformation reaction mixtures were plated onto minimal synthetic dropout (SD) medium lacking leucine and tryptophan and incubated at $30{ }^{\circ} \mathrm{C}$ for 3-5 days. Co-transformants were then replicated on two different selective media: SD/-His for activation of the GAL1HIS3 reporter gene and SD/-His-Ade for the activation of both the GAL1-HIS3 and the GAL2-ADE2 reporter gene. In each assay, empty vectors pGADT7 and pGBKT7 were used as negative controls, and pGADT7-T/pGBKT7-53 as a positive control. At least two independent co-transformants were tested for each assay.

\subsubsection{Colony-lift filter assay}

The colony-lift filter assay is used to detect reporter lacZ gene activity. It measures the $\beta$-galactosidase activity encoded by lacZ. It is used primarily to screen the large number of cotransformants that survived the nutritional selection. It can also be used to assay for an interaction between two known proteins in a GAL4 two-hybrid system.

Plates were incubated at $30^{\circ} \mathrm{C}$ until colonies appear and grew to a size of 1-2 $\mathrm{mm}$, and this usually took 4-5 days. For each plate of transformants assayed, a sterile Whatman \#5 or VWR grade 410 filter was used. It was placed in 2.5-5.0 $\mathrm{ml}$ of $\mathrm{Z}$ buffer/X-gal solution in a clean $150 \mathrm{~mm}$ plate. Using clean forceps, a clean dry filter was placed over the surface of the plate of colonies and gently rubbed with the side of the forceps, which helped the colonies to cling to the filter. After the filter was evenly wetted, it was carefully lifted off the agar plate and transferred to a pool of liquid nitrogen (colonies facing up). Liquid nitrogen lyses the yeast cells, thus allowing detection of the reporter gene. The filters were submerged for 10 seconds after which they were completely thawed at 
room temperature. The filter colony side facing up was then cautiously placed on the presoaked filter, with care not to trap any bubbles between the two filters. Filters were incubated at $30^{\circ} \mathrm{C}$ and checked periodically for the appearance of blue colonies.

\section{$\underline{Z \text { buffer }}$}

\begin{tabular}{|c|c|}
\hline $\mathrm{Na}_{2} \mathrm{HPO}_{4} .7 \mathrm{H}_{2} \mathrm{O}$ & $16.1 \mathrm{~g} / \mathrm{L}$ \\
\hline $\mathrm{NaH}_{4} \mathrm{PO}_{4} \cdot \mathrm{H}_{2} \mathrm{O}$ & $5.50 \mathrm{~g} / \mathrm{L}$ \\
\hline $\mathrm{KCl}$ & $0.75 \mathrm{~g} / \mathrm{L}$ \\
\hline $\mathrm{MgSO}_{4} \cdot 7 \mathrm{H}_{2} \mathrm{O}$ & $0.246 \mathrm{~g} / \mathrm{L}$ \\
\hline
\end{tabular}

X-gal stock solution

$20 \mathrm{mg} / \mathrm{ml}$ in DMF

Z buffer/ X-gal solution

$\begin{array}{ll}100 \mathrm{ml} & \text { Z-buffer } \\ 0.27 \mathrm{ml} & \beta \text {-mercaptoethanol } \\ 1.67 \mathrm{ml} & \text { X-gal stock solution }\end{array}$

\subsubsection{Chemiluminescence $\beta$-galactosidase assay}

The chemiluminescence $\beta$-galactosidase assay can be used to verify and quantify $\beta$-galactosidase activity in two-hybrid assays. In this work, I detected the potential effect of the point mutations of U5-220K on the interactions of this protein with U5-116K and U5-200K (see section 4.10.3) using the luminescence $\beta$-galactosidase detection kit II from Clontech (Palo Alto, USA).

As an example, the pGBKT7-116-3 and pGADT7- $\Delta \mathrm{N}-\mathrm{P} 2301 \mathrm{~T}$ were cotransformed into yeast Y187. The cells were plated on the medium SD/-LeuTrp and incubated at $30^{\circ} \mathrm{C}$ until colonies appear and grew to size of 1-2 mm, and this usually took 4-5 days. The colonies were grown in $5 \mathrm{ml} \mathrm{SD/-Leu-Trp}$ liquid medium overnight at $30^{\circ} \mathrm{C}$ and the $\mathrm{OD} 600$ should be $0.5-1.0$ in the next day. $2 \mathrm{ml}$ of overnight culture was added to $8 \mathrm{ml}$ of YPD medium and the ratio was adjusted so that the $\mathrm{OD} 600$ is approximately 0.2 . The culture was incubated at $30^{\circ} \mathrm{C}$ for $3-5$ hours with shaking $(250 \mathrm{rpm})$ until the OD600 reaches 0.4-0.6. 1.5 $\mathrm{ml}$ of the culture was harvested and the pellet was washed once with $1.5 \mathrm{ml}$ of $\mathrm{Z}$ buffer. The cells were resuspended in approximately $300 \mu \mathrm{l}$ of $Z$ buffer to bring the OD 600 to $\sim 2.5 .100 \mu \mathrm{l}$ aliquot was transferred into a fresh tube. The tube was placed in liquid nitrogen until the cells were frozen and then moved to a $37^{\circ} \mathrm{C}$ water bath for 30-60 seconds to thaw the cells. This freeze/thaw cycle was 
repeated twice. The tube was centrifuged for 5 minutes at maximum speed and the supernatant (i.e. yeast extract) was then transferred to a fresh tube and kept on ice. Three aliquots of $25 \mu \mathrm{l}$ of the yeast extract were prepared and each was mixed with $200 \mu \mathrm{l}$ of reaction buffer $(4 \mu \mathrm{l}$ reaction substrate $+196 \mu \mathrm{l}$ reaction buffer supplied in the kit). The mixture was incubated at room temperature (20$25^{\circ} \mathrm{C}$ ) for 60 minutes. For measuring, the sample was transferred into a luminometer tube (Cuvettes for Monolight 3010, 12X75 mm) and measured in the Luminometer Monolight 3010 in the Department of Molecular Developmental Biology in MPlbpc. The light emission was recorded as 5second integrals. The data from different samples including the negative and positive control groups were collected. The linear range of the assay was determined accordingly.

\subsubsection{X- $\alpha-G a l$ assay}

$\mathrm{X}$ - $\alpha$-Gal is a chromogenic substrate for $\alpha$-galactosidase, the product of the yeast MEL1 gene in response to GAL4 activation. It can be used to detect GAL4-based two-hybrid interactions directly on the nutritional selection plates. As $\alpha$-galactosidase accumulates in the medium, it hydrolyses $\mathrm{X}-\alpha-\mathrm{Gal}$, causing yeast colonies to turn blue. In this work, the $X-\alpha-G a l$ assay was used in the yeast two-hybrid screening with pGBK-200K-1 (see section 4.11 for results).

The yeast dropout medium was poured onto the $15-\mathrm{cm}$ plates and allowed to cool down and harden at room temperature. $250 \mu \mathrm{l}$ of X- $\alpha$-Gal stock solution (2 $\mathrm{mg} / \mathrm{ml}$ in DMF) was then evenly spread onto a $15-\mathrm{cm}$ plate. When plates dried, cells were plated and incubated at $30^{\circ} \mathrm{C}$ until blue colonies formed.

\subsubsection{LiAc-mediated yeast co-transformation}

Yeast colonies were grown in $15 \mathrm{ml}$ YPDA/Kan medium overnight at $30^{\circ} \mathrm{C}$ to stationary phase $\left(\mathrm{OD}_{600}>1.5\right)$ and were used to inoculate $150 \mathrm{ml}$ of YPD medium containing $0.003 \%$ adenine sulphate and $30 \mu \mathrm{g} / \mathrm{ml}$ kanamycin to produce an $\mathrm{OD}_{600}$ of $0.2-0.3$. The flask was incubated at $30^{\circ} \mathrm{C}$ for $3-5$ hours with shaking (230-270 rpm) to get a mid-log phase measuring an $\mathrm{OD} 600$ of 0.4-0.6. This culture is sufficient for 30 transformations. The culture was harvested in sterile $50 \mathrm{ml}$ centrifuge tube at $2000 \mathrm{rpm}$ (Megafuge 1.0R) for $5 \mathrm{~min}$ at room 
temperature $\left(20^{\circ} \mathrm{C}\right)$. The medium was poured off and $15 \mathrm{ml}$ of sterile distilled water was added to resuspend the cells. The cells were collected in one tube and centrifuged again to remove the water. $3.0 \mathrm{ml}$ of PEG/LiAc solution was added to the pellet and the tube was vortexed to resuspend the cells. This allows permeabilization of the yeast cells, resulting in competent cells. $100 \mu \mathrm{l}$ yeast competent cells were added to each $1.5-\mathrm{ml}$ sterile microcentrifuge tubes containing $5 \mu \mathrm{l}$ salmon sperm DNA $(10 \mathrm{mg} / \mathrm{ml})$ and $\sim 1.0 \mu \mathrm{g}$ DNA plasmids from bait and prey and were mixed well by pipetting. The tubes were incubated at $42^{\circ} \mathrm{C}$ for 20-30 minutes for heat shock. The cells were chilled on ice for 1-2 minutes, and were centrifuged at $7000 \mathrm{rpm}$ for 10 seconds to remove the supernatant. $50-100 \mathrm{ml}$ of sterile $\mathrm{dH}_{2} \mathrm{O}$ was added to the tubes and the pellet was resuspended by pipetting gently. The transformation mix was spread on an $\mathrm{SD} /$-Leu-Trp. The plates were incubated at $30^{\circ} \mathrm{C}$ until colonies appeared.

$1 \mathrm{ml} \mathrm{PEG/LiAc} \mathrm{solution} \mathrm{(prepare} \mathrm{fresh} \mathrm{just} \mathrm{prior} \mathrm{to} \mathrm{use)}$

$800 \mu \mathrm{l} \quad 50 \%$ PEG3350

$100 \mu \mathrm{l} 1 \mathrm{M} \mathrm{LiAc} \mathrm{pH7.5}$

$100 \mu \mathrm{l} 10 \times \mathrm{TE} \mathrm{pH} 7.5$

\subsubsection{Yeast two-hybrid screen with the N-terminal region of U5-200K}

The fragment 200-1 of U5-200K (amino acids 1-434) was constructed as a bait fusion (pGBKT7-200-1) as described in section 3.2.1.8. Before it was used for screening library, the following tests were performed. (1) This fusion protein was transformed into $\mathrm{AH} 109$, and the protein expression was confirmed by western blotting (see sections 3.2.2.8 and 3.2.2.9 for the methods). (2) It was confirmed that this fusion protein had no toxicity on the host strain by comparing the growth rate in liquid culture (SD/-Trp) of cells transformed with the empty vector pGBKT7 and cells transformed with pGBKT7-200-1. (3) The AH109 strain transformed with pGBKT7-200-1 exhibited background growth on SD/-His medium, but the background was eliminated by adding $20 \mathrm{mM} 3-\mathrm{AT}$; it was confirmed that there was no background growth on SD/-Ade-His medium.

The above experiments indicated that pGBKT7-200-1 was a suitable bait for the library screening. The pGBKT7-200-1 was therefore transformed into AH109 and grown on the medium SD/-Trp for 5 days. A single colony $(2-3 \mathrm{~mm}$ in 
diameter) was inoculated into $50 \mathrm{ml}$ of SD/-Trp medium and incubated overnight ( 23 hours) at $30^{\circ} \mathrm{C}$; the OD600 was 1.6 on the following day. The cells were harvested by centrifugation at $2000 \mathrm{rpm}$ (Megafuge $1.0 \mathrm{R}$ ) for $5 \mathrm{~min}$ at $4^{\circ} \mathrm{C}$. The cell pellet was resuspended in $5 \mathrm{ml}$ SD/-Trp medium and kept in room temperature. Just before use, one frozen aliquot $(\sim 1.0 \mathrm{ml})$ of the pretransformed human HeLa cDNA library in Y187 (see below for description) was thawed in a room-temperature water bath and mixed gently. $10 \mu \mathrm{l}$ was taken out and kept on ice for later titrating. The entire AH109:pGBKT7-200-1 culture and the $\sim 1 \mathrm{ml}$ library culture were combined in a 2-L sterile flask and $45 \mathrm{ml}$ of 1 X YPD containing $0.003 \%$ adenine sulphate and $15 \mu \mathrm{g} / \mathrm{ml}$ kanamycin were subsequently added. The flask was incubated overnight ( 24 hours) at $30^{\circ} \mathrm{C}$ with gentle swirling (40 rpm). The mating mixture was transferred to a sterile 50 $\mathrm{ml}$ centrifuge tube and the cells were harvested by centrifugation at $1500 \mathrm{rpm}$ for 10 minutes at $4^{\circ} \mathrm{C}$. Meanwhile, the mating flask was rinsed with 1X YPD (2X $25 \mathrm{ml}$ ), and the rinses were used to resuspended the first pellet, and the cells were spun down again and resuspended in $10 \mathrm{ml}$ of $0.5 \mathrm{X}$ YPD medium. This is the library mating mixture. $100 \mu$ of the mixture was used for mating efficiency analysis and the rest was then spread on the 50 large $(150-\mathrm{mm})$ plates of SD/Leu-Trp-His-Ade at $200 \mu \mathrm{l}$ per plate. The plates were incubated at $30^{\circ} \mathrm{C}$. The positive clones were selected between 5 and 12 days after incubation. These clones were reselected on the more stringent plates of SD/-Leu-Trp-His-Ade+ $20 \mathrm{mM}$ 3-AT+X-a-Gal. From this step, 126 positive clones were selected for preparing plasmid DNA samples (see section 3.2.2.7 for the method). The samples were then sequenced. The data were collected and analysed (see Results 4.11).

The pretransformed human HeLa cDNA library was purchased from Clontech (Palo Alto, USA). It was cloned into pGAD GH and amplified in E. coli strain DH10B. The plasmid DNA was isolated and used to transform yeast strain Y187.

\subsubsection{Quick preparation of plasmid DNA from yeast}

(Method from the Hahn laboratory)

The positive colony (2-3 $\mathrm{mm}$ in diameter) from the plate of SD/-Leu-Trp-HisAde $+20 \mathrm{mM} 3-\mathrm{AT}+\mathrm{X}-\alpha-\mathrm{Gal}$ was picked and resuspended in $200 \mu \mathrm{l}$ of lysis buffer. 
An equal volume of glass beads (425-600 microns; Sigma) was added and the mixture was mixed on a vortexer at top speed for 1 minute. $200 \mu$ of phenol/ $\mathrm{CHCl}_{3}(2: 1)$ was then added for extraction. The sample was centrifuged at $13000 \mathrm{rpm}$ at $4^{\circ} \mathrm{C}$ for 12 minutes. The supernatant was mixed with 2.5 volumes of $100 \%$ ethanol for precipitation of DNA at $-20^{\circ} \mathrm{C}$ for one hour. The DNA pellet was washed once with $80 \%$ ethanol. DNA was then dried and resuspended in $100 \mu \mathrm{T}$ TE buffer and used to transform $E$. coli.

\begin{tabular}{ll} 
Lysis buffer & $(10 \mathrm{ml})$ \\
\hline $100 \mathrm{mM}$ & $\mathrm{NaCl}$ \\
$10 \mathrm{mM}$ & Tris- $\mathrm{HCl} \mathrm{pH8.0}$ \\
$1 \mathrm{mM}$ & EDTA \\
$0.1 \%$ & SDS \\
& \\
\multicolumn{1}{l}{ TE buffer } & pH8.0 \\
\hline $10 \mathrm{mM}$ & Tris- $\mathrm{HCl} \mathrm{pH} 8.0$ \\
$1 \mathrm{mM}$ & EDTA pH 8.0
\end{tabular}

\subsubsection{Preparation of yeast protein extract (Urea/SDS method)}

For each transformed yeast strain assayed, a $5 \mathrm{ml}$ overnight culture (using SD/Leu or SD/-Trp medium) was used to inoculate $50 \mathrm{ml}$ of YPD medium containing $0.003 \%$ adenine sulphate and $30 \mu \mathrm{g} / \mathrm{ml}$ kanamycin to produce an OD600 0.4-0.6. 15 OD600 units of each culture were taken (e.g. if OD600=0.5, take $30 \mathrm{ml}$ of the culture) for centrifugation at $4^{\circ} \mathrm{C}$ and the cells were washed once with cold water. The pellet can be stored at $-80^{\circ} \mathrm{C}$ or go further for the next step. The pellet was resuspended in $200 \mu \mathrm{l}$ pre-warmed cracking buffer $\left(60^{\circ} \mathrm{C}\right)$ and the suspension was transferred to a $1.5-\mathrm{ml}$ microcentrifuge tube containing $150 \mu \mathrm{l}$ of glass beads. The mixtures were heated at $70^{\circ} \mathrm{C}$ for 10 minutes and then vortexed vigorously for 1 minute. Unbroken cells and debris were removed by centrifugation at $13000 \mathrm{rpm}$ for 5 minutes at $4^{\circ} \mathrm{C}$. The supernatant was transferred into a fresh tube, boiled for 3 minutes and loaded onto the protein gel.

\begin{tabular}{ll}
\multicolumn{2}{c}{ Cracking buffer stock solution } \\
\hline $8 \mathrm{M}$ & Urea \\
$5 \%(\mathrm{w} / \mathrm{v})$ & SDS \\
$40 \mathrm{mM}$ & Tris-HCl pH 6.8 \\
$0.1 \mathrm{mM}$ & EDTA \\
$0.4 \mathrm{mg} / \mathrm{ml}$ & Bromophenol blue
\end{tabular}

Cracking buffer

$1 \mathrm{ml} \quad$ Cracking buffer stock solution

$10 \mu \mathrm{l} \quad \beta$-mercaptoethanol

$70 \mu \mathrm{l} \quad$ protease inhibitor cocktail

$50 \mu \mathrm{l} \quad 0.1 \mathrm{M} \mathrm{PMSF}$ 


\subsubsection{Western blotting}

Proteins were separated by SDS-PAGE (a pre-stained MW standards from BioRad were applied onto one lane as an indication of a successful transfer) and transferred to Hybond $\mathrm{C}$ or Hybond $\mathrm{P}$ membrane using a semi-dry transfer apparatus (Biometra). The gel, membrane and sheets of Whatman paper 3MM were soaked in transfer buffer, and the sandwich containing the gel and membrane was placed between sheets of 3MM paper. The transfer was performed for 45 minutes at $10 \mathrm{~W}$. To decrease non-specific binding of antibodies, the membrane was blocked in TBS-Tween buffer containing 5\% non-fat dried milk for two hours at room temperature or at $4^{\circ} \mathrm{C}$ overnight on a rocking platform. All further manipulations were carried out in TBS-Tween buffer containing $1 \%$ non-fat dried milk. After blocking, the membrane was washed 3 times, and then incubated with primary antibody against the protein of interest for one hour at room temperature on a rocking platform. The optimum dilution of the antibody was determined by titration and was typically in the range of $1: 500$ to $1: 5000$.

The membrane was washed three times for 15 minutes each and then incubated with either a secondary antibody or protein $A$, conjugated to horseradish peroxidase (HRP), in a manner described for the primary antibody. Protein A-HRP was used at $50 \mathrm{ng} / \mathrm{ml}$, whereas the appropriate concentration for the secondary antibody was determined by titration. The membrane was washed three times and developed with enhanced chemiluminescence (ECL) detection reagents (Amersham). Equal volumes of Amersham detection reagents 1 and $2(50-100 \mu \mathrm{l}$ per $1 \mathrm{~cm} 2$ of the filter) were mixed and applied to the membrane. After incubation for $60-90$ seconds at room temperature, the membrane was drained, wrapped in plastic film and exposed to X-ray film for 10 seconds to 5 minutes. The membrane could be re-probed with a different antibody after stripping it of the previous one. For this purpose, the membrane was incubated in stripping buffer at $50^{\circ} \mathrm{C}$ for 30 minutes.

10x Transfer buffer ( 1 liter)

\begin{tabular}{ll}
\hline $30.3 \mathrm{~g}$ & Trizma base $(=0.25 \mathrm{M})$ \\
$144 \mathrm{~g}$ & Glycine $(=1.92 \mathrm{M})$ \\
$\mathrm{pH}$ should be 8.3; do not adjust
\end{tabular}


$1 \mathrm{x}$ Transfer buffer (1 liter)

\begin{tabular}{|c|c|}
\hline $\begin{array}{l}100 \mathrm{ml} \\
200 \mathrm{ml} \\
700 \mathrm{ml}\end{array}$ & $\begin{array}{l}\text { 10x Transfer buffer } \\
\text { Methanol } \\
\mathrm{H}_{2} \mathrm{O}\end{array}$ \\
\hline \multicolumn{2}{|c|}{ TBS-Tween } \\
\hline $20 \mathrm{mM}$ & Tris-HCl pH 7.5 \\
\hline $150 \mathrm{mM}$ & $\mathrm{NaCl}$ \\
\hline $1 \%(v / v)$ & Tween-20 \\
\hline \multicolumn{2}{|c|}{ Stripping buffer } \\
\hline $\begin{array}{l}62.5 \mathrm{mM} \\
2 \% \\
100 \mathrm{mM}\end{array}$ & $\begin{array}{l}\text { Tris-HCl pH } 6.7 \\
\text { SDS (w/v) } \\
\beta \text {-mercaptoethan }\end{array}$ \\
\hline
\end{tabular}

\subsubsection{In vitro Biochemical Methods}

\subsubsection{Transcription and translation in vitro}

The T7 promoter of pGADT7 and pGBKT7 vectors is positioned immediately upstream of the epitope tag (HA or c-Myc, respectively) and the insertion site of the cloned cDNA. All constructs could therefore be used as transcription templates in transcription/translation reactions in vitro to produce $\left[{ }^{35} \mathrm{~S}\right]$-labelled HA- or c-Myc-tagged proteins, using $\left[{ }^{35} \mathrm{~S}\right]-$ methionine. The TNT T7 coupled reticulocyte lysate system (Promega, Madison, USA) was used. The procedure was followed according to the manufacture's instructions. Briefly, the reaction components were assembled in a 1.5- $\mathrm{ml}$ microcentrifuge tube and the reaction was incubated at $30^{\circ} \mathrm{C}$ for 90 minutes. This lysate was used for the subsequent co-immunoprecipitation experiments.

$\underline{50 \mu \mathrm{l} \text { volume of reaction component }}$

\begin{tabular}{ll}
\hline $25 \mu \mathrm{l}$ & TNT rabbit reticulocyte lysate \\
$2 \mu \mathrm{l}$ & TNT reaction buffer \\
$1 \mu \mathrm{l}$ & TNT T7 RNA polymerase \\
$1 \mu \mathrm{l}$ & amino acid mixture, minus methionine $(1 \mathrm{mM})$ \\
$2 \mu \mathrm{l}$ & $\left.{ }^{35} \mathrm{~S}\right]$-methionine $(1000 \mathrm{Ci} / \mathrm{mmol}$, Amersham Pharmacia Biotech) \\
$1 \mu \mathrm{l}$ & RNasin ribonuclease inhibitor $(40 \mathrm{U} / \mu \mathrm{l})$ \\
$2 \mu \mathrm{l}$ & DNA template $(\sim 0.5 \mu \mathrm{g} / \mu \mathrm{l})$ \\
$16 \mu \mathrm{l}$ & nuclease-free $\mathrm{H}_{2} \mathrm{O}$
\end{tabular}




\subsubsection{GST-102K pull-down assays (figures 4.9B, 4.11, 4.14B, 4.22A)}

\section{- Expression of U5-102K protein in E. coli}

To express U5-102K protein in E. coli cells, pNoT-102K was digested with Ndel and Sall, and the insert was subcloned into the same sites of pGEX-6P-1+, which has been modified from pGEX-6P-1 by insert the Ndel site to the multiple cloning site. The resulted pGEX-6P-102K plasmid was transformed into E. coli strain BL21(DE3) for expression. Several small expression tests were performed before the following step was started. $200 \mathrm{ml}$ culture was induced at OD 600 of 0.6 with $0.5 \mathrm{mM}$ IPTG at $20^{\circ} \mathrm{C}$ for 3 hours. The culture was then harvested and resuspended in $10 \mathrm{ml}$ ice-cold 1x PBS (140 mM NaCl, $2.7 \mathrm{mM}$ $\mathrm{KCl}, 10 \mathrm{mM} \mathrm{Na}_{2} \mathrm{HPO}_{4}, 1.8 \mathrm{mM} \mathrm{KH}_{2} \mathrm{PO}_{4}, \mathrm{pH}$ 7.3) containing 1 x complete proteinase-Inhibitor cocktail (Roche). The proteins were released from cell by sonification for $4 \times 15$ seconds on ice. $20 \%$ Triton X-100 was added to a final concentration of $1 \%$ and incubated by mixing gently at $4{ }^{\circ} \mathrm{C}$ for 30 minutes to aid in solubilisation of the fusion protein. The sample was centrifuged at $15,000 \times \mathrm{g}$ for 10 minutes at $4^{\circ} \mathrm{C}$ and the supernatant was added to $500 \mu \mathrm{l}$ bed volume of glutathione-Sepharose, and incubation at $4^{\circ} \mathrm{C}$ for 20 minutes. The beads were washed several times with 1 x PBS buffer, and the next steps were followed below.

\section{- GST pull-down assays}

For GST pull-down assays, the GST-102K fusion protein bound to glutathioneSepharose $4 \mathrm{~B}$ beads was washed four times with binding buffer $(20 \mathrm{mM}$ HEPES pH 7.9, $100 \mathrm{mM} \mathrm{KCl,} 2.5 \mathrm{mM} \mathrm{MgCl}_{2}, 0.2 \mathrm{mM}$ EDTA, 0.1\% Triton X-100, $1 \mathrm{mM}$ DTT and protease inhibitor cocktail). For each reaction, $20 \mu \mathrm{l}$ of beads (containing $\sim 5 \mu \mathrm{g}$ GST-102K protein) and $10 \mu \mathrm{l}$ of $\left[{ }^{35} \mathrm{~S}\right]$-labelled protein, prepared as described above, were incubated in $300 \mu$ l of binding buffer for 2 hours at $4{ }^{\circ} \mathrm{C}$. Beads were washed five times with binding buffer, and bound proteins were eluted in SDS sample buffer and analysed by SDS-PAGE followed by autoradiography. 


\subsubsection{GST-61K pull-down assays (figure 4.10B)}

This assay has been described by Makarova et al. (2002). Briefly, aliquots of the $\left[{ }^{35} \mathrm{~S}\right]$-labelled protein $102 \mathrm{~K}$, prepared by translation in vitro, were incubated in $400 \mu \mathrm{l}$ of TBST buffer $(20 \mathrm{mM}$ Tris- $\mathrm{HCl}$ pH 8.0, $150 \mathrm{mM} \mathrm{NaCl}, 0.1 \%$ Triton X100 ) with either a recombinant fusion protein GST-61K or recombinant GST alone. After incubation for 2 hours at $4^{\circ} \mathrm{C}$, glutathione-Sepharose beads were added to the mixtures and incubated for another 2 hours. Beads were recovered by centrifugation, washed, and the bound material was eluted in SDS sample buffer and analysed by SDS-PAGE.

\subsubsection{His pull-down assays (figure 4.14C)}

This assay has been described by Laggerbauer et al. (2005). Full-length 52K protein and the truncated $52 \mathrm{C}$ protein were first subcloned into the pET28a vector and the recombinant His-tagged proteins were then expressed in E. coli BL21 and purified by affinity chromatography on Talon beads as described by the manufacturer (Qiagen). $\sim 6 \mu \mathrm{g}$ of purified His-tagged $52 \mathrm{~K}$ or $52 \mathrm{C}$ protein was incubated with $10 \mu \mathrm{l}$ of $\left[{ }^{35} \mathrm{~S}\right]$-labelled HA-tagged $15 \mathrm{~K}$ protein, which was produced from pGADT7-15K by translation in vitro as described in section 3.2.3.1, and $30 \mu \mathrm{l}$ Talon beads in $250 \mu \mathrm{l}$ IP buffer $(20 \mathrm{mM}$ Tris- $\mathrm{HCl} \mathrm{pH} 8.0$, $150 \mathrm{mM} \mathrm{NaCl}, 0.5 \mathrm{mM} \beta-\mathrm{ME}, 0.5 \% \mathrm{NP}-40$ ) at $4{ }^{\circ} \mathrm{C}$ for $2 \mathrm{~h}$. In the control reaction, recombinant protein was omitted. Subsequently, beads were washed four times with $0.8 \mathrm{ml}$ of IP buffer. Bound proteins were eluted in SDS sample buffer, analysed by SDS-PAGE, and visualised by autoradiography.

\subsubsection{Co-immunoprecipitations}

For the co-immunoprecipitations shown in figure 4.4B, $10 \mu \mathrm{g}$ of purified His-90K was incubated with $20 \mu \mathrm{l}$ of HA-tagged $60 \mathrm{~K}$ protein prepared by translation in vitro for 1 hour at $4{ }^{\circ} \mathrm{C}$. $1.6 \mu \mathrm{g}$ of anti-pentahistidine antibody (mouse IgG1, Qiagen) and $25 \mu$ l protein G-Sepharose were incubated in $400 \mu$ l buffer IP (20 $\mathrm{mM}$ Tris- $\mathrm{HCl} \mathrm{pH} 8,150 \mathrm{mM} \mathrm{NaCl}, 0.05 \% \mathrm{NP}-40)$. The two tubes were then combined for a further incubation for 1 hour at $4{ }^{\circ} \mathrm{C}$ until collection of beads. Precipitates were washed four times with IP buffer and precipitated proteins were analysed by SDS-PAGE followed by autoradiography. 
For the co-immunoprecipitations shown in figure 4.9C, $10 \mu \mathrm{g}$ of His-tagged $15 \mathrm{~K}$ protein (Reuter et al., 1999) together with $1.6 \mu \mathrm{g}$ anti-pentahistidine antibodies and $25 \mu$ l protein A-Sepharose were incubated in $400 \mu \mathrm{IIP}$ buffer at $4{ }^{\circ} \mathrm{C}$ for 2 hours. His-tagged $15 \mathrm{~K}$ was omitted in the control. Beads were spun down and resuspended in $300 \mu \mathrm{IP}$ buffer. $10 \mu \mathrm{l}$ of c-Myc-102K protein prepared by translation in vitro were added to the sample and control reactions, and incubation was continued for 2 hours. Beads were washed five times with $0.8 \mathrm{ml}$ of IP buffer. Bound proteins were eluted in SDS sample buffer and analysed by SDS-PAGE followed by autoradiography.

For the co-immunoprecipitations shown in figures $4.12 \mathrm{~B}$ and $4.22 \mathrm{~B}$, the purified His-tagged $110 \mathrm{~K}$ protein was dialysed against a buffer containing $20 \mathrm{mM}$ Tris$\mathrm{HCl} \mathrm{pH} \mathrm{8.0,} 300 \mathrm{mM} \mathrm{NaCl}$ and 0.05\% NP-40. [ ${ }^{35}$ S]-labelled full-length proteins and fragments were prepared by translation in vitro as described above. $100 \mu \mathrm{l}$ of protein A-Sepharose beads were pre-incubated for 3 hours at $4{ }^{\circ} \mathrm{C}$ with $100 \mu \mathrm{l}$ of affinity-purified anti-pep 110 antibody (Makarova et al., 2001) in a total volume of $1 \mathrm{ml}$ of phosphate-buffered saline (PBS) $\mathrm{pH} 8.0$, containing $0.5 \mathrm{mg} / \mathrm{ml}$ $B S A$ and $50 \mu \mathrm{g} / \mathrm{ml}$ total yeast tRNA. Beads were then washed four times with $1 \mathrm{ml}$ PBS and resuspended in $100 \mu \mathrm{l}$ IP buffer, resulting in a final volume of $200 \mu \mathrm{l}$ of a-pep-110 protein A-Sepharose beads. For each reaction, $30 \mu \mathrm{l}$ of these beads was incubated for 2 hours at $4{ }^{\circ} \mathrm{C}$ in $250 \mu \mathrm{l}$ IP buffer together with $10 \mu \mathrm{l}$ of $\left[{ }^{35} \mathrm{~S}\right]$-labelled proteins in the presence or absence of His-tagged $110 \mathrm{~K}$ protein. Beads were then washed four times with IP buffer, and bound proteins were eluted with SDS sample buffer and analysed by SDS-PAGE followed by autoradiography. The cloning, expression and purification of the $110 \mathrm{~K}$ protein have already been described (Makarova et al., 2001).

For the co-immunoprecipitation assays shown in figures 4.17 and $4.22 \mathrm{C}$, the coding sequences of the $90 \mathrm{~K}$ and $60 \mathrm{~K}$ proteins were transcribed in vitro with T7 RNA polymerase from the pGBKT7 constructs and translated with $\left[{ }^{35} \mathrm{~S}\right]$-labelled methionine by using a TNT coupled reticulocyte lysate system (Promega). A total of $15 \mu$ of translation reaction mixture was incubated with $500 \mathrm{ng}$ of baculovirus-expressed full-length p110 protein for 2 hours at $4^{\circ} \mathrm{C}$ in $250 \mu \mathrm{l}$ of buffer IP (20 mM Tris- $\mathrm{HCl}$ pH7.4, $120 \mathrm{~mm} \mathrm{NaCl}, 5 \mathrm{mM} \mathrm{MgCl} 2,50 \mathrm{mM} \mathrm{KCl}$, 
0.05\% NP-40, 1 mM PMSF, 1 mM DTT). Complexes formed were precipitated with p110 antibodies prebound to protein A-Sepharose, followed by seven washes with $0.75 \mathrm{ml}$ each of buffer IP. The bound proteins were eluted by being heated in protein sample buffer, fractionated by SDS-PAGE, and visualized by autoradiography. 


\section{Results}

The yeast two-hybrid $(\mathrm{Y} 2 \mathrm{H})$ system and in vitro binding assays were used to detect protein-protein interaction in this study. The first part will present the cloning work which is necessary for the complete yeast two-hybrid screening (section 4.1). The following several parts are focused on the results of proteinprotein interactions within the tri-snRNP particle (sections 4.2-4.7). Furthermore, the interactions of protein 90K with U6-p110 and U2-SPF30/SMNrp are described (sections 4.8, 4.9). The analysis of point mutations related to retinitis pigmentosa is shown in section 4.10. The final section concerns the $\mathrm{Y} 2 \mathrm{H}$ screen with the $\mathrm{N}$-terminal region of protein $200 \mathrm{~K}$.

\section{1 cDNA cloning}

As shown in the table 3.3 in the Materials and Methods, cDNAs for the following proteins had previously been cloned in the laboratory of Prof. Lührmann: U4/U6-specific proteins $15.5 \mathrm{~K}, 20 \mathrm{~K}, 61 \mathrm{~K}$, and 90K; U5-specific proteins $15 \mathrm{~K}$, $40 \mathrm{~K}, 52 \mathrm{~K}, 100 \mathrm{~K}, 102 \mathrm{~K}$ and 116K; U4/U6.U5-specific proteins $27 \mathrm{~K}, 65 \mathrm{~K}$ and 110K. The U6-p110 (SART1) cDNA was generously donated by the laboratory of Prof. A. Bindereif (Medenbach et al., 2004). The cDNAs for the proteins 60K, 200K, 220K, and SPF30/SMNrp were cloned directly from a human MarathonReady cDNA library (Clontech) in this study.

Since the sequence of the previously published U5-specific protein $200 \mathrm{~K}$ (Lauber et al. 1996; GenBank accession no. gi|12643640) does not provide the entire N-terminal sequence, the complete $200 \mathrm{~K}$ gene was cloned using 5'-RACE PCR techniques with a published partial cDNA sequence (Nagase et al., 1998) as described in Materials and Methods. The full-length cDNA encodes a protein that has 2136 amino acids and a calculated molecular mass of $244517 \mathrm{Da}$. The sequence has been deposited with GenBank (accession no. gi|45861371). The protein not only contains two helicase domains; in addition, each helicase domain is followed by a SEC63 domain, a domain of as yet unknown function, possibly anchoring proteins to RNP complexes (shown schematically in the lower part of figure 4.1) (Ponting, 2000). Orthologues of human $200 \mathrm{~K}$ protein display a high degree of conservation throughout the eukaryotic kingdom, suggesting that this DExH-box RNA helicase plays an 
important role in all eukaryotes. The alignment of the $\mathrm{N}$-terminal region (amino acids 1-870) including the first (N-terminal) helicase domain is shown in figure 4.1. A putative nuclear localization sequence, RRAKRRKR, is present at amino acids 67 to 74 of the human $200 \mathrm{~K}$ protein. The $\mathrm{C}$ terminus of the second (Cterminal) helicase domain (HELICc domain) shows little conservation, which is consistent with its non-essential nature, in contrast to the first helicase domain, which contains lethal mutation sites (Kim and Rossi, 1999).
H.S.
(1) MADVTARSLQYEYKANSNLVLQADRSLIDR - - -TRRDEPTGEVLSL
S.C.
(1) TKDKAKKIREIYRYDEMSNKVLKVDKRFMNTSQNPQRDAEISQPKSM
A.g.
D.m.
A.t.
S.p.
C.e.

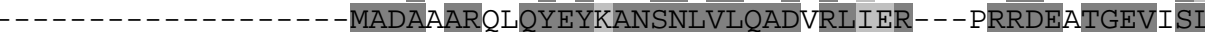

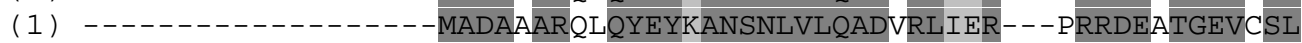
(1) - - - - - - - - - MANLGGGAEAHARFKQYEYRANSSLVLTTDNRPR - - - - DTHEPTGEPETL
(1) MSSAHPKGDSKEPPKHGNSKEKPNYGQSQYSYSAMSNLVTQADRRFVSR - - - RDAEPTGEPESL
(1) - - - - - - - - - - - - - - - - RADELARIQQYEYRQNSNLVLSVDYNLTDR - - RGREEPTGEVLPI

NLS

H.S. (44) VG-KLEGTRMGDKAQRTKP - - - - -QMQEERRAKRRKR - - - - DEDRHDINKMKGYTLLSEGIDE

S.c. (53) SG-RISAKDMGQGLCNNIN - - - - KGLKENDVAVEKTG - - - - KSASLKKIQQHNTILNSSSD

A.g. (44) VG-KLDGTRMGDRAQRSKP - . - - EKTEERKAKRQKR - - - - DEAQYDFNSMKGATLLSEGIDE

D.m. (44) VG-KLDGTRMGDRYQRTKP - - - - EKTEERKVKRQKR - - - - DEAQYDFERMKGATLLSEGIDE

A.t. (47) WG-KIDPRSFGDRVAKGRP - - - - QELEDKLKKSKKKERDVVDDMVNIRQSKRRRLREESVLTD

S.p. (62) VN-RVSIADMGSRARIEKPSTLPLELTQEVQEVRLPRKDAESLEIGIRQPEREKRSSAILKYFDS

c.e. (44) TDKEMRKMKMGDRAIKGKA - - - - PVQDQKKKRKKKD - - - -DEKAQQFG - - - RNVLVDNNEL

H.S. (97) MVGIIYKPKTKETRETYEVLLSFIQAALG-DQPRDILCGAADEVLAVLK - - - NEKLRDKERRKE

S.c. (105) FR-LHYYPKDPSNVETYEQILQWVTEVLGNDIPHDLIIGTADIFIRQLKENEENEDGNIEERKEK

A.g. (97) MVGIVYRPKTQETRQTYEVLLSFIQEAIG-DQPRDILRGAADEILAVLK - - -NDRMKEREKKRE

D.m. (97) MVGIVYRPKTQETRQTYEVLLSFIQEALG-DQPRDILCGAADEILAVLK - - - NDRLKDRERKKD

A.t. (105) TDDAVYQPKTKETRAAYEAMLGLIQKQLG-GQPPSIVSGAADEILAVLK - - -NDAFRNPEKKME

S.p. (126) FEILKYNPLTDETREVYDYILSFIQQYLG-DQSPEILRSAADLIIELLK- - - DSSLDEQGRKKQ

C.e. (94) MG--AYKPRTQETKQTYEVILSFILDALG-DVPREVLCGAADEVLLTLK- - - NDKFRDKEKKKE

H.S. (157) IDLLLG-QTDDTRYHVLVNLGKKITDYG - . . - . - - - GDKEIQN - MDDNIDETYGVNVQFE

S.c. (169) IQHELGINIDSLKFNELVKLMKNITDYETHPDNSNKQAVAILADDEKSDEEEVTEMSNNANVLGG

A.g. (157) IDGLLG-SVADERFALLVNLGKKITDFGSDAATA - . - IGGAGQAGPGGDEPIDETYGINVRFE

D.m. (157) IDSLLG-AVTDERFALLVNLGKKITDFGSDAVNA - - - - LTAAPNN - - - EEQIDETYGINVQFE

A.t. (165) IEKLLN - KIENHEFDQLVSIGKLITDFQEG - . . . - - - GDSGGGRANDDEGLDDDLGVAVEFE

S.p. (186) IEEVLSTELPQDRFSQLVNLGNRLTDYTVE- - - - - - - - QEEELNEEGVNES-GVPVLFN

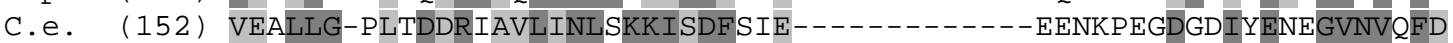

H.S. (207) SDEEEGDEDVYGEVREEASDDDMEGDEAVVRCTLSANLVASGELMS - - S - - - - - KKK-DLHPR

S.c. (234) EINDNEDDDEEYDYNDVEVNSKKKNKRALPNIENDIIKLSDSKTSN - - - - - - - IESVPIY

A.g. (216) ESEEESDEDKYGEVREDDGQDEGE- -EARDDGILHAENLGGGEDMN - -K - - - - - - KEK-ALDPR

D.m. (212) ESEEESDNDMYGEIRDDDAQDEGE- -EARIDHTLHAENLANEEAANNVK - - - - - KER-SLHPL

A.t. (219) ENEEDDEESDPDMVEEDDDEEDDEPTRTGGMQVDAGINDEDAGDAN - . - . - . - - EGTNLNVQ

S.p. (236) EADEE-EEAVEAMEEDEVAEDEDVVLETSISQEEEKKNIENPDTEVTFISADTKKVTEIPTVHPR

c.e. (203) SDEEEDDGGMVNEIKGDSEEESEE--EEGVDTDYTATLKGDGHLTEDEQ - - - - - -KARGILHPR

H.S. (262) DIDAFWLQRQLSRFYDDAIVSQK - - KADEVLEILKTASDDRECENQLVLLLGFNTFDFIKVLRQ

S.c. (287) SIDEFFLQRKLRSELGYKDTSVIQDLSEKILNDIETLEHNPVALEQKLVDLLKFENISLAEFILK

A.g. (269) DIDAHWLQRCLRKYYNDSMMSQA - -KALEVLSVLKESGDDRECENQLVLLLGYDCFDFIKQLKK

D.m. (267) DIDAYWLQRCLSKFYKDAMVSQS - - KAADVLKILKDAADDRDCENQLVLLLGYDCFDFIKQLKL

A.t. (273) DIDAYWLQRKISQAYEQQIDPQQCQVLAEELLKILAEG-DDRVVEDKLLMHLQYEKFSLVKFLLR

s.p. (300) EIDAFWLQREIAKYFADAVVCQE-- -KTNQAFEALSADYDLGELENELMSIFDYEHFYLVQLLTK

c.e. (259) DIDAHWIQRSLAKYFKDPLIAQQ - - KQTEVIGILKNAADDRDAENQLVLLLGFDQFEFIKCLRQ 
H.S. (324) HRMMILYCTLLASAQSEAEKERIMGKMEAD-PELSKFLYQLHETEKEDLIREE - - - - - - - RS

S.c. (352) NRSTIFWGIRLAKST-ENEIPNLIEKMVAKG - -LNDLVEQYKFRETTHSKR - . . . . . . . . . .

A.g. (331) NRQMILYCTMLAQSQSESDRAKLRDRMKSD - AALAKILRQLDTGKQEAQEA - . - . - . - . - .

D.m. (329) NRQMVLYCTMLASAQTDSERQRIREKMRGN-SALAKILRQLDTGKSEDQEE - . . . . . . . . . . .

A.t. (337) NRLKVVWCTRLARAEDQEERNRIEEEMRGLGPELTAIVEQLHATRATAKEREENLQKSINEEARR

s.p. (362) NRWTIVSCTMLKRAATDEERLGVEEQIRAA - -GRSWILEALRPGAITIPDDGLN - - - - - - - EL

c.e. (321) NRLMILYCTLLRQAN-EKERLQIEDDMRSR-PELHPILALLQETDEGSVVQVE - . - . - . - KS

H.S. (378) RRERVRQSRMDTDLETMDLDQ - GGEALAPRQVLDLEDLVFTQGSHFMANKRCQLPDGSFRRQRKG

S.c. (400) ----ELDSGDDQPQSSEAKRTKFSNPAIPPVIDLEKIKFDESSKLMTVTKVSLPEGSFKRVKPQ

A.g. (381) -RDYANGGGADGSDTKTSLRS-RGTILGNRTVLELDELAFTQGSHLMANKRCQLPDGSFRKQRKG

D.m. (379) -GEARGSKRGKGDAEDGGAAA-AGQVAGVRQLLELEEMAFTQGSHFMANKRCQLPDGSYRKQRKG

A.t. (4仓2) LKDETGGDGGRGRRDVADRDSESGWVKGQRQMLDLESLAFDQGGLLMANKKCDLPPGSYRSHGKG

S.p. (416) NNNVVEKAEPAPVSEIPLSKTLTSHKIVPKHQVDLENYVFTEGSRLMSNKAVKLPEGSFRRTGKG

c.e. (374) KRDAEKSKK--AATAANEAIS-AGQWQAGRKMLDLNDLTFSQGSHLMSNKRCELPDGSYRRQKKS

DEXHC

H.S. (442) YEEVHVPALKPKPFGSEEQLLPVEKLPKYAQAGFEG - - FKTLNRIQSKLYRAALETDENLLLCAP

S.c. (460) YDEIHIPAPS - KPVIDYELKEITSLPDWCQEAFPSSETTSLNPIQSKVFHAAFEGDSNMLICAP

A.g. (444) YEEVHVPALKPRPFDEDEELIAIEKLPKYVQPVFSG - -FKTLNRIQSRLYKSALESDENLLLCAP

D.m. (442) YEEVHVPALKPVPFDANEELQPVDKLPKYVQPVFEG- -FKTLNRIQSRLYKAALDSDENMLLCAP

A.t. (467) YDEVHVPWVS-KKVDRNEKLVKITEMPDWAQPAFKG - MQQLNRVQSKVYDTALFKAENILLCAP

S.p. (481) YEEIHVPAPNKAVLGADERLVKIKELPEWSHQAFLN - -TQSLNRIQSHLYPIAFGTDENILLCAP

c.e. (436) YEEIHVPALKPRPFAEGEKLVSVSELPKWAQPAFDG - YKSLNRIQSRLCDSALRSKEHLLLCAP

H.S. (505) TGAGKTNVALMCMLREIGKHIN-MDGTINVDDFKIIYIAPMRSLVQEMVGSFGKRLATYGITVAE

S.c. (523) TGSGKTNIALLTVLKALSHHYNPKTKKLNLSAFKIVYIAPLKALVQEQVREFQRRLAFLGIKVAE

A.g. (507) TGAGKTNVALLTMMREIGKHIN-DDGTINVDEFKIIYIAPMRSLVQEMVGNFGRRLATYNLTVAE

D.m. (505) TGAGKTNVALLTMMREIGKHIN-EDGTINAQDFKIIYVAPMKSLVQEMVGNFGRRLACYNLTVSE

A.t. (529) TGAGKTNVAMLTILQQLEMNRN-TDGTYNHGDYKIVYVAPMKALVAEVVGNLSNRLKDYGVIVRE

S.p. (544) TGAGKTNVAMLCILNELQKHLR-EDLSFNLQNFKIVYIAPLKALVQEMVNNFSKRLTPYNIRVAE

c.e. (499) TGAGKTNVALLTMLQEIGNHLA-EDGSVKLDEFKIVYIAPMKSLVQEMVGSFSKRLAPFGITVGE

H.S. (569) LTGDHQLCKEEISATQIIVCTPEKWDIITRKGGERTYTQLVRLIILDEIHLLHDDRGPVLEALVA

S.c. (588) LTGDSRLSRKQIDETQVLVSTPEKWDITTRNSNNLAIVELVRLLIIDEIHLLHDDRGPVLESIVA

A.g. (571) LTGDHQLSREQIAATQVIVCTPEKWDIITRKGGEKTYTQFVRLVIIDEIHLLHDERGPVLEALVA

D.m. (569) LTGDHQLTREQIAATQVIVCTPEKWDIITRKGGERTFVSLVRLVIIDEIHLLHDERGPVLEALVA

A.t. (593) LSGDQSLTGREIEETQIIVTTPEKWDIITRKSGDRTYTQLVRLLIIDEIHLLHDNRGPVLESIVA

S.p. (608) LTGDSQLTKQQISETQIIVTTPEKWDIITRKANDLSYVNLVRLVIIDEVHLLHDERGPVLESIVA

c.e. (563) MTGDAQMSKEQFMATQVIVCTPEKYDVVTRKGGERAYNQMVRLLIIDEIHLLHDDRGPVLESIVV

HELICC

H.S. (634) RAIRNIEMTQEDVRLIGLSATLPNYEDVATFLRVDPAKGLFYFDNSFRPVPLEQTYVGITEKKAI

S.c. (653) RTFWASKYGQEYPRIIGLSATLPNYEDVGRFLRVPKEG-LFYFDSSFRPCPLSQQFCGIKERNSL

A.g. (636) RTIRNIETTQEDVRLVGLSATLPNYQDVSTFLRVRPETGLFYFDNSYRPVALEQQYIGVTEKKAL

D.m. (634) RTIRNIETTQEEVRLVGLSATLPNYQDVATFLRVKPDKGLFYFDNSYRPVSLEQQYIGVTEKKAL

A.t. (658) RTLRQIETTKENIRLVGLSATLPNYEDVALFLRVDLKKGLFKFDRSYRPVPLHQQYIGISVKKPL

s.p. (673) RIFRHQEETLEQVRLVGLSATLPNYTDVASFLHVDPKKGLFYFDSTYRPCPLKQEFIGITEKTPF

c.e. (628) RTIRQMEQNHDECRLVGLSATLPNYQDVATFLRVKPEH-LHFFDNSYRPVPLEQQYIGVTEKKAL

H.S. (699) KRFQIMNEIVYEKIMEHAGK-NQVLVFVHSRKETGKTARAIRDMCLEKDTLGLFLREGSASTEVL

S.c. (717) KKLKAMNDACYEKVLESINEGNQIIVFVHSRKETSRTATWLKNKFAEENITHKLTKNDAGSKQIL

A.g. (701) KRFQVMNDIVYEKVMEHAGR-NQVLVFVHSRKETGKTARAIRDMCLEKDTLGTFLRDGSASMEVL

D.m. (699) KRFQVMNEIVYEKTMEHAGR-NQVLVFVHSRKETGKTARAVRDMCLEQDTLGSFLKEGSASMEVL

A.t. (723) QRFQLMNDLCYQKVLAGAGK-HQVLIFVHSRKETSKTARAIRDTAMANDTLSRFLKEDSVTRDVL

s.p. (738) KRMQTTNEACYEKVMQHAGK-NQVLIFVHSRKETAKTARFIRDKALEEETIGHLLRSDAASREIL

c.e. (692) KRFQAMNEVVYDKIMEHAGK-SQVLVFVHSRKETAKTAKAIRDACLEKDTLSAFMREGSASTEIL 


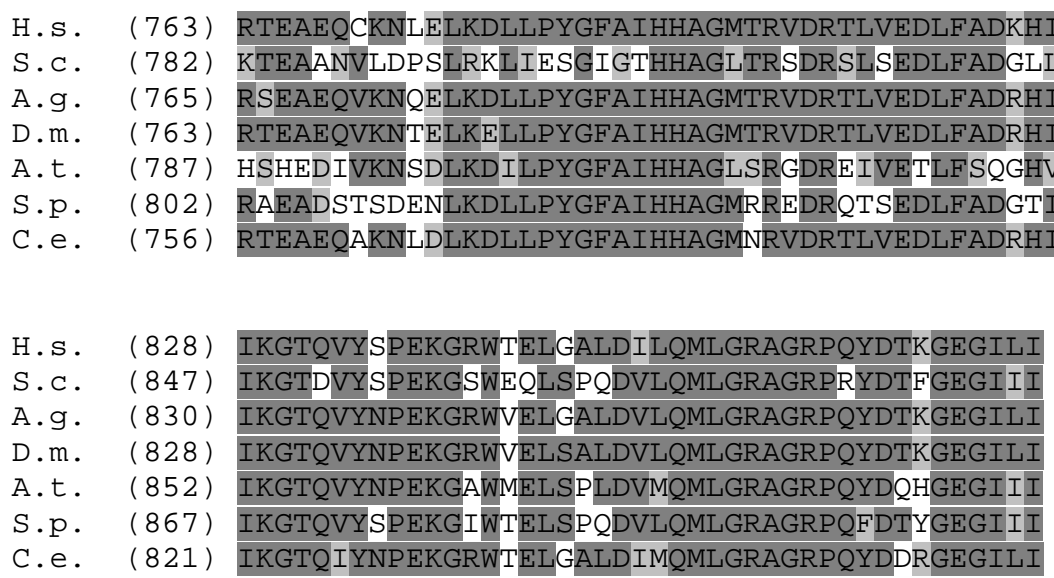

DEYHC HELIC SEC63 DEYHC HELIC

Figure 4.1. Alignment of the N-terminal region of putative hBrr2 orthologues from Homo sapiens (H.s., gi|45861372), Saccharomyces cerevisiae (S.c., gi|6321020), Anopheles gambiae (A.g., gi|31242349), Drosophila melanogaster (D.m., gi|28574898), Arabidopsis thaliana (A.t., gi|15218086), Schizosaccharomyces pombe (S.p., gi|19114258), Caenorhabditis elegans (C.e., gi|17537127). NLS, putative nuclear localization sequence. Identical and similar residues are indicated through dark grey or light grey boxes, respectively. The schematic drawing below depicts the domain structure of the protein: DEXHc, DEXH-box helicases; HELICc, helicase superfamily C-terminal domain; SEC63 domain of unknown function found in SEC63p. The domain structure was predicted from NCBI's Conserved Domain Database and Search Service, v2.02.

Because of inconsistencies between the various sequences deposited for the 60K protein in published GenBank databases (accession no. gi|2653735, Lauber et al., 1997; accession no. gi|2708304, Horowitz et al., 1997; accession no. gi|2853286, Wang et al., 1997), the cDNA was cloned again by PCR from the same cDNA library used for protein 200K. This new sequence has been deposited with GenBank (accession no. gi|45861373). Figure 4.2 shows the alignment of the new cloned sequence with Horowitz's human sequence (gi|2708304) and several homologue sequences from other organisms. Two human $60 \mathrm{~K}$ sequences are nearly identical. Protein $60 \mathrm{~K}$ contains two highly conserved domains, the SFM domain in the $\mathrm{N}$-terminal region and the WD40 domain in the C-terminal region. However, yeast homologue proteins lack the SFM near the $\mathrm{N}$-terminus. 
H.S. $60 \mathrm{~K}(1)$ H.S. $60 \mathrm{~K}(2)$

P.p. $60 \mathrm{~K}$

S.c. $60 \mathrm{~K}$

S.p. $60 \mathrm{~K}$

C.e. $60 \mathrm{~K}$

D.m. $60 \mathrm{~K}$

A.t. $60 \mathrm{~K}$

H.S. $60 \mathrm{~K}(1)$ H.S. $60 \mathrm{~K}(2)$

P.p. $60 \mathrm{~K}$

S.C. $60 \mathrm{~K}$

S.p. $60 \mathrm{~K}$

c.e. $60 \mathrm{~K}$

D.m. $60 \mathrm{~K}$

A.t. $60 \mathrm{~K}$
(1)

(1)

(1)

(1)

(1)

(1)

(1) - MAENGNFAVPAPPRQFGSLANAES

(1) MSDDDDIQYIKRQRTLHYGSLEESERKRQNAAASGAAATTTSGTTASSGAGTTTTGTGGQLEDIDSDEDY

(1) - . - MEPNKDDNVSLAATAQISAPPVLQDASS - LPGFSAIPPVVPPSFPPPMAPIPMMPHPPV
H.S. $60 \mathrm{~K}(1)$ H.S. $60 \mathrm{~K}(2)$

P.p. $60 \mathrm{~K}$

S.c. $60 \mathrm{~K}$

S.p. $60 \mathrm{~K}$

C.e. $60 \mathrm{~K}$

D.m. $60 \mathrm{~K}$

A.t. $60 \mathrm{~K}$

H.S. $60 \mathrm{~K}(1)$ H.S. $60 \mathrm{~K}(2)$

P.p. $60 \mathrm{~K}$

S.C. $60 \mathrm{~K}$

s.p. $60 \mathrm{~K}$

C.e. $60 \mathrm{~K}$

D. m. $60 \mathrm{~K}$

A.t. $60 \mathrm{~K}$

H.S. $60 \mathrm{~K}(1)$ H.s. $60 \mathrm{~K}(2)$

P.p. 60K

S.c. $60 \mathrm{~K}$

S.p. $60 \mathrm{~K}$

C.e. 60K

D.m. $60 \mathrm{~K}$

A.t. $60 \mathrm{~K}$

(40) ERLAKGESGILGKDGLKAGIEAGNINITSGEVFEIEEHIS-ERQAEVLAEF-ERRKRARQINVSTDDSEV (41) ERLAKGESGILGKDGLKAGIEAGNINITSGEVFEIEERIS-ERQAEVLAEF-ERRKRARQINVSTDDSEV

(40) ERLAKGESGILGKEGLKAGIEAGNINITSGEVFEIEEHIS-ERQAEVLAEF-ERRKRARQINVSTDDSEV

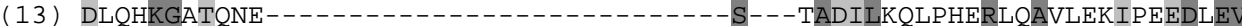

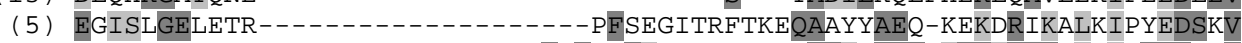

(25) VNAILNAQQQN - - - - - - - - - - GPTVSLERMEVSNQADSRHDAEMFAEF-DRRRRARTLTLPTDDVQV

(71) EESTKKTSNAK - QAGAPPPTAATLANKIDDDYFDLEMEME-RDKVALLEEF-ERKKRARQINVSTDDTEI

(59) ARPPTFRPPVSQNGGVKTSDSDSESDDEHIEISEESKQVR-ERQEKALQDL - LVKRRAAAMAVPTNDKAV

SFM

(108) KACLRALGEPITLFGEGPAERRERLRNILSVVGTDALKKTKKDDEKSKKS - - - - - KEEYQQTWYHEGPN (109) KACLRALGEPITLFGEGPAERRERLRNILSVVGTDALKKTKKDDEKSKKS - - - - - KEEYQQTWYHEGPN

(108) KACLRALGEPITLFGEGPAERRERLRNILSVVGTDALKKTKKDDEKSKKS - - - - - KEEYQQTWYHEGPN

(52) RRLLSILKKPEVVENEDVQQRRIRLAEILMVDEIDLENINNMENINGEEVD - - - - - EEDDEDFFTPATS

(54) REYLRRYGEPITYFGEDALARRQRLQQLMIEKSLEGDNPLDVDQG - ASEN - - - - - - - - IEKETYVQGSH

(82) KLKLRALNQPICLFGEDALDRRERLRALLSTMSEDEIAAVLHTDEVNADK - - - - - - ADEETVTWYHRGPI

(138) KSNLRQLNEPICYFGEGPAERRRRLKELLAGLGENAINKRQYEDEERKQQQ - - - - REQDQATWYHEGPD

(127) RDRLRRLGEPITLFGEQEMERRARLTQLLTRYDINGQLDKLVKDHEEDVTPKEEVDDEVLEYPFFTEGPK

* L185S

$\rightarrow$ 1. WD40

(172) SLKVARLWIANYSLPRAMKRLEEARL-HKEIPETTRTSQMQELHKSLRSLNNFCSQIGDDRPISYCHFSP (173) SLKVARLWIANYSLPRAMKRLEEARL-HKEIPETTRTSQMQELHKSLRSLNNFCSQIGDDRPISYCHFSP

(172) SLKVARLWIANYSLPRAMKRLEEARL - HKEIPETTRASQMQELHKSLRSLNNFCSQIGDDRPISYCHFSP (116) ELIFARRFLINYSLERSRKRLQKEMERHQKFNTRQELLSRRTELQRMANLELAGSQLVSTKPISAVSLST (114) ELLVARKKIALYSLEKAKLRLKKERE-ISEIPVPEIVLSGKSSIEHLQKAELMGSQIGGERPIAIVRFSN (146) ELRMARVSIADFSLRKAKLRLDKARE-EAARPAHEKALARQEAHKWVQQINLHASQVADTRPVAFCEFSA

(203) SLRIARLWLADYSLPRAKDRLVRARE-ALEVPSAARAGRMVEMQKKLQSLAPLCSQVGDTRPVSSAAFSE

(197) ELREARIEIAKFSVKRAAVRIQRAKR-RRDDPDEDMDAETKWALKHAKHMALDCSNFGDDRPLTGCSFSR

2. WD40

(241) NSKMLATACWSGLCKLWSVPDCN-LLHTLRGHNTNVGAIVFHPKS-TVSLDPKDVNLASCAADGSVKLWS (242) NSKMLATACWSGLCKLWSVPDCN-LLHTLRGHNTNVGAIVFHPKS-TVSLDPKDVNLASCAADGSVKLWS

(241) NSKMLATACWSGLCKLWSVPDCN - LLHTLRGHNTNVGAIVFHPKS - TVSLDQKDVNLASCAADGSVKLWS (186) DDMVVATGSWAGDLQVLNSQTLQPLTQKLDSHVGKIGAIDWHPDS - - $\mathrm{N}-\mathrm{N}-\mathrm{-}^{-}-\mathrm{-}$ QMISCAEDGLIKNFQ (183) NGNHFASGSWGGQVKVWNSDNLS-EVQLFRGHTDRVSGLDWYPLCQAWDADSEQLTLATGAADNTVCLWK (215) DSEHIVTAGWSGSVAVWKREQCA-QEIKFIGHSSQAGCARFHPGA-FTQNDYSSLNVVSCSYDGTVLLWS (272) DSSLLLTSSWSGLCKLWSVPDCE-LKQTLRGHASYVGGVALRPG - -VKADEENVVAMASGGHDGAVKLWG (266) DGKILATCSLSGVTKLWEMPQVTNTIAVLKDHKERATDVVFSPVD - - - - - - D - - CLAATASADRTAKLWK

$\mathrm{D} 350 \mathrm{E} * \rightarrow 4$. WD40

H.s. 60K(1) (309) LDSDEPVADIEGHT - - - VRVARVMWHPSGRFLGTTCYDRSWRLWDLEAQEEILHQEGHSMGVYDIAFHQ H.S. $60 K(2)$ (310) LDSDEPVADIEGHT - - - VRVARVMWHPSGRFLGTTCYDRSWRLWDLEAQEEILHQEGHSMGVYDIAFHQ

P.p. 60K (309) LDSDEPVADIEGHT - - - -VRVARVMWHPSGRFLGTTCYDRSWRLWDLEAQEEILHQEGHSMGVYDIAFHQ

S.c. $60 \mathrm{~K}$ (248) YSNEEGGLRLLGDLVGHERRISDVKYHPSGKFIGSASHDMTWRLWDASTHQELLLQEGHDKGVFSLSFQC

S.p. $60 \mathrm{~K}$

C.e. $60 \mathrm{~K}$

D.m. $60 \mathrm{~K}$ (252) ASOSTPLLRLEGHL - - - ARVGRVAFHPSGDYLVSASFDTTWRLWDVHTGVELLMOEGHSEGIFSIACQP

(283) LSQESPIGELEQHP - - - QRVSKVAFHPNGHHLATACFDSTWRMYDLTTKKELLYQEGHSKSVADVAFHP

(339) FNNEESIADITGHMP - - - HRVSKVAFHPSGRFLATACYDSSWRLWDLEQKTEVLHQEGHAKPVHCLSYHS

(327) TDG - TLLQTFEGHL - - - DRLARVAFHPSGKYLGTTSYDKTWRLWDINTGAELLLQEGHSRSVYGIAFQQ 


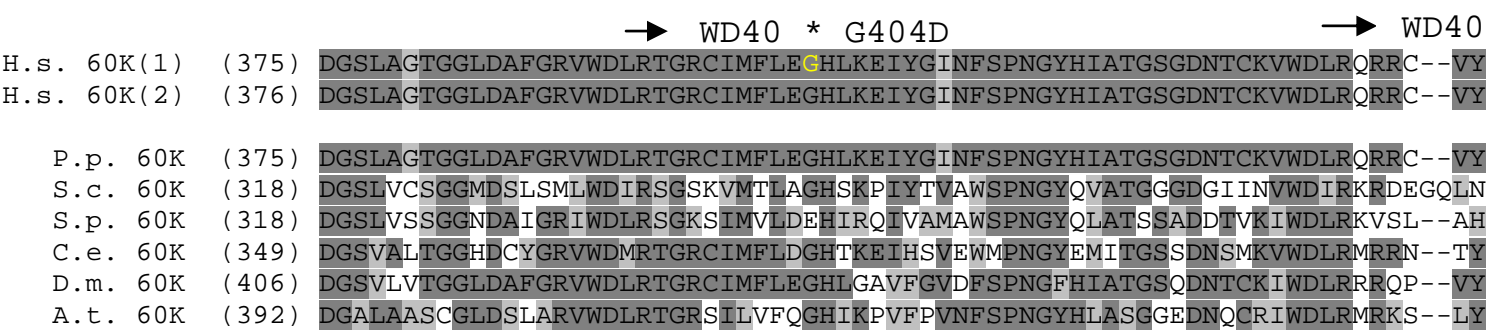

$$
\text { * A446P }
$$

$\rightarrow$ 7. WD40

C509Y *

H.S. $60 \mathrm{~K}(1)$

H.S. $60 \mathrm{~K}(2)$

P.p. $60 \mathrm{~K}$

S.C. $60 \mathrm{~K}$

S.p. $60 \mathrm{~K}$

C.e. $60 \mathrm{~K}$

D.m. $60 \mathrm{~K}$

A.t. $60 \mathrm{~K}$

(443) TIPAHQNLVTGVKFEP-IHGNFLLTGAYDNTAKIWTHPGWSPLKTLAGHEGKVMGLDISSDGQLIAT SY
(444) TIPAHQNLVTGVKFEP-IHGNFLLTGAYDNTAKIWTHPGWSPLKTLAGHEGKVMGLDISSDGQLIATCSY

(443) TIPAHQNLVTGVKFEP - IHGNFLLTGAYDNTAKIWTHPGWSPLKTLAGHEGKVMGLDISSDGQLIATCSY

(388) QILAHRNIVTQVRFSKEDGGKKLVSCGYDNLINVYSSDTWLKMGSLAGHTDKIISLDISNNSHFLVSGGW

(386) TIPAHSSLVSDVRYIESGVNRFIATSGYDGCVKLWNPLNCSLIKSMVGHEEKVMSVDGYGDR - -FISSGY

(417) TMPAHTSVVTRVRAD - -AAGQYLVSASFDCTLKMWSTTGWQPLRQLQGHDTRILCVDISPDGQWMCSSAF

(474) TIPAHTNLISDVKYOQ -ECGSFLVTCSYDSTTKIWSNKTWOPLKTLQGHDNKVISVDIAPNSOYIATTSF

(460) IIPAHANLVSQVKYEP-QEGYFLATASYDMKVNIWSGRDFSLVKSLAGHESKVASLDITADSSCIATVSH

P.p. 60K (512) DRTFKLWMAE-

S.C. 60K (458) DRSIKLWN-

S.p. $60 \mathrm{~K}$ (454) DRTIKLWYP-........

C.e. $60 \mathrm{~K}$ (485) DRTFKLWAQSDY

D.m. 60K (543) DRTFKLWSPDS -...........

A.t. 60K (529) DRTIKLWTSSGNDDEDEEKETMDIDL

Figure 4.2. Alignment of putative $60 \mathrm{~K}$ orthologues from Homo sapiens (H.s.(1), gi| 45861373; H.s.(2), gi|2708304), Pongo pygmaeus (P.p., gi| 56403896), Saccharomyces cerevisiae (S.c., gi|6325435), Schizosaccharomyces pombe (S.p., gi|19113878), Caenorhabditis elegans (C.e., gi|17505895), Drosophila melanogaster (D.m., gi| 21355245), Arabidopsis thaliana (A.t., gi|30794128). The variations in the two positions between the two human sequences are shown in red. The N-terminal SFM domain and the seven C-terminal WD40 repeats are indicated above the sequences. SFM, Splicing Factor Motif, present also in Prp18p. The residues shown in yellow and marked with an asterisk $\left(^{*}\right)$ above the residues were replaced in the mutant $60 \mathrm{~K}$ clone. This clone was used for the subsequent binding study, as described below. Identical and similar residues are indicated by dark and light grey boxes, respectively.

The cloning of cDNA for the $220 \mathrm{~K}$ protein is described in Materials and Methods. The entire sequence encoding the protein is nearly identical to the sequence published in the GenBank database (gi|3661609; Luo et al., 1999), and the sequence is given in the Appendix. 


\subsection{Protein-protein interactions within U4/U6-snRNP particle}

\subsubsection{The interactions of proteins in the $20 \mathrm{~K} \cdot 60 \mathrm{~K} \cdot 90 \mathrm{~K}$ RNA-free heterotrimer}

Five U4/U6-specific proteins remain associated with the U4/U6 snRNA duplex under high-salt conditions, when the tri-snRNP dissociates into the U4/U6 and U5 snRNPs. These proteins are $90 \mathrm{~K}, 61 \mathrm{~K}, 60 \mathrm{~K}, 20 \mathrm{~K}$ and $15.5 \mathrm{~K}$. The stable binding defines them as U4/U6-specific proteins (reviewed by Will and Lührmann, 2001). Of these, $20 \mathrm{~K}, 60 \mathrm{~K}$ and $90 \mathrm{~K}$ form a stable RNA-free heterotrimeric complex (Horowitz et al., 1997; Teigelkamp et al., 1998). The latter two proteins are also referred to as hPrp4 and hPrp3, since they are the orthologues of the S. cerevisiae Prp4 and Prp3 splicing factors, respectively. To investigate the binding interactions among these five proteins, each was subcloned into the pGADT7 and pGBKT7 vectors to generate bait and prey fusions respectively, and these plasmids were co-transformed into yeast and tested for interaction as described in Materials and Methods. Consistently with the previous co-immunoprecipitation results (Teigelkamp et al., 1998), the interaction between the $20 \mathrm{~K}$ and $60 \mathrm{~K}$ proteins was confirmed during $\mathrm{Y} 2 \mathrm{H}$ analysis with each protein serving in turn as bait or prey (figure 4.3). Remarkably, this interaction remained the only one that could be detected among the five U4/U6 proteins by the two-hybrid method (figure 4.3).

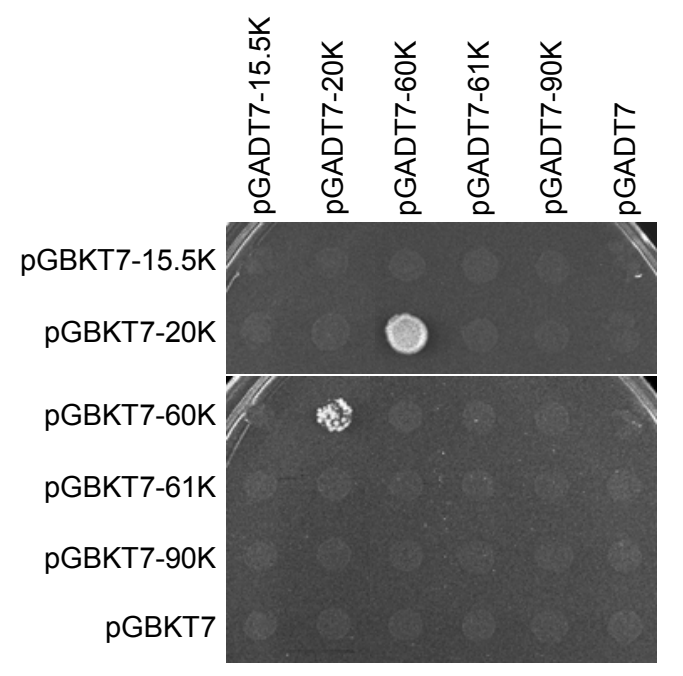


Figure 4.3. Y2H interactions between proteins $20 \mathrm{~K}$ and $60 \mathrm{~K}$. Binding was selected on the minimal synthetic dropout medium lacking leucine, tryptophan, histidine, and adenine (hereafter termed SD/-Leu-Trp-His-Ade) at $30^{\circ} \mathrm{C}$ for 3-5 days. Gal4 DNAbinding domain fusion protein 20K (pGBKT7-20K) interacts with Gal4 activation domain fusion protein $60 \mathrm{~K}$ (pGADT7-60K). The same result was observed in the reciprocal combination (i.e. pGADT7-20K/pGBKT7-60K). The empty vector pGADT7 or pGBKT7 served as a negative control.

Using in vitro binding assays, one could observe the interaction between $60 \mathrm{~K}$ and $90 \mathrm{~K}$, in addition to the interaction between $20 \mathrm{~K}$ and $60 \mathrm{~K}$ (figure 4.4). In one experiment, all proteins were produced and labelled with $\left[{ }^{35} \mathrm{~S}\right]-$ methionine by in vitro translation as described in the Materials and Methods. As shown in figure 4.4A, $\left[{ }^{35} \mathrm{~S}\right.$ ]-labelled HA-tagged 20K (lane 5) and 90K protein (lane 7) can be co-precipitated with c-Myc-tagged 60K using anti-c-Myc antibody. However, the binding efficiency of $90 \mathrm{~K}$ is much lower than that of $20 \mathrm{~K}$ (compare lanes 5 and 7). The same results were obtained when these two proteins were added together in one reaction (lane 8 ). The binding of $60 \mathrm{~K}$ to $90 \mathrm{~K}$ was also observed when $90 \mathrm{~K}$ was expressed as a recombinant His-tagged protein and $60 \mathrm{~K}$ was translated in vitro as an HA-tagged protein. Figure 4.4B shows that His-tagged $90 \mathrm{~K}$ protein specifically co-precipitated HA-60K protein that had been prepared by translation in vitro, and the level of HA-60K was significantly above the background level obtained in the absence of His-tagged 90K protein. Several conclusions can be drawn from above studies. First, proteins $60 \mathrm{~K}$ and $90 \mathrm{~K}$ are indeed associated in vitro, although this association was not observed in the $\mathrm{Y} 2 \mathrm{H}$ system. This is in agreement with the recent result of another group, who observed binding between $60 \mathrm{~K}$ and $90 \mathrm{~K}$ by using co-immunoprecipitation and isothermal titration calorimetry (Gonzalez-Santos et al., 2002). Second, in the $20 \mathrm{~K} \cdot 60 \mathrm{~K} \cdot 90 \mathrm{~K}$ complex, each interaction occurs independently (see figure $4.4 \mathrm{~A}$ : lane 5 and 7). Third, in the complex, one interaction does not affect the other, implying that the proteins $20 \mathrm{~K}$ and $90 \mathrm{~K}$ bind to distinct domains of $60 \mathrm{~K}$ (see figure 4.4A: lane 8). The observed $\mathrm{Y} 2 \mathrm{H}$ interactions between $60 \mathrm{~K}$ and $20 \mathrm{~K}$ (above) and between 90K and tri-snRNP-110K, U6-p110, SPF30/SMNrp (figures $4.12,4.17,4.19$ ) indicate that $60 \mathrm{~K}$ and $90 \mathrm{~K}$ are both properly expressed in the yeast cell. The failure of $60 \mathrm{~K}$ and $90 \mathrm{~K}$ to show an interaction in the $\mathrm{Y} 2 \mathrm{H}$ system must therefore be attributed to another cause (see Discussion). 


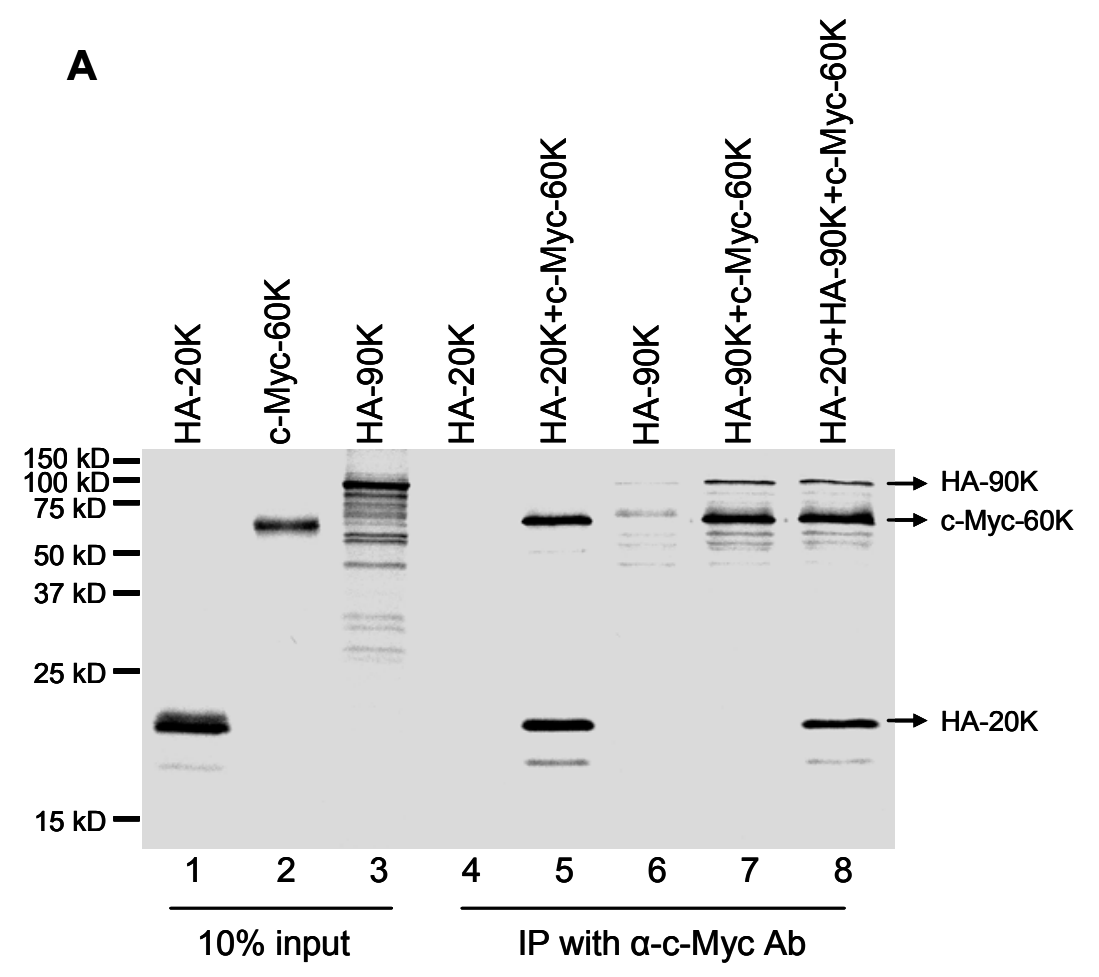

B

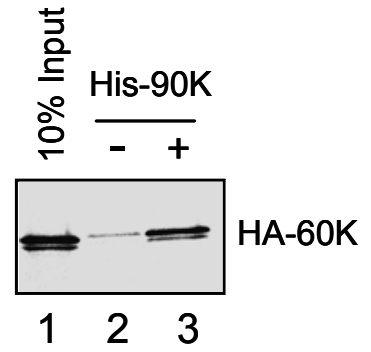

Figure 4.4. In vitro interactions between proteins $20 \mathrm{~K}, 60 \mathrm{~K}$ and $90 \mathrm{~K}$. (A) $\left[{ }^{35} \mathrm{~S}\right]$-labelled fusion proteins HA-20K, c-Myc-60K and HA-90K were produced in vitro respectively and the protein positions on the SDS-PAGE are shown on the right of the panel. c-Myc$60 \mathrm{~K}$ was incubated with HA-20K or/and 90K (lane 5, 7, 8), respectively, in $250 \mu 1$ buffer (20 mM Tris- $\mathrm{HCl} \mathrm{pH} 8.0,150 \mathrm{mM} \mathrm{NaCl}, 0.05 \% \mathrm{NP}-40)$ and precipitated by cMyc Ab which immobilised to protein-A Sepharose. HA-20K (lane 4) or HA-90K (lane 6) alone was incubated with $\mathrm{c}-\mathrm{Myc} \mathrm{Ab}$ immobilised beads in the negative control reaction. $10 \%$ of each translates was loaded on gel as input (lane 1,2,3). Molecular marker is indicated on the left of panel. (B) In vitro interactions between $60 \mathrm{~K}$ and $90 \mathrm{~K}$ proteins. Purified recombinant His-tagged $90 \mathrm{~K}$ was first incubated with in vitro translated $\left[{ }^{35} \mathrm{~S}\right]$-labelled HA-tagged $60 \mathrm{~K}$ protein and then with anti-pentahistidine antibodies and protein G-Sepharose to precipitate His-tagged 90K. The precipitated proteins were fractionated by SDS-PAGE and visualized by autoradiography. Mock precipitations without His-tagged $90 \mathrm{~K}$ were included as a negative control. The input lane represents $10 \%$ of the $60 \mathrm{~K}$ amount added to the reaction. 
In the complex of $20 \mathrm{~K} \cdot 60 \mathrm{~K} \cdot 90 \mathrm{~K}$, it has been shown that human $20 \mathrm{~K}$ protein binds to the SFM domain in the N-terminus of 60K (Horowitz et al., 2002; Reidt et al., 2003). In yeast, the C-terminal WD40 domain of Prp4p, which is conserved in the human homologue $60 \mathrm{~K}$ protein, is required for the binding of protein Prp3p (Ayadi et al., 1998). One may ask whether the same WD40 domain in human $60 \mathrm{~K}$ protein is also involved in the $90 \mathrm{~K}$ binding. To obtain more information on the $90 \mathrm{~K}$ binding sites, one $60 \mathrm{~K}$ mutant clone, obtained during the cloning of wild-type $60 \mathrm{~K}$, was used for the binding assays. This clone contains six point mutations: L185S, D350E, G404D, A446P, C509Y, and A520L, which are indicated as asterisks $\left({ }^{*}\right)$ above the residues in the figure 4.2. The position of L185S is near to the upstream of the WD40 domain; the mutation D350E, G404D, A446P, C509Y is located in the third, fifth, sixth, and seventh WD40 repeats respectively; A520L is in the position of the second-last amino acid at the 3' end. Of these mutations, the residues L185, D350, G404, A446 are highly conserved among the putative 60K orthologues (see figure 4.2). The experimental data show that the mutant $60 \mathrm{~K}$, like its wild type, efficiently binds to $20 \mathrm{~K}$ in the $\mathrm{Y} 2 \mathrm{H}$ system (data not shown) and in the coimmunoprecipitation assay as well (figure 4.5, left panel). However, it failed to bind $90 \mathrm{~K}$ protein in both systems (figure 4.5 and $\mathrm{Y} 2 \mathrm{H}$ data not shown). As positive control, the wild-type $60 \mathrm{~K}$ protein could specifically bind $90 \mathrm{~K}$ as shown in the figure 4.5 (left panel). Again, this could be shown by another assay, where only wild-type $60 \mathrm{~K}$, but not mutant clone, was co-precipitated by recombinant His-tagged $90 \mathrm{~K}$ protein (right panel of the figure 4.5). Taken together, these point mutants in the gene of $60 \mathrm{~K}$ completely disrupt the interaction with $90 \mathrm{~K}$, while the interaction between $20 \mathrm{~K}$ and $60 \mathrm{~K}$ remains unaffected. Considering that most of these mutations are located in the WD40 domain and the rest close to this domain, one may propose that the WD40 domain is indeed responsible for the binding of $90 \mathrm{~K}$ protein. 


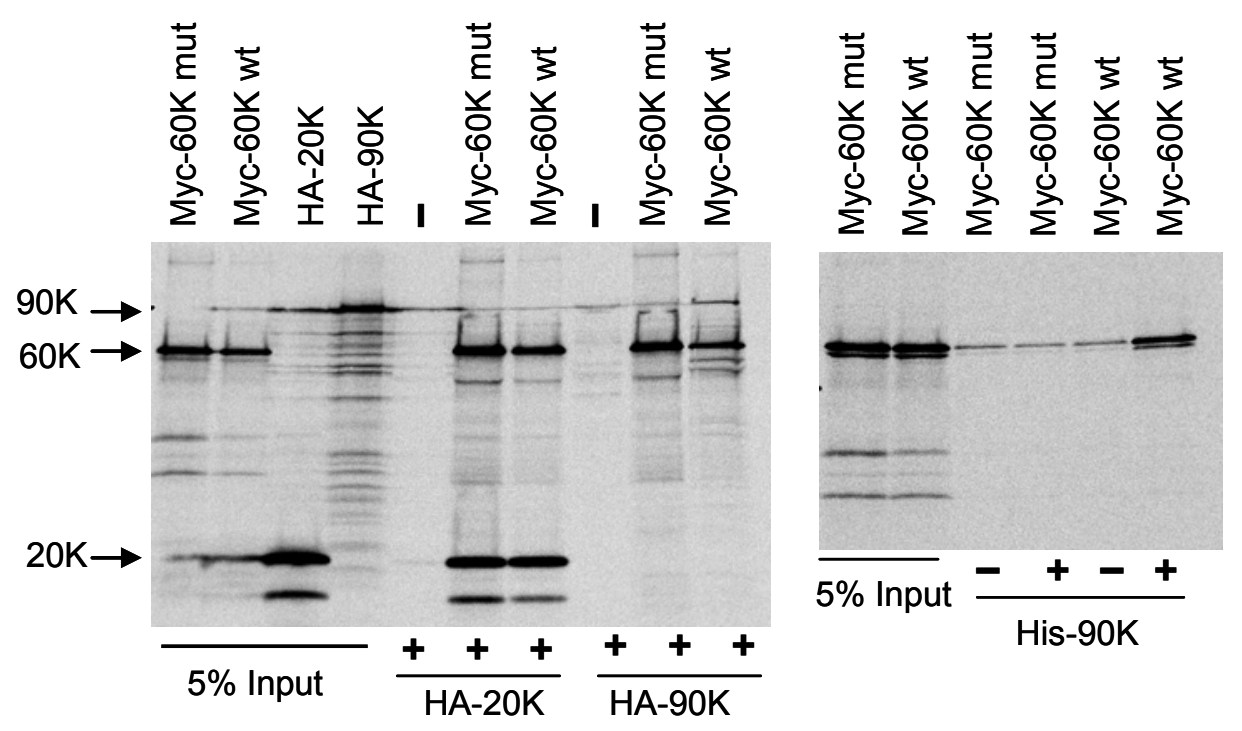

Figure 4.5. Mutational analysis of the in vitro interaction between proteins $20 \mathrm{~K}, 60 \mathrm{~K}$ and 90K. Left panel: $\left[{ }^{35}\right.$ S]-labelled fusion proteins HA-20K, HA-90K and c-Myc-60K (wild-type and mutant clones) were produced in vitro respectively as mentioned in the Materials and Methods and the protein positions on the SDS-PAGE are shown on the left of the panel. c-Myc-60K wild-type or mutant fusion protein was incubated with HA-20K or $90 \mathrm{~K}$ in $400 \mu \mathrm{l}$ buffer $(20 \mathrm{mM}$ Tris- $\mathrm{HCl} \mathrm{pH} 7.4,150 \mathrm{mM} \mathrm{NaCl}, 0.05 \% \mathrm{NP}-$ 40) and precipitated by c-Myc Ab which immobilised to protein-G Sepharose. HA-20K or HA-90K alone was incubated with c-Myc Ab immobilised beads in the negative control reaction. $5 \%$ of each translates was loaded on gel as input. The precipitated proteins were fractionated by $12 \%$ SDS-PAGE and visualized by autoradiography. Right panel: Purified recombinant His-tagged 90K was first incubated with in vitro translated $\left[{ }^{35} \mathrm{~S}\right]$-labelled HA-tagged $60 \mathrm{~K}$ wild-type and mutant fusion proteins respectively and then with anti-pentahistidine antibodies and protein G-Sepharose to precipitate His-tagged $90 \mathrm{~K}$ in $400 \mu \mathrm{l}$ buffer $(20 \mathrm{mM}$ Tris- $\mathrm{HCl} \mathrm{pH} 7.4,150 \mathrm{mM} \mathrm{NaCl}$, $0.05 \%$ NP-40). The precipitated proteins were fractionated by $12 \%$ SDS-PAGE and visualized by autoradiography. Mock precipitations without His-tagged $90 \mathrm{~K}$ were included as a negative control. The input lane represents $5 \%$ of the $60 \mathrm{~K}$ amount added to the reaction.

\subsection{Protein-protein interactions within the U5-snRNP particle}

\subsubsection{Interactions between U5 snRNP proteins in the RNA-free $220 \mathrm{~K} \cdot 200 \mathrm{~K} \cdot 116 \mathrm{~K} \cdot 40 \mathrm{~K}$ heterotetramer}

The U5-specific proteins $220 \mathrm{~K}, 200 \mathrm{~K}, 116 \mathrm{~K}$ and $40 \mathrm{~K}$, form an RNA-free protein complex which remains stable even in $0.2 \mathrm{M} \mathrm{NaSCN}$. Dissociation studies identified the U5-220K as the hub of this complex (Achsel et al., 1998). Y2H was applied to analyse the interactions between these proteins in more detail. 
The use of full-length coding sequences of $220 \mathrm{~K}, 200 \mathrm{~K}, 116 \mathrm{~K}$ and $40 \mathrm{~K}$ in bait or prey constructs did not result in the appearance of any clear protein-protein interactions (figure 4.6B). Occasionally, two-hybrid interaction between two fulllength proteins (especially for the large proteins) is just undetectable. Similar behaviour has been observed by others in the case of yeast Prp8p (van Nues and Beggs, 2001); full-length Prp8p as bait did not produce such obviously specific interactions as its fragments did. In a more detailed investigation, each of these proteins was truncated for bait and prey construction (figure 4.6A). For proteins $200 \mathrm{~K}$ and $116 \mathrm{~K}$, the truncated proteins corresponded to recognisable, known protein domains. Thus, $200 \mathrm{~K}$ was divided into five overlapping fragments on the basis of the structural domains deducible from the amino-acid sequence: fragments 2 and 4 cover the two helicase domains, while fragments 3 and 5 harbour the two SEC63 domains (see figures 4.1, 4.6A). Likewise, protein $116 \mathrm{~K}$ was divided up by following the boundaries of the conserved GTPase structural features known from EF-2. The first fragment contains the GTP-binding domain of EF-2, while fragments 2 and 3 cover domain II and domains IV+V in the EF-2 nomenclature (figure 4.6A). In contrast to these two proteins, the sequence of $220 \mathrm{~K}$, although highly conserved in all eukaryotes, does not offer any clues as to the structural organization of the protein. $220 \mathrm{~K}$ was therefore divided into six arbitrary fragments of roughly equal size (315-477 amino acids; figure 4.6 A).

Bait and prey constructs with full-length and truncated proteins were again tested in the $\mathrm{Y} 2 \mathrm{H}$ assay. Binding between the three proteins $220 \mathrm{~K}, 200 \mathrm{~K}, 116 \mathrm{~K}$ became clearly visible (figure 4.6B). The domain contacts deduced are shown schematically in figure 4.6C. The N-terminal fragment 220-1 (aa 1-387) and the C-terminal fragment 220-6 (aa 1986-2335) of 220K interact with each other, as well as with fragment 200-4 of 200K (aa 1301-1816). This fragment contains the C-terminal helicase domain of $200 \mathrm{~K}$ and in turn interacts with the central and Cterminal fragments of the $116 \mathrm{~K}$ protein (116-2: aa 279-692 and 116-3: aa 603972). The central fragment of $116 \mathrm{~K}(116-2)$ interacts with both terminal fragments of $220 \mathrm{~K}(220-1$ and 220-6), while the C terminal fragment (116-3) of $116 \mathrm{~K}$ interacts with the C-terminal fragment of $220 \mathrm{~K}(220-6)$, thus closing the circle of these three proteins. All fragments that interact with fragments of $116 \mathrm{~K}$ 
also interact with full-length $116 \mathrm{~K}$, indicating that protein $116 \mathrm{~K}$ is properly expressed and correctly folded in yeast. It thus appears that contacts between specific conserved functional domains of the three large proteins make a major contribution to the creation of the heterotetrameric complex.

\section{A}

$220 \mathrm{~K}$

220-1

220-2

220-3

220-4

220-5

220-6

200K

200-1

200-2

$200-3$

200-4

200-5

$116 K$

116-1

116-2

116-3

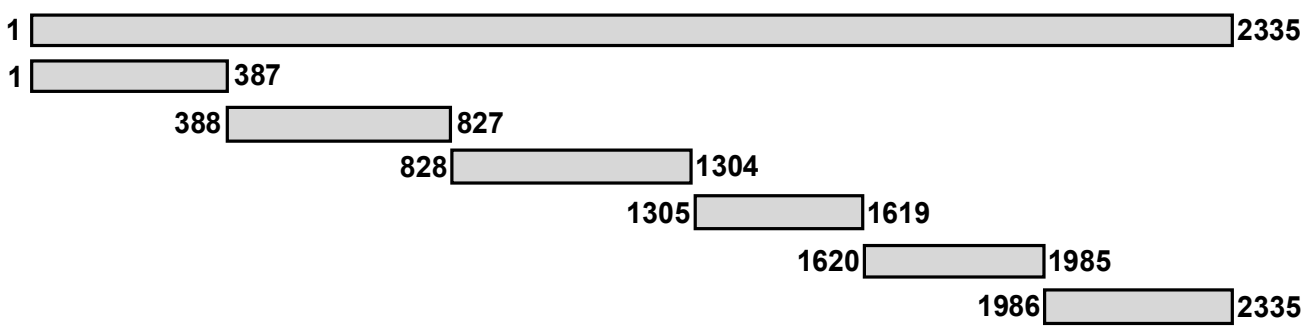

DEXHC HELICC SEC63 DEXHC HELICC SEC63

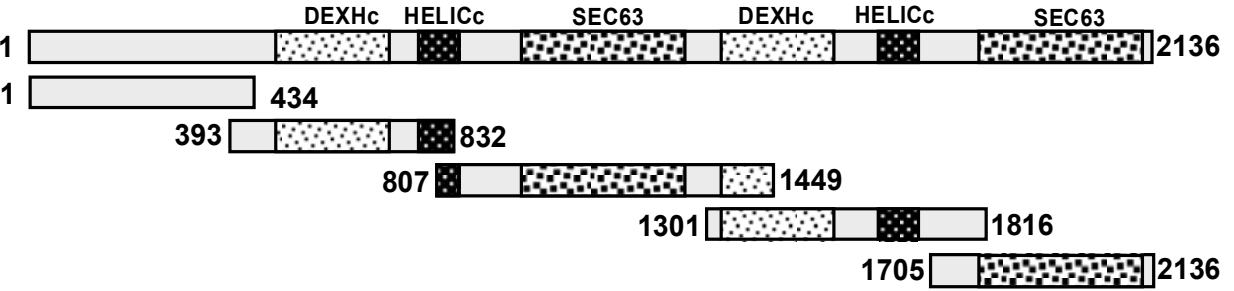



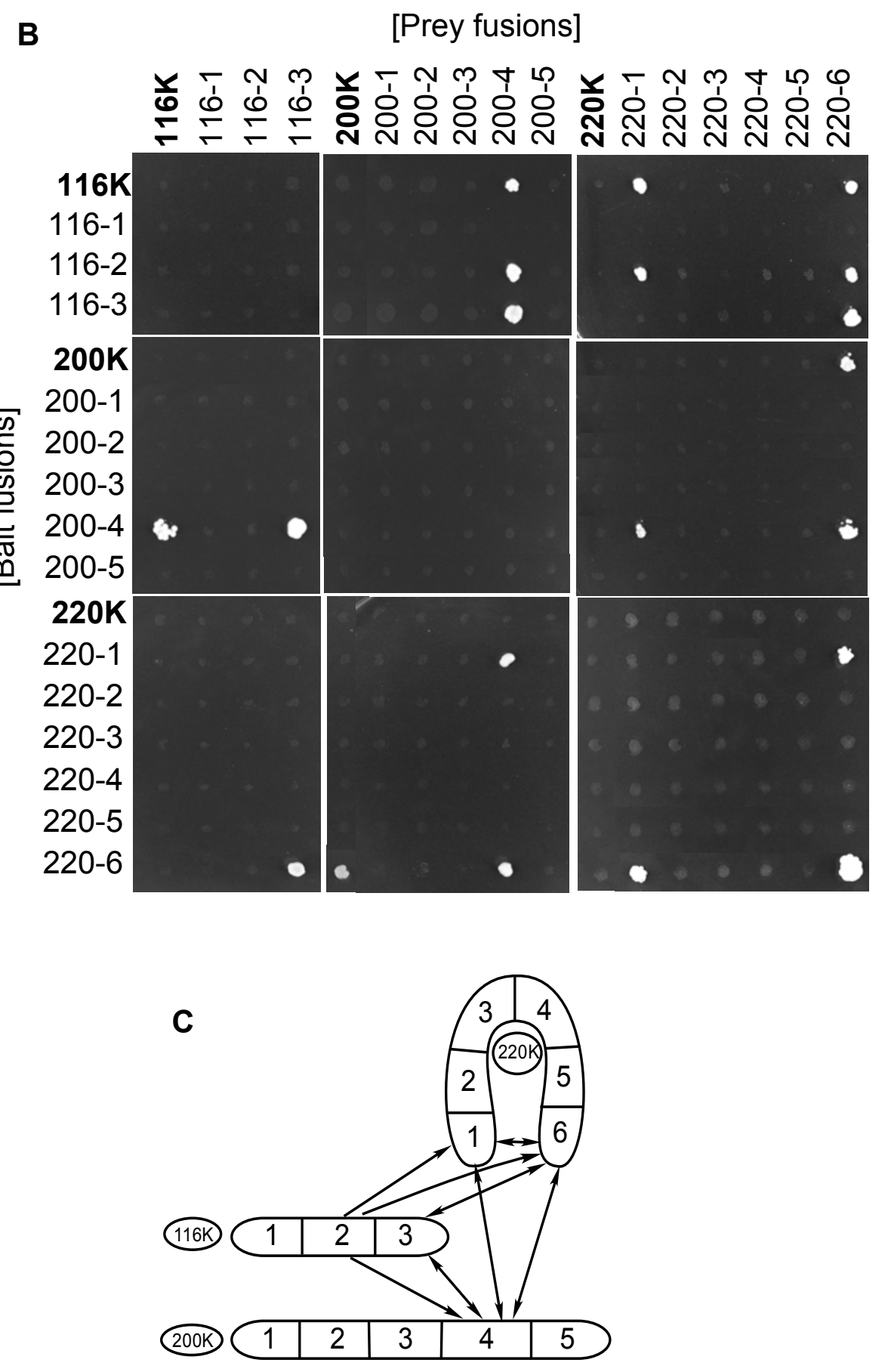

Figure 4.6. (A) Schematic representation of the $220 \mathrm{~K}, 200 \mathrm{~K}$ and $116 \mathrm{~K}$ proteins and their fragments used in the yeast two-hybrid assays. DEXHc, DEXH-box helicases; HELICc, helicase superfamily C-terminal domain; SEC63, domain of unknown function in Sec63p and other proteins; EF-2_G, eukaryotic elongation factor 2 GTPbinding domain; EF-2_II (IV, V), eukaryotic elongation factor 2 domains II, IV and V. (B) $\mathrm{Y} 2 \mathrm{H}$ interaction between the three large U5-specific proteins $220 \mathrm{~K}, 200 \mathrm{~K}$ and $116 \mathrm{~K}$. All the three proteins and truncated fragments were cloned in the both pGADT7 and pGBKT7 respectively, and then were co-transformed into AH109 cells in all combinations. The positive results were observed on the selective medium SD/-LeuTrp-His-Ade at $30^{\circ} \mathrm{C}$ for 3-7 days. (C) Schematic presentation of the domain interactions between protein $220 \mathrm{~K}, 200 \mathrm{~K}$ and $116 \mathrm{~K}$ found in $\mathrm{Y} 2 \mathrm{H}$ system (B). 
Binding partners of protein $40 \mathrm{~K}$ could not be identified with any full-length or truncated proteins by $\mathrm{Y} 2 \mathrm{H}$ analysis (data not shown). In a previous paper Achsel et al. have described binding interactions of protein $220 \mathrm{~K}$ with protein $40 \mathrm{~K}$ and $116 \mathrm{~K}$ using far-western blot analysis (Achsel et al., 1998). In this study, the interaction was confirmed by the fact that $\left[{ }^{35} \mathrm{~S}\right.$-labelled c-Myc-tagged protein $40 \mathrm{~K}$ co-immunoprecipitated with $\left[{ }^{35} \mathrm{~S}\right]$-labelled HA-tagged $220 \mathrm{~K}$, using protein A-Sepharose and anti-HA antibodies (figure 4.7).

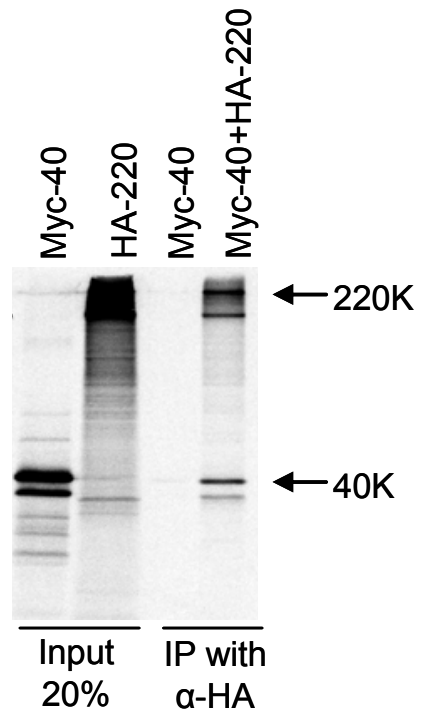

Figure 4.7. In vitro interactions between $40 \mathrm{~K}$ and $220 \mathrm{~K}$ proteins. In vitro translated $\left[{ }^{35} \mathrm{~S}\right]-$ labelled HA-tagged $220 \mathrm{~K}$ protein was incubated with c-Myc-tagged 40K protein, and then precipitated with anti-HA antibodies and protein A-Sepharose. The precipitated proteins were fractionated by SDS-PAGE and visualized by autoradiography. Mock precipitation without HA-tagged $220 \mathrm{~K}$ was included as a negative control. The input lane represents $20 \%$ of the proteins amount added to the reaction.

\subsubsection{Overexpression of the protein fragments from $220 \mathrm{~K}$ and $200 \mathrm{~K}$}

In order to obtain recombinant proteins for biochemical study, all $220 \mathrm{~K}$ and $200 \mathrm{~K}$ fragments used in the $\mathrm{Y} 2 \mathrm{H}$ were subcloned into the $\mathrm{pET} 28 \mathrm{a}-\mathrm{c}$ expression vectors. The plasmids were introduced into BL21(DE3) and the cell cultures were induced in $1 \mathrm{mM} \mathrm{IPTG}$ at $37^{\circ} \mathrm{C}$ for 3 hours. Most proteins were found to be expressed but insoluble. As an example, figure 4.8 shows the fractions of some fragments of $220 \mathrm{~K}$ protein eluted under denaturing conditions with urea. Compared with fragments $220-1$ and 220-4, the yields of 220-5 and 220-6 are much higher. The denatured protein 220-5 was used to produce antibodies in rabbits. The resulted anti-200-5 antibodies were found to be very specific and exhibited no cross reactions (data not shown). 


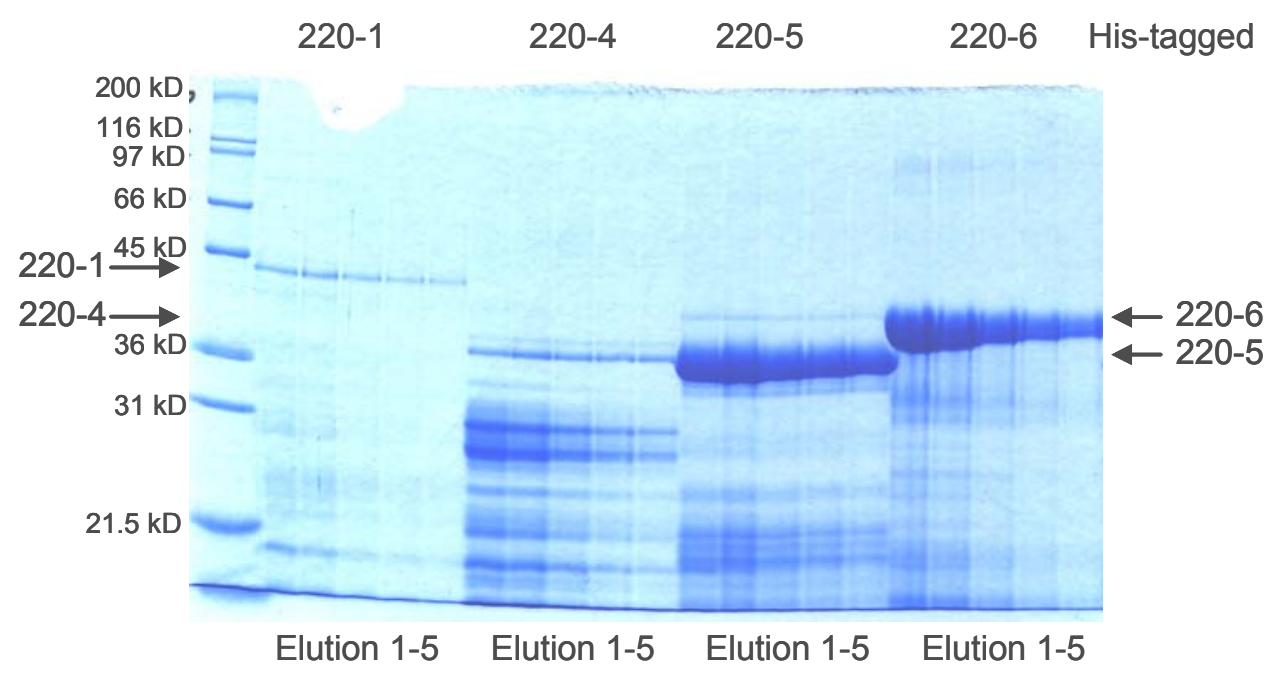

Figure 4.8. Expression of protein $220 \mathrm{~K}$ fragments in E. coli. Five different inclusion body fractions of each protein were run on a $13 \%$ SDS-PAGE gel and stained with Coomassie blue.

\subsubsection{Multiple interactions of $102 \mathrm{~K}$ with other U5 snRNP proteins within the tri-snRNP particle}

Previous studies had indicated that $102 \mathrm{~K}$ is stably associated with U5 snRNP via protein-protein interactions (Makarov et al., 2000). However, little is known about its interacting partner. By the yeast two-hybrid method, protein $102 \mathrm{~K}$ was tested against the full-length U5 snRNP proteins including $15 \mathrm{~K}, 40 \mathrm{~K}, 100 \mathrm{~K}$, $102 \mathrm{~K}, 116 \mathrm{~K}, 200 \mathrm{~K}$, and $220 \mathrm{~K}$, and subsequently the fragments from the latter three proteins, which are described in section 4.3.1. Figure 4.9A shows the outcome when protein $102 \mathrm{~K}$ was used as a bait fusion. Multiple interactions were identified. First, protein $102 \mathrm{~K}$ interacts with the full-length proteins $15 \mathrm{~K}$, $116 \mathrm{~K}$, and $102 \mathrm{~K}$ itself. In the next experiment, protein $102 \mathrm{~K}$ was demonstrated to interact with distinct domains of each of the three large proteins, which include 116K fragments 2 and 3,200K fragments 2 and 4, and 220K fragments 1 and 6 . The interaction between $102 \mathrm{~K}$ and $15 \mathrm{~K}$ were able to be observed in the reverse combinations, where $102 \mathrm{~K}$ was constructed as a prey fusion (data not shown).

To confirm the results of $\mathrm{Y} 2 \mathrm{H}$ analysis, an in vitro GST pull-down assay was performed. Proteins $15 \mathrm{~K}$ and $102 \mathrm{~K}$, protein $116 \mathrm{~K}$ and its mutants, protein $200 \mathrm{~K}$ fragments 2 and 4 , protein $220 \mathrm{~K}$ fragments 1 and 6 - all produced by in vitro 
translation - were incubated with immobilized GST-102K or GST. GST-102K (lane 3), but not GST (lane 2), significantly binds [ $\left.{ }^{35} \mathrm{~S}\right]-$ labelled c-Myc-102K, c-Myc-200-4 (aa 1301-1816), and c-Myc-220-1 (aa 1-387), but not protein $116 \mathrm{~K}$ or its mutants, or fragments 200-2 and 220-6 (lower panel of figure 4.9B and data not shown). Protein $102 \mathrm{~K}$ and $200-4$ show higher binding efficiency than 220-1 does. Fragments 116-2 and 200-2 (the degraded band) display signals only slightly above background. The Coomassie blue staining gel shows that nearly equal amounts of recombinant proteins in each reaction were eluted from glutathione-Sepharose beads (figure 4.9B, upper panel). The fact that GST-102K fails to interact with the $15 \mathrm{~K}$ protein can be attributed to the $\mathrm{N}$ terminal GST tag possibly blocking the binding site for $15 \mathrm{~K}$. Therefore, to confirm the interaction between $102 \mathrm{~K}$ and $15 \mathrm{~K}$ proteins, a coimmunoprecipitation experiment with His-tagged $15 \mathrm{~K}$ was performed. Figure $4.9 \mathrm{C}$ shows that $\left[{ }^{35} \mathrm{~S}\right]$-labelled $\mathrm{c}-\mathrm{Myc}-102 \mathrm{~K}$ is now specifically precipitated with His-tagged $15 \mathrm{~K}$. The expression and purification of His-tagged $15 \mathrm{~K}$ protein was described previously (Reuter and Ficner, 1999). In summary, the binding assay in vitro independently confirmed the interactions of protein $102 \mathrm{~K}$ with proteins $15 \mathrm{~K}, 102 \mathrm{~K}, 220-1$, and 200-4. However, there are no significant in vitro interactions of protein $102 \mathrm{~K}$ with protein $116 \mathrm{~K}$ or fragments $200-2$ and $220-6$.

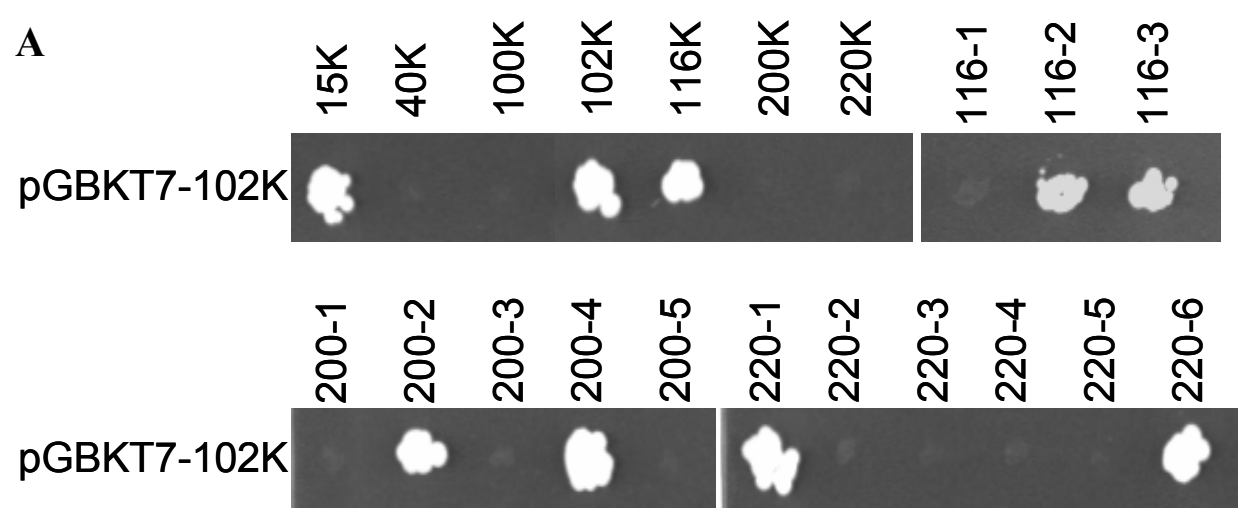


B

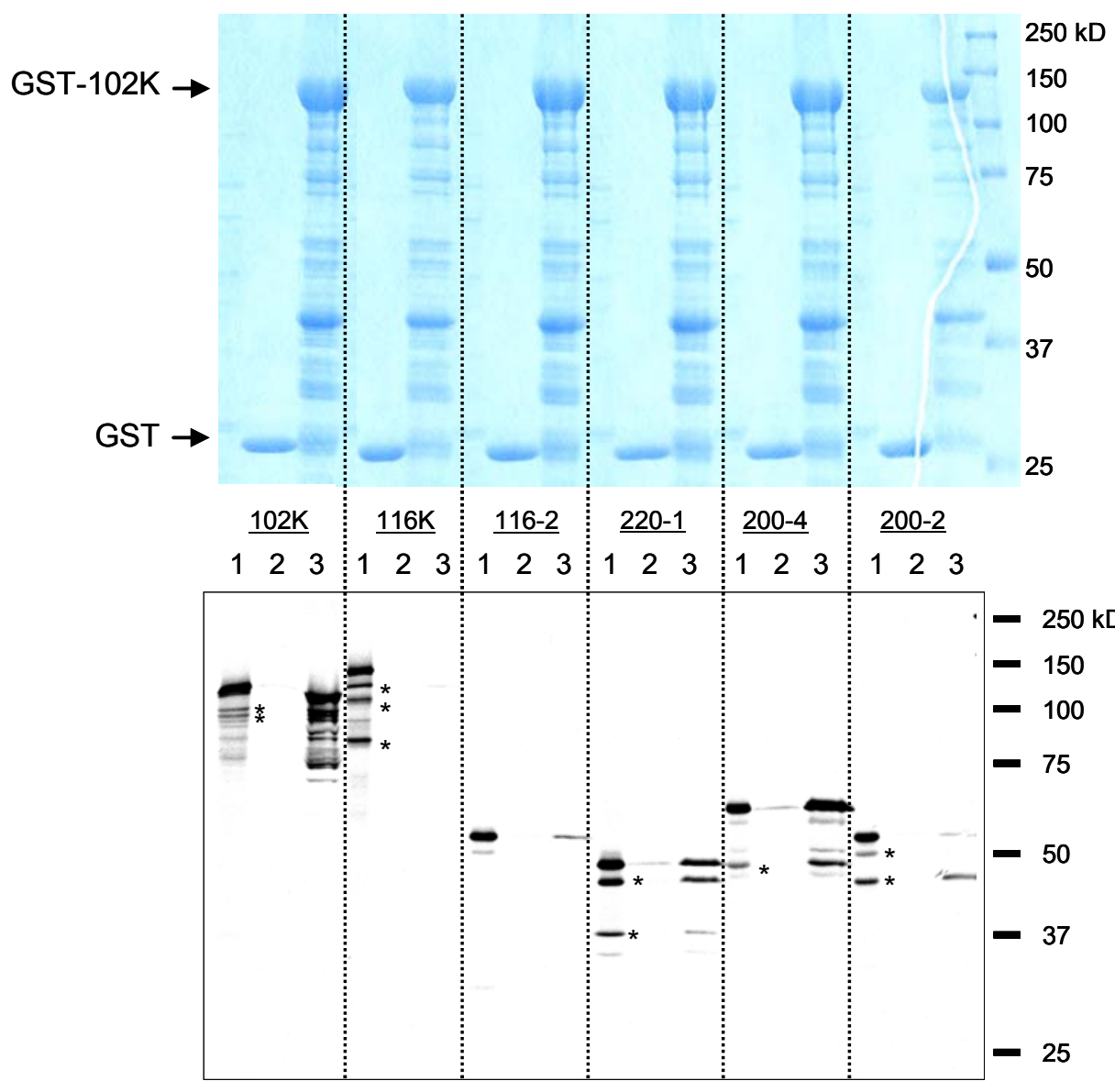

C

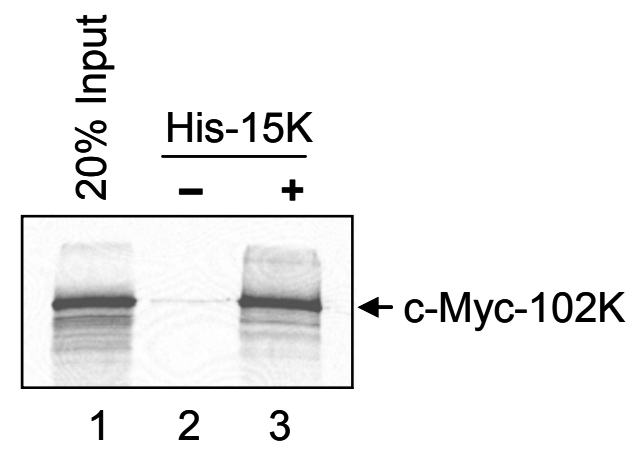

Figure 4.9. Interactions of protein $102 \mathrm{~K}$ with other U5-specific proteins. (A) $\mathrm{Y} 2 \mathrm{H}$ interaction assay of $102 \mathrm{~K}$. Protein $102 \mathrm{~K}$ was cloned into pGBKT7 vector as a bait fusion, while the testing partners of U5-specific proteins as indicated in the figure were cloned into pGADT7 as prey fusions. The positive results were selected on the SD/Leu-Trp-His-Ade medium at $30^{\circ} \mathrm{C}$ for 6 days. (B) In vitro interactions of GST-102K. 10 $\mu \mathrm{l}$ of $\left[{ }^{35} \mathrm{~S}\right]$-labelled samples of interest were incubated with GST, or GST-102K immobilized on glutathione-Sepharose beads. Bound proteins were eluted in SDS sample buffer and analyzed with SDS-PAGE. The input lane (lane 1) contains $10 \%$ of the total amount of in vitro translated protein added to each reaction. The gel was first subjected to Coomassie blue staining to show that equivalent amount of expressed proteins were eluted from beads (upper panel). Subsequently, the gel was dried and 
exposed to X-ray film (lower panel). Arrowheads indicate the position of GST or GST$102 \mathrm{~K}$ protein. Asterisks $(*)$ indicate the degraded form of the translated proteins. The protein size markers are shown on the right of the panel. (C) The interaction of His-15K with $102 \mathrm{~K}$ protein prepared by translation in vitro. Purified His-tagged $15 \mathrm{~K}$ protein was first incubated with anti-pentahistidine antibodies and protein A-Sepharose, and subsequently with $\left[{ }^{35} \mathrm{~S}\right]$-labelled c-Myc-102K protein prepared in vitro (lane 3 ). Bound proteins were again visualized by autoradiography following SDS-PAGE. A mock precipitation without His-tagged $15 \mathrm{~K}$ is included as a negative control (lane 2). The input lane represents $20 \%$ of the c-Myc- $102 \mathrm{~K}$ products added to the reaction (lane 1 ).

\subsection{Protein-protein interactions between U4/U6 and U5 snRNP particles}

\subsubsection{U5-102K binds specifically to U4/U6-61K in the $\mathrm{Y} 2 \mathrm{H}$ system and in vitro}

While some information has been accumulated on protein-protein and proteinRNA interactions within the individual U4/U6 or U5 snRNP, little is known about the interactions that connect the U4/U6 and U5 snRNPs. Several lines of evidence have suggested that protein-protein interaction may contribute to the formation of the tri-snRNP. Therefore, the interactions between the U4/U6 and U5 snRNP particles were tested in the yeast two-hybrid system. Figure 4.10A shows the results from the combinations of all the prey fusions of the U4/U6specific proteins with bait fusions of the U5-specific proteins. The protein fragments from the three large proteins $116 \mathrm{~K}, 200 \mathrm{~K}$ and $220 \mathrm{~K}$ were included in the experiment. Surprisingly, only one interaction - between pGADT7-61K and pGBKT7-102K - was identified. The same results were obtained in the reciprocal two-hybrid screen, where U4/U6-specific proteins were constructed as bait fusions but U5-specific proteins as prey fusions (data not shown). The interaction between the $61 \mathrm{~K}$ and $102 \mathrm{~K}$ proteins was independently confirmed using a biochemical method (figure 4.10B). In the GST pull-down assay in vitro translated, $\left[{ }^{35} \mathrm{~S}\right]$-labelled $102 \mathrm{~K}$ protein binds strongly to a purified recombinant GST-tagged $61 \mathrm{~K}$ fusion protein. The expression and purification of GST-61K fusion protein was described previously (Makarova et al., 2002; Nottrott et al., 2002). This interaction is specific, as only a low level of $102 \mathrm{~K}$ protein was precipitated with beads containing GST alone. In summary, these results indicated that the binding between $102 \mathrm{~K}$ and $61 \mathrm{~K}$ is specific and stable which 
may contribute to the formation of tri-snRNP from the U4/U6 and U5 snRNPs.

This result was published recently in the EMBO Journal (Makarova et al., 2002).
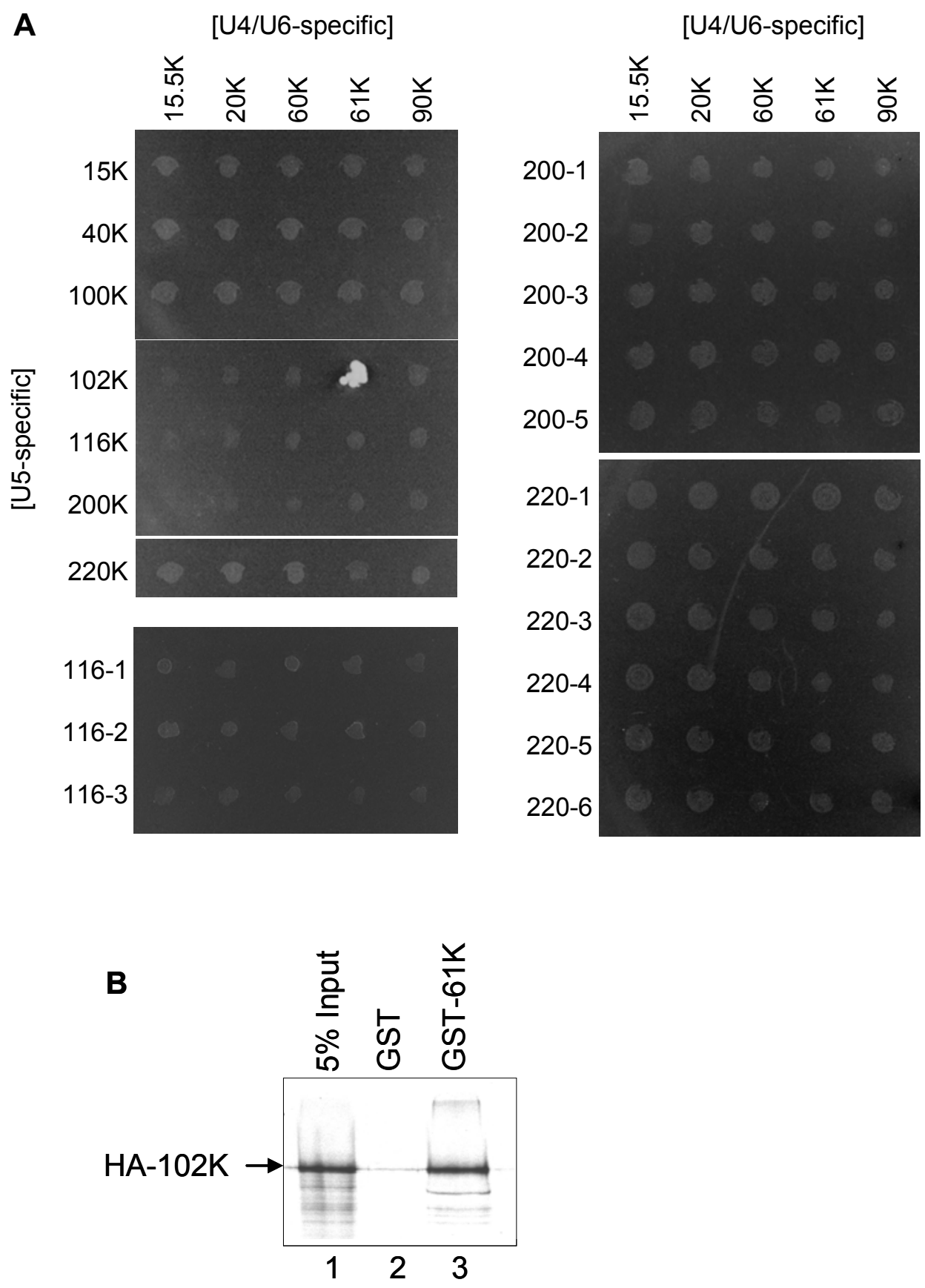

Figure 4.10. Protein $102 \mathrm{~K}$ interacts specifically with $61 \mathrm{~K}$. (A) Y2H interaction between U4/U6 and U5 snRNP particles. All the U4/U6-specific proteins were cloned into pGADT7 as prey fusions, while the U5-specific proteins were cloned into pGBKT7 as bait fusions. The positive colony in the combination of pGADT7-61K and pGBKT7$102 \mathrm{~K}$ was observed after growth on the selective medium of SD/-Leu-Trp-His-Ade at $30^{\circ} \mathrm{C}$ for 5 days. (B) In vitro interaction between protein $102 \mathrm{~K}$ and $61 \mathrm{~K}$. [ ${ }^{35} \mathrm{~S}$ ]-labelled, in vitro translated protein $102 \mathrm{~K}$ was incubated with GST (lane 2) or GST-61K fusion protein(lane 3 ) in the presence of glutathione-Sepharose. The precipitated proteins were 
fractionated by SDS-PAGE and visualized by fluorography. The input lane represents $5 \%$ of the $102 \mathrm{~K}$ amount added to the reaction.

\subsubsection{The U5-102K binds specifically to the C-terminal region of U4/U6-90K in in vitro binding assay}

As pointed out in section 4.2.1, an interaction between the U4/U6-specific proteins $60 \mathrm{~K}$ and $90 \mathrm{~K}$ could not be detected using the two-hybrid-system, but was clearly detectable in the in vitro binding assay. This suggested that other interactions of both proteins may have eluded detection in the $\mathrm{Y} 2 \mathrm{H}$ system. The GST-102K fusion protein was therefore used in binding assays with $60 \mathrm{~K}$ and $90 \mathrm{~K}$ prepared by translation in vitro, and with $61 \mathrm{~K}$ as a positive control (its interaction with $102 \mathrm{~K}$ was described above; Makarova et al., 2002). While 90K bound very strongly to GST-102K, 60K did not (figure 4.11A).

To delimit further the boundaries of the interacting domain in the $90 \mathrm{~K}$, the protein was dissected into four fragments according to the design by GonzalezSantos et al. (2002), with two additional fragments respectively comprising the $\mathrm{N}$ - and $\mathrm{C}$-terminal halves of the protein (see figure 4.21 for diagram). All six fragments were subcloned in pGBKT7, and subsequently were used for yeast two-hybrid testing with $102 \mathrm{~K}$, or used as templates to generate $\left[{ }^{35} \mathrm{~S}\right]$-labelled c-Myc-tagged proteins for GST pull-down experiments respectively (see section 3.2.3.2 for methods). The full-length $90 \mathrm{~K}$ protein was tested as well. Consistently, no binding was identified in the $\mathrm{Y} 2 \mathrm{H}$ assay (figure 4.11B, upper panel). In contrast, the in vitro binding assay shows that the C-terminal fragments (C267, C381, and C489) strongly bind GST-102K, while the $\mathrm{N}$-terminal fragments do not result in signals above background (figure 4.11B, lower panel). It therefore appears that a C-terminal region of the $90 \mathrm{~K}$, comprising amino acids $417-683$, suffices to establish binding to $102 \mathrm{~K}$. 

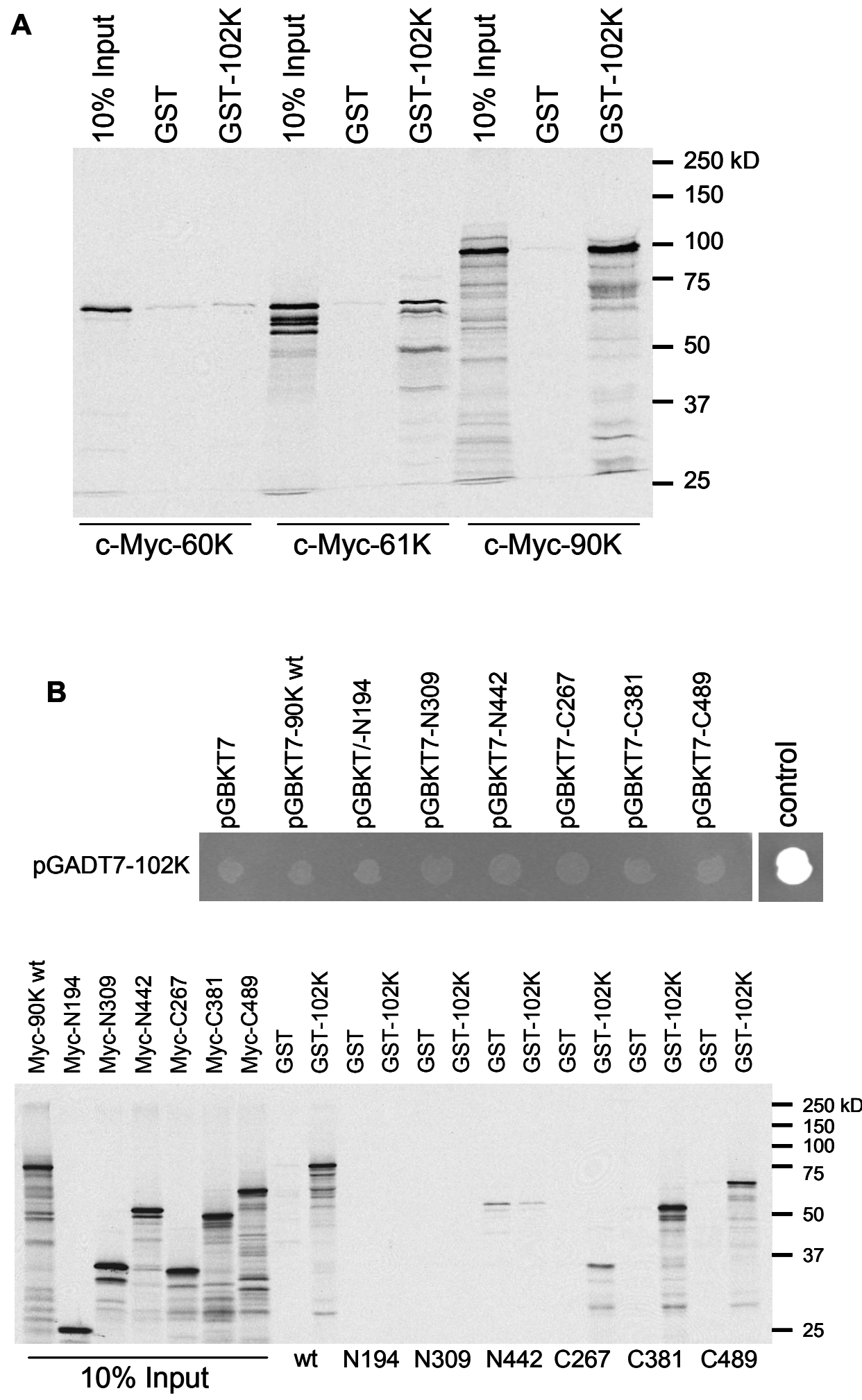

Figure 4.11. (A) In vitro interaction between proteins $102 \mathrm{~K}$ and $90 \mathrm{~K} .10 \mu 1$ of $\left[{ }^{35} \mathrm{~S}\right]-$ labelled samples of interest were incubated with GST, or GST-102K immobilized on glutathione-Sepharose beads. Bound proteins were eluted in SDS sample buffer and analyzed with SDS-PAGE and visualized by autoradiography. The input lane contains $10 \%$ of the total amount of in vitro translated protein added to each reaction. The protein size markers are shown on the right of the panel. (B) Upper panel: $\mathrm{Y} 2 \mathrm{H}$ analysis to search for the $102 \mathrm{~K}$ binding domain in $90 \mathrm{~K}$. pGADT7-102K was tested against six 
90K fragments constructed in pGBKT7; the combination of pGADT7-T/pGBKT7-p53 served as a positive control. The positive interaction was observed by growing on the selective medium of $\mathrm{SD} /$-Leu-Trp-His at $30^{\circ} \mathrm{C}$ for 3 days. Lower panel: Coimmunoprecipitation assay to search for the $102 \mathrm{~K}$ binding domain in $90 \mathrm{~K}$. The same procedure as described in the legend for (A) was used.

\subsection{The interactions of the tri-snRNP-specific protein $110 \mathrm{~K}$}

Three proteins, the $110 \mathrm{~K}, 65 \mathrm{~K}$ and $27 \mathrm{~K}$ proteins, show specific stable association with the tri-snRNP (Makarova et al., 2001; Fetzer et al., 1997), but less so or not at all with its separate snRNP components. I was interested in identifying the binding partners of these three proteins. In $\mathrm{Y} 2 \mathrm{H}$ experiments, full-length $110 \mathrm{~K}$ was found to bind to the U4/U6-specific protein $90 \mathrm{~K}$ and also to the full-length U5-specific proteins $102 \mathrm{~K}$ and $200 \mathrm{~K}$ (figure $4.12 \mathrm{~A}$ ). In the case of protein $200 \mathrm{~K}$, the interaction with $110 \mathrm{~K}$ appears to depend on the C-terminal fragments 200-4 (aa 1301-1816) and 200-5 (aa 1705-2136) (figure 4.12A). Interactions were again confirmed by co-immunoprecipitations: in the presence of His-tagged $110 \mathrm{~K}$ recombinant protein, the anti-pep-110 antibody coprecipitated [ $\left.{ }^{35} \mathrm{~S}\right]$-labelled full-length c-Myc-90K, c-Myc-102K and c-Myc-200K protein as well as the c-Myc-200-4 and HA-200-5 fragments of 200K (figure 4.12B). Yeast two-hybrid interactions involving the U4.U6/U5-27K or the $65 \mathrm{~K}$ protein could not be detected (data not shown). The expression and purification of His-tagged $110 \mathrm{~K}$ recombinant protein has been described by Makarova et al. (2001).

The interacting domain of $90 \mathrm{~K}$ was further investigated in the $\mathrm{Y} 2 \mathrm{H}$ system. Like its full-length 90K protein, the two larger C-terminal fragments (C381 and C489) interact with $110 \mathrm{~K}$, while the three $\mathrm{N}$-terminal fragments and the short $\mathrm{C}$ terminal fragment do not (figure 4.12C). In summary, for the binding of protein $110 \mathrm{~K}$, a larger C-terminal region of $90 \mathrm{~K}$, comprising amino acids 303-683, is required, comparing to the binding for protein $102 \mathrm{~K}$ (see section 4.4.2) and p110 (section 4.8), which need only amino acids 417-683.

The human $110 \mathrm{~K}$ protein comprises 800 amino acids residues and contains an $\mathrm{RS}$ domain in the $\mathrm{N}$-terminal region of about 120 residues, which is absent in the yeast homologue protein Snu66p. The remaining part of the $110 \mathrm{~K}$ sequence does not contain known motifs that would suggest additional potential functions 
of this protein (Makarova et al., 2001). To evaluate the domain function, the full-length $110 \mathrm{~K}$ was split into two segments, RS and $\Delta R S$. RS contains the RS domain (1-111 amino acids), while $\triangle \mathrm{RS}$ contains the $\mathrm{C}$-terminal region lacking RS domain (112-800 amino acids). Two segments were subcloned into pGBKT7 for testing interaction with known partners $90 \mathrm{~K}, 102 \mathrm{~K}$ and $200 \mathrm{~K}$ Cterminal fragments of $200-4$ and $200-5$ in $\mathrm{Y} 2 \mathrm{H}$ system. The results clearly showed that the RS domain of $110 \mathrm{~K}$ is not required for the binding, while the Cterminal region lacking $\mathrm{RS}$ domain is sufficient for the binding with protein $90 \mathrm{~K}$, $102 \mathrm{~K}$ and $200 \mathrm{~K}$ fragments (figure 4.12D). Consistently with this, yeast homologue protein Snu66p, which lacks RS domain in nature, is able to bind to the Brr2p (200K in human) and Prp6p (102K in human) (van Nues and Beggs, 2001). The potential role of the RS domain in the human $110 \mathrm{~K}$ protein is discussed in the Discussion.
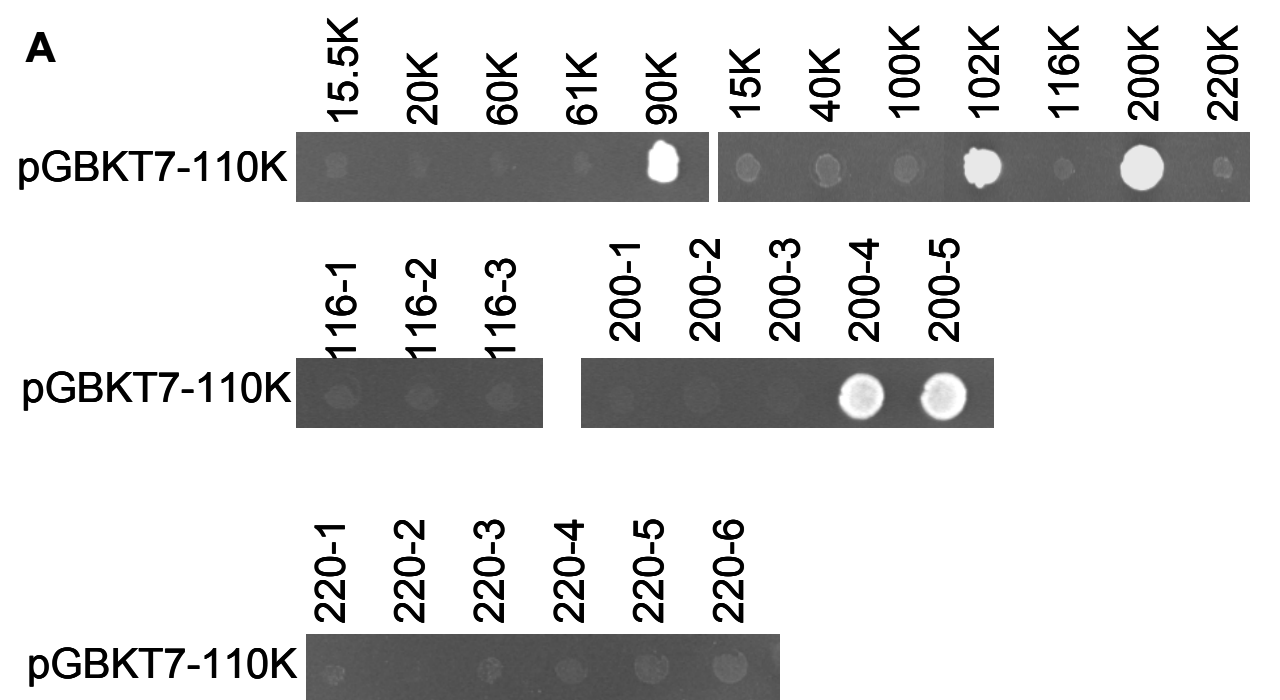

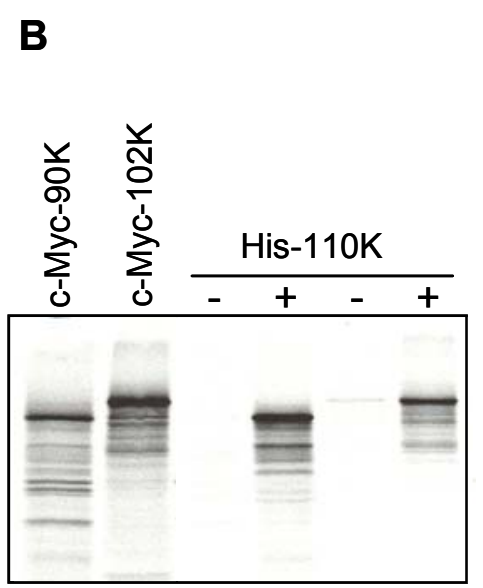

$20 \%$ Input

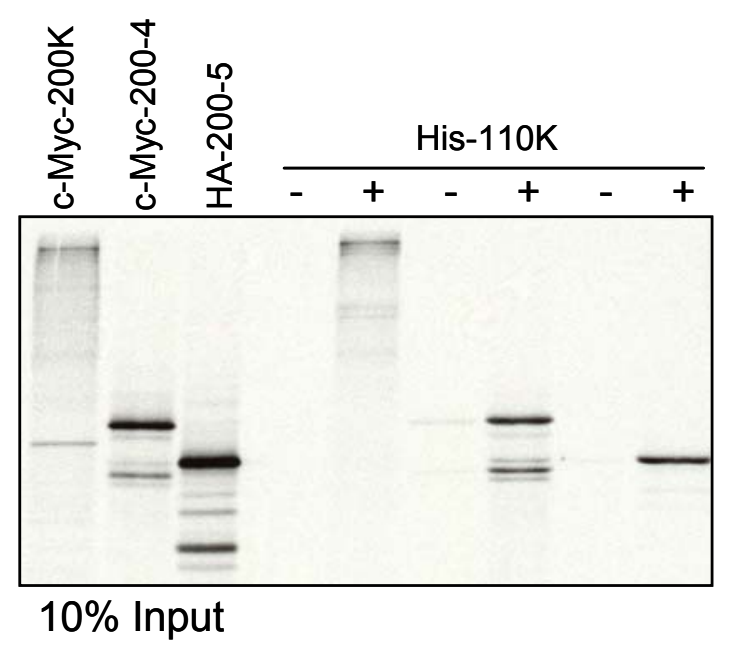

$10 \%$ Input 

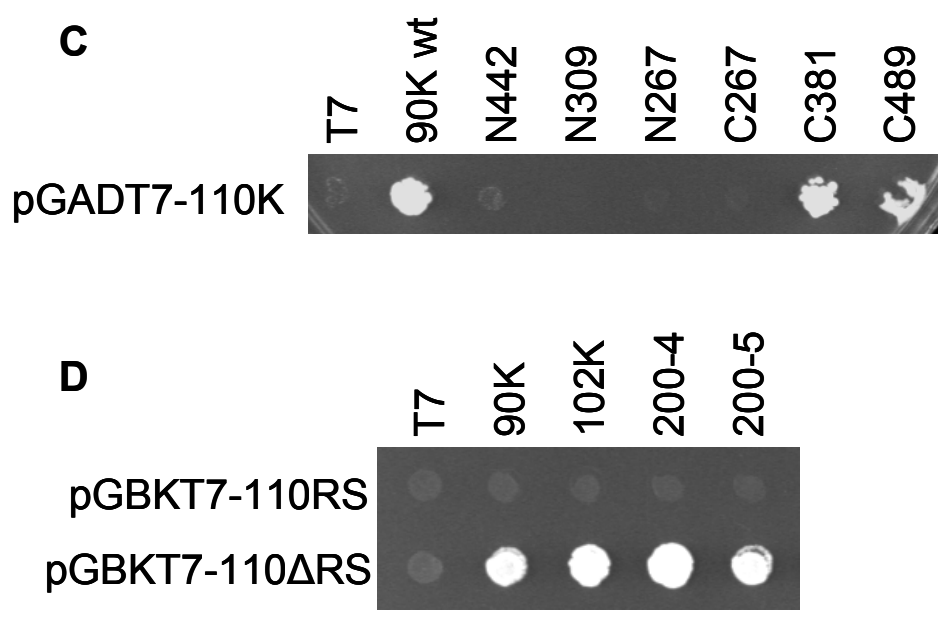

Figure 4.12. Analysis of the interactions of $110 \mathrm{~K}$ protein. (A) $\mathrm{Y} 2 \mathrm{H}$ investigation of the interaction between $110 \mathrm{~K}$ and U5- and U4/U6-specific proteins. Protein $110 \mathrm{~K}$ was cloned into pGBKT7 as a bait fusion, while all the U4/U6- and U5-specific proteins were cloned into pGADT7 as prey fusions. The positive interaction was observed by growing on the selective medium of SD/-Leu-Trp-His-Ade at $30^{\circ} \mathrm{C}$ for 3-6 days. (B) Analysis of interactions between $110 \mathrm{~K}$ protein and in vitro-prepared fusion proteins of $90 \mathrm{~K}$ and $102 \mathrm{~K}$ (left panel), and the full length $200 \mathrm{~K}$ protein as well as fragments $200-4$, 200-5 (right panel). Purified His-tagged $110 \mathrm{~K}$ was incubated with anti-pep-110 antibodies bound to protein A-Sepharose and $\left[{ }^{35} \mathrm{~S}\right]$-labelled proteins produced by in vitro translation. The precipitated proteins were fractionated by SDS-PAGE and visualized by autoradiography. Mock precipitations without His-tagged 110K protein were included as a negative control. (C) $\mathrm{Y} 2 \mathrm{H}$ analysis to search for the $110 \mathrm{~K}$ binding domain in $90 \mathrm{~K}$. pGADT7-110K was tested against six $90 \mathrm{~K}$ fragments constructed in pGBKT7; the empty vector and the full-length $90 \mathrm{~K}$ served as controls. The positive interaction was observed by growing on the selective medium of SD/-Leu-Trp-His at $30^{\circ} \mathrm{C}$ for 3 days. (D) Analysis of protein $110 \mathrm{~K}$ domain structure in the Y2H system. Protein 110K mutants were constructed in pGBKT7 and were tested for interaction with other proteins. The positive interaction was observed by growing on the selective medium of $\mathrm{SD} /$-Leu-Trp-His-Ade at $30^{\circ} \mathrm{C}$ for 3 days.

\subsection{The interaction domains of $\mathrm{U} 5-102 \mathrm{~K}$ protein}

The $102 \mathrm{~K}$ protein comprises an $\mathrm{N}$-terminal domain followed by 19 repeats of TPR (tetratricopeptide) motif, as shown in Figure 4.13A (Makarov et al., 2000). Comparison with other TPR proteins revealed that the motifs in the protein $102 \mathrm{~K}$ belong to a TPR protein subfamily which appears restricted to RNA processing proteins such as Prp39p, Prp42p, Rna14p, and Clf1p (Chung et al., 1999; McLean and Rymond, 1998). The TPR repeats in this subfamily were also called HAT (half a TPR) repeats (Preker and Keller, 1998) or cl-TPR (crooked neck-like TPR) repeats (Chung et al., 1999). The N-terminal domain (NTD) is rich in charged amino acids and conserved in the homologues of $102 \mathrm{~K}$ 
protein. However, this region contains no known sequence motifs. To obtain a more detailed view of which particular regions interact with the various proteins, protein $102 \mathrm{~K}$ was dissected into three fragments (see figure 4.13A). NTD (amino acids 1 to 293) lacks the entire C-terminal TPR domain, while TPR_M (amino acids 294 to 592) and TPR_C (amino acids 593 to 941) contain first 9 TPR repeats and second 10 TPR repeats respectively. All protein-protein interactions of $102 \mathrm{~K}$, as identified by both $\mathrm{Y} 2 \mathrm{H}$ and by in vitro GST pull-down experiments (see figures $4.9,4.10,4.12$ ), were further examined with the $102 \mathrm{~K}$ fragments used either as bait (figure 4.13B) or as prey (figure 4.13C). Figure 4.13D schematically summarises the interactions observed from figure 4.13B and $\mathrm{C}$. The $\mathrm{N}$-terminal domain was found to bind to $15 \mathrm{~K}$ protein, while the central TPR_M fragment bound to $110 \mathrm{~K}$, the $200-4$ fragment of $200 \mathrm{~K}$ and the 220-1 fragment of $220 \mathrm{~K}$. The $61 \mathrm{~K}$ protein interacts with both TPR_M and TPR_C fragments. In summary, it appears that distinct regions of $102 \mathrm{~K}$ are dedicated to interactions with different proteins.

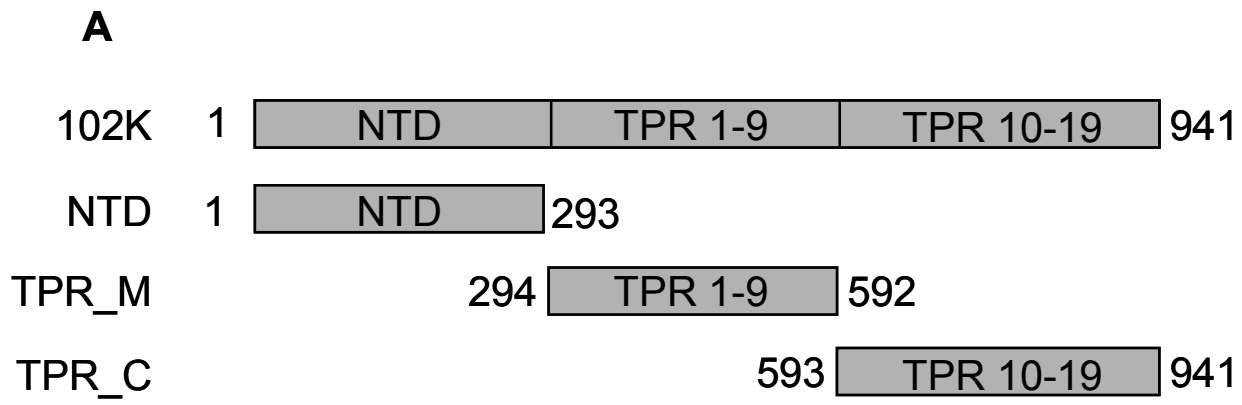

B

\begin{tabular}{|c|c|c|c|c|c|c|}
\hline \multirow{2}{*}{$\begin{array}{c}\text { Gal4-BD } \\
\text { hybrid }\end{array}$} & \multicolumn{6}{|c|}{ Gal4-AD hybrid } \\
\hline & pGADT7 & $15 \mathrm{~K}$ & $61 \mathrm{~K}$ & $110 \mathrm{~K}$ & $200-4$ & $220-1$ \\
\hline \multicolumn{7}{|l|}{ pGBKT7 } \\
\hline NTD & & ND & ND & ND & ND & ND \\
\hline \multicolumn{7}{|l|}{ TPR_M } \\
\hline TPR_C & & & & & & \\
\hline
\end{tabular}


C

\begin{tabular}{|c|c|c|c|c|c|c|}
\hline \multirow{2}{*}{$\begin{array}{c}\text { Gal4-AD } \\
\text { hybrid }\end{array}$} & \multicolumn{6}{|c|}{ Gal4-BD hybrid } \\
\hline & pGBKT7 & $15 \mathrm{~K}$ & $61 \mathrm{~K}$ & $110 \mathrm{~K}$ & $200-4$ & $220-1$ \\
\hline \multicolumn{7}{|l|}{ pGADT7 } \\
\hline \multicolumn{7}{|l|}{ NTD } \\
\hline \multicolumn{7}{|l|}{ TPR_M } \\
\hline TPR_C & & & & & & \\
\hline
\end{tabular}

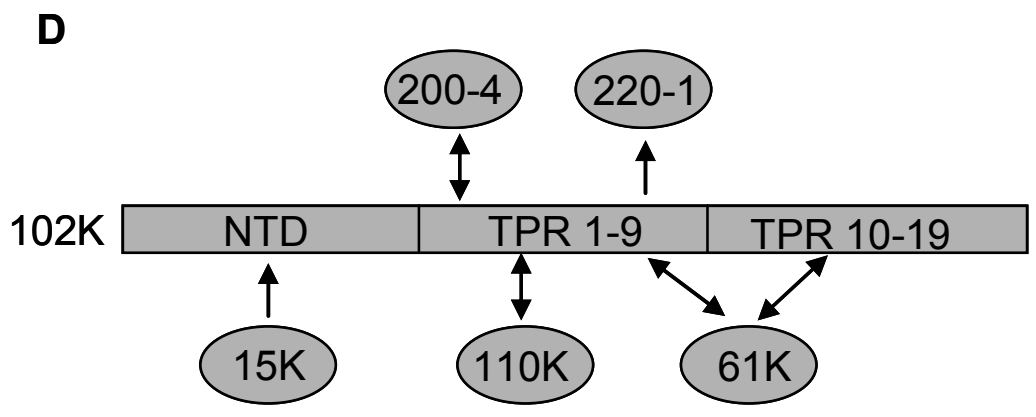

Figure 4.13. $\mathrm{Y} 2 \mathrm{H}$ analysis of $102 \mathrm{~K}$ domains involved in the protein-protein interactions. (A) Schematic representation of the protein fragments derived from full-length $102 \mathrm{~K}$ used in two-hybrid assays. (B) Yeast strain AH109 was transformed with pGBKT7 carrying $102 \mathrm{~K}$ fragments and pGADT7 carrying protein $15 \mathrm{~K}, 61 \mathrm{~K}, 110 \mathrm{~K}$ and fragments 200-4 from 200K and 220-1 from 220K. Empty vectors were included as a negative control. Combinations labelled ND were not determined because of self-activation of the bait. Grey squares represent interactions selected on SD/Leu-Trp-His-Ade, hatched squares those selected on SD/Leu-Trp-His. White squares represent no interactions. (C) Interactions of inversed bait-prey pairs. (D) Schematic drawing of the observed bait $\rightarrow$ prey interactions involving $102 \mathrm{~K}$ fragments.

\subsection{Specific binding of the U5-52K protein to the U5 snRNP $102 \mathrm{~K}$ and $15 \mathrm{~K}$ proteins}

The $52 \mathrm{~K}$ protein is readily visible in immunoaffinity-purified 20-25S snRNPs (Behrens and Lührmann, 1991). The gene encoded for this protein was subsequently cloned in the laboratory of Prof. Lührmann. Database searches revealed that the sequence of the $52 \mathrm{~K}$ protein is identical to that of a previously described protein, CD2BP2, which interacts with CD2, a surface marker of T cells, which facilitates activation of $T$ lymphocytes on binding to its ligand CD58 (Laggerbauer et al., 2005; Nishizawa et al., 1998). The protein 52K contains in the C-terminal region a GYF motif which has been shown to has the 
ability to bind a proline-rich tandem repeat in the cytoplasmic tail of CD2 (Freund et al., 2002; Freund et al., 1999), and all of the residues that play a direct part in this binding (Tyr285, Trp287, Pro298, Phe299, Met304, Trp307, Tyr312 and Phe313) are well conserved among the homologue proteins. In S. cerevisiae the Snu40p/Lin1p can be clearly identified as the homologue of $52 \mathrm{~K}$, because it shares the other characteristic sequence motifs and also associates with the yeast U5 snRNP (Stevens et al., 2001).

To investigate whether the $52 \mathrm{~K}$ protein is associated with both $20 \mathrm{~S}$ U5 snRNP and 25S tri-snRNP, HeLa nuclear extract was loaded onto a glycerol gradient and the distribution of the $52 \mathrm{~K}$ protein was analysed by SDS-PAGE followed by western blotting. For determination of the sedimentation coefficients, RNA was isolated from aliquots of each fraction, separated by PAGE and visualised by silver staining. The results showed that almost all of the $52 \mathrm{~K}$ protein is present in a $20 \mathrm{~S}$ complex, presumably the U5 snRNP, and the $52 \mathrm{~K}$ protein appears to be excluded from the tri-snRNP. To test the latter conclusion, the $25 \mathrm{~S}$ tri-snRNP were purified from a mixture of spliceosomal snRNPs by immunoaffinity chromatography and fractionated by glycerol gradient centrifugation; the protein and RNA content of each fraction was analysed by PAGE. The $52 \mathrm{~K}$ protein was also absent in this snRNP particle. These results demonstrate clearly that the $52 \mathrm{~K}$ protein is not a component of the $25 \mathrm{~S}$ U4/U6.U5 tri-snRNP, and indicates that it dissociates from the U5 snRNP during the formation of the tri-snRNP particle (Laggerbauer et al., 2005).

Since the $52 \mathrm{~K}$ protein is associated with the U5 snRNP in such a specific manner, it is of particular interest to examine how the protein is integrated into this particle. In this study, yeast two-hybrid analysis was first used to study the interactions of the $52 \mathrm{~K}$ protein with other proteins. As bait, I tested all the U5 snRNP-specific proteins (proteins 15K, 40K, 100K, 102K, 116K, 200K and $220 \mathrm{~K})$, the tri-snRNP-specific proteins (27K, $65 \mathrm{~K}$ and $110 \mathrm{~K})$, and the U4/U6-snRNP-specific proteins (15.5K, 20K, 60K, 61K and 90K). Of all these proteins, only the U5 snRNP proteins $15 \mathrm{~K}$ and $102 \mathrm{~K}$ were found to bind to the $52 \mathrm{~K}$ protein (figure 4.14A, left column, and data not shown). In contrast, neither of the tri-snRNP or U4/U6 snRNP proteins interacted with the 52K protein (data 
not shown). The $52 \mathrm{~K}$ protein contains a known protein-protein interaction motif, namely the GYF domain in the protein's C-terminal 86 residues (Freund et al., 1999; Freund et al., 2002). Therefore, I next asked whether this C-terminal fragment is necessary, or possibly even sufficient, for the interaction with protein $15 \mathrm{~K}$ or $102 \mathrm{~K}$. For this purpose, the full-length $52 \mathrm{~K}$ was split into two fragments: 52N (amino acids 1-255) lacks the GYF motif, while 52C (amino acids 256-341) contains only this domain. As shown in figure 4.14A (right column), protein $15 \mathrm{~K}$ binds to $52 \mathrm{C}$, but not with $52 \mathrm{~N}$. In contrast, protein $102 \mathrm{~K}$ binds to $52 \mathrm{~N}$, but not $52 \mathrm{C}$. The negative controls with empty prey (pGADT7) or bait (pGBKT7) vector showed no cell growth on the selective medium, confirming that none of the constructs used here induced the reporter gene on its own.

To confirm the interactions observed in the two-hybrid system, I performed pulldown assays (see sections 3.2.3.2 and 3.2.3.4 for methods). As shown in figure 4.14B, the GST-102K fusion protein, but not GST alone, efficiently precipitated the radio-labelled $52 \mathrm{~K}$ protein from reaction mixtures in which it had been generated by translation in vitro. This assay also confirms that protein $102 \mathrm{~K}$ interacts with the $\mathrm{N}$-terminal two-thirds of the $52 \mathrm{~K}$ protein, and not with the GYF domain (figure 4.14B, lower panels). Similarly, I used the His-tagged 52K protein to precipitate protein $15 \mathrm{~K}$ prepared by translation in vitro. As expected, a significant amount of protein $15 \mathrm{~K}$ was precipitated in the presence of the Histagged $52 \mathrm{~K}$ protein, but not on the beads alone (figure $4.14 \mathrm{C}$, lanes 2 and 3 ). As predicted form the two-hybrid results, the C-terminal GYF domain also precipitates protein $15 \mathrm{~K}$, and the efficiency of this precipitation is even higher than for the full-length protein (lane 4).

In conclusion, the data from both the yeast two-hybrid system and the binding assays in vitro demonstrate clearly that the $52 \mathrm{~K}$ protein associates with the U5 snRNP particle by binding to proteins $102 \mathrm{~K}$ and $15 \mathrm{~K}$. Interestingly, two different domains of the $52 \mathrm{~K}$ protein are involved in these interactions, suggesting that they can occur simultaneously. 

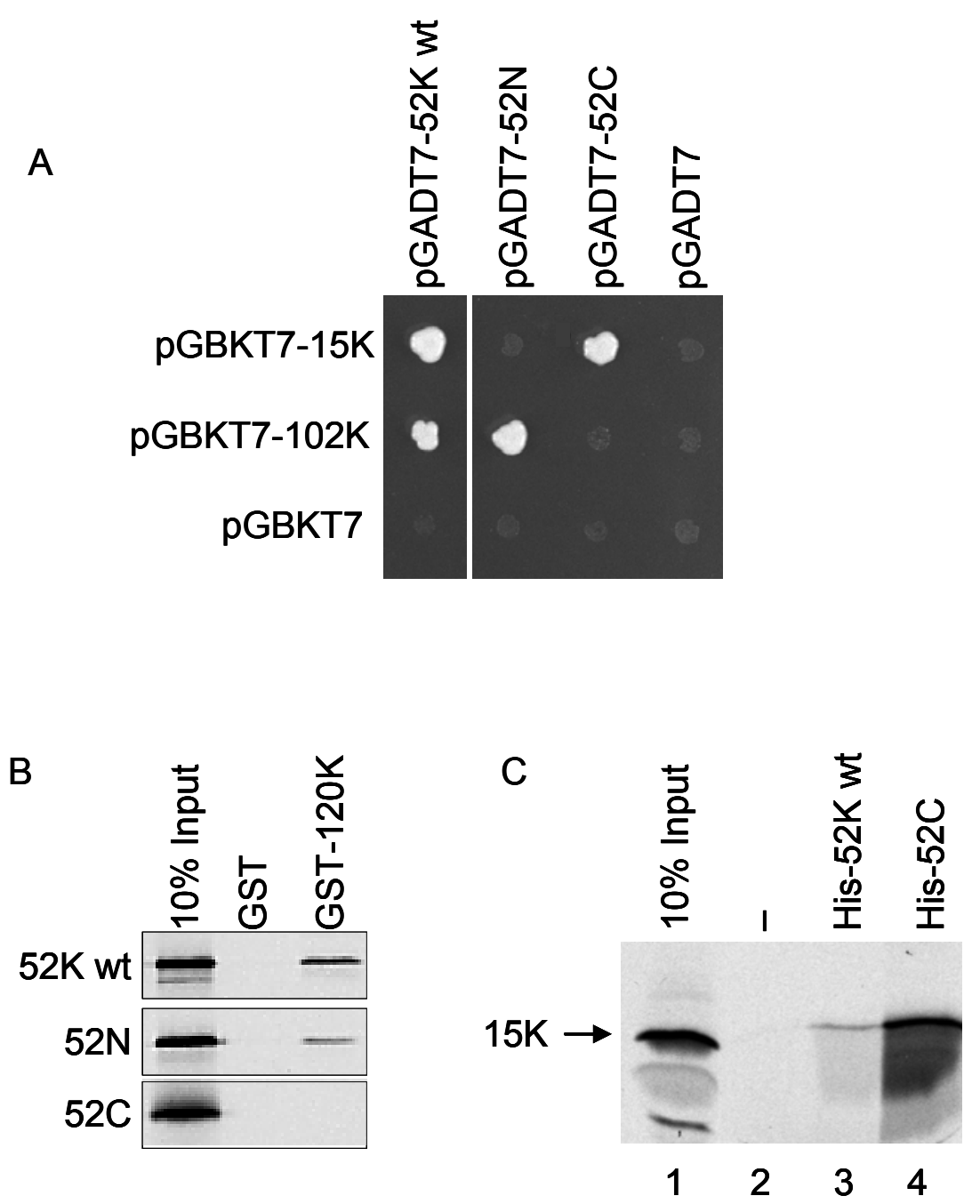

Figure 4.14. Association of protein $52 \mathrm{~K}$ with U5 snRNP through the U5-specific proteins $15 \mathrm{~K}$ and $102 \mathrm{~K}$. (A) Two-hybrid analysis. Plasmid pairs were co-transformed into yeast host AH109 as indicated in the figure, and the interactions of the full-length (left panel) or truncated $52 \mathrm{~K}$ protein (right panel) with $15 \mathrm{~K}$ and $102 \mathrm{~K}$ proteins were detected by growth on selective medium SD/-Leu-Trp-His-Ade at $30{ }^{\circ} \mathrm{C}$ for three days. The empty vector pGADT7 or pGBKT7 served as a negative control. (B) GST pulldown assay. In vitro $\left[{ }^{35} \mathrm{~S}\right]$-labelled, c-Myc-tagged $52 \mathrm{~K}$ constructs were incubated with $102 \mathrm{~K}$ protein fused to a GST tag and precipitated by glutathione-Sepharose. $10 \%$ of the translation products were loaded as input. (C) His pull-down assay. In vitro $\left[{ }^{35} \mathrm{~S}\right]$-labelled HA-tagged $15 \mathrm{~K}$ protein was incubated with His-tagged fusion protein $52 \mathrm{~K}$ wild type or C-terminal fragment and precipitated with Talon beads. $10 \%$ of the translation products were loaded as input.

\subsubsection{Overexpression of U5-52K proteins and X-ray crystallography study of 52K GYF domain in complex with U5-15K}

As described in the Materials and Methods, protein $52 \mathrm{~K}$ wild-type and two deletion mutations (52N and 52C) were subcloned in pET28a expressing vector. The plasmids were transformed into BL21(DE3) and the cell culture was 
induced in $1 \mathrm{mM}$ IPTG at $37^{\circ} \mathrm{C}$ for 3 hours. The expressed proteins were bound to Ni-NTA beads. After washing, the proteins were eluted in the elution buffer (20 mM Tris- $\mathrm{HCl} \mathrm{pH}$ 8.0, $100 \mathrm{mM} \mathrm{NaCl}, 100 \mathrm{mM}$ Imidazole). Figure 4.15 shows the first and second elution fractions of the proteins. Protein 52K wt (lane 1,4) and $52 \mathrm{C}$ fragment (lane 3,6 ) express high amount of proteins and are soluble, whereas the $52 \mathrm{~N}$ does not (lane 2,5$)$.

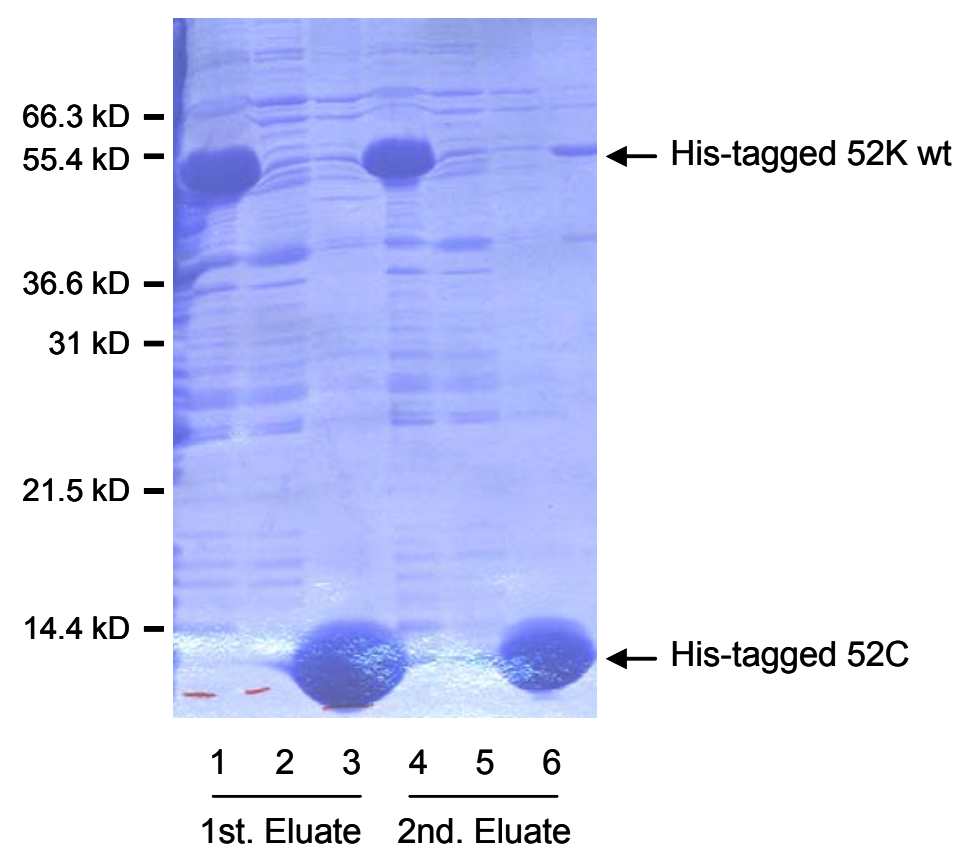

Figure 4.15. Protein 52K wt and deletion mutants were expressed in E. coli. The soluble fraction of each protein was run on a $15 \%$ SDS-PAGE gel and stained with Coomassie blue.

A crystallography study of the 52K GYF domain in the complex with U5-15K in the laboratory of Prof. R. Ficner (Nielsen et al., in preparation) shows that the distinct residues of GYF domain are used for the binding of $15 \mathrm{~K}$ comparing to the binding of CD2 protein. In the functional complex the GYF-domain and the U5-15K protein are bound mainly by polar interactions, including a salt bridge between Glu111, OE1 (U5-15K) and GIn328, NE2 (U5-52K), hydrogen bonds between side chains of Asp114, OD2, Glu117, OE2 and Ser132, OG (U5-15K) and side chains of Tyr330, OH, Lys321, NZ and Arg334, NH2 (U5-52K) and between main chains Ser132, O (U5-15K) and side chains Arg334, NE (U5$52 \mathrm{~K})$. Finally there is a hydrogen bond between the side chain of Lys125, NZ (U5-15K) and the C-terminal oxygen of Thr341 (U5-52K). CD1 and CD2 from 
residue Leu339 (U5-52K) make hydrophobic contacts with Val130, CG2 and Gly122, CA (U5-15K).
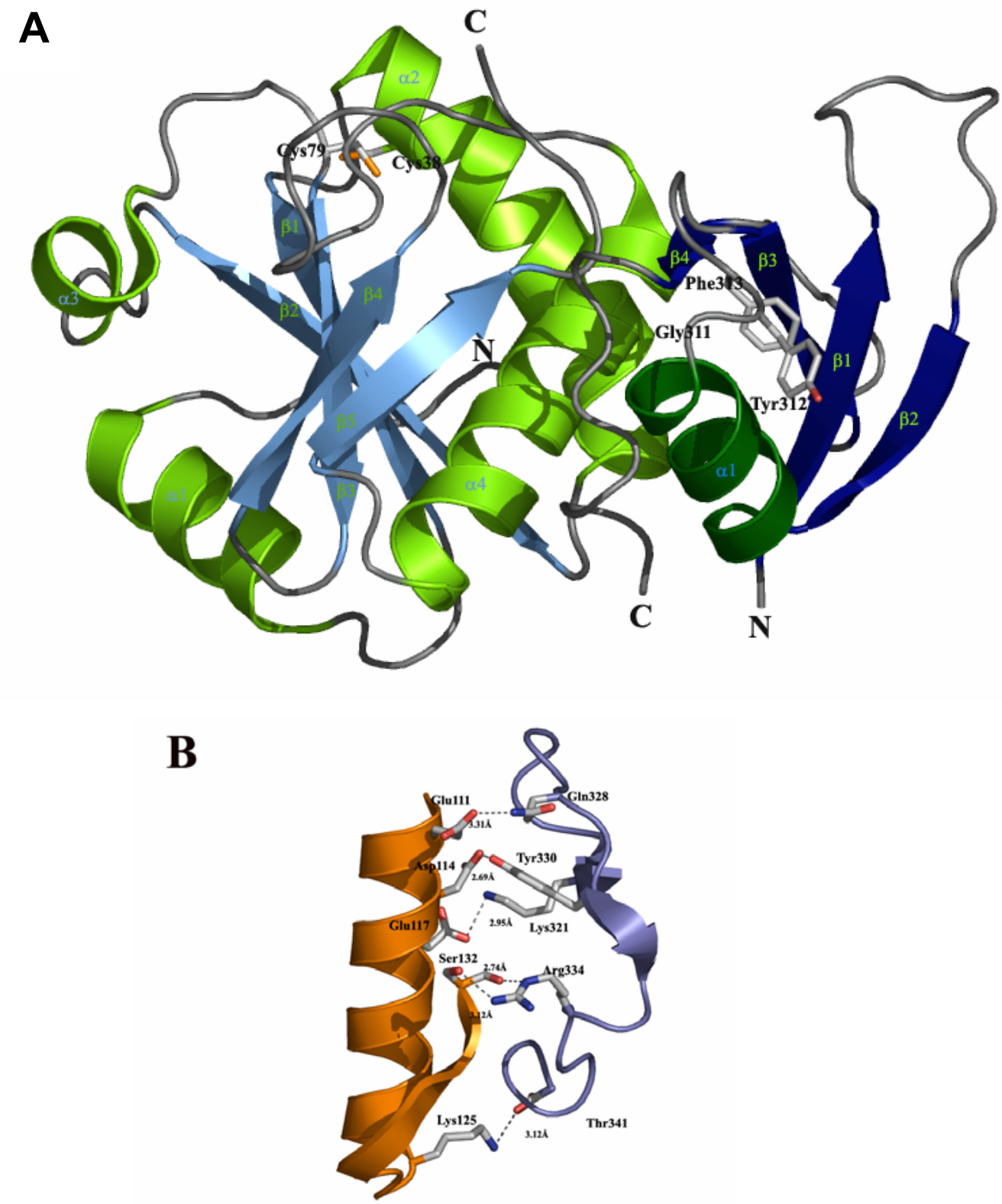

Figure 4.16. (A) Cartoon representation of the U5-15K:U5-52K complex. U5-15K is shown on the left in the lighter colours. Cysteine 38 and cysteine 79 are shown in balland-stick representation. The GYF domain of U5-52K is shown on the right in darker blue and green. Gly311, Tyr312 are Phe312 displayed in ball-and-stick representation. (B) A stereo picture of the polar interactions and the distances between the interacting atoms. U5-15K is shown in orange and U5-52K in blue. The contacts between the two molecules were determined with the program CONTACT from the CCP4 program package. The interactions are found in all three molecules. The distances are from molecules $\mathrm{A}+\mathrm{B}$, but the distances in $\mathrm{C}+\mathrm{D}$ and $\mathrm{E}+\mathrm{F}$ are almost the same. This figure is provided by Tine Kragh Nielsen in the laboratory of Prof. R. Ficner (unpublished data). 


\subsection{The interaction of the U4/U6-90K with U6-p110}

The recycling factor $\mathrm{p} 110$ is associated with mammalian U6 and U4/U6 snRNPs, but not with U4/U6.U5 tri-snRNP. Recombinant $\mathrm{p} 110$ binds in vitro specifically to human U6 snRNA (Bell et al., 2002). To investigate the potential role of U4/U6-specific proteins in this respect, yeast two-hybrid assay was performed to detect the association between $\mathrm{p} 110$ and U4/U6 snRNP-specific $15.5 \mathrm{~K}, 61 \mathrm{~K}$, $20 \mathrm{~K}, 60 \mathrm{~K}$, and $90 \mathrm{~K}$ proteins. Of these proteins, only the $90 \mathrm{~K}$ protein showed an interaction with the full-length $\mathrm{p} 110$ protein (figure 4.17 , left panel). The specific association of $\mathrm{p} 110$ and the U4/U6-90K protein was confirmed by a coimmunoprecipitation assay (see section 3.2.3.5 for methods). After incubation with recombinant His-tagged p110 protein, an in vitro-translated 90K protein could be efficiently co-immunoprecipitated with anti-p110 antibodies (figure 4.17, right panel). The recombinant $\mathrm{N}$-terminal His-tagged p110 (amino acids 2 to 963) which has been expressed and purified from baculovirus-transfected SF21 cells was obtained from laboratory of Prof. A. Bindereif (Bell et al., 2002).

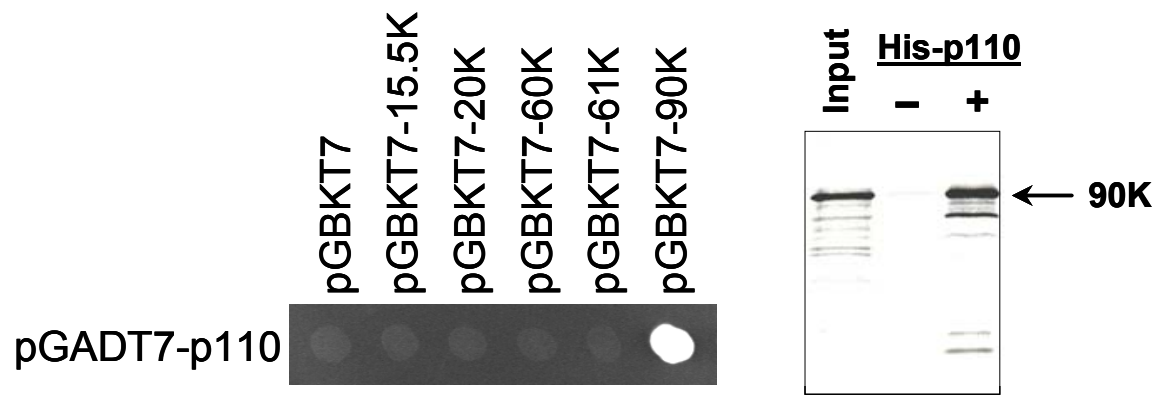

Figure 4.17. $\mathrm{Y} 2 \mathrm{H}$ assay of interactions between $\mathrm{p} 110$ and U4/U6-specific proteins (left panel). p110 was constructed as a prey fusion, while U4/U6-specific proteins as bait fusions. Protein-protein interactions were assayed by selection on $\mathrm{SD} /$-Leu-Trp-His-Ade medium at $30^{\circ} \mathrm{C}$ for 3 days. Analysis of the $\mathrm{p} 110-90 \mathrm{~K}$ protein interaction by in vitro binding assay (right panel). $\left[{ }^{35} \mathrm{~S}\right]$-labelled c-Myc-tagged $90 \mathrm{~K}$ was incubated with Hisp110 protein, followed by precipitating with anti-p110 antibodies. Co-precipitated proteins were fractionated by SDS-PAGE and visualized by autoradiography. The input lane presents $10 \%$ of the $90 \mathrm{~K}$ protein used in the reaction. The mobilities of the $90 \mathrm{~K}$ protein is marked on the right.

The domain structure of the human U6-p110 protein consists of a large Nterminal region with at least seven tetratricopeptide repeat (TPR) motifs, two RNA recognition motifs (RRMs) in the C-terminal half of U6-p110, and a stretch of 10 highly conserved amino acids at the $C$ terminus (Bell et al., 2002; Rader and Guthrie, 2002). A splice variant of the human protein has been reported as 
a full-length cDNA (AF 387506) (Liu et al., 2002) which arises through the usage of a different 5 ' splice site in exon 7; this usage is expected to result in a truncated protein carrying only three of the seven TPR motifs. The $\mathrm{p} 110$ domain organization is conserved in many other eukaryotes, including Caenorhabditis elegans, Arabidopsis thaliana, Schizosaccharomyces pombe, and Drosophila melanogaster (Bell et al., 2002; Rader and Guthrie, 2002); of the orthologues, only the well-known yeast Prp24 protein deviates from this domain organization, in that it lacks the entire N-terminal half with the TPR domain. Therefore, I was particularly interested in the possible role of the conserved TPR domain in U4/U6 snRNP formation and recycling.

To delineate the domain structure of $p 110$, a series of $p 110$ mutant derivatives were constructed for yeast two-hybrid assay (figure 4.18A, upper panel). p110 $\Delta \mathrm{N}$ (amino acids 537 to 963 ) lacks the entire $\mathrm{N}$-terminal TPR domain but contains the putative nuclear localization signal region, the two RRMs, and the C-terminal 10 amino acids. p110 $\Delta C$ (amino acids 2 to 688) carries the entire TPR domain, including the putative nuclear localization signal region, but not the two RRMs and the C-terminal 10 amino acids. A natural splice variant, AF 387506 (see above), is truncated within the fourth TPR motif and contains amino acids 2 to 350 , followed by 14 additional amino acids, RSTTESKGFGFICT. The p110-90K protein interaction depended on the $90 \mathrm{~K}$ protein component and was specific, since p110 $\Delta \mathrm{N}$ gave a negative result; in contrast, both $\mathrm{p} 110 \Delta \mathrm{C}$ and the natural splice variant $\mathrm{AF} 387506$ gave a positive result for the $90 \mathrm{~K}$ protein interaction (figure 4.18A, lower panel).

Mutational analysis of the $90 \mathrm{~K}$ protein showed in two-hybrid assays that the $\mathrm{N}$ terminal half of the 90K protein (N442, N309 and N194) did not interact with p110. In contrast, C-terminal fragments of the 90K protein (C267, C381 and C489) were positive for the $\mathrm{p} 110$ interaction. When the $\mathrm{p} 110$ mutant derivative $\Delta C$ was used instead of full-length $p 110$, identical results were obtained, consistent with the TPR domain mediating the interaction between $\mathrm{p} 110$ and the $90 \mathrm{~K}$ protein (figure $4.18 \mathrm{~B}$ ). In summary, the results showed that U6-p110 interacts through its TPR domain with a C-terminal region (amino acids 417 to 683 ) of the U4/U6-90K protein. 
A
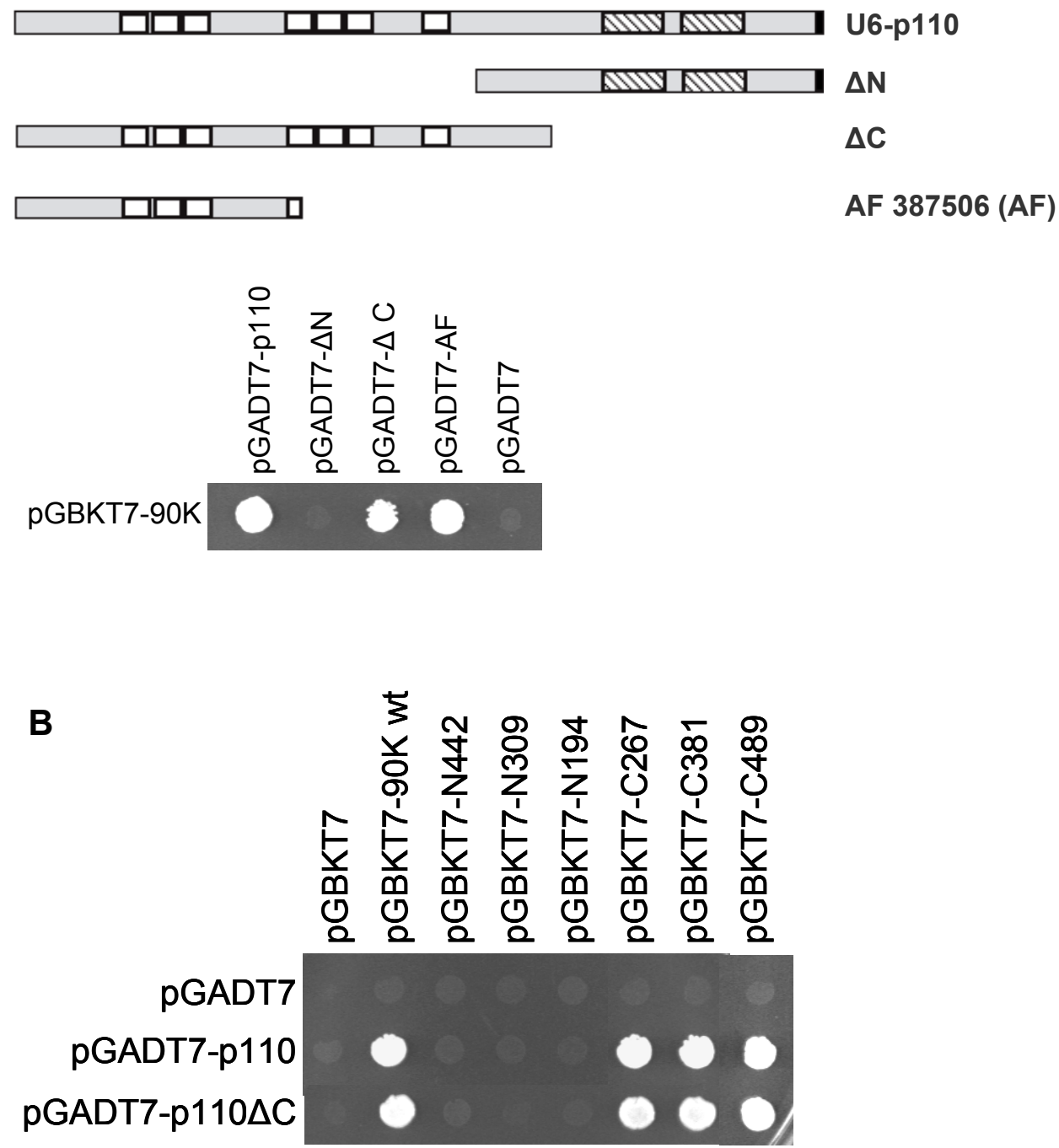

Figure 4.18. U6-p110 interacts through its TPR domain with a C-terminal region (amino acids 417 to 683 ) of the U4/U6 snRNP-specific 90K protein. (A) Upper panel: The p110 domain structure is schematically represented (RRMs, striped boxes; HAT or TPR domain, white boxes; conserved C-terminal region, black boxes). Lower panel: Y2H assay of interactions between p110 mutant derivatives and the U4/U6-specific 90K protein. Yeast strain AH109 was transformed with plasmid pGADT7-p110, pGADT7$\Delta \mathrm{N}$, pGADT7- $\triangle \mathrm{C}$, pGADT7-AF 387506 (AF) or pGADT7 (as a control) in combination with plasmid pGBKT7-90K. Selection was done for 3 days at $30^{\circ} \mathrm{C}$ on $\mathrm{SD}$-Leu-Trp-His-Ade medium. (B) Y2H assay of interactions between p110 and U4/U6-specific $90 \mathrm{~K}$ protein mutant derivatives. In the yeast strain AH109, p110 and its $\Delta \mathrm{C}$ mutant were expressed as prey fusions, while $90 \mathrm{~K}$ and its mutant derivatives were expressed as bait fusions. Interactions were observed on SD/-Leu-Trp-His-Ade medium at $30^{\circ} \mathrm{C}$ for 3 days. 


\subsection{The $\mathrm{N}$-terminal region of the $\mathrm{U} 4 / \mathrm{U} 6-90 \mathrm{~K}$ is required for binding of U2-associated protein SPF30/SMNrp}

Recent studies suggested that SPF30/SMNrp is an essential protein-splicing factor whose function is required for the recruitment of the tri-snRNP to the $A$ complex during spliceosome assembly (Meister et al., 2001; Rappsilber et al., 2001). The data from an in vitro binding assay indicated that SPF30/SMNrp interacts with the U4/U6.U5 tri-snRNP by a direct interaction with U4/U6-specific protein 90K (Meister et al., 2001). Here the in vivo $\mathrm{Y} 2 \mathrm{H}$ system was used to investigate this interaction and the domain of $90 \mathrm{~K}$ involved. For this purpose, the cDNA of SPF30/SMNrp was first cloned from a human Marathon-Ready cDNA library (Clontech) as described in Materials and Methods. The cloned fulllength cDNA sequence which composes of 717 nucleotides is identical to the published data base from Neubauer et al. (1998, accession no. gi|3746841). NCBI protein-protein blast could find the potential orthologues in the organisms such as Pongo pygmaeus, Pan troglodytes, Xenopus tropicalis, Drosophila melanogaster, Arabidopsis thaliana, Oryza sativa japonica, Gallus gallus, Macaca fascicularis and Schizosaccharomyces pombe. However, no homologue could be detected in Saccharomyces cerevisiae. SPF30, also termed SMNrp, is the first and so far only reported homologue of SMN1, the gene responsible for spinal muscular atrophy. Both proteins share a central Tudor domain. Note that the Tudor domain is not conserved in the homologous protein of Schizosaccharomyces pombe. For the $\mathrm{Y} 2 \mathrm{H}$ assay, SPF30/SMNrp was subcloned into yeast two-hybrid vectors as described in the Materials and Methods, and was subsequently tested for interacting with U4/U6-90K and its six truncated fragments which have been described above. SPF30/SMNrp indeed interacts with $90 \mathrm{~K}$ protein as a prey or bait fusion, and mutational analysis showed that the N-terminus of 1-442 amino acids (N442) is responsible for the binding (figure 4.19). The interactions are specific since the other five truncated proteins did not display any signals. Interestingly, the $\mathrm{Y} 2 \mathrm{H}$ signal of $\mathrm{N}$ terminus is much stronger than the one of the full-length protein. In conclusion, the in vivo two-hybrid analysis successfully defines the SPF30/SMNrp binding domain in $90 \mathrm{~K}$, and further confirms the interaction demonstrated previously by the in vitro binding study (Meister et al., 2001). 


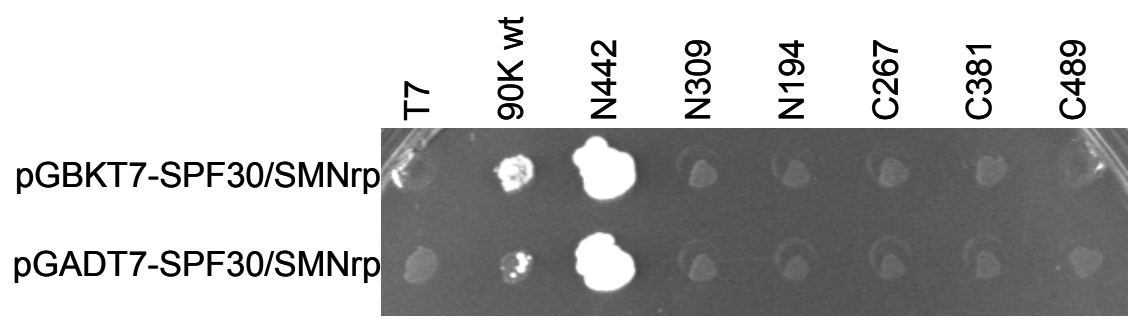

Figure 4.19. Y2H analysis of the interaction of U4/U6-90K with U2-SPF30/SMNrp. $90 \mathrm{~K}$ wild-type (wt) and the truncated fragments as shown above the panel were incorporated into pGADT7 or pGBKT7 and co-transformed in combination with pGBKT7-SPF30/SMNrp or pGADT7-SPF30/SMNrp in turn. The positive colonies were selected on the $\mathrm{SD}$-Leu-Trp-His-Ade medium at $30^{\circ} \mathrm{C}$ for 7 days.

\subsection{Analysis of point mutations related to the retinitis pigmentosa}

Recent investigations first demonstrated that a number of mutations in the trisnRNP proteins are related to the autosomal dominant retinitis pigmentosa (Vithana et al., 2001; McKie et al., 2001; Chakarova et al., 2002). The identified genes and the related missense mutations were listed in the table 4.1. However, molecular mechanism for retinitis pigmentosa caused by mutations in these three tri-snRNP proteins is unclear at present. From the current interacting data, it is reasonable to ask whether the mutations have an effect on protein-protein interactions.

Table 4.1. Missense mutations related to retinitis pigmentosa

\begin{tabular}{|c|l|l|l|l|}
\hline Protein & Gene & $\begin{array}{c}\text { Missense } \\
\text { mutation }\end{array}$ & $\begin{array}{l}\text { Locus } \\
\text { name }\end{array}$ & Publication \\
\hline $\begin{array}{c}\text { U4/U6-61K } \\
\text { (hPrp31p) }\end{array}$ & PRPF31 & A194E, A216P & RP11 & $\begin{array}{c}\text { Vithana et al., } \\
2001\end{array}$ \\
\hline $\begin{array}{c}\text { U4/U6-90K } \\
\text { (hPrp9p) }\end{array}$ & $\begin{array}{c}\text { PRPF3 } \\
\text { (HPRP3) }\end{array}$ & P493S, T494M & RP18 & $\begin{array}{c}\text { Chakarova et al., } \\
2002\end{array}$ \\
\hline $\begin{array}{l}\text { U5-220K } \\
\text { (hPrp8p) }\end{array}$ & $\begin{array}{c}\text { PRPF8 } \\
\text { (PRPC8) }\end{array}$ & $\begin{array}{c}\text { P2301T, F2304L, } \\
\text { H2309P, H2309R, } \\
\text { R2310G, R2310K, } \\
\text { F2314L }\end{array}$ & RP13 & $\begin{array}{c}\text { McKie et al., } \\
2001\end{array}$ \\
\hline
\end{tabular}




\subsubsection{Analysis of U4/U6-61K mutations identified in retinitis pigmentosa}

As described in section 4.4 .1 , protein $61 \mathrm{~K}$ interacts specifically with protein $102 \mathrm{~K}$, and this interaction is critical for the formation of tri-snRNP (Makarova et al., 2002; Schaffert et al., 2004). Y2H analysis was used to investigate whether the mutations have an effect on such an interaction. Hence, the two mutant plasmids, pGBKT7-61K-A194E and pGBKT7-61K-A216P, were constructed as described in Materials and Methods. Subsequently they were co-transformed individually with pGADT7-102K in the yeast strain $\mathrm{AH} 109$ and were examined for the interaction. The results are shown in figure 4.20. While the clone bearing A216P shows a similar result to the wild type (compare spots 2 and 4 in middle and lower panels), the clone bearing A194E is hardly seen on the selective medium lacking histidine and adenine after 2 days (spot 3 in the middle panel) and has only grown slightly after 3 days at $30^{\circ} \mathrm{C}$ (spot 3 , compare with spots 1 and 2 and 4 in the lower panel). As indicated on the growing medium of SD/Leu-Trp, the upper panel shows that the cells are equally applied on the plates. In conclusion, the two-hybrid result suggested that one of the $61 \mathrm{~K}$ mutants, namely A194E, significantly reduces the binding to $102 \mathrm{~K}$ protein.

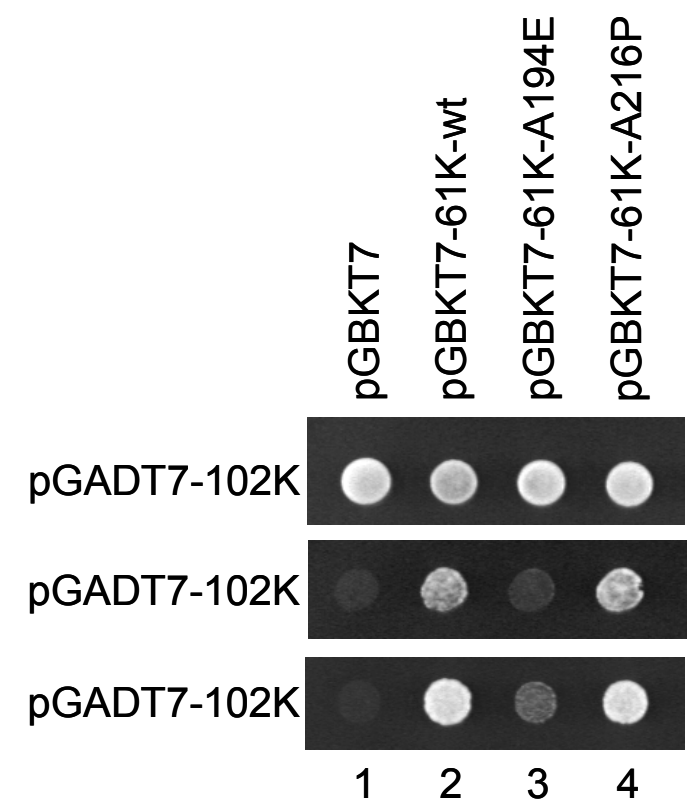

Figure 4.20. Mutational analysis of $61 \mathrm{~K}$ interactions. Protein $102 \mathrm{~K}$ was cloned into pGADT7 and cotransformed with pGBKT7 (as a control) and protein $61 \mathrm{~K}$ wt and mutants which were cloned into pGBKT7, respectively. The cotransformants were replica plated on the growing medium SD/-Leu-Trp (upper panel), the selective medium $\mathrm{SD}$-Leu-Trp-His-Ade at $30^{\circ} \mathrm{C}$ for 2 days (middle panel) and for 3 days (lower panel). 


\subsubsection{Analysis of $90 \mathrm{~K}$ mutations identified in retinitis pigmentosa}

As described above, U4/U6-specific protein 90K interacts with U4/U6-60K (section 4.2.1), U5-102K (section 4.4.2), tri-snRNP-specific 110K (section 4.5), recycling factor U6-p110 (section 4.8) and U2-associated protein SPF30/SMNrp (section 4.9). Figure 4.21 summarises these interactions and the $90 \mathrm{~K}$ domains involved. Obviously, the C-terminal domains containing the residues related to the two mutations are required for the binding of protein $102 \mathrm{~K}, \mathrm{p} 110$ and probably $110 \mathrm{~K}$, but are dispensable for the binding of SPF30/SMNrp. It is unlikely that the mutations are involved in the binding of $60 \mathrm{~K}$ since the $\mathrm{N}$ terminal region (N442) alone is sufficient for the binding.

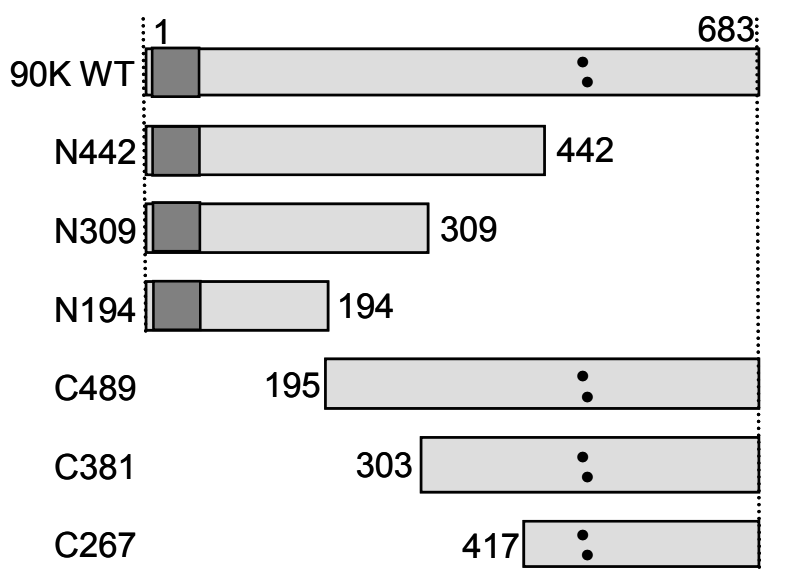

\section{protein-protein interactions} $60 \mathrm{~K} 102 \mathrm{~K} 110 \mathrm{~K}$ p110 SPF30

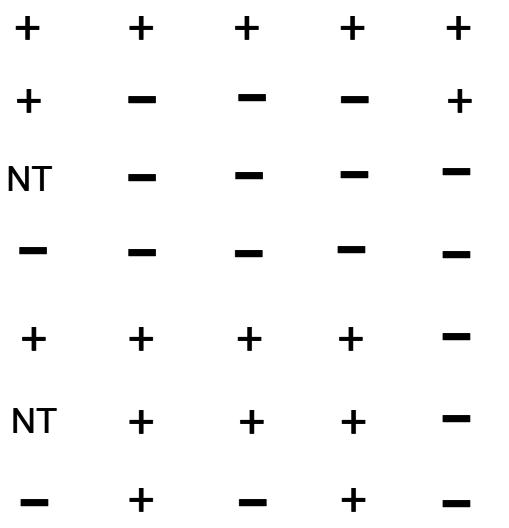

Figure 4.21. U4/U6-90K wild-type protein (683 amino acids [aa]) and mutant derivatives N442 (1-442 aa), N309 (1-309 aa), N194 (1-194 aa), C489 (195-683 aa), C381 (303-683 aa) and C267 (417-683 aa) are schematically represented. The dark grey boxes indicate the N-terminal PWI domain, and two black points show the positions of two point mutations (P493S and T494M) found in RP. The abilities of 90K wild type (WT) and mutant derivatives to interact with other proteins are shown on the right $(+$ or -). The $60 \mathrm{~K}$ interaction data were published by Gonzalez-Santos et al. (2002), and the N309 and C381 were not tested (NT). The interactions of $90 \mathrm{~K}$ with protein $110 \mathrm{~K}, \mathrm{p} 110$ and SPF30/SMNrp are observed in both the $\mathrm{Y} 2 \mathrm{H}$ system and the in vitro binding assay, while the interactions with $60 \mathrm{~K}$ and $102 \mathrm{~K}$ are detected only in the in vitro binding assay.

Therefore, mutational analyses are focused on the interactions between the $90 \mathrm{~K}$ and the $102 \mathrm{~K}, \mathrm{p} 110$ and $110 \mathrm{~K}$ proteins. To do this, the two mutant clones, pGBKT7-90K-P493S and pGBKT7-90K-T494M, were generated from wild-type plasmid pGBKT7-90K using PCR as described in Materials and Methods. These two mutant constructs, along with the wild-type $90 \mathrm{~K}$ protein, were used 
for the $\mathrm{Y} 2 \mathrm{H}$ assay and as templates for in vitro transcription/translation to produce $\left[{ }^{35} \mathrm{~S}\right]$-labelled $\mathrm{c}$-Myc-tagged proteins for the following in vitro binding assays. First, GST pull-down assay as described in section 3.2.3.2 was used for analysis of the interaction between $102 \mathrm{~K}$ and $90 \mathrm{~K}$ (figure 4.22A). GST-102K could precipitate both the recombinant $\left[{ }^{35} \mathrm{~S}\right]$-labelled $90 \mathrm{~K}$ wild-type protein and two mutant proteins (P493S or T494M). The binding affinities are not significantly different. Second, an immunoprecipitation experiment as described in section 3.2.3.5 was applied to analyse the interaction between $110 \mathrm{~K}$ and $90 \mathrm{~K}$ (figure 4.22B). In the presence of His-tagged 110K protein, anti-pep-110K antibodies could efficiently precipitate the $\left[{ }^{35} \mathrm{~S}\right]$-labelled $90 \mathrm{~K}$ wild-type protein and both mutant proteins (P493S or T494M) as well. Finally, the interaction between $\mathrm{p} 110$ and $90 \mathrm{~K}$ was examined in both the $\mathrm{Y} 2 \mathrm{H}$ and in the in vitro binding assay (figure $4.22 \mathrm{C}$ ). In the two-hybrid assay, two mutant clones grow as well as the wild-type on the selective medium SD/-Leu-Trp-His-Ade (figure 4.22C, left panel). Similarly, immunoprecipitation (see section 3.2.3.5 for methods) shows that, in the presence of His-tagged p110 protein, anti-p110 antibodies could precipitate the $\left[{ }^{35} \mathrm{~S}\right]$-labelled $90 \mathrm{~K}$ wild-type protein and both mutant proteins (P493S or T494M) almost equally well (figure 4.22C, right panel). The specificity of the interaction was demonstrated by the fact that a $60 \mathrm{~K}$ protein prepared by translation in vitro, another U4/U6-specific protein, was not co-immunoprecipitated. In conclusion, the in vitro binding assays, and also the $\mathrm{Y} 2 \mathrm{H}$ method in the case of $\mathrm{p} 110-90 \mathrm{~K}$, could not demonstrate any clear-cut effect of the two mutations P493S and T494M on the binding of protein $90 \mathrm{~K}$ to either the $102 \mathrm{~K}$, the $110 \mathrm{~K}$ or the $\mathrm{p} 110$ protein.

A

B

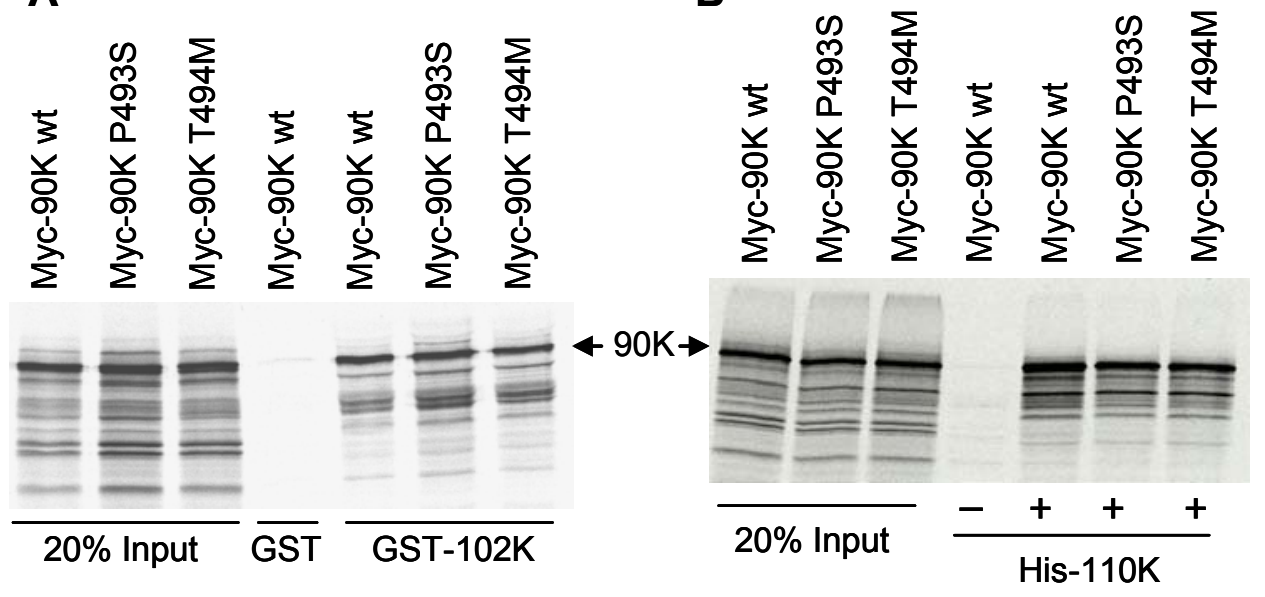




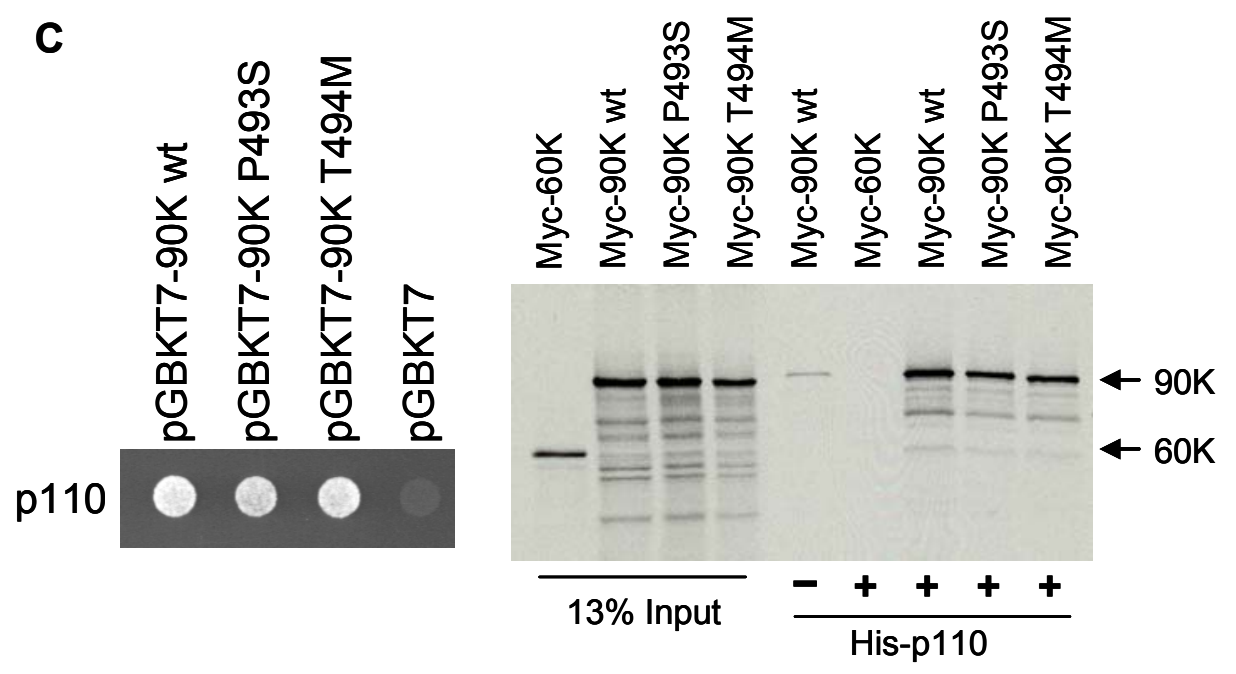

Figure 4.22. Mutational analysis of $90 \mathrm{~K}$ interactions. (A) The interaction of GST-102K fusion protein and in vitro translated $\left[{ }^{35} \mathrm{~S}\right]$-labelled c-Myc-tagged $90 \mathrm{~K}$ mutant proteins; the wild-type $90 \mathrm{~K}$ protein served as a control. $10 \mu \mathrm{l}$ of $\left[{ }^{35} \mathrm{~S}\right]$-labelled samples of interest were incubated with GST, or GST-102K immobilized on glutathione-Sepharose beads. Bound proteins were eluted in SDS sample buffer and analyzed with SDS-PAGE and visualized by autoradiography. The input lane contains $20 \%$ of the total amount of in vitro translated protein added to each reaction. (B) The interaction of His-110K fusion protein and in vitro translated $\left[{ }^{35} \mathrm{~S}\right]$-labelled c-Myc-tagged $90 \mathrm{~K}$ mutant proteins; the wild-type $90 \mathrm{~K}$ protein served as a control. Purified His-tagged $110 \mathrm{~K}$ was incubated with anti-pep-110 antibodies bound to protein A-Sepharose and $\left[{ }^{35} \mathrm{~S}\right]$-labelled proteins. The precipitated proteins were fractionated by SDS-PAGE and visualized by autoradiography. The input lane contains $20 \%$ of the total amount of in vitro translated protein added to each reaction. (C) Left panel: $\mathrm{Y} 2 \mathrm{H}$ assay of interactions between $\mathrm{p} 110$ and $90 \mathrm{~K}$ mutant proteins. pGADT7-p110 was tested against mutant proteins pGBKT790K-P493S and pGBKT7-90K-T494M; the wild-type 90K protein and the empty vector served as controls. Interactions were observed on SD/-Leu-Trp-His-Ade medium at $30^{\circ} \mathrm{C}$ for 3 days. Right panel: The interaction of His-p110 fusion protein and in vitro translated $\left[{ }^{35} \mathrm{~S}\right]$-labelled c-Myc-tagged $90 \mathrm{~K}$ mutant proteins; the wild-type $90 \mathrm{~K}$ protein and the U4/U6-60K protein served as controls. $\left[{ }^{35} \mathrm{~S}\right]$-labelled $90 \mathrm{~K}$ was incubated with His-p110 protein, followed by precipitating with anti-p110 antibodies. Co-precipitated proteins were fractionated by SDS-PAGE and visualized by autoradiography. The input lane presents $13 \%$ of the in vitro translated protein used in the reaction.

\subsubsection{Analysis of $220 \mathrm{~K}$ mutations found in retinitis pigmentosa}

As shown in table 4.1, seven point mutations were found in the RP. Strikingly, all the mutations are related to the last 35 amino acids encoded by exon 42 of human 220K gene (PRPF8). Protein alignment at exon 42 between human PRP8 and its orthologues in other species was carried out previously by McKie et al. (2001) and again as shown below. Particularly striking is the level of homology around residues 2309 and 2310 and the absolute conservation of 
these two residues throughout the species shown in the multiple alignment. Additionally, the proline residue at position 2301 has the same high degree of conservation. The remaining missense mutations alter the amino acid residues 2304 and 2314 , which are also conserved, but to a lesser degree.

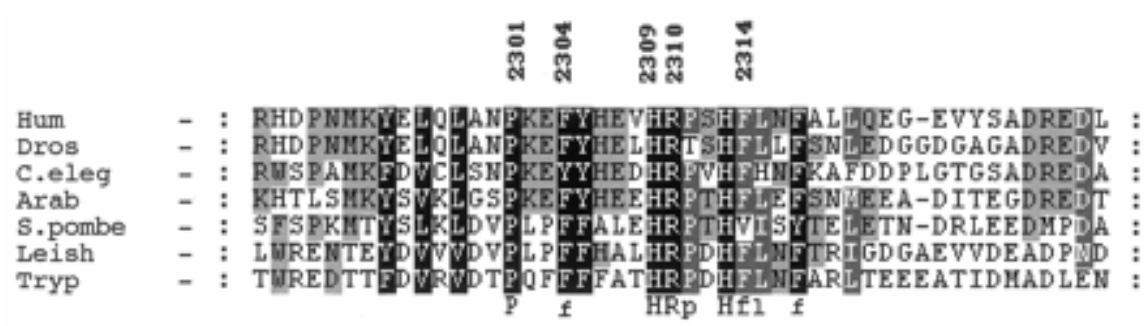

Figure 4.23. The amino acid sequence of human PRP8 exon 42 is aligned with that of Drosophila melanogaster (Dros), Caenorhabditis elegans (C.eleg), Arabidopsis thaliana (Arab), Schizosaccharomyces pombe (S.pombe), Leishmania major (Liesh) and Trypanosoma bruceii (Tryp) using the programme Clustal. The shaded boxes were created using the programme Mac-Boxshade with the default parameters set. The intensity of shading represents the relative degree of conservation and physico-chemical similarities. Hence the black boxes indicate amino acid identity or only highly conservative variation, while lesser shaded boxes show conservation but with more variation and with less conservative amino acid substitutions. The five amino acid residues mutated in the adRP cases are highlighted above with the codon number. Adapted from McKie et al., 2001.

As shown in the $\mathrm{Y} 2 \mathrm{H}$ analysis in section 4.3.1, the $220 \mathrm{~K}$ protein's C-terminal fragment 220-6 (amino acids 1986 to 2335) participates in the interaction with its own N-terminal fragment (220-1), fragment 4 of protein $200 \mathrm{~K}(200-4)$ and the C-terminal fragment of protein 116K (116-3). This raises the question of whether the mutations affect these interactions. In an attempt to answer this question, the 220-6 fragment was first dissected into two pieces. $\Delta \mathrm{C}$ (amino acids 1986 to 2300 ) lacks the last 35 amino acids related to seven point mutations; $\Delta \mathrm{N}$ comprises the last 97 amino acids (2239 to 2335) containing the region related to the mutations. Figure 4.24A schematically represents the truncation strategy (also see figure 4.6A). $\Delta \mathrm{C}$ and $\Delta \mathrm{N}$ were subcloned into pGADT7 and were then tested for interaction with 116-3, 200-4 and 220-1. The plasmid pGADT7-220-6 was used as a positive control, and the blank pGADT7 vector as a negative control. Figure 4.24B shows that the $\Delta N$, like 220-6, displays full binding activities in the three different combinations (compare spots 2 and 4 in the upper, middle and lower panels), whereas the $\Delta \mathrm{C}$ completely lost 
the binding abilities (compare spots 1 and 3 ). These results clearly suggest that the $\Delta \mathrm{N}$ fragment is sufficient for the binding and imply that the mutations may have an effect on this. Therefore, the further experiments were done to check each of the seven point mutations. The PCR-based site directed mutagenesis method was used to generate the mutant constructs using pGADT7- $\Delta \mathrm{N}$ plasmid as PCR template (see section 3.2.1.7 in the Materials and Methods). Subsequently, they were tested in the $\mathrm{Y} 2 \mathrm{H}$ system. The strength of these interaction was estimated from comparing the growth of indicator yeast AH109 bearing wild-type and mutant alleles of $220-6 \Delta \mathrm{N}$ on medium lacking histidine and/or adenine, and containing different concentrations of 3-amino-1,2,4triazole (3-AT). 3-AT inhibits the activity of the His3 reporter protein, and growth at higher concentrations of 3-AT indicates that more His3 is being synthesized and implies that the interaction is stronger. Typical results are shown in figure 4.24C. On the selective medium SD/-Leu-Trp-His-Ade, all mutant clones show similar growth patterns as the wild-type $\Delta \mathrm{N}$ protein (upper panel). However, on the plates of SD/-Leu-Trp-His plus 3-AT, the clones bearing mutation R2310G (spot 7), R2310K (spot 8), or F2314L (spot 9) grow obviously slowly compared with the wild type (spot 2) in all three combinations; similar results were obtained for clones bearing P2301T (spot 3) and F2304L (spot 4) in the combination with 200-4, but only a slight - or no - difference was seen for the combination with 116-3 and 220-1. Instead, the clones bearing H2309P (spot 5) and H2309R (spot 6) appear to show faster growth than the wild-type clone (spot 2) does. To investigate the significance of this, a chemiluminescence $\beta$ galactosidase assay was used. However, this method did not give consistent results when repeated (data not shown). In conclusion, the exon-42-encoded region of $220 \mathrm{~K}$ protein related to all seven mutations identified in RP is indeed required for several protein-protein interactions. Most of the single point mutations affect the ability of this region to interact with its binding partners. However, the biological significances are still under investigation. 
A

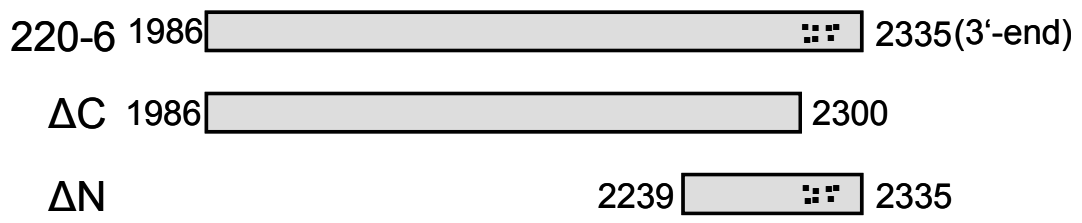

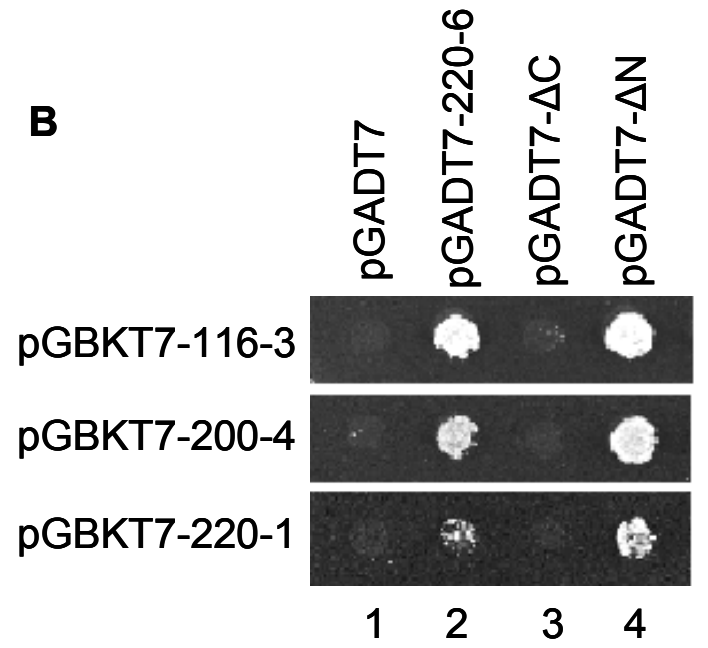

C

[pGADT7 constructs]

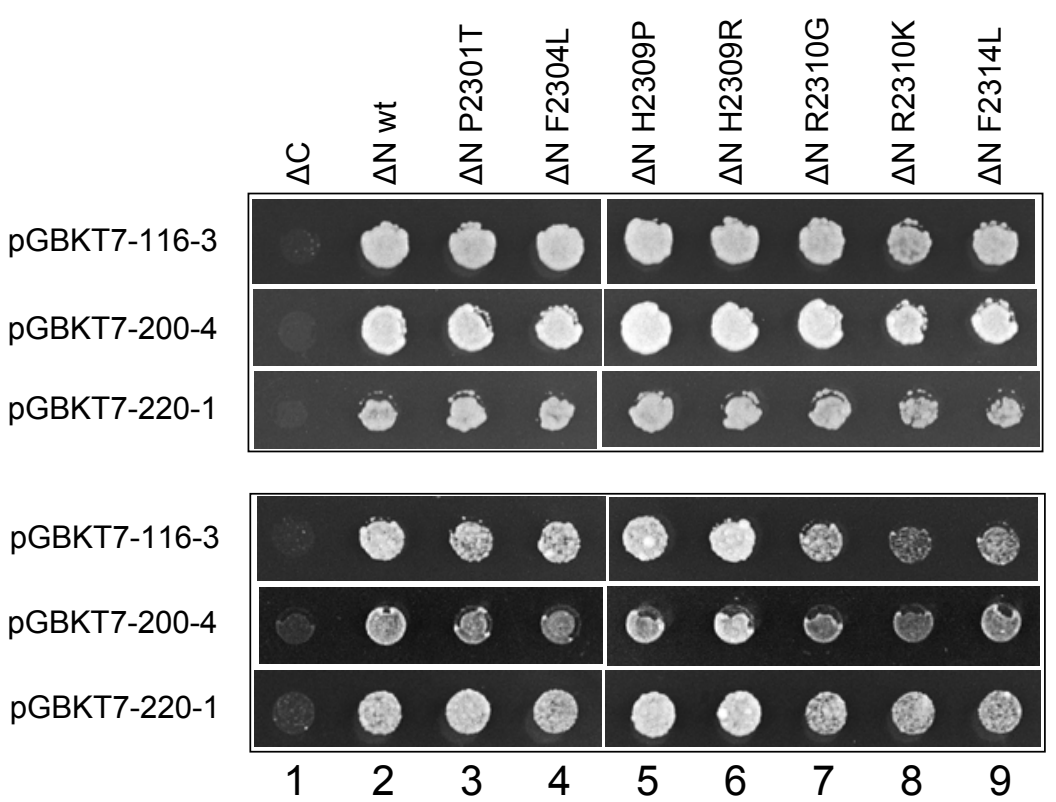

Figure 4.24. (A) Human U5-220K C-terminal fragment 220-6 (1986-2335 amino acids [aa]) and deletion mutations $\Delta \mathrm{C}(1986-2300$ aa), $\Delta \mathrm{N}(2239-2335$ aa) are schematically represented. The black points show the positions of the seven point mutations. (B) Y2H examination of the deletion mutation clones as indicated in the figure. Yeast cell growth was monitored on the selective medium of SD/-Leu-Trp-His-Ade for 3-4 days at $30^{\circ} \mathrm{C}$. (C) $\mathrm{Y} 2 \mathrm{H}$ examination of the point mutation clones as indicated above the panels. Yeast 
cell growth was monitored on the selective medium of SD/-Leu-Trp-His-Ade for 3-4 days (upper panel), and on the medium of SD/-Leu-Trp-His $+0.2 \mathrm{mM} 3-\mathrm{AT}$ for 3 days for the combinations with 116-3, SD/-leu-Trp-His+1.5 mM 3-AT for 3 days for the combinations with 200-4, and SD/-Leu-Trp-His+0.1 mM 3-AT for 6 days for the combinations with $220-1$ (lower panel). All plates were incubated at $30^{\circ} \mathrm{C}$ and were observed from day to day. $\Delta \mathrm{C}$ clone was included as a negative control.

\subsection{1 $\mathrm{Y} 2 \mathrm{H}$ screen with the $\mathrm{N}$-terminal 434 amino acids of protein U5-200K}

Protein $200 \mathrm{~K}$ is a DExD/H box RNA helicase containing two helicase domains which play an important role in the splicing process. RNA helicases often have large amino- or carboxy-terminal extensions that are not typically found in DNA helicases. These extensions are presumed to have additional functions such as an additional enzymatic activity, nuclear signalling, or providing specificity through interaction with protein cofactors (Tanner and Linder, 2001). Indeed, the cloning of the full-length $200 \mathrm{~K}$ protein in this work has identified an additional 435-residues sequence in the amino-terminus which is absent in the previously published $200 \mathrm{~K}$ sequence (Lauber et al., 1998). This region is conserved among the orthologues of $200 \mathrm{~K}$ protein, as shown in the multiple alignment in figure 4.1. For this region (also termed 200-1), a $\mathrm{Y} 2 \mathrm{H}$ assay has been performed to identify the interaction within tri-snRNP particle as described above. However, no interaction has been found so far. To understand the potential function of the N-terminal 200-1 fragment, yeast two-hybrid screening was used to search for the putative interaction partners. The plasmid pGBKT7200-1 used as bait was transformed into yeast strain $\mathrm{AH} 109$, and was subsequently mated with a pretransformed human HeLa cDNA library in yeast strain Y187 from Clontech. The mating efficiency was $1 \%$ and about $10^{6}$ clones were screened. $235 \mathrm{His}^{+}$and $\mathrm{Ade}^{+}$clones were selected after incubation at $30^{\circ} \mathrm{C}$ for 5-12 days on the $50150-\mathrm{mm}$ plates containing selective medium SD/Leu-Trp-His-Ade. These clones were reselected by their ability to grow in the presence of $20 \mathrm{mM}$ 3-amino-triazole (3-AT) and their ability to activate the MEL1 reporter gene, as detected in a $\alpha$ - galactosidase assay on the highstringency medium SD/-Leu-Trp-His-Ade+20 mM 3-AT+X-a-Gal. From this step, 126 positive clones were selected for preparing plasmid DNA samples. The samples were then sequenced at Sequence Laboratories Göttingen $\mathrm{GmbH}$. 
NCBI Blast was used to analyse all the sequence data obtained. Based on the DNA sequence of their inserts, 26 putative clones were identified and shown in the table 4.2. The clones that express non-biological peptides, i.e. anti-sense, intergenic region or non-protein-encoding regions, are excluded from the table of results. Most candidates are fused to the Gal4 sequence in the reading frame of the human gene, while some of them are out of frame. However, it was found that at least in some cases, frame-shifted translation occurs (Fromont-Racine et al., 1997). Nine candidates related to ribosomal protein, mitochondrial protein, zinc finger protein, proteasome, etc., which are marked with an asterisk in table 4.2 , are probably false positive readouts, as suggested by previous studies (see 'Table of false positives' at http://www.fccc.edu/research/labs/golemis/Table1.html). However, some putative interactors may have biological relevance. For example, the identification of the import receptor karyopherin $\alpha 2$ implies that protein $200 \mathrm{~K}$ may be recognized by this protein via its $\mathrm{N}$-terminal nuclear localization signal for transport through the NPC. Identification of the nuclear export protein p270/Tpr suggests that it may function for the mRNA export, and subsequently may be involved in protein expression by association with the eukaryotic translation elongation factor 1 and translation initiation factor 3. Clearly, further work is needed to elucidate these questions.

Table 4.2. Outcome of two-hybrid screening using the N-terminal fragment of protein 200K (200-1: 1-434 amino acids) fused to the Gal4 DNA binding domain. The first column shows the number of identified clones for each gene. The asterisks $\left(^{*}\right)$ show that the protein encoded by this gene often displays a false positive result in the two-hybrid screens (see next page). 


\begin{tabular}{|c|c|c|c|}
\hline $\begin{array}{l}\text { Clone } \\
\text { No. }\end{array}$ & Putative human gene & Accession No. & $\begin{array}{l}\text { Frame } \\
\text { of insert }\end{array}$ \\
\hline 1 & kinesin family member 21A (KIF21A) & gi|38569483 & in frame \\
\hline 3 & kinesin family member 23 (KIF23) & gi|20143966 & in frame \\
\hline 1 & $\begin{array}{l}\text { eukaryotic translation elongation factor } 1, \\
\text { alpha } 1 \text { (eEF1A1) }\end{array}$ & gi|25453469 & in frame \\
\hline 1 & $\begin{array}{l}\text { eukaryotic translation initiation factor } 3 \text {, } \\
\text { subunit } 10 \text { (EIF3S10) }\end{array}$ & gi|4503508 & not clear \\
\hline 1 & $\begin{array}{l}\text { karyopherin alpha } 2 \text { (KPNA2) } \\
\text { (RAG cohort 1; importin alpha 1) }\end{array}$ & gi|4504896 & in frame \\
\hline 1 & p270/Tpr (translocated promoter region) & gi|4507658 & in frame \\
\hline 1 & $\begin{array}{l}\text { fanconi anemia, complementation group } \mathrm{G} \\
\text { (FANCG) }\end{array}$ & gi|4759335 & in frame \\
\hline 1 & $\begin{array}{l}\text { androgen-induced proliferation } \\
\text { inhibitor (APRIN) }\end{array}$ & gi|7657268 & in frame \\
\hline 1 & $\begin{array}{l}\text { chromosome X open reading frame } 53 \\
\text { (CXorf53) }\end{array}$ & gi| 13236582 & in frame \\
\hline 2 & $\begin{array}{l}\text { topoisomerase II binding protein-1 } \\
\text { (TOP-BP1) * }\end{array}$ & gi|20143948 & in frame \\
\hline 1 & $\begin{array}{l}\text { proteasome (prosome, macropain) } \\
\text { subunit, alpha type } 6 \text { (PSMA6) * }\end{array}$ & gi|23110943 & in frame \\
\hline 1 & mitochondrial ATP synthase epsilon chain * & gi|21327678 & in frame \\
\hline 2 & Zinc finger protein $143($ ZNF 143) $*$ & gi||18874091 & in frame \\
\hline 5 & unnamed protein product (OXR1-like?) & gi|21753814 & in frame \\
\hline 1 & NONO (p54nrb) & gi|34932413 & not clear \\
\hline 2 & $\begin{array}{l}\text { unknown DNA sequence from chromosome } \\
16\end{array}$ & gi|15375156 & not clear \\
\hline 1 & DNA sequence from Chromosome 14 & gi|12641568 & not clear \\
\hline 1 & $\begin{array}{l}\text { splicing factor, arginine/serine-rich 5(SFRS5) } \\
\text { (HRS,SRP40) }\end{array}$ & gi|33869323 & frame-1 \\
\hline 4 & $\begin{array}{l}\text { chromosome } 10 \text { open reading frame } 61 \\
(\mathrm{C} 10 \text { orf61) }\end{array}$ & gi|24308108 & frame-1 \\
\hline 5 & $\begin{array}{l}\text { nuclease sensitive element binding protein } 1 \\
\text { (NSEP1) }\end{array}$ & gi|34098945 & frame-1 \\
\hline 1 & S-adenosylhomocysteine hydrolase (AHCY) & gi|9951914 & frame +1 \\
\hline 1 & threonyl-tRNA synthetase (TARS) $*$ & gi|38202254 & frame +1 \\
\hline 1 & $\begin{array}{l}\text { voltage-dependent anion channel 2(VDAC2); } \\
\text { (mitochondrion) * }\end{array}$ & gi|42476280 & frame +1 \\
\hline 1 & $\begin{array}{l}\text { NADH dehydrogenase (ubiquinone) Fe-S } \\
\text { protein } 3 \text { (NADH-coenzyme Q reductase) } \\
\text { (NDUFS3)* }\end{array}$ & gi|4758787 & frame +1 \\
\hline 1 & ribosomal protein L28 (RPL28) * & gi|34486095 & frame +1 \\
\hline 1 & ribosomal protein S15a (RPS15A) * & gi|34335150 & frame +1 \\
\hline
\end{tabular}




\section{Discussion}

The tri-snRNP is especially important for the splicing reaction as it contains many essential components of the spliceosome. However, the mechanism of the tri-snRNP assembly and its roles in the activation of the spliceosome and in catalysis are still poorly understood. There is evidence that the protein-protein interactions play a critical role in these processes.

In this work the yeast two-hybrid techniques and in vitro biochemical methods were established to investigate the protein-protein interactions within the individual U4/U6 and U5 snRNPs, as well as protein contacts between these two snRNPs in the tri-snRNP particle. All the positive results are summarised in table 5.1. The data comprise $\mathrm{Y} 2 \mathrm{H}$ screening for 43 full-length proteins and protein fragments derived from 15 protein components of the human tri-snRNP and from the U5-52K protein, which associates with the U5 snRNP but not the tri-snRNP. In total, 46 pairs of interacting proteins were detected in $\mathrm{Y} 2 \mathrm{H}$ analysis. Of these, 20 interacting pairs were examined by in vitro binding assays and 15 pairs were again verified, making up $75 \%$ of the total examined samples. Six additional pairs of interacting proteins were observed in in vitro binding assays only. Table 5.2 presents some additional data on protein-protein interactions between the $90 \mathrm{~K}$ protein and the recycling factor U6-p110, and the U2-associated protein SPF30/SMNrp. Eleven interactions were identified in the $\mathrm{Y} 2 \mathrm{H}$ assay (table 5.2). 


\begin{tabular}{|c|c|c|c|}
\hline Protein pair & $\mathrm{Y} 2 \mathrm{H}$ interaction & $\begin{array}{c}\text { In vitro biochemical } \\
\text { interaction }\end{array}$ & $\begin{array}{l}\text { Section in } \\
\text { the Results }\end{array}$ \\
\hline $20 \mathrm{~K} / 60 \mathrm{~K}$ & + & + & \multirow{2}{*}{4.2} \\
\hline $60 \mathrm{~K} / 90 \mathrm{~K}$ & - & + & \\
\hline $116 \mathrm{~K} / 200-4$ & + & NT & \multirow{14}{*}{4.3 .1} \\
\hline $116 \mathrm{~K} / 220-1$ & + & NT & \\
\hline $116 \mathrm{~K} / 220-6$ & + & NT & \\
\hline $116-2 / 200-4$ & + & NT & \\
\hline $116-2 / 220-1$ & + & NT & \\
\hline $116-2 / 220-6$ & + & NT & \\
\hline $116-3 / 200-4$ & + & NT & \\
\hline $116-3 / 220-6$ & + & NT & \\
\hline $200 \mathrm{~K} / 220-6$ & + & NT & \\
\hline $200-4 / 220-1$ & + & NT & \\
\hline $200-4 / 220-6$ & + & NT & \\
\hline $220-1 / 220-6$ & + & NT & \\
\hline $220-6 / 220-6$ & + & NT & \\
\hline $220 \mathrm{~K} / 40 \mathrm{~K}$ & - & + & \\
\hline $102 \mathrm{~K} / 15 \mathrm{~K}$ & + & + & \\
\hline $102 \mathrm{~K} / 102 \mathrm{~K}$ & + & + & \\
\hline $102 \mathrm{~K} / 116 \mathrm{~K}$ & + & - & \\
\hline $102 \mathrm{~K} / 116-2$ & + & - & \\
\hline $102 \mathrm{~K} / 116-3$ & + & - & 4.3.2 \\
\hline $102 \mathrm{~K} / 200-2$ & + & - & \\
\hline $102 \mathrm{~K} / 200-4$ & + & + & \\
\hline $102 \mathrm{~K} / 220-1$ & + & + & \\
\hline $102 \mathrm{~K} / 220-6$ & + & - & \\
\hline $102 \mathrm{~K} / 61 \mathrm{~K}$ & + & + & 4.4 .1 \\
\hline $102 \mathrm{~K} / 90 \mathrm{~K}$ & - & + & \\
\hline $102 \mathrm{~K} / 90 \mathrm{~K}$ C267 & - & + & \\
\hline $102 \mathrm{~K} / 90 \mathrm{~K}$ C381 & - & + & 4.4 .2 \\
\hline $102 \mathrm{~K} / 90 \mathrm{~K} \quad 489$ & - & + & \\
\hline $110 \mathrm{~K} / 90 \mathrm{~K}$ & + & + & \\
\hline 110K/90K_C381 & + & NT & \\
\hline $110 \mathrm{~K} / 90 \mathrm{~K} \_\mathrm{C} 489$ & + & NT & \\
\hline $110 \mathrm{~K} / 102 \mathrm{~K}$ & + & + & \\
\hline $110 \mathrm{~K} / 110 \mathrm{~K}$ & + & ? (high background) & \\
\hline $110 \mathrm{~K} / 200 \mathrm{~K}$ & + & + & 15 \\
\hline $110 \mathrm{~K} / 200-4$ & + & + & $4 . J$ \\
\hline $110 \mathrm{~K} / 200-5$ & + & + & \\
\hline $110 \Delta \mathrm{RS} / 90 \mathrm{~K}$ & + & NT & \\
\hline $110 \Delta \mathrm{RS} / 102 \mathrm{~K}$ & + & NT & \\
\hline $110 \Delta \mathrm{RS} / 200-4$ & + & NT & \\
\hline $110 \Delta \mathrm{RS} / 200-5$ & + & NT & \\
\hline $102 \mathrm{~K} \_\mathrm{NTD} / 15 \mathrm{~K}$ & + & NT & \\
\hline $102 \mathrm{~K} \_\mathrm{TPR} \_\mathrm{M} / 61 \mathrm{~K}$ & + & NT & \\
\hline 102K_TPR_M/110K & + & NT & 16 \\
\hline $102 \mathrm{~K}$ TPR M/200-4 & + & NT & 4.0 \\
\hline 102K_TPR_M/220-1 & + & NT & \\
\hline 102K_TPR_C/61K & + & NT & \\
\hline $52 \mathrm{~K} / 102 \mathrm{~K}$ & + & + & \\
\hline $52 \mathrm{~K} / 15 \mathrm{~K}$ & + & + & 47 \\
\hline $52 \mathrm{~N} / 102 \mathrm{~K}$ & + & + & 4.1 \\
\hline $52 \mathrm{C} / 15 \mathrm{~K}$ & + & + & \\
\hline Summary & $46(+) ; 6(-)$ & $21(+) ; 25(\mathrm{NT}) ; 1(?) ; 5(-)$ & \\
\hline
\end{tabular}


Table 5.1. Summary of the protein-protein interactions within the U4/U6 and the U5 snRNP, and between them in the tri-snRNP particle. NT, not tested for in vitro binding in this work (grey background).

\begin{tabular}{|c|c|c|c|}
\hline Protein pair & $\mathrm{Y} 2 \mathrm{H}$ interaction & $\begin{array}{c}\text { In vitro biochemical } \\
\text { interaction }\end{array}$ & $\begin{array}{l}\text { Section in } \\
\text { the Results }\end{array}$ \\
\hline $90 \mathrm{~K} / \mathrm{p} 110$ & + & + & \multirow{9}{*}{4.8} \\
\hline $90 \mathrm{~K} / \mathrm{p} 110 \Delta \mathrm{C}$ & + & NT & \\
\hline $90 \mathrm{~K} / \mathrm{p} 110-\mathrm{AF}$ & + & NT & \\
\hline 90K_C267/p110 & + & $+*$ & \\
\hline 90K_C381/p110 & + & NT & \\
\hline 90K_C489/p110 & + & NT & \\
\hline $90 \mathrm{~K} \_\mathrm{C} 267 / \mathrm{p} 110 \Delta \mathrm{C}$ & + & NT & \\
\hline 90K C381/p110 & + & NT & \\
\hline $90 \mathrm{~K} \_\mathrm{C} 489 / \mathrm{p} 110 \Delta \mathrm{C}$ & + & NT & \\
\hline $90 \mathrm{~K} / \mathrm{SPF} 30$ & + & $+*$ & \multirow{2}{*}{4.9} \\
\hline 90K_N442/SPF30 & + & NT & \\
\hline Summary & $11(+)$ & $3(+) ; 8(\mathrm{NT})$ & \\
\hline
\end{tabular}

Table 5.2. Summary of the protein-protein interactions between $90 \mathrm{~K}$ protein and the protein U6-p110 or SPF30/SMNrp. NT, not tested for the in vitro binding in this work (grey background). * The result was shown previously (Medenbach et al., 2004; Meister et al., 2001).

\subsection{Protein associations within the U4/U6-snRNP particle}

U4/U6 snRNP contains five particle-specific proteins, namely $15.5 \mathrm{~K}, 61 \mathrm{~K}$ and the $20 \mathrm{~K}, 60 \mathrm{~K}, 90 \mathrm{~K}$. $\mathrm{Y} 2 \mathrm{H}$ and in vitro binding assays were used to investigate how they bind to one another in the absence of snRNAs.

The well known paucity of interactions among U4/U6 snRNP proteins was again clearly confirmed by $\mathrm{Y} 2 \mathrm{H}$ and by in vitro binding experiments (section 4.2.1). The interactions of $60 \mathrm{~K}$ with $90 \mathrm{~K}$ (in vitro binding assay only) and the $20 \mathrm{~K}$ protein ( $\mathrm{Y} 2 \mathrm{H}$ and in vitro) remain the only ones observed. These interactions establish the biochemically stable $20 \mathrm{~K} \cdot 60 \mathrm{~K} \cdot 90 \mathrm{~K}$ heterotrimeric complex (Horowitz et al., 1997; Teigelkamp et al., 1998). Previous studies showed that the $\mathrm{N}$-terminal SFM domain of $60 \mathrm{~K}$ is essential for the binding of $20 \mathrm{~K}$ protein (Horowitz et al., 2002; Reidt et al., 2003), while the analysis of a mutant clone in this study indicated that the C-terminal WD40 domain of $60 \mathrm{~K}$ is involved in the binding of $90 \mathrm{~K}$ protein (section 4.2.1). Consistently with the distinct domains involved, co-immunoprecipitation results showed that one interaction does not 
affect the other in the $20 \mathrm{~K} \cdot 60 \mathrm{~K} \cdot 90 \mathrm{~K}$ complex (figure $4.4 \mathrm{~A}$ ). The failure of $\mathrm{Y} 2 \mathrm{H}$ to demonstrate an interaction between $60 \mathrm{~K}$ and $90 \mathrm{~K}$ could have a trivial reason, such as folding problems or lack of a necessary post-translational modification.

It has been shown that the U4/U6 snRNP-specific protein $15.5 \mathrm{~K}$ binds directly to a specific sequence element of U4 snRNA through a novel RNA-binding domain (Vidovic et al., 2000). The $20 \mathrm{~K} \cdot 60 \mathrm{~K} \cdot 90 \mathrm{~K}$ complex and $61 \mathrm{~K}$ follow after this initiating step only (Nottrott et al., 2002). It is not known whether the initial step forms a protein-RNA "nucleus" for the attachment of the other proteins or whether the function of protein $15.5 \mathrm{~K}$ is simply to assist the correct folding of the U4 snRNA. However, the general failure to detect strong pairwise interactions between the heterotrimer, $61 \mathrm{~K}$ and $15.5 \mathrm{~K}$ would rather seem to point to a possible co-operative activity in complex formation, presumably involving the U4 snRNA, that disfavours the formation of 1:1 complexes such as are detected in $\mathrm{Y} 2 \mathrm{H}$ and pull-down experiments of the type conducted in this work. Indirect support for the latter interpretation is afforded by the fact that proteins $61 \mathrm{~K}$ and $90 \mathrm{~K}$ can both be cross-linked to U4 snRNA and U6 snRNA respectively by photolysis (Nottrott et al., 2002).

\subsection{Protein associations within the U5-snRNP particle}

In contrast to the U4/U6 snRNP, the U5-snRNP particle assembles mostly via protein-protein interactions, as demonstrated in this work. These proteins exhibit a wide range of binding affinities, and dissociate from the spliceosome at different stages.

\subsubsection{Interactions of the RNA-free $220 \mathrm{~K} \cdot 200 \mathrm{~K} \cdot 116 \mathrm{~K} \cdot 40 \mathrm{~K}$ heterotetramer}

By combining two-hybrid assay with mutational analysis, the interactions between $220 \mathrm{~K}, 200 \mathrm{~K}$ and $116 \mathrm{~K}$, and the domains contributions were for the first time described in detail (section 4.3.1). Currently, I have not yet found a conventional biochemical method to confirm these $\mathrm{Y} 2 \mathrm{H}$ interactions, since there was no functional recombinant protein for $220 \mathrm{~K}, 200 \mathrm{~K}$ or $116 \mathrm{~K}$ available (see section 4.3.1.1 for an example). However, several lines of evidence from previous studies indicate that these interactions are specific and biologically relevant. First, these three proteins, together with the $40 \mathrm{~K}$ protein, can form a 
stable RNA-free complex at high salt in vitro (Achsel et al., 1998). Second, one of the interactions between $220 \mathrm{~K}$ and $116 \mathrm{~K}$ has previously been observed by using far-western blotting (Achsel et al., 1998). Third, as discussed below, most of the binding domains were also identified in the interactions of the orthologous proteins of yeast: Prp8p, Brr2p and Snu114p.

In a previous $\mathrm{Y} 2 \mathrm{H}$ study van Nues and Beggs used this technique to establish a protein network within a different set of yeast spliceosomal proteins, such as the tri-snRNP-specific protein Snu66p and the U5 snRNP-specific proteins Prp8p and Brr2p. From their data a picture emerges of Brr2p as the hub of numerous protein-protein interactions, and Brr2p is therefore assigned the role of a central organizer not only of the tri-snRNP, but also of spliceosomal protein dynamics in general. Apart from its task of unwinding the U4/U6 snRNA duplex, Brr2p, through its C-terminus, appears to be involved in second-step factor recruitment and other protein contacts to $\mathrm{U} 1, \mathrm{U} 2$ as well as tri-snRNP specific proteins. My two-hybrid experiments confirm the critical function of this C-terminus in proteinprotein interactions for protein $200 \mathrm{~K}$, the human orthologue of Brr2p. This includes the interactions within the RNA-free heterotetramer (through interactions with $220 \mathrm{~K}$ and $116 \mathrm{~K}$ ) and with $110 \mathrm{~K}$. The region in the C-terminal half of $200 \mathrm{~K}$ required for these interactions seems to be conserved between yeast and man (van Nues and Beggs, 2001). Interactions of a full-length 200K protein were observed only with the $220 \mathrm{~K}$ fragment $6(220-6)$ and the $110 \mathrm{~K}$ protein (see section 5.4.1).

The human $200 \mathrm{~K}$ protein, like its yeast orthologue, follows the design of a Cterminal helicase domain with low sequence conservation in domains $\mathrm{V}$ and $\mathrm{VI}$ (following the nomenclature of Tanner and Linder, 2001). For a group of yeast spliceosomal DEAH RNA helicases, comprising Prp2p, Prp16p, Prp22p and Prp43p, it has been shown recently that the interaction domain with the spliceosome resides outside of the catalytic helicase domain (Edwalds-Gilbert et al., 2004). For the yeast Brr2p it has been reported that only the $\mathrm{N}$-terminal helicase domain is required for the unwinding of the U4/U6 snRNA duplex (Kim and Rossi, 1999; Raghunathan and Guthrie, 1998). The poorly conserved Cterminus of the second helicase domain therefore possibly serves exclusively 
as a protein-protein interaction domain. A case of conversion of an RNAbinding domain into a protein-binding domain was recently reported for the Y14 -Mago interaction (Fribourg et al., 2003). The 200-5 fragment of 200K interacts with $110 \mathrm{~K}$ protein in $\mathrm{Y} 2 \mathrm{H}$ and in vitro binding assays. The fragment comprises a SEC63 domain which through its high density of negative charge is suspected to mediate protein-protein interactions particularly in the context of RNA-protein complexes (Willer et al., 2003; Ponting, 2000).

The $220 \mathrm{~K}$ protein, like its yeast orthologue Prp8p, is a large protein with only few recognizable domain features. The observed $\mathrm{Y} 2 \mathrm{H}$ interaction of yeast Prp8p with Lin1p (the orthologue of the human U5 snRNP $52 \mathrm{~K}$ protein) is predicted to be based on the interaction of the GYF domain of Lin1p with the proline-rich N-terminus of yeast Prp8p (Bialkowska and Kurlandzka, 2002; Freund et al., 2002). A small region in the centre of yeast Prp8p (aa 1166-1193) is reported to interact with Snp1p, the orthologue of the human U1-70K protein (Awasthi et al., 2001), while a neighbouring region (aa 1066-1107) was identified as a modulator of yeast Brr2p helicase activity (Kuhn et al., 2002). In addition, Prp8p interacts genetically with Prp28p, the helicase which removes the U1 snRNA from the 5'-SS, and with second-step splicing factors Prp16p, Slu7p, and Prp22p (Umen and Guthrie, 1995; Schneider et al., 2004). In contrast to the paucity of reported protein contacts, protein $220 \mathrm{~K}$ maintains a broad variety of RNA contacts with U5 and U6 snRNA (Dix et al., 1998; Vidal et al., 1999) as well as with the $5^{\prime}$ and $3^{\prime}$ splice site and the branchpoint of the premRNA (Teigelkamp et al., 1995; Query and Konarska, 2004). The current data show that 220K protein, like the yeast Prp8p (van Nues and Beggs, 2001), establishes protein contacts exclusively through its immediate $\mathrm{N}$ - or C-termini (fragments 220-1 and 220-6). In this way the protein establishes contacts to $200 \mathrm{~K}, 116 \mathrm{~K}$ and $102 \mathrm{~K}$ proteins within the U5 snRNP (figures 4.6 and 4.9). Although $\mathrm{Y} 2 \mathrm{H}$ could not identify any interaction of protein $40 \mathrm{~K}$, protein $40 \mathrm{~K}$ is able to bind the protein $220 \mathrm{~K}$ efficiently in the in vitro co-immunoprecipitation experiment (figure 4.7), consistently with the result obtained by far western blotting (Achsel et al., 1998). Therefore, either protein 40K or its interaction partners may be folded incorrectly and thus fail to exhibit stable protein-protein interactions in the $\mathrm{Y} 2 \mathrm{H}$ system. 
These data confirm $220 \mathrm{~K}$ as the centre of the heterotetrameric $220 \mathrm{~K} \cdot 200 \mathrm{~K} \cdot 116 \mathrm{~K} \cdot 40 \mathrm{~K}$ complex. These proteins remain stably associated throughout the spliceosomal cycle and the final release of the post-spliceosomal 35S complex (Makarov et al., 2002; Makarova et al., 2004). Query and Konarska recently identified yeast Prp8p mutations that act as suppressors of the branchpoint $A->G$ mutation by improving the second step of splicing, possibly through stabilization of the second-step core catalytic structure. The authors point out that the available genetic data most favourably supports a model in which Prp8p, acting co-ordinately with U6 snRNA and Prp16p, serves as the modulator for major conformational rearrangements occurring between steps one and two of the splicing reaction (Query and Konarska, 2004).

\subsubsection{Poly-TPR protein $102 \mathrm{~K}$ is stably bound to U5-snRNP particle via multiple protein-protein interactions}

Previous work showed that protein $102 \mathrm{~K}$ remains tightly associated with U5 snRNP particle at salt concentrations of $700 \mathrm{mM} \mathrm{NaCl}$ (Makarov et al., 2000). Further experiments demonstrated that both U5 snRNA and Sm core proteins are not required for the association. In contrast, protein $102 \mathrm{~K}$ binds efficiently to the in vitro isolated RNA-free heteromeric complexes from U5 snRNP, namely the complex $220 \mathrm{~K} \cdot 200 \mathrm{~K} \cdot 116 \mathrm{~K} \cdot 40 \mathrm{~K}$ and $220 \mathrm{~K} \cdot 116 \mathrm{~K} \cdot 40 \mathrm{~K}$. These observations are strongly supported by the protein-protein interaction data obtained in this work. The $\mathrm{Y} 2 \mathrm{H}$ assay revealed that protein $102 \mathrm{~K}$ interacts with U5-specific protein $15 \mathrm{~K}$, and distinctive regions from each of the three proteins $116 \mathrm{~K}, 200 \mathrm{~K}$, and $220 \mathrm{~K}$ within the tri-snRNP particle (section 4.3.2). The specificity of the interactions was confirmed by in vitro binding assays for most of the proteins except protein $116 \mathrm{~K}$ (section 4.3.2). Thus, the interaction between protein $102 \mathrm{~K}$ and $116 \mathrm{~K}$ (or its fragments) may be too weak to be detectable by the in vitro binding assay. The stable association of $102 \mathrm{~K}$ with U5 snRNP is probably important for the subsequent functions of $102 \mathrm{~K}$ in the spliceosome assembly; it will be discussed below that protein $102 \mathrm{~K}$ also interacts with the U4/U6-specific proteins $61 \mathrm{~K}$ and $90 \mathrm{~K}$ as bridging factor, with the tri-snRNP specific protein $110 \mathrm{~K}$, and with protein $52 \mathrm{~K}$ (which binds to the U5 particle only). 
This broad spectrum of interactions of protein $102 \mathrm{~K}$ is consistent with the 19 TPR repeats of the protein. This protein-binding motif was first recognized as a distinct TPR subfamily in the characterization of the Drosophila melanogaster crooked neck (CRN) gene product (Zhang et al., 1991), and appears restricted to RNA-processing proteins such as U1 snRNP proteins Prp39p and Prp42p, crn homologues (Clf1p in yeast and hCRN in human), the human recycling factor U6-p110 and U5-102K protein in this study (Chung et al., 1999; McLean et al., 1998). The crn-like TPR variant, also termed HAT (half a TPR) repeat (Preker and Keller, 1998), is distinguished from the more general TPR repeat most notably by the absence of the conserved glycine at position 8 , by the substitution of a glutamic acid for a hydrophobic residue at position 11, and by the prevalence of basic residues at positions $19,21,26$. There is also a bias towards leucine, isoleucine or valine at positions 3, 5, 23, 28 (figure 5.1). The unique sequence characteristics of this subfamily presumably configure a TPR structure with distinct protein folding or ligand selection properties. However, the semi-conserved hydrophobic amino acids of the HAT motif are slightly different in position from the generalized TPR consensus, but still lie within the predicted nonpolar core of the motif, suggesting a similar overall structure.

$$
\begin{aligned}
& \text { crn TPR consensus } \\
& \text { U6-p110 TPR consensus } \\
& \text { U5-102K TPR consensus } \\
& \text { generalized TPR consensus }
\end{aligned}
$$

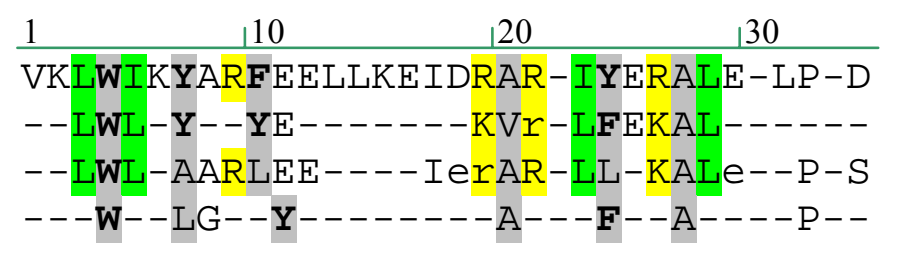

Figure 5.1. Comparison of the generalized TPR consensus with the consensus from a subtype of Drosophila crn, human U5-102K and U6-p110. The hydrophobic residues in the conserved or semi-conserved space through the TPR motifs are shaded in grey and the aromatic residues are highlighted in bold type. The leucine and isoleucine, existing mostly in the subfamily, are shaded in bright green, while the basic residues are shown in yellow.

The deletion approach in this work has shown that the TPR repeats of 102K protein are each dedicated to interactions with specific partners. All repeats participate in the interaction with the U4/U6-61K, whereas only the first nine repeats interact with $110 \mathrm{~K}$, the 200-4 fragment of $200 \mathrm{~K}$ and the 220-1 fragment of $220 \mathrm{~K}$. Makarov et al. reported that antibodies raised against the C-terminal TPR repeats (TPR 10-19) efficiently precipitate free U5 snRNP, but not the U4/U6.U5 tri-snRNP, from HeLa nuclear extracts (Makarov et al., 2000). 
Binding of the U4/U6-61K protein to the C-terminal domain could explain this observation. The $\mathrm{N}$-terminal fragment of $102 \mathrm{~K}$, predicted to contain a coiled-coil domain (Makarov et al., 2000), interacts with protein 15K.

Based on its highly repetitive TPR structure and the experimental data presented here, I propose that protein $102 \mathrm{~K}$ probably acts as a scaffolding to drive the assembly of spliceosome by binding several other spliceosomal proteins.

\subsubsection{The U5-52K protein interacts with the U5-specific proteins $102 \mathrm{~K}$ and $15 \mathrm{~K}$, but dissociates upon tri-snRNP formation}

The following evidence found in this study and other studies in the laboratory of Prof. Lührmann supports the conclusion that the $52 \mathrm{~K}$ protein described here is indeed a U5 snRNP-specific protein (Laggerbauer et al., 2005; Behrens and Lührmann, 1991). First of all, antibodies against the recombinant 52K protein expressed in E. coli recognise only one protein of the appropriate size; this protein co-fractionates with U5 SnRNP, and is also part of highly purified 20S U5 particles. Secondly, immunofluorescence studies with the same antibodies demonstrate that the $52 \mathrm{~K}$ protein is found predominantly in the nucleus, and this finding was confirmed with an exogenous HA-tagged 52K protein. Thirdly, the $52 \mathrm{~K}$ protein is stably associated with the purified U5 snRNP particle, and binds specifically to the U5 snRNP-specific proteins $102 \mathrm{~K}$ and $15 \mathrm{~K}$. Therefore, unspecific aggregation of the $52 \mathrm{~K}$ protein with snRNPs, e.g., during extract preparation, seems highly unlikely.

Database searches revealed that the sequence of the $52 \mathrm{~K}$ protein is identical to that of a previously described protein, CD2BP2, which interacts with CD2, a surface marker of $T$ cells, which facilitates activation of $T$ lymphocytes on binding to its ligand CD58 (Laggerbauer et al., 2005; Nishizawa et al., 1998). Since CD2 resides in the plasma membrane of lymphocytes, the characterisation of the same protein as a component of nuclear U5 snRNPs raises interesting questions as to the mechanism(s) by which the 52K/CD2BP2 protein may exert different functions. In this respect it is interesting to note that the 52K protein is phosphorylated (Behrens and Lührmann, 1991) and post- 
translational modification might well create isoforms with different association behaviour. Indeed, CD2 association may not be the only alternative function of the protein. The yeast orthologue of the $52 \mathrm{~K}$ protein, Lin $1 \mathrm{p}$, interacts with factors involved in chromosome segregation, and Lin1p has therefore been proposed to play a role in this process (Bialkowska and Kurlandzka, 2002).

The distribution of the $52 \mathrm{~K}$ protein in glycerol gradients and its behaviour in immunoaffinity purification experiments both demonstrate that it associates only with the U5 snRNP (Laggerbauer et al., 2005). This raises the question of which contacts of the $52 \mathrm{~K}$ protein with other components of the U5 snRNP might mediate its specific interaction with this particle. Recently, it was shown that the GYF domain of CD2BP2/52K interacts strongly with a particular polyproline motif that is also found in the common snRNP protein SmB. The GYF domain, overexpressed in mammalian cells, was shown to precipitate SmB from cell extracts, suggesting that the $52 \mathrm{~K}$ protein might interact with all splicing snRNPs (Kofler et al., 2004). These findings are not easily reconcilable with our observation that the $52 \mathrm{~K}$ protein does not associate with the other spliceosomal snRNPs, which each contain a set of the Sm proteins. In particular, the Sm proteins of the 12S U1 snRNP are largely exposed to the solvent (Stark et al., 2001). Nonetheless, we do not observe that the $52 \mathrm{~K}$ protein co-fractionates with $\mathrm{U} 1$ in glycerol gradients. The yeast orthologue of the $52 \mathrm{~K}$ protein, Lin $1 \mathrm{p}$, interacts with the yeast U5 snRNP protein Prp8p, presumably through the extensive polyproline stretches at the $\mathrm{N}$ terminus of Prp8p (Bialkowska and Kurlandzka, 2002). I do not detect an interaction of the $52 \mathrm{~K}$ protein with the human Prp8/220K protein, nor with any of six overlapping fragments of the protein, at least by two-hybrid analysis, and, indeed, the proline-rich $\mathrm{N}$ terminus of Prp8 is absent in the mammalian Prp8 protein. Instead, employing yeast twohybrid analysis and in vitro binding assays, I find specific contacts of the $52 \mathrm{~K}$ protein with the $20 \mathrm{~S}$ U5-specific $102 \mathrm{~K}$ and $15 \mathrm{~K}$ proteins. These two interactions may well occur simultaneously, as different domains of the $52 \mathrm{~K}$ protein are involved; the $\mathrm{N}$-terminal two-thirds bind to $102 \mathrm{~K}$ while the $\mathrm{C}$-terminus, including the GYF domain, binds to the $15 \mathrm{~K}$ protein (figure 4.14). I therefore believe that these contacts are responsible for the specific integration of the $52 \mathrm{~K}$ protein into the $20 S$ U5 particle. 
Considering that the GYF domain has been characterised as a polyprolinetargeting molecule (Freund et al., 2003; Freund et al., 1999; Nishizawa et al., 1998), my observation that it forms a specific complex with the $15 \mathrm{~K}$ protein came as a surprise, as $15 \mathrm{~K}$ is devoid of potential proline-rich binding motifs (Reuter et al., 1999). Thus my data indicate for the first time that a GYF domain can also engage in specific protein-protein interactions in a proline-independent manner. A crystallography study of 52K GYF domain in the complex with U5$15 \mathrm{~K}$ indeed showed that the distinct surface of GYF domain binds to the nonproline-rich $15 \mathrm{~K}$ (figure 4.16).

The $52 \mathrm{~K}$ protein is the only U5 snRNP protein that is not present in the U4/U6.U5 tri-snRNP particle. Since the same is true of its yeast orthologue (Stevens et al., 2001), this characteristic property appears to be universally conserved. As U5 snRNP enters the spliceosome as part of the U4/U6.U5 tri-snRNP, the $52 \mathrm{~K}$ protein does not appear to have a function in the splicing reaction itself. Consistently, deletion of the $52 \mathrm{~K}$ protein or the yeast homologue of the $52 \mathrm{~K}$ protein (Lin1p) is not lethal (Laggerbauer et al., 2005; Bialkowska and Kurlandzka, 2002). This suggests that the $52 \mathrm{~K}$ protein functions in a pathway that is auxiliary or redundant for the splicing process, and it is tempting to speculate that this function may have something to do with snRNP assembly/recycling; the $52 \mathrm{~K}$ protein is the only U5 snRNP protein that leaves the $20 S$ U5 snRNP when the latter is integrated into the U4/U6.U5 tri-snRNP. In this respect, it resembles the U6-p110 protein (Prp24p in yeast), which is a component of the U6 and U4/U6 snRNPs but not of the tri-snRNP (see section 5.5). Possibly, the $52 \mathrm{~K}$ protein covers a protein-protein interaction site that is necessary for the association of the U5 and U4/U6 snRNPs. In support of this idea, the $52 \mathrm{~K}$ protein interacts with the $102 \mathrm{~K}$ protein in the U5 snRNP (figure 4.14). The $102 \mathrm{~K}$ protein forms part of the bridge between the U5 and U4/U6 particles (Schaffert et al., 2004; Makarova et al., 2002) and may well need to be masked to prevent premature incorporation of U5 particles, which are not fully assembled, into the tri-snRNP (Makarov et al., 2000). Alternatively, the 52K protein could act as a chaperone for the $15 \mathrm{~K}$ and $102 \mathrm{~K}$ proteins. These two proteins form a dimer independently of the $52 \mathrm{~K}$ protein (section 4.3.2), which $52 \mathrm{~K}$ contacts via two independent interactions. Interestingly, both $15 \mathrm{~K}$ and $102 \mathrm{~K}$ 
are not present in the $35 \mathrm{~S}$ U5 SnRNP which very likely represents a postspliceosomal U5 intermediate in the spliceosomal disassembly process (Makarov et al., 2002). Therefore these proteins appear to leave the U5 part of the tri-snRNP before or during the catalytic steps of the splicing reactions. Since two-thirds of the $102 \mathrm{~K}$ protein consist of tetratricopeptide repeats, which are protein motifs capable of accommodating several simultaneous protein-protein interactions, it is conceivable that this protein needs a chaperone to avoid unfavourable interactions or aggregation before it is reincorporated into the $20 \mathrm{~S}$ U5 snRNP and then into the 25S U4/U6.U5 tri-snRNP. It will be interesting to see, in future studies, what role the $52 \mathrm{~K}$ protein may play in the dynamic restructuring of U5 snRNP-particles in the context of the nuclear pre-mRNA splicing machinery.

\subsection{The interaction between $\mathrm{U} 5-102 \mathrm{~K}$ and $\mathrm{U} 4 / \mathrm{U} 6-61 \mathrm{~K}$ is critical for the formation of U4/U6.U5 tri-snRNP}

The formation of the U4/U6.U5 tri-snRNP seems to be exclusively proteinmediated, since there is no interaction between the U5 and U4/U6 snRNAs. Previous experiments showed that the $102 \mathrm{~K}$ protein, prepared by in vitro translation, is efficiently co-precipitated with 13S U4/U6 snRNP by antibodies directed against the U4/U6-specific 60K protein (Makarov et al., 2000), and that the $\left[{ }^{35} \mathrm{~S}\right.$-labelled $61 \mathrm{~K}$ protein prepared by in vitro translation binds to purified $20 \mathrm{~S}$ U5 snRNP, as demonstrated by co-immunoprecipitation of $61 \mathrm{~K}$ with U5 snRNP at low salt concentration using anti-Sm (Y12) antibodies (Makarova et al., 2002). This study is the first time that the direct one-to-one protein-protein interactions between the two particles have been identified; the U5 snRNPspecific protein 102K interacts specifically with U4/U6 snRNP-specific proteins $61 \mathrm{~K}$ and $90 \mathrm{~K}$. Additional evidence from different experimental approaches supports the critical role of the $102 \mathrm{~K}-61 \mathrm{~K}$ interaction for tri-snRNP formation (Makarova et al., 2002; Schaffert et al., 2004). First, removal of protein $61 \mathrm{~K}$ from HeLa nuclear extracts by immunodepletion inhibits tri-snRNP formation, subsequent spliceosome assembly, and pre-mRNA splicing. Complementation with recombinant $61 \mathrm{~K}$ protein restores each of these steps. However, the removal of protein $61 \mathrm{~K}$ from nuclear extract does not affect the stability of the accumulating U4/U6 or U5 snRNP particles (Makarova et al., 2002). Second, 
Schaffert et al. (2004) demonstrated that, after knockdown of the U4/U6-specific $61 \mathrm{~K}$ or the U5-specific $102 \mathrm{~K}$ protein in HeLa cells using RNA interference, trisnRNP formation is inhibited and stable U5 snRNP and U4/U6 snRNP containing U4/U6 proteins and the U4/U6 recycling factor p110 accumulate. Thus, both U5-102K and U4/U6-61K are essential for the interaction between U5 snRNP and U4/U6 snRNP in vivo.

\subsection{The recruitment of tri-snRNP to the pre-spliceosome}

The final step in the formation of the mature spliceosome is the binding of the U4/U6.U5 tri-snRNP to the pre-spliceosome (complex A), leading to the complete spliceosome (complex B). The data from this study have confirmed that several tri-snRNP proteins are involved in this step.

\subsubsection{The C-terminal region of tri-snRNP-110K is required for anchoring protein $110 \mathrm{~K}$ to the tri-snRNP while the $\mathrm{N}$-terminal RS domain potentially mediates the association with the pre-spliceosome}

Unlike $102 \mathrm{~K}$ and $61 \mathrm{~K}$ proteins, the tri-snRNP specific protein $110 \mathrm{~K}$, like the trisnRNP specific 65K protein, is not required for tri-snRNP stability (Makarova et al., 2001). While Snu66p is not an essential protein in yeast (Stevens et al. 2001 ), proteins $110 \mathrm{~K}$ and $65 \mathrm{~K}$ are required for joining the human tri-snRNP to the pre-spliceosomal complex A. I was able to identify interactions of the $110 \mathrm{~K}$ protein (hSnu66) with specific U4/U6- and U5-snRNP proteins, namely the $90 \mathrm{~K}$ and the $102 \mathrm{~K}, 200 \mathrm{~K}$ proteins through the C-terminal region lacking RS domain. Since the absence of $110 \mathrm{~K}$ protein does not compromise the stability of the trisnRNP, it appears reasonable that anchoring $110 \mathrm{~K}$ to these proteins is required to position protein $110 \mathrm{~K}$ properly for its contribution in connecting the tri-snRNP to the A-complex. For all three tri-snRNP specific proteins, $110 \mathrm{~K}, 65 \mathrm{~K}$ and the $27 \mathrm{~K}$, this interaction is probably mediated through $\mathrm{N}$-terminal $\mathrm{RS}$ domains (Makarova et al., 2001; Fetzer et al., 1997). It has been shown that RS domains function by directly interacting with the RS domains of other splicing factors. For example, the interaction between SR protein SF2/ASF and the SR-related protein $\mathrm{U} 1-70 \mathrm{~K}$ is mediated by their RS domains, which facilitating recruitment of U1 snRNP to the pre-mRNA substrate (Kohtz et al., 1994). This observation suggests that the interactions between SR proteins and one or more of the tri- 
snRNP SR-related proteins may well contribute to the stable association of the U4/U6.U5 tri-snRNP complex with the pre-spliceosome. Consistently with this, indirect evidence has been provided previously that the SR proteins are necessary to recruit the tri-snRNP to the spliceosome (Roscigno and GarciaBlanco, 1995). However, there was no interaction for $65 \mathrm{~K}$ and $27 \mathrm{~K}$ identified in two-hybrid assay. This might due to the folding problems or lack of a necessary post-translational modification.

\subsubsection{The N-terminal region of U4/U6-90K is essential for the binding of U2- SPF30/SMNrp required for the formation of the mature spliceosome}

The in vivo two-hybrid assay (this study) and in vitro binding assay (Meister et al., 2001) both point to a direct interaction between U4/U6-90K and the U2 snRNP-associated protein SPF30/SMNrp (figure 4.19). Mutational analysis further showed that the $90 \mathrm{~K} \mathrm{~N}$-terminal region, comprising amino acids 1 to 442 , participates efficiently in the interaction. This region contains a conserved PWI motif at its $\mathrm{N}$ terminus (amino acids 3 to 76 ). The presence of PWI motifs in known splicing factors suggests that it may be important for numerous interactions within splicing complexes (Szymczyna et al., 2003; Blencowe and Ouzounis, 1999). However, it seems not to be required for, or at least not efficient in, the binding of protein $90 \mathrm{~K}$, since the shorter $\mathrm{N}$-terminal fragment (amino acids 1-194) containing the PWI domain does not bind to the 90K. The 90K-SPF30/SMNrp interaction appears to be an important link between trisnRNP and pre-spliceosomal A-complex, in addition to the RS-domain interactions of the tri-snRNP-specific proteins. The presence of SPF30/SMNrp in the $B \Delta U 1$ complex, but its absence in the activated spliceosome of the $B^{*}$ complex, lends support to the idea of the 90K-SPF30/SMNrp interaction being an important temporary link to build a spliceosome of increasing molecular complexity (Makarov et al., 2002; Makarova et al., 2004). Removal of SPF30/SMNrp from nuclear extract by immunodepletion inhibits the first step of pre-mRNA splicing by preventing the formation of mature spliceosome (complex B). Re-addition of recombinant SPF30/SMNrp to the immunodepleted extract reconstitutes both spliceosome formation and splicing (Meister et al., 2001; Rappsilber et al., 2001). It is interesting to identify the U2 snRNP protein(s) to which SPF30/SMNrp binds, and to characterize the domains involved in the 
event. Detailed knowledge about the conditions and the temporal order of these interactions will be required in order to clarify whether SPF30/SMNrp acts as a bridging factor between the two snRNPs, or whether it actively induces a structural rearrangement required for their stable association.

Since there is no known yeast orthologue of the human SPF30/SMNrp, and the yeast homologue proteins Snu66p (110K in human) and Sad1p (65K) lack RS domains, yeast probably uses a different mechanism to establish a connection between the tri-snRNP and the A complex. Experiments with ts mutants of yeast Prp31p, which is not required for tri-snRNP stability, were interpreted by assuming that in yeast Prp31p connects the tri-snRNP to complex $A$ (Weidenhammer et al., 1997).

\subsection{The link between the C-terminal region of U4/U6-90K and the TPR domain of U6-p110 is necessary for the recycling of U4/U6 snRNPs}

After each spliceosome cycle, the U4 and U6 snRNAs are released separately and are recycled to the functional U4/U6 snRNP, requiring in the mammalian system the U6-specific RNA-binding protein p110 (SART3). p110 contains in its C-terminal region two RNA recognition motifs (RRMs), and an extensive Nterminal TPR domain which is absent in the yeast orthologue protein Prp24p (figure 5.2).

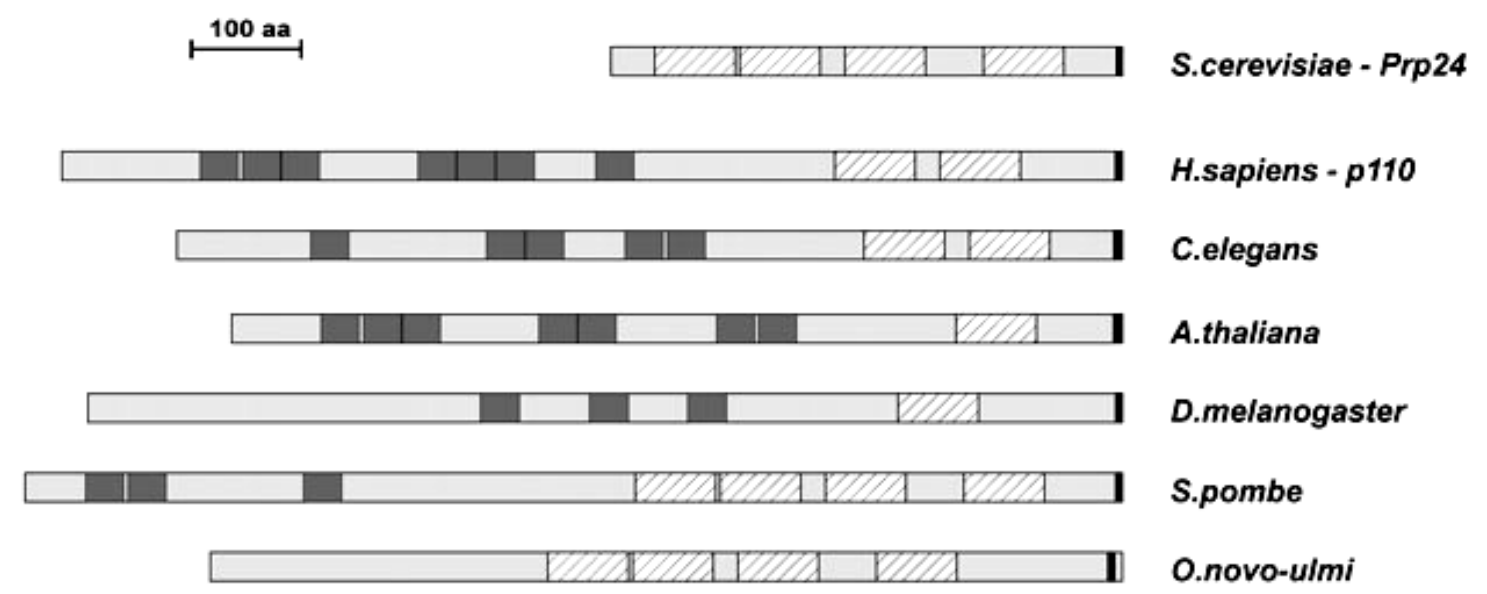

Figure 5.2. Domain structure of the S. cerevisiae Prp24 protein, human p110 and related proteins from other species. The proteins are aligned relative to their C-termini. The RRM (striped boxes) and TPR (HAT) motifs (in dark grey) as well as the short Cterminal region (in black) are indicated. Adapted from Bell et al., 2002. 
TPR protein-protein interaction domain in $\mathrm{p} 110$ belong to the same subfamily of U5-102K, thus indicating that this protein may function by interacting with other splicing factors, probably the U4/U6 snRNP proteins. Indeed, two-hybrid screening with $\mathrm{p} 110$ allowed the identification of an interacting partner of protein $90 \mathrm{~K}$ out of the five U4/U6-specific proteins. The specificity of the interaction was confirmed by an in vitro binding assay. Mutational analysis further showed that the N-terminal TPR domain, or the set of three $\mathrm{N}$-terminal TPR motifs alone, appears to be sufficient for $90 \mathrm{~K}$ protein binding. As no other protein motifs are predicted in this $\mathrm{N}$-terminal part of $\mathrm{p} 110$, the results strongly suggest that the TPR motifs mediate the specific interaction with the 90K protein. There seems to be some redundancy in the interaction, since the number of TPR motifs varies at least between three and seven in the known orthologues (figure 5.2). These domain structure data would also be consistent with the finding that the three $\mathrm{N}$-terminal TPR motifs present in the splice variant AF 387506 appear to suffice for interaction with the $90 \mathrm{~K}$ protein (figure $4.18 \mathrm{~A}$ ). The latter finding raises the interesting question as to whether the splicing variant (i.e. AF 387506) may act as a negative regulator of $\mathrm{p} 110$ function, competing for the $90 \mathrm{~K}$ protein interaction but lacking the RNA binding and recycling functions. Alternatively, p110 may associate some other unknown proteins through its additional TPR repeats for other functions.

In the $90 \mathrm{~K}$ protein, the C-terminal region (amino acids $417-683$ ) suffices for the p110 interaction (figure 4.18B). This region provides a novel bridge between the U6 snRNA-bound p110 and the U4/U6-specific protein components and most probably plays an important role in U4/U6 snRNP assembly. It is notable that the $90 \mathrm{~K}$ protein - within the $20 \mathrm{~K} / 60 \mathrm{~K} / 90 \mathrm{~K}$ complex - is in contact with the U6 snRNA in the stem II region (Nottrott et al., 2002), and this event may stabilize the newly formed U4/U6 base-paired structure.

These data, along with the other data from the co-operating laboratory of Prof. Bindereif, were published recently in the journal of Molecular and Cellular Biology (Medenbach et al., 2004). In this paper, it was further shown that the two RRM domains at the $C$ terminus are required for U6 snRNA binding, while the N-terminal TPR domain is not. Moreover, the in vitro 
depletion/complementation experiments showed that both the $\mathrm{N}$-terminal TPR domain and the C-terminal RRMs are required for the U4/U6 snRNP recycling activity. This can explained by the observations that the TPR domain is required for the binding of U4/U6-90K, and that the RRMs domain is essential for the U6 snRNA binding.

How do these findings fit to the model of the U4/U6 snRNP assembly pathway? In contrast to the yeast protein, the mammalian p110 protein carries only two RRMs homologous to the highly conserved second and third RRMs of Prp24p. As proposed by others (Rader and Guthrie, 2002), the additional RRMs of Prp24p, 1 and 4, may recognize U4 snRNA and thereby promote the U4/U6 interaction. Perhaps this U4 interaction has shifted from an RNA-protein interaction (such as in yeast Prp24 RRMs 1 and 4 with the U4 snRNA) in the mammalian and other systems to a protein-protein interaction (p110 TPR domain with the $90 \mathrm{~K}$ protein).

The recycling factor $\mathrm{p} 110$ is associated with human U6 and U4/U6 snRNPs, but it dissociates after the formation of tri-snRNP. What makes p110 leave the reassembled U4/U6 snRNP? Most probably, this signal is provided by the association with U5 snRNP, which results in U4/U6.U5 tri-snRNP formation. The data from this study suggest that U5-102K may play a role in the release of p110. Protein $102 \mathrm{~K}$ is the only U5-specific protein that interacts with U4/U6snRNPs, namely protein $61 \mathrm{~K}$ and $90 \mathrm{~K}$ (section 4.4 ). As discussed in section 5.3 , the interaction between $\mathrm{U} 5-102 \mathrm{~K}$ and $\mathrm{U} 4 / \mathrm{U} 6-61 \mathrm{~K}$ is critical for the formation of tri-snRNP. The interaction between U5-102K and U4/U6-90K may play a similar role. However, it is also possible that $\mathrm{U} 5-102 \mathrm{~K}$ binds $90 \mathrm{~K}$ and its function is to replace the $\mathrm{p} 110$. This suggestion is supported by the fact that both proteins bind to the same region in $90 \mathrm{~K}$ (amino acids 417-683) through the same domain structure of TPR motifs (see figure 5.1). Note that the yeast Prp6p (102K in human) behaves as a genuine U4/U6 snRNP protein (Stevens et al., 2001) and not as a U5 snRNP protein such as protein $102 \mathrm{~K}$. 


\subsection{The role of tri-snRNP splicing factors in retinitis pigmentosa}

Retinitis pigmentosa (RP) is a genetic disease characterized by progressive degeneration of the peripheral retina leading to night blindness and loss of visual fields. RP can be inherited in autosomal dominant, autosomal recessive, $X$-linked, mitochondrial and genetically more complex modes. To date, more than 30 genes have been found to be implicated in this disease. Recently, mutations in $61 \mathrm{~K}, 90 \mathrm{~K}$ and $220 \mathrm{~K}$, the respective gene expression products of PRPF31, PRPF3, and PRPF8, have been associated with autosomal dominant retinitis pigmentosa (adRP) (McKie et al., 2001; Withana et al., 2001; Chakarova et al., 2002). Given the overwhelming evidence, there is no doubt that mutations within these splicing factors result in RP; however, why ubiquitously expressed genes with such an apparently crucial function only cause a disease of the photoreceptors is still largely a mystery.

Results from initial functional studies on $61 \mathrm{~K}$ protein have provided some clues to the effects of its mutations in vivo (Deery et al., 2002). An in vivo assay of splicing function in human cells using a bovine rod opsin splicing template did not detect any defect in splicing efficiency or accuracy attributable to either protein $61 \mathrm{~K}$ mutation (A194E or A216P), suggesting that there is no dominant negative effect on the wild-type protein and that the pathology more probably arises from other causes as indicated by other experiments. Analysis in cell culture has offered some evidence of reduced protein solubility in those $61 \mathrm{~K}$ proteins that incorporate missense mutations. If this observation holds true under the physiological conditions of the photoreceptors, it might result in insoluble protein aggregates accumulating over time, eventually causing apoptosis. Alternatively, some of the experimental data suggest that the lack of solubility might result in less protein being transported from the cytosol to its site of action in the nucleus. The authors therefore suggested that the reduction in concentration of functional $61 \mathrm{~K}$ protein in the nucleus could lead to an insufficiency of splicing function. Photoreceptors shed their outer segments discs, where rhodopsin resides, on a daily basis and, therefore, require sufficient levels of rhodopsin transcript to replace the protein continually. Such transcripts obviously require splicing before translation. Rather than mutations in $61 \mathrm{~K}$ causing a dominant-negative effect, the disease phenotype might be 
related to thresholds in the levels of splicing. In other words, the photoreceptors of patients might survive until the level of splicing of rhodopsin, or other mRNAs, drops below a crucial level, at which point the cell would be irrevocably damaged, eventually leading to apoptosis. In support of this theory, families with $61 \mathrm{~K}$ mutations exhibit an 'all or none' mode of incomplete penetration.

$\mathrm{Y} 2 \mathrm{H}$ assay in this study showed that the yeast strain $\mathrm{AH} 109$ co-transformed with pGADT7-102K and pGBKT7-61K-A194E appears to grow when incubated on the selective medium lacking histidine and adenine at $30^{\circ} \mathrm{C}$ for more than two days. However, the strain grows much more slowly than the cells co-transformed with $102 \mathrm{~K}$ and $61 \mathrm{~K}$ wild-type or A216P. This indicates that the A194E mutant has a significant but relatively mild effect on the interaction between $102 \mathrm{~K}$ and $61 \mathrm{~K}$. Consequently, this may reduce the formation of the functional U4/U6.U5 tri-snRNP that would lead to a lower the rate of splicing in the cell. This could result in the disease as proposed above by Deery et al. The weak interaction between protein $61 \mathrm{~K}$ and $102 \mathrm{~K}$ might be due to the lower solubility of the mutant protein as observed by Deery et al. However, the A216P mutant appears to have no such effect on the protein interaction, although one cannot exclude the possibility that it may reduce the binding to the U4 snRNA.

A similar explanation can be used for the observation of $220 \mathrm{~K}$ mutants, since some $220 \mathrm{~K}$ mutations such as R2310G, R2310K and F2314L display a weak interaction with protein $116 \mathrm{~K}$ and $220 \mathrm{~K}$. Interestingly, the work from Beggs' group (Grainger et al., 2003) has revealed that, in yeast, Prp8-RP13 mutations affect the interaction between Prp8p and Brr2p. 


\subsection{The model of the human U4/U6.U5 tri-snRNP assembly}

Based on currently available data, figure 5.3 presents the model of the assembly and the structural organisation of human tri-snRNP. In the U5 snRNP particle, three large proteins $220 \mathrm{~K}, 200 \mathrm{~K}$ and $116 \mathrm{~K}$ associate with one another to form a basic protein-protein network for the subsequent assembly steps. The proteins $40 \mathrm{~K}$ and $102 \mathrm{~K}$ join this network by connecting with $220 \mathrm{~K}$ (for $40 \mathrm{~K}$ ) or all the three proteins (for $102 \mathrm{~K}$ ). Protein $52 \mathrm{~K}$ and $15 \mathrm{~K}$ follow by binding to protein $102 \mathrm{~K}$. U 5 snRNA binds to the protein component, probably to proteins $220 \mathrm{~K}$ and $116 \mathrm{~K}$ (Dix et al., 1998). For the U4/U6-snRNP particle, a hierarchical assembly has been proposed previously (Nottrott et al., 2002) and is confirmed and discussed in this work (see section 5.1 for details). This study and others further showed that, at least under recycling conditions, protein p110 is required for the formation of U4/U6 snRNP (Bell et al., 2002; Medenbach et al., 2004). For this function, U6-p110 interacts with U4/U6-90K through the TPR domain and with U6 snRNA through the RRM motifs (see section 5.5 for details). During the assembly of the U4/U6.U5 tri-snRNP, the U5-102K protein binds to the U4/U6specific proteins $61 \mathrm{~K}$ and $90 \mathrm{~K}$ and thus makes a connection between the U4/U6 and U5 snRNPs. In the meantime, the tri-snRNP-specific $110 \mathrm{~K}$ protein (probably also $65 \mathrm{~K}$ and $27 \mathrm{~K}$, which are not shown in this model) joins by binding to U5$102 \mathrm{~K}, 200 \mathrm{~K}$ and U4/U6-90K. These interactions promote the dissociation of U552K from U5-snRNP and U6-p110 from U4/U6-snRNP, resulting in the U4/U6.U5 tri-snRNP. The final step in the formation of the mature spliceosome (complex $B$ ) is the recruitment of the pre-assembled U4/U6.U5 tri-snRNPs to the pre-spliceosome (complex A). In this work, I confirmed that the U4/U6-90K mediates the process through interacting with U2-SPF30/SMNrp. 


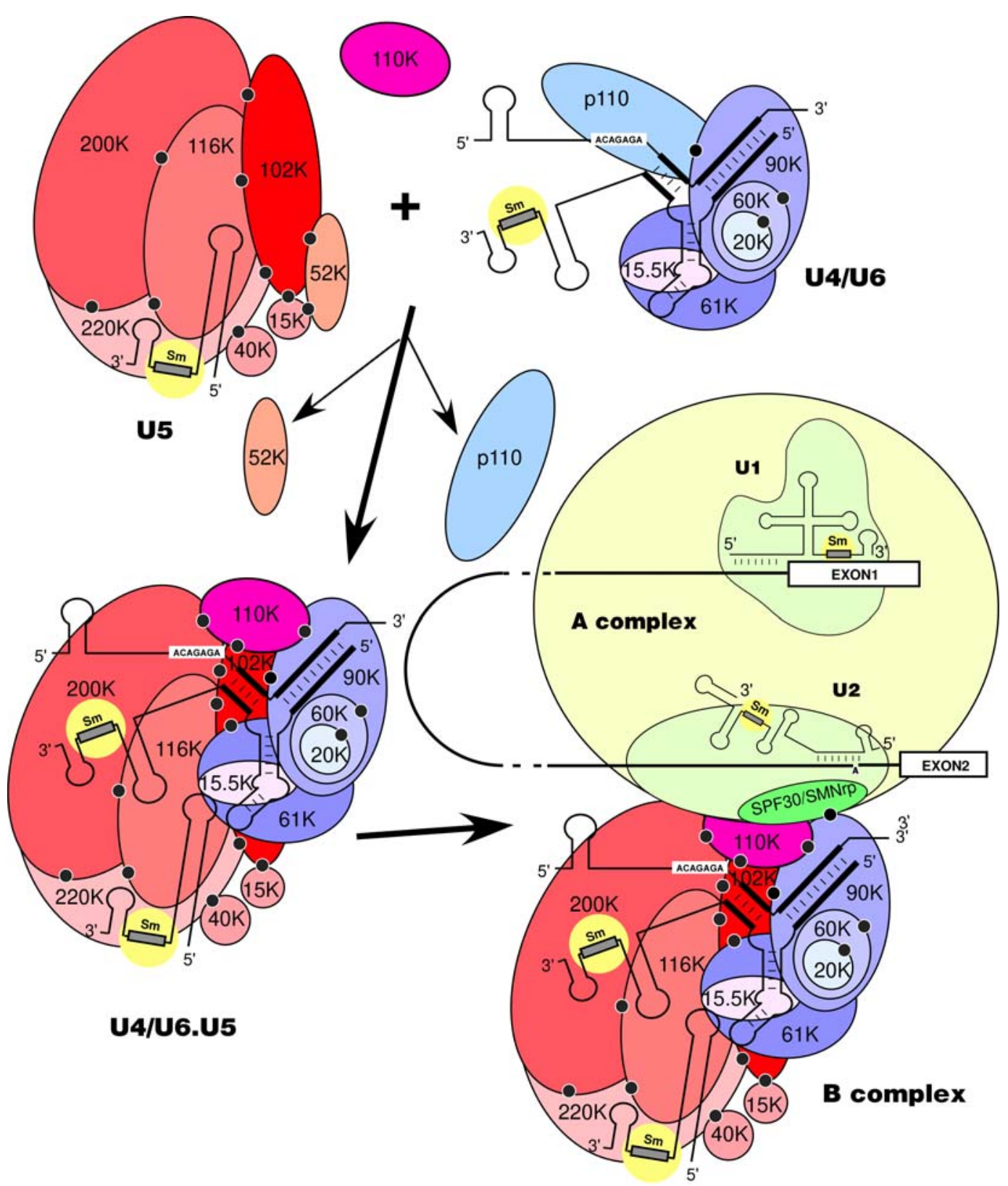

Figure 5.3. Model of the structural organisation and the assembly of human U4/U6.U5 tri-snRNP. The black spots denote the direct protein-protein interactions identified in this study. 


\subsection{Outlook}

The protein-protein interaction data obtained in this work provide a basic knowledge on which further studies of the three-dimensional structure of the U4/U6, U5, and U4/U6.U5 snRNP particles by methods such as X-ray crystallography will be able to build. One example is the study of the U5-52K GYF domain in complex with U5-15K in the cooperation with the laboratory of Prof. R. Ficner at the University of Göttingen (figure 4.16). The crystallography study of the U4/U6 snRNP particle will answer the question of whether the $15.5 \mathrm{~K}$ protein associates with $61 \mathrm{~K}$ and $20 \mathrm{~K} \cdot 60 \mathrm{~K} \cdot 90 \mathrm{~K}$ heterotrimer in the presence of U4/U6 snRNA and how this protein promotes the assembly of the U4/U6 snRNP.

As demonstrated in this work, the U5-102K and U6-p110 interact with the same region of U4/U6-90K, suggesting that the U5-102K interacts with $90 \mathrm{~K}$ to replace the U6-p110. If this is true, the addition of the recombinant U5-102K protein to the nuclear extract under recycling conditions will probably inhibit the function of p110 in the recycling of the U4/U6 snRNPs and thus the splicing of pre-mRNA. The interaction between U5-102K and U4/U6-61K is critical for the formation of the U4/U6.U5 tri-snRNP (section 5.3). One of the 61K mutants (A194E) - one that contributes to the autosomal dominant retinitis pigmentosa - displays reduced interaction with 102K (figure 4.20). Recent work has demonstrated that, after knockdown of the U4/U6-61K protein in HeLa cells using RNAi, tri-snRNP formation is inhibited (Schaffert et al., 2004). Therefore, I and my colleagues in the laboratory of Prof. Lührmann are working on the question of whether overexpression of the wild-type protein $61 \mathrm{~K}$ or its mutants can restore the formation of tri-snRNP in HeLa cells lacking 61K.

The U4/U6-90K protein is involved in the assembly/reassembly of U4/U6 snRNP, the formation of tri-snRNP and the recruitment of tri-snRNP to the pre-spliceosome. Therefore, it will be interesting to see how the spliceosome assembles after the depletion/complementation of the full-length or truncated $90 \mathrm{~K}$ protein. 
The $52 \mathrm{~K}$ protein is the only U5-specific protein that is not integrated into the trisnRNP. Therefore, an attractive idea would be to purify the U5 snRNP particle by immunoaffinity selection using anti-52K antibodies and to analyse the protein component by mass spectrometry. This may yield purified U5 snRNP for the subsequent structural and functional studies. 


\section{Acknowledgments}

First of all, I would like to thank Professor Reinhard Lührmann for giving me the opportunity to work in his laboratory, for providing excellent experimental facilities, for his support and consideration.

I would like to thank Hans-Peter Vornlocher for all his help in the first two years of my work, for giving me an excellent introduction into the exciting field of the yeast two-hybrid system.

I am grateful to Paul Woolley for checking the English of this dissertation and for his valuable suggestions and timely help.

I should like to express my appreciation to the University of Göttingen for accepting me as a PhD student. I wish to express my gratitude to the following professors for agreeing to be members of my examination committee: Prof. Ralf Ficner, Prof. Hans-Joachim Fritz, Prof. Dietrich Gradmann, PD Dr. Stefan Irniger, Prof. Oliver Einsle and Prof. Ernst A. Wimmer. I would like to give my special thanks to my referee Prof. Ficner for his advice and help during my study.

I wish to express my thanks to Hans-Peter Vornlocher, Patrizia Fabrizio, Evgeny Makarov, Olga Makarova, Stephanie Nottrott, Tilmann Achsel, Dierk Ingelfinger for providing me with original cDNA cloning; to Juliane Moses for her helpful work; to Christian Merz and Irene Öchsner for their help in lab 114; to Marion Killian, Gabi Heyne and Dagmar Meyer for the sequencing runs; to Klaus Hartmut, Berthold Kastner and the IT team for solving computer-related problems; to Reinhard Rauhut for the useful bio-information.

I would like to thank all the past and present members in the laboratory of Prof. Lührmann for their help and kindness. 
I would like to thank Markus Wahl for his special interest, and also to his previous and present group members Thomas Conrad, Simon Trowitzsch, Gert Weber, Mihaela Diaconu, Nina Müllers, Catharina Netter, Elke Penka, Ulrich Reidt and Li-chi Chang for the warm and friendly working atmosphere.

I would also like to thank all my friends in the church for their support and prayer.

Lastly, I address my very special thanks to my wife Yan for her support and her love; thanks also to my mother-in-law and my grandmother-in-law for helping my wife to take care of my newborn son Joseph while I was writing this dissertation. 


\section{References}

A

Abovich, N., Legrain, P. and Rosbash, M. (1990) The yeast PRP6 gene encodes a U4/U6 small nuclear ribonucleoprotein particle (snRNP) protein, and the PRP9 gene encodes a protein required for U2 snRNP binding. Mol Cell Biol, 10, 6417-6425.

Achsel, T., Ahrens, K., Brahms, H., Teigelkamp, S. and Lührmann, R. (1998) The human U5-220kD protein (hPrp8) forms a stable RNA-free complex with several U5-specific proteins, including an RNA unwindase, a homologue of ribosomal elongation factor EF-2, and a novel WD-40 protein. Mol Cell Biol, 18, 6756-6766.

Anthony, J.G., Weidenhammer, E.M. and Woolford, J.L., Jr. (1997) The yeast Prp3 protein is a U4/U6 snRNP protein necessary for integrity of the U4/U6 snRNP and the U4/U6.U5 tri-snRNP. RNA, 3, 1143-1152.

Awasthi, S., Palmer, R., Castro, M., Mobarak, C.D. and Ruby, S.W. (2001) New roles for the Snp1 and Exo84 proteins in yeast pre-mRNA splicing. J Biol Chem, 276, 31004-31015.

Ayadi, L., Callebaut, I., Saguez, C., Villa, T., Mornon, J.P. and Banroques, J. (1998) Functional and structural characterization of the prp3 binding domain of the yeast prp4 splicing factor. J Mol Biol, 284, 673-687.

Ayadi, L., Miller, M. and Banroques, J. (1997) Mutations within the yeast U4/U6 snRNP protein Prp4 affect a late stage of spliceosome assembly. RNA, 3, 197209.

B

Bach, M. and Lührmann, R. (1991) Protein-RNA interactions in 20 S U5 snRNPs. Biochim Biophys Acta, 1088, 139-143.

Bach, M., Winkelmann, G. and Lührmann, R. (1989) 20 S small nuclear ribonucleoprotein U5 shows a surprisingly complex protein composition. Proc Natl Acad Sci U S A, 86, 6038-6042.

Banroques, J. and Abelson, J.N. (1989) PRP4: a protein of the yeast U4/U6 small nuclear ribonucleoprotein particle. Mol Cell Biol, 9, 3710-3719.

Bartels, C., Klatt, C., Lührmann, R. and Fabrizio, P. (2002) The ribosomal translocase homologue Snu114p is involved in unwinding U4/U6 RNA during activation of the spliceosome. EMBO Rep, 3, 875-880.

Bartels, C., Urlaub, H., Lührmann, R. and Fabrizio, P. (2003) Mutagenesis suggests several roles of Snu114p in pre-mRNA splicing. J Biol Chem, 278, 28324-28334. 
Behrens, S.E. and Lührmann, R. (1991) Immunoaffinity purification of a [U4/U6.U5] tri-snRNP from human cells. Genes Dev, 5, 1439-1452.

Bell, M., Schreiner, S., Damianov, A., Reddy, R. and Bindereif, A. (2002) p110, a novel human U6 snRNP protein and U4/U6 snRNP recycling factor. EMBO J, 21, 2724-2735.

Bialkowska, A. and Kurlandzka, A. (2002) Proteins interacting with Lin 1p, a putative link between chromosome segregation, mRNA splicing and DNA replication in Saccharomyces cerevisiae. Yeast, 19, 1323-1333.

Bjorn, S.P., Soltyk, A., Beggs, J.D. and Friesen, J.D. (1989) PRP4 (RNA4) from Saccharomyces cerevisiae: its gene product is associated with the U4/U6 small nuclear ribonucleoprotein particle. Mol Cell Biol, 9, 3698-3709.

Black, D.L. and Pinto, A.L. (1989) U5 small nuclear ribonucleoprotein: RNA structure analysis and ATP-dependent interaction with U4/U6. Mol Cell Biol, 9, 3350-3359.

Blatch, G.L. and Lassle, M. (1999) The tetratricopeptide repeat: a structural motif mediating protein-protein interactions. Bioessays, 21, 932-939.

Blencowe, B.J. and Ouzounis, C.A. (1999) The PWI motif: a new protein domain in splicing factors. Trends Biochem Sci, 24, 179-180.

Boelens, W.C., Palacios, I. and Mattaj, I.W. (1995) Nuclear retention of RNA as a mechanism for localization. RNA, 1, 273-283.

Branlant, C., Krol, A., Ebel, J.P., Lazar, E., Haendler, B. and Jacob, M. (1982) U2 RNA shares a structural domain with U1, U4, and U5 RNAs. EMBO J, 1, 1259-1265.

Brosi, R., Hauri, H.P. and Kramer, A. (1993) Separation of splicing factor SF3 into two components and purification of SF3a activity. J Biol Chem, 268, 1764017646.

Brow, D.A. (2002) Allosteric cascade of spliceosome activation. Annu Rev Genet, 36, 333-360.

Burge, C.B., Tuschl, T. and Sharp, P.A. (1999) Splicing of Precursors to mRNAs by the Spliceosomes. In Gesteland, Cech and Atkins (eds.) The RNA world. Cold Spring Harbor Laboratory Press, New York, pp. 525-560.

C

Caspary, F. and Seraphin, B. (1998) The yeast U2A'/U2B complex is required for pre-spliceosome formation. EMBO J, 17, 6348-6358.

Caspary, F., Shevchenko, A., Wilm, M. and Seraphin, B. (1999) Partial purification of the yeast U2 snRNP reveals a novel yeast pre-mRNA splicing factor required for pre-spliceosome assembly. EMBO J, 18, 3463-3474. 
Cech, T.R. (1990a) Nobel lecture. Self-splicing and enzymatic activity of an intervening sequence RNA from Tetrahymena. Biosci Rep, 10, 239-261.

Cech, T.R. (1990b) Self-splicing of group I introns. Annu Rev Biochem, 59, 543568.

Chakarova, C.F., Hims, M.M., Bolz, H., Abu-Safieh, L., Patel, R.J., Papaioannou, M.G., Inglehearn, C.F., Keen, T.J., Willis, C., Moore, A.T., Rosenberg, T., Webster, A.R., Bird, A.C., Gal, A., Hunt, D., Vithana, E.N. and Bhattacharya, S.S. (2002) Mutations in HPRP3, a third member of pre-mRNA splicing factor genes, implicated in autosomal dominant retinitis pigmentosa. Hum Mol Genet, 11, 87-92.

Chen, J.Y., Stands, L., Staley, J.P., Jackups, R.R., Jr., Latus, L.J. and Chang, T.H. (2001) Specific alterations of U1-C protein or U1 small nuclear RNA can eliminate the requirement of Prp28p, an essential DEAD box splicing factor. Mol Cell, 7, 227-232.

Cheng, S.C. and Abelson, J. (1987) Spliceosome assembly in yeast. Genes Dev, 1, 1014-1027.

Chung, S., McLean, M.R. and Rymond, B.C. (1999) Yeast ortholog of the Drosophila crooked neck protein promotes spliceosome assembly through stable U4/U6.U5 snRNP addition. RNA, 5, 1042-1054.

Collins, C.A. and Guthrie, C. (1999) Allele-specific genetic interactions between Prp8 and RNA active site residues suggest a function for Prp8 at the catalytic core of the spliceosome. Genes Dev, 13, 1970-1982.

Collins, C.A. and Guthrie, C. (2000) The question remains: is the spliceosome a ribozyme? Nat Struct Biol, 7, 850-854.

Cooper, M., Johnston, L.H. and Beggs, J.D. (1995) Identification and characterization of Uss1p (Sdb23p): a novel U6 snRNA-associated protein with significant similarity to core proteins of small nuclear ribonucleoproteins. EMBO J, 14, 2066-2075.

\section{D}

Dahlberg, J.E. and Lund, E. (1991) How does III x II make U6? Science, 254, 1462-1463.

Das, B.K., Xia, L., Palandjian, L., Gozani, O., Chyung, Y. and Reed, R. (1999) Characterization of a protein complex containing spliceosomal proteins SAPs 49, 130, 145, and 155. Mol Cell Biol, 19, 6796-6802.

Deery, E.C., Vithana, E.N., Newbold, R.J., Gallon, V.A., Bhattacharya, S.S., Warren, M.J., Hunt, D.M. and Wilkie, S.E. (2002) Disease mechanism for retinitis pigmentosa (RP11) caused by mutations in the splicing factor gene PRPF31. Hum Mol Genet, 11, 3209-3219. 
Dix, I., Russell, C.S., O'Keefe, R.T., Newman, A.J. and Beggs, J.D. (1998) Protein-RNA interactions in the U5 snRNP of Saccharomyces cerevisiae. RNA, 4, 1675-1686.

Dziembowski, A., Ventura, A.P., Rutz, B., Caspary, F., Faux, C., Halgand, F., Laprevote, O. and Seraphin, B. (2004) Proteomic analysis identifies a new complex required for nuclear pre-mRNA retention and splicing. EMBO J, 23, 4847-4856.

E

Edwalds-Gilbert, G., Kim, D.H., Silverman, E. and Lin, R.J. (2004) Definition of a spliceosome interaction domain in yeast Prp2 ATPase. RNA, 10, 210-220.

$\mathbf{F}$

Fabrizio, P., Esser, S., Kastner, B. and Lührmann, R. (1994) Isolation of S. cerevisiae snRNPs: comparison of $\mathrm{U} 1$ and U4/U6.U5 to their human counterparts. Science, 264, 261-265.

Fabrizio, P., Laggerbauer, B., Lauber, J., Lane, W.S. and Lührmann, R. (1997) An evolutionarily conserved U5 snRNP-specific protein is a GTP-binding factor closely related to the ribosomal translocase EF-2. EMBO J, 16, 4092-4106.

Fetzer, S., Lauber, J., Will, C.L. and Lührmann, R. (1997) The [U4/U6.U5] trisnRNP-specific $27 \mathrm{~K}$ protein is a novel SR protein that can be phosphorylated by the snRNP-associated protein kinase. RNA, 3, 344-355.

Fields, S. and Song, O. (1989) A novel genetic system to detect protein-protein interactions. Nature, 340, 245-246.

Fischer, U. and Lührmann, R. (1990) An essential signaling role for the m3G cap in the transport of U1 snRNP to the nucleus. Science, 249, 786-790.

Freund, C., Dotsch, V., Nishizawa, K., Reinherz, E.L. and Wagner, G. (1999) The GYF domain is a novel structural fold that is involved in lymphoid signaling through proline-rich sequences. Nat Struct Biol, 6, 656-660.

Freund, C., Kuhne, R., Park, S., Thiemke, K., Reinherz, E.L. and Wagner, G. (2003) Structural investigations of a GYF domain covalently linked to a prolinerich peptide. J Biomol NMR, 27, 143-149.

Freund, C., Kuhne, R., Yang, H., Park, S., Reinherz, E.L. and Wagner, G. (2002) Dynamic interaction of $\mathrm{CD} 2$ with the GYF and the $\mathrm{SH} 3$ domain of compartmentalized effector molecules. EMBO J, 21, 5985-5995.

Fribourg, S., Gatfield, D., Izaurralde, E. and Conti, E. (2003) A novel mode of RBD-protein recognition in the Y14-Mago complex. Nat Struct Biol, 10, 433-439. 
Fromont-Racine, M., Rain, J.C. and Legrain, P. (1997) Toward a functional analysis of the yeast genome through exhaustive two-hybrid screens. Nat Genet, 16, 277-282.

\section{G}

Galisson, F. and Legrain, P. (1993) The biochemical defects of prp4-1 and prp6-1 yeast splicing mutants reveal that the PRP6 protein is required for the accumulation of the [U4/U6.U5] tri-snRNP. Nucleic Acids Res, 21, 1555-1562.

Gautier, T., Berges, T., Tollervey, D. and Hurt, E. (1997) Nucleolar KKE/D repeat proteins Nop56p and Nop58p interact with Nop1p and are required for ribosome biogenesis. Mol Cell Biol, 17, 7088-7098.

Gonzalez-Santos, J.M., Wang, A., Jones, J., Ushida, C., Liu, J. and $\mathrm{Hu}$, J. (2002) Central region of the human splicing factor Hprp3p interacts with Hprp4p. J Biol Chem, 277, 23764-23772.

Gottschalk, A., Neubauer, G., Banroques, J., Mann, M., Lührmann, R. and Fabrizio, P. (1999) Identification by mass spectrometry and functional analysis of novel proteins of the yeast [U4/U6.U5] tri-snRNP. EMBO J, 18, 4535-4548.

Gozani, O., Feld, R. and Reed, R. (1996) Evidence that sequence-independent binding of highly conserved U2 snRNP proteins upstream of the branch site is required for assembly of spliceosomal complex A. Genes Dev, 10, 233-243.

Grainger, R.J. and Beggs J.D, (2003) Prp8 and the retinitis pigmentosa mutations in the yeast Saccharromyces cerevisiae. RNA 2003, $8^{\text {th }}$ Annual Meeting of the RNA Society Vienna, Austria, pp357

H

Hall, S.L. and Padgett, R.A. (1996) Requirement of U12 snRNA for in vivo splicing of a minor class of eukaryotic nuclear pre-mRNA introns. Science, 271, 1716-1718.

Hamm, J., Dathan, N.A., Scherly, D. and Mattaj, I.W. (1990) Multiple domains of U1 snRNA, including U1 specific protein binding sites, are required for splicing. EMBO J, 9, 1237-1244.

Hermann, H., Fabrizio, P., Raker, V.A., Foulaki, K., Hornig, H., Brahms, H. and Lührmann, R. (1995) snRNP Sm proteins share two evolutionarily conserved sequence motifs which are involved in Sm protein-protein interactions. EMBO J, 14, 2076-2088.

Horowitz, D.S., Kobayashi, R. and Krainer, A.R. (1997) A new cyclophilin and the human homologues of yeast Prp3 and Prp4 form a complex associated with U4/U6 snRNPs. RNA, 3, 1374-1387.

Horowitz, D.S., Lee, E.J., Mabon, S.A. and Misteli, T. (2002) A cyclophilin functions in pre-mRNA splicing. EMBO J, 21, 470-480. 
I

Igel, H., Wells, S., Perriman, R. and Ares, M., Jr. (1998) Conservation of structure and subunit interactions in yeast homologues of splicing factor $3 \mathrm{~b}$ (SF3b) subunits. RNA, 4, 1-10.

$\mathbf{J}$

Jurica, M.S. and Moore, M.J. (2003) Pre-mRNA splicing: awash in a sea of proteins. Mol Cell, 12, 5-14.

K

Kim, D.H. and Rossi, J.J. (1999) The first ATPase domain of the yeast 246-kDa protein is required for in vivo unwinding of the U4/U6 duplex. RNA, 5, 959-971.

Kofler, M., Heuer, K., Zech, T. and Freund, C. (2004) Recognition sequences for the GYF domain reveal a possible spliceosomal function of CD2BP2. J Biol Chem, 279, 28292-28297.

Kohtz, J.D., Jamison, S.F., Will, C.L., Zuo, P., Lührmann, R., Garcia-Blanco, M.A. and Manley, J.L. (1994) Protein-protein interactions and 5'-splice-site recognition in mammalian mRNA precursors. Nature, 368, 119-124.

Konarska, M.M. and Sharp, P.A. (1986) Electrophoretic separation of complexes involved in the splicing of precursors to mRNAs. Cell, 46, 845-855.

Konarska, M.M. and Sharp, P.A. (1987) Interactions between small nuclear ribonucleoprotein particles in formation of spliceosomes. Cell, 49, 763-774.

Konarska, M.M. and Sharp, P.A. (1988) Association of U2, U4, U5, and U6 small nuclear ribonucleoproteins in a spliceosome-type complex in absence of precursor RNA. Proc Natl Acad Sci U S A, 85, 5459-5462.

Krämer, A., Mulhauser, F., Wersig, C., Groning, K. and Bilbe, G. (1995) Mammalian splicing factor SF3a120 represents a new member of the SURP family of proteins and is homologous to the essential splicing factor PRP21p of Saccharomyces cerevisiae. RNA, 1, 260-272.

Kuhn, A.N. and Brow, D.A. (2000) Suppressors of a cold-sensitive mutation in yeast U4 RNA define five domains in the splicing factor Prp8 that influence spliceosome activation. Genetics, 155, 1667-1682.

Kuhn, A.N., Li, Z. and Brow, D.A. (1999) Splicing factor Prp8 governs U4/U6 RNA unwinding during activation of the spliceosome. Mol Cell, 3, 65-75.

Kuhn, A.N., Reichl, E.M. and Brow, D.A. (2002) Distinct domains of splicing factor Prp8 mediate different aspects of spliceosome activation. Proc Natl Acad Sci U S A, 99, 9145-9149. 
$\mathbf{L}$

Laggerbauer, B., Achsel, T. and Lührmann, R. (1998) The human U5-200kD DEXH-box protein unwinds U4/U6 RNA duplices in vitro. Proc Natl Acad Sci U $S$ A, 95, 4188-4192.

Laggerbauer, B., Liu, S., Makarov, E., Vornlocher, H.P., Makarova, O., Ingelfinger, D., Achsel, T. and Lührmann R. (2005) The human U5 snRNP 52K protein (CD2BP2) interacts with U5-102K (hPrp6), a U4/U6.U5 tri-snRNP bridging protein, but dissociates upon tri-snRNP formation. RNA, 11, 598-608.

Lauber, J., Fabrizio, P., Teigelkamp, S., Lane, W.S., Hartmann, E. and Lührmann, R. (1996) The HeLa 200 kDa U5 snRNP-specific protein and its homologue in Saccharomyces cerevisiae are members of the DEXH-box protein family of putative RNA helicases. EMBO J, 15, 4001-4015.

Lauber, J., Plessel, G., Prehn, S., Will, C.L., Fabrizio, P., Groning, K., Lane, W.S. and Lührmann, R. (1997) The human U4/U6 snRNP contains 60 and $90 \mathrm{kD}$ proteins that are structurally homologous to the yeast splicing factors Prp4p and Prp3p. RNA, 3, 926-941.

Lerner, M.R. and Steitz, J.A. (1979) Antibodies to small nuclear RNAs complexed with proteins are produced by patients with systemic lupus erythematosus. Proc Natl Acad Sci U S A, 76, 5495-5499.

Liu, Y., Li, J., Kim, B.O., Pace, B.S. and He, J.J. (2002) HIV-1 Tat proteinmediated transactivation of the HIV-1 long terminal repeat promoter is potentiated by a novel nuclear Tat-interacting protein of $110 \mathrm{kDa}$, Tip110. J Biol Chem, 277, 23854-23863.

Lührmann, R., Kastner, B. and Bach, M. (1990) Structure of spliceosomal snRNPs and their role in pre-mRNA splicing. Biochim Biophys Acta, 1087, 265292.

Luo, H.R., Moreau, G.A., Levin, N. and Moore, M.J. (1999) The human Prp8 protein is a component of both U2- and U12-dependent spliceosomes. RNA, $\mathbf{5}$, 893-908.

Lustig, A.J., Lin, R.J. and Abelson, J. (1986) The yeast RNA gene products are essential for mRNA splicing in vitro. Cell, 47, 953-963.

M

Makarov, E.M., Makarova, O.V., Achsel, T. and Lührmann, R. (2000) The human homologue of the yeast splicing factor prp6p contains multiple TPR elements and is stably associated with the U5 snRNP via protein-protein interactions. J Mol Biol, 298, 567-575.

Makarov, E.M., Makarova, O.V., Urlaub, H., Gentzel, M., Will, C.L., Wilm, M. and Lührmann, R. (2002) Small nuclear ribonucleoprotein remodeling during catalytic activation of the spliceosome. Science, 298, 2205-2208. 
Makarova, O.V., Makarov, E.M., Liu, S., Vornlocher, H.P. and Lührmann, R. (2002) Protein 61K, encoded by a gene (PRPF31) linked to autosomal dominant retinitis pigmentosa, is required for U4/U6*U5 tri-snRNP formation and pre-mRNA splicing. EMBO J, 21, 1148-1157.

Makarova, O.V., Makarov, E.M. and Lührmann, R. (2001) The 65 and $110 \mathrm{kDa}$ SR-related proteins of the U4/U6.U5 tri-snRNP are essential for the assembly of mature spliceosomes. EMBO J, 20, 2553-2563.

Makarova, O.V., Makarov, E.M., Urlaub, H., Will, C.L., Gentzel, M., Wilm, M. and Lührmann, R. (2004) A subset of human 35S U5 proteins, including Prp19, function prior to catalytic step 1 of splicing. EMBO J, 23, 2381-2391.

Mattaj, I.W. (1986) Cap trimethylation of $U$ snRNA is cytoplasmic and dependent on U snRNP protein binding. Cell, 46, 905-911.

Mattaj, I.W. and De Robertis, E.M. (1985) Nuclear segregation of U2 snRNA requires binding of specific snRNP proteins. Cell, 40, 111-118.

Mattaj, I.W., Habets, W.J. and van Venrooij, W.J. (1986) Monospecific antibodies reveal details of U2 snRNP structure and interaction between U1 and U2 snRNPs. EMBO J, 5, 997-1002.

McKie, A.B., McHale, J.C., Keen, T.J., Tarttelin, E.E., Goliath, R., van LithVerhoeven, J.J., Greenberg, J., Ramesar, R.S., Hoyng, C.B., Cremers, F.P., Mackey, D.A., Bhattacharya, S.S., Bird, A.C., Markham, A.F. and Inglehearn, C.F. (2001) Mutations in the pre-mRNA splicing factor gene PRPC8 in autosomal dominant retinitis pigmentosa (RP13). Hum Mol Genet, 10, 15551562.

McLean, M.R. and Rymond, B.C. (1998) Yeast pre-mRNA splicing requires a pair of U1 snRNP-associated tetratricopeptide repeat proteins. Mol Cell Biol, 18, 353-360.

McPheeters, D.S. and Muhlenkamp, P. (2003) Spatial organization of proteinRNA interactions in the branch site-3' splice site region during pre-mRNA splicing in yeast. Mol Cell Biol, 23, 4174-4186.

Medenbach, J., Schreiner, S., Liu, S., Lührmann, R. and Bindereif, A. (2004) Human U4/U6 snRNP recycling factor $p 110$ : mutational analysis reveals the function of the tetratricopeptide repeat domain in recycling. Mol Cell Biol, 24, 7392-7401.

Meister, G., Hannus, S., Plottner, O., Baars, T., Hartmann, E., Fakan, S., Laggerbauer, B. and Fischer, U. (2001) SMNrp is an essential pre-mRNA splicing factor required for the formation of the mature spliceosome. EMBO J, 20, 2304-2314.

Michel, F. and Jacquier, A. (1987) Long-range intron-exon and intron-intron pairings involved in self-splicing of class II catalytic introns. Cold Spring Harb Symp Quant Biol, 52, 201-212. 
$\mathbf{N}$

Nagai, K. and Mattaj, I.W. (1994) RNA-Protein interactions (Nagai, K. and Mattaj, I.W., eds), pp. 150-177, Oxford University Press, Oxford

Nagase, T., Ishikawa, K., Suyama, M., Kikuno, R., Miyajima, N., Tanaka, A., Kotani, H., Nomura, N. and Ohara, O. (1998) Prediction of the coding sequences of unidentified human genes. XI. The complete sequences of 100 new cDNA clones from brain which code for large proteins in vitro. DNA Res, $\mathbf{5}$, 277-286.

Nelissen, R.L., Will, C.L., van Venrooij, W.J. and Lührmann, R. (1994) The association of the U1-specific $70 \mathrm{~K}$ and $\mathrm{C}$ proteins with $\mathrm{U} 1$ snRNPs is mediated in part by common U snRNP proteins. EMBO J, 13, 4113-4125.

Neubauer, G., King, A., Rappsilber, J., Calvio, C., Watson, M., Ajuh, P., Sleeman, J., Lamond, A. and Mann, M. (1998) Mass spectrometry and ESTdatabase searching allows characterization of the multi-protein spliceosome complex. Nat Genet, 20, 46-50.

Nishikimi, A., Mukai, J., Kioka, N. and Yamada, M. (1999) A novel mammalian nuclear protein similar to Schizosaccharomyces pombe Prp1p/Zer1p and Saccharomyces cerevisiae Prp6p pre-mRNA splicing factors. Biochim Biophys Acta, 1435, 147-152.

Nishizawa, K., Freund, C., Li, J., Wagner, G. and Reinherz, E.L. (1998) Identification of a proline-binding motif regulating CD2-triggered $\mathrm{T}$ lymphocyte activation. Proc Natl Acad Sci U S A, 95, 14897-14902.

Nomura, N., Miyajima, N., Sazuka, T., Tanaka, A., Kawarabayasi, Y., Sato, S., Nagase, T., Seki, N., Ishikawa, K. and Tabata, S. (1994) Prediction of the coding sequences of unidentified human genes. I. The coding sequences of 40 new genes (KIAA0001-KIAA0040) deduced by analysis of randomly sampled cDNA clones from human immature myeloid cell line KG-1. DNA Res, 1, 27-35.

Nottrott, S., Hartmuth, K., Fabrizio, P., Urlaub, H., Vidovic, I., Ficner, R. and Lührmann, R. (1999) Functional interaction of a novel 15.5kD [U4/U6.U5] trisnRNP protein with the $5^{\prime}$ 'stem-loop of U4 snRNA. EMBO J, 18, 6119-6133.

Nottrott, S., Urlaub, H. and Lührmann, R. (2002) Hierarchical, clustered protein interactions with U4/U6 snRNA: a biochemical role for U4/U6 proteins. EMBO J, 21, 5527-5538.

O

O'Keefe, R.T., Norman, C. and Newman, A.J. (1996) The invariant U5 snRNA loop 1 sequence is dispensable for the first catalytic step of pre-mRNA splicing in yeast. Cell, 86, 679-689.

Oubridge, C., Ito, N., Evans, P.R., Teo, C.H. and Nagai, K. (1994) Crystal structure at $1.92 \mathrm{~A}$ resolution of the RNA-binding domain of the U1A spliceosomal protein complexed with an RNA hairpin. Nature, 372, 432-438. 
$\mathbf{P}$

Padgett, R.A. and Shukla, G.C. (2002) A revised model for U4atac/U6atac snRNA base pairing. RNA, 8, 125-128.

Patel, A.A. and Steitz, J.A. (2003) Splicing double: insights from the second spliceosome. Nat Rev Mol Cell Biol, 4, 960-970.

Ponting, C.P. (2000) Proteins of the endoplasmic-reticulum-associated degradation pathway: domain detection and function prediction. Biochem J, 351 Pt 2, 527-535.

Preker, P.J. and Keller, W. (1998) The HAT helix, a repetitive motif implicated in RNA processing. Trends Biochem Sci, 23, 15-16.

Q

Query, C.C. and Konarska, M.M. (2004) Suppression of multiple substrate mutations by spliceosomal prp8 alleles suggests functional correlations with ribosomal ambiguity mutants. Mol Cell, 14, 343-354.

Query, C.C., Strobel, S.A. and Sharp, P.A. (1996) Three recognition events at the branch-site adenine. EMBO J, 15, 1392-1402.

$\mathbf{R}$

Rader, S.D. and Guthrie, C. (2002) A conserved Lsm-interaction motif in Prp24 required for efficient U4/U6 di-snRNP formation. RNA, 8, 1378-1392.

Raghunathan, P.L. and Guthrie, C. (1998) RNA unwinding in U4/U6 snRNPs requires ATP hydrolysis and the DElH-box splicing factor Brr2. Curr Biol, 8, 847-855.

Raker, V.A., Hartmuth, K., Kastner, B. and Lührmann, R. (1999) Spliceosomal $\mathrm{U}$ snRNP core assembly: Sm proteins assemble onto an Sm site RNA nonanucleotide in a specific and thermodynamically stable manner. Mol Cell Biol, 19, 6554-6565.

Rappsilber, J., Ajuh, P., Lamond, A.I. and Mann, M. (2001) SPF30 is an essential human splicing factor required for assembly of the U4/U5/U6 tri-small nuclear ribonucleoprotein into the spliceosome. J Biol Chem, 276, 31142-31150.

Reidt, U., Reuter, K., Achsel, T., Ingelfinger, D., Lührmann, R. and Ficner, R. (2000) Crystal structure of the human U4/U6 small nuclear ribonucleoprotein particle-specific SnuCyp-20, a nuclear cyclophilin. J Biol Chem, 275, 7439-7442.

Reidt, U., Wahl, M.C., Fasshauer, D., Horowitz, D.S., Lührmann, R. and Ficner, R. (2003) Crystal structure of a complex between human spliceosomal cyclophilin $\mathrm{H}$ and a U4/U6 snRNP-60K peptide. J Mol Biol, 331, 45-56. 
Reuter, K. and Ficner, R. (1999) Overproduction, purification, crystallization and preliminary $\mathrm{x}$-ray diffraction studies of the human spliceosomal protein U5-15kD. Acta Crystallogr D Biol Crystallogr, 55 ( Pt 4), 888-890.

Reuter, K., Nottrott, S., Fabrizio, P., Lührmann, R. and Ficner, R. (1999) Identification, characterization and crystal structure analysis of the human spliceosomal U5 snRNP-specific 15 kD protein. J Mol Biol, 294, 515-525.

Reyes, J.L., Gustafson, E.H., Luo, H.R., Moore, M.J. and Konarska, M.M. (1999) The C-terminal region of hPrp8 interacts with the conserved GU dinucleotide at the 5 ' splice site. RNA, 5, 167-179.

Rhode, B.M., Hartmuth, K., Urlaub, H. and Lührmann, R. (2003) Analysis of site-specific protein-RNA cross-links in isolated RNP complexes, combining affinity selection and mass spectrometry. RNA, 9, 1542-1551.

Roscigno, R.F. and Garcia-Blanco, M.A. (1995) SR proteins escort the U4/U6.U5 tri-snRNP to the spliceosome. RNA, 1, 692-706.

Ruby, S.W. and Abelson, J. (1991) Pre-mRNA splicing in yeast. Trends Genet, 7, 79-85.

S

Schaffert, N., Hossbach, M., Heintzmann, R., Achsel, T. and Lührmann, R. (2004) RNAi knockdown of hPrp31 leads to an accumulation of U4/U6 disnRNPs in Cajal bodies. EMBO J, 23, 3000-3009.

Schneider, C., Will, C.L., Makarova, O.V., Makarov, E.M. and Lührmann, R. (2002) Human U4/U6.U5 and U4atac/U6atac.U5 tri-snRNPs exhibit similar protein compositions. Mol Cell Biol, 22, 3219-3229.

Schneider, S., Campodonico, E. and Schwer, B. (2004) Motifs IV and V in the DEAH box splicing factor Prp22 are important for RNA unwinding, and helicasedefective Prp22 mutants are suppressed by Prp8. J Biol Chem, 279, 8617-8626.

Schwer, B. (2001) A new twist on RNA helicases: DExH/D box proteins as RNPases. Nat Struct Biol, 8, 113-116.

Seraphin, B. (1995) Sm and Sm-like proteins belong to a large family: identification of proteins of the U6 as well as the U1, U2, U4 and U5 snRNPs. EMBO J, 14, 2089-2098.

Sharp, P.A. (1987) Splicing of messenger RNA precursors. Science, 235, 766771.

Siatecka, M., Reyes, J.L. and Konarska, M.M. (1999) Functional interactions of Prp8 with both splice sites at the spliceosomal catalytic center. Genes Dev, 13, 1983-1993. 
Singh, R. and Reddy, R. (1989) Gamma-monomethyl phosphate: a cap structure in spliceosomal U6 small nuclear RNA. Proc Natl Acad Sci U S A, 86, 8280-8283.

Staknis, D. and Reed, R. (1994) Direct interactions between pre-mRNA and six U2 small nuclear ribonucleoproteins during spliceosome assembly. Mol Cell Biol, 14, 2994-3005.

Staley, J.P. and Guthrie, C. (1999) An RNA switch at the 5' splice site requires ATP and the DEAD box protein Prp28p. Mol Cell, 3, 55-64.

Stark, H., Dube, P., Lührmann, R. and Kastner, B. (2001) Arrangement of RNA and proteins in the spliceosomal U1 small nuclear ribonucleoprotein particle. Nature, 409, 539-542.

Stevens, S.W. and Abelson, J. (1999) Purification of the yeast U4/U6.U5 small nuclear ribonucleoprotein particle and identification of its proteins. Proc Natl Acad Sci U S A, 96, 7226-7231.

Stevens, S.W., Barta, I., Ge, H.Y., Moore, R.E., Young, M.K., Lee, T.D. and Abelson, J. (2001) Biochemical and genetic analyses of the U5, U6, and U4/U6 $\mathrm{x}$ U5 small nuclear ribonucleoproteins from Saccharomyces cerevisiae. RNA, 7, 1543-1553.

Szymczyna, B.R., Bowman, J., McCracken, S., Pineda-Lucena, A., Lu, Y., Cox, B., Lambermon, M., Graveley, B.R., Arrowsmith, C.H. and Blencowe, B.J. (2003) Structure and function of the PWI motif: a novel nucleic acid-binding domain that facilitates pre-mRNA processing. Genes Dev, 17, 461-475.

T

Tang, J., Abovich, N. and Rosbash, M. (1996) Identification and characterization of a yeast gene encoding the U2 small nuclear ribonucleoprotein particle B" protein. Mol Cell Biol, 16, 2787-2795.

Tanner, N.K. and Linder, P. (2001) DExD/H box RNA helicases: from generic motors to specific dissociation functions. Mol Cell, 8, 251-262.

Tarn, W.Y. and Steitz, J.A. (1996a) A novel spliceosome containing U11, U12, and U5 snRNPs excises a minor class (AT-AC) intron in vitro. Cell, 84, 801-811.

Tarn, W.Y. and Steitz, J.A. (1996b) Highly diverged U4 and U6 small nuclear RNAs required for splicing rare AT-AC introns. Science, 273, 1824-1832.

Teigelkamp, S., Achsel, T., Mundt, C., Gothel, S.F., Cronshagen, U., Lane, W.S., Marahiel, M. and Lührmann, R. (1998) The 20kD protein of human [U4/U6.U5] tri-snRNPs is a novel cyclophilin that forms a complex with the U4/U6-specific 60kD and 90kD proteins. RNA, 4, 127-141. 
Teigelkamp, S., Mundt, C., Achsel, T., Will, C.L. and Lührmann, R. (1997) The human U5 snRNP-specific 100-kD protein is an RS domain-containing, putative RNA helicase with significant homology to the yeast splicing factor Prp28p. RNA, 3, 1313-1326.

Teigelkamp, S., Newman, A.J. and Beggs, J.D. (1995) Extensive interactions of PRP8 protein with the $5^{\prime}$ and $3^{\prime}$ splice sites during splicing suggest a role in stabilization of exon alignment by U5 snRNA. EMBO J, 14, 2602-2612.

Teigelkamp, S., Whittaker, E. and Beggs, J.D. (1995) Interaction of the yeast splicing factor PRP8 with substrate RNA during both steps of splicing. Nucleic Acids Res, 23, 320-326.

Terns, M.P., Dahlberg, J.E. and Lund, E. (1993) Multiple cis-acting signals for export of pre-U1 snRNA from the nucleus. Genes Dev, 7, 1898-1908.

Turner, I.A., Norman, C.M., Churcher, M.J. and Newman, A.J. (2004) Roles of the U5 snRNP in spliceosome dynamics and catalysis. Biochem Soc Trans, 32, 928-931.

U

Umen, J.G. and Guthrie, C. (1995) Prp16p, Slu7p, and Prp8p interact with the 3' splice site in two distinct stages during the second catalytic step of pre-mRNA splicing. RNA, 1, 584-597.

\section{V}

Valadkhan, S. and Manley, J.L. (2001) Splicing-related catalysis by protein-free snRNAs. Nature, 413, 701-707.

Vankan, P., McGuigan, C. and Mattaj, I.W. (1990) Domains of U4 and U6 snRNAs required for snRNP assembly and splicing complementation in Xenopus oocytes. EMBO J, 9, 3397-3404.

van Nues, R.W. and Beggs, J.D. (2001) Functional contacts with a range of splicing proteins suggest a central role for Brr2p in the dynamic control of the order of events in spliceosomes of Saccharomyces cerevisiae. Genetics, 157, 1451-1467.

van Venrooij, W.J. (1987) Autoantibodies against small nuclear ribonucleoprotein components. J Rheumatol Suppl, 14 Suppl 13, 78-82.

Vidal, V.P., Verdone, L., Mayes, A.E. and Beggs, J.D. (1999) Characterization of U6 snRNA-protein interactions. RNA, 5, 1470-1481.

Vidovic, I., Nottrott, S., Hartmuth, K., Lührmann, R. and Ficner, R. (2000) Crystal structure of the spliceosomal $15.5 \mathrm{kD}$ protein bound to a U4 snRNA fragment. Mol Cell, 6, 1331-1342. 
Villa, T., Pleiss, J.A. and Guthrie, C. (2002) Spliceosomal snRNAs: Mg(2+)dependent chemistry at the catalytic core? Cell, 109, 149-152.

Vithana, E.N., Abu-Safieh, L., Allen, M.J., Carey, A., Papaioannou, M., Chakarova, C., Al-Maghtheh, M., Ebenezer, N.D., Willis, C., Moore, A.T., Bird, A.C., Hunt, D.M. and Bhattacharya, S.S. (2001) A human homolog of yeast premRNA splicing gene, PRP31, underlies autosomal dominant retinitis pigmentosa on chromosome 19q13.4 (RP11). Mol Cell, 8, 375-381.

\section{W}

Wang, A., Forman-Kay, J., Luo, Y., Luo, M., Chow, Y.H., Plumb, J., Friesen, J.D., Tsui, L.C., Heng, H.H., Woolford, J.L., Jr. and Hu, J. (1997) Identification and characterization of human genes encoding Hprp3p and Hprp4p, interacting components of the spliceosome. Hum Mol Genet, 6, 2117-2126.

Wang, Q. and Rymond, B.C. (2003) Rds3p is required for stable U2 snRNP recruitment to the splicing apparatus. Mol Cell Biol, 23, 7339-7349.

Watkins, N.J., Dickmanns, A. and Lührmann, R. (2002) Conserved stem II of the box C/D motif is essential for nucleolar localization and is required, along with the $15.5 \mathrm{~K}$ protein, for the hierarchical assembly of the box C/D snoRNP. Mol Cell Biol, 22, 8342-8352.

Watkins, N.J., Segault, V., Charpentier, B., Nottrott, S., Fabrizio, P., Bachi, A., Wilm, M., Rosbash, M., Branlant, C. and Lührmann, R. (2000) A common core RNP structure shared between the small nucleoar box C/D RNPs and the spliceosomal U4 snRNP. Cell, 103, 457-466.

Weidenhammer, E.M., Ruiz-Noriega, M. and Woolford, J.L., Jr. (1997) Prp31p promotes the association of the U4/U6 x U5 tri-snRNP with prespliceosomes to form spliceosomes in Saccharomyces cerevisiae. Mol Cell Biol, 17, 3580-3588.

Wells, S.E., Neville, M., Haynes, M., Wang, J., Igel, H. and Ares, M., Jr. (1996) CUS1, a suppressor of cold-sensitive U2 snRNA mutations, is a novel yeast splicing factor homologous to human SAP 145. Genes Dev, 10, 220-232.

Will, C.L. and Lührmann, R. (1997) Protein functions in pre-mRNA splicing. Curr Opin Cell Biol, 9, 320-328.

Will, C.L. and Lührmann, R. (2001) Spliceosomal UsnRNP biogenesis, structure and function. Curr Opin Cell Biol, 13, 290-301.

Will, C.L., Schneider, C., Reed, R. and Lührmann, R. (1999) Identification of both shared and distinct proteins in the major and minor spliceosomes. Science, 284, 2003-2005.

Will, C.L., Urlaub, H., Achsel, T., Gentzel, M., Wilm, M. and Lührmann, R. (2002) Characterization of novel SF3b and 17S U2 snRNP proteins, including a human Prp5p homologue and an SF3b DEAD-box protein. EMBO J, 21, 4978-4988. 
Willer, M., Jermy, A.J., Young, B.P. and Stirling, C.J. (2003) Identification of novel protein-protein interactions at the cytosolic surface of the Sec63 complex in the yeast ER membrane. Yeast, 20, 133-148.

Wyatt, J.R., Sontheimer, E.J. and Steitz, J.A. (1992) Site-specific cross-linking of mammalian U5 snRNP to the 5 ' splice site before the first step of pre-mRNA splicing. Genes Dev, 6, 2542-2553.

\section{$\mathbf{Y}$}

Yean, S.L., Wuenschell, G., Termini, J. and Lin, R.J. (2000) Metal-ion coordination by U6 small nuclear RNA contributes to catalysis in the spliceosome. Nature, 408, 881-884.

\section{$\mathbf{Z}$}

Zhang, K., Smouse, D. and Perrimon, N. (1991) The crooked neck gene of Drosophila contains a motif found in a family of yeast cell cycle genes. Genes Dev, 5, 1080-1091.

Zieve, G.W. and Sauterer, R.A. (1990) Cell biology of the snRNP particles. Crit Rev Biochem Mol Biol, 25, 1-46. 


\section{Appendix}

\subsection{Abbreviations}

$\begin{array}{ll}\text { aa } & \text { amino acid } \\ \text { Ab } & \text { antibody } \\ \text { BLAST } & \text { Basic Local Alignment Search Tool } \\ \text { bp } & \text { base pair } \\ \text { ß-gal } & \text { ß-galactosidase } \\ \text { CDNA } & \text { complementary DNA } \\ \text { CSM } & \text { Complete Supplement Mixture } \\ \text { DMSO } & \text { dimethyl sulfoxide } \\ \text { DNA } & \text { deoxyribonucleic acid } \\ \text { DOB } & \text { Dropout Base medium } \\ \text { DOBA } & \text { Dropout Base with Agar } \\ \text { DTT } & \text { dithiothreitol } \\ \text { EDTA } & \text { ethylene-diamine-tetraacidic acid } \\ \text { EtBr } & \text { ethidium bromide } \\ \text { GST } & \text { glutathione S-transferase } \\ \text { HEPES } & \text { N-2-hydroxyethylpiperazine-N'-2-ethanesulfonic acid } \\ \text { kb } & \text { kilobases } \\ \text { kDa } & \text { kiloDalton } \\ \text { LB } & \text { Luria Bertani medium } \\ \text { MCS } & \text { multiple cloning site } \\ \text { mRNA } & \text { messenger RNA } \\ \text { MW } & \text { molecular weight } \\ \text { NP-40 } & \text { Nonidet P-40 } \\ \text { OD } & \text { optical density } \\ \text { Oligo } & \text { oligonucleotide } \\ \text { ORF } & \text { open reading frame } \\ \text { PAGE } & \text { polyacrylamide gel electrophoresis } \\ \text { PBS } & \text { phosphate-buffered saline } \\ \text { PCR } & \text { polymerase chain reaction } \\ \text { RBD } & \text { RNA-binding domain } \\ \text { rpm } & \text { revolutions per minute } \\ \text { RNA } & \text { ribonucleic acid } \\ \text { SD } & \text { Synthetic Defined medium } \\ \text { snRNP } & \text { small nuclear ribonucleoprotein particle } \\ \text { TBS } & \text { Tris-buffered saline } \\ \text { UV } & \text { ultraviolet } \\ \text { Y2H } & \text { yeast two-hybrid } \\ \text { YPD } & \text { yeast peptone dextrose medium } \\ & \end{array}$




\section{Amino acids}

$\begin{array}{llllll}\text { A } & \text { Ala } & \text { Alanine } & \text { L } & \text { Leu } & \text { Leucine } \\ \text { R } & \text { Arg } & \text { Arginine } & \text { K } & \text { Lys } & \text { Lysine } \\ \text { N } & \text { Asn } & \text { Asparagine } & \text { M } & \text { Met } & \text { Methionine } \\ \text { D } & \text { Asp } & \text { Aspartic acid } & \text { F } & \text { Phe } & \text { Phenylalanine } \\ \text { C } & \text { Cys } & \text { Cysteine } & \text { P } & \text { Pro } & \text { Proline } \\ \text { Q } & \text { Gln } & \text { Glutamine } & \text { S } & \text { Ser } & \text { Serine } \\ \text { E } & \text { Glu } & \text { Glutamic acid } & \text { T } & \text { Thr } & \text { Threonine } \\ \text { G } & \text { Gly } & \text { Glycine } & \text { W } & \text { Trp } & \text { Tryptophan } \\ \text { H } & \text { His } & \text { Histidine } & \text { Y } & \text { Tyr } & \text { Tyrosine } \\ \text { I } & \text { Ile } & \text { Isoleucine } & \text { V } & \text { Val } & \text { Valine }\end{array}$




\section{2 pGADT7 map and MCS}

(from Clontech)

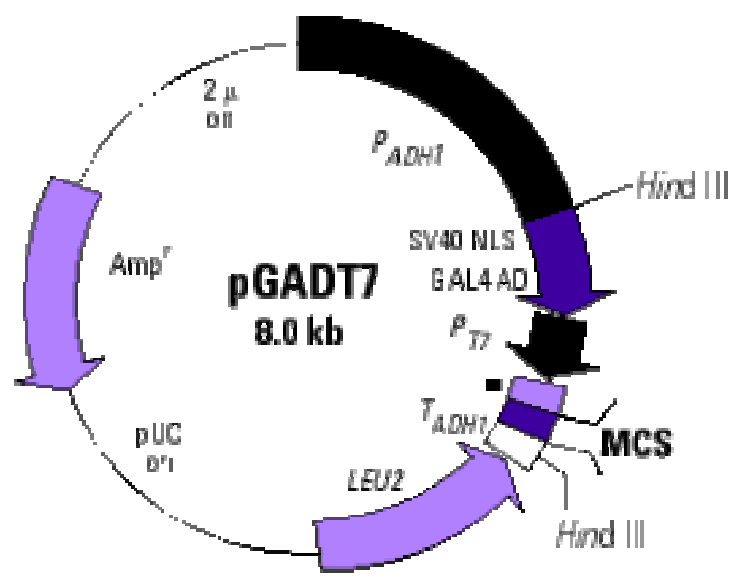

- HA epitope tag

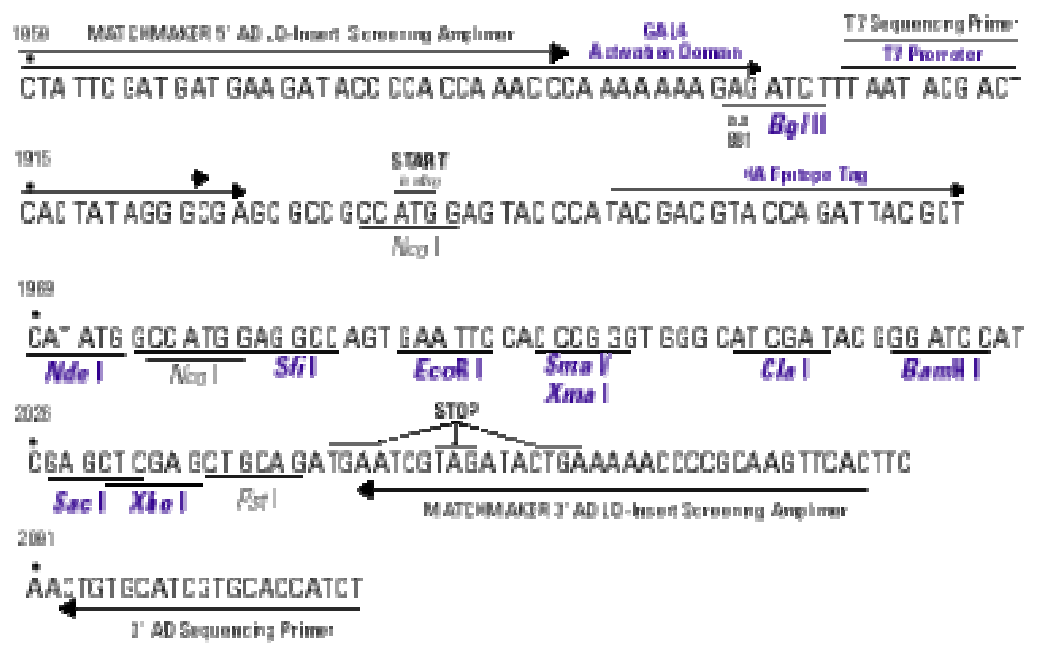




\section{3 pGBKT7 map and MCS}

(from Clontech)

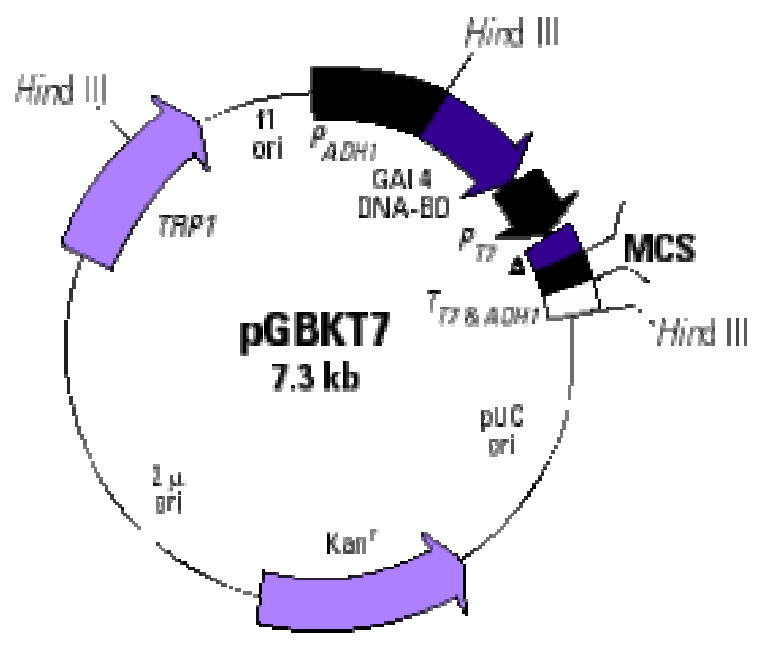

A c-Myc epitope tag

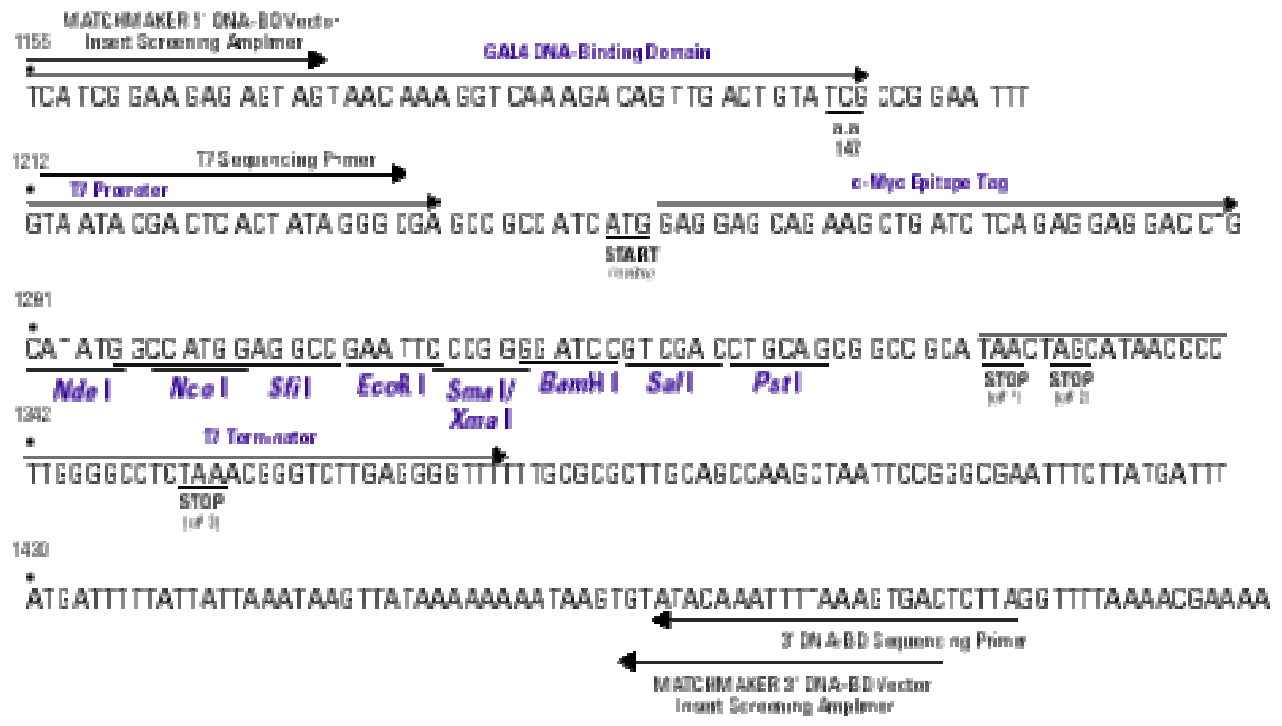




\section{4 cDNA sequence of U5-220K (ORF)}

1 ATGGCCGGAGTGTTTCCTTATCGAGGGCCGGGTAACCCGGTGCCTGGCCCTCTAGCCCCG

61 CTACCGGACTACATGTCGGAGGAGAAGCTGCAGGAGAAAGCTCGAAAATGGCAGCAATTG

121

181

241

301

361

421

481

541

601

661

721

781

841

901

961

1021

1081

1141

1201

1261

1321

1381

1441

1501

1561

1621

1681

1741

1801

1861

1921

1981

2041

2101

2161

2221

2281

2341

2401

2461

2521

2581

2641

2701

2761

2821

2881

2941

3001

3061

3121

3181

3241

3301

3361

3421

3481

3541
CAGGCCAAGCGCTATGCAGAAAAGCGGAAGTTTGGGTTTGTGGATGCCCAGAAGGAAGAC ATGCCCCCAGAACATGTCAGGAAGATCATTCGAGACCATGGAGACATGACCAACAGGAAG TTCCGCCATGACAAAAGGGTTTACTTGGGTGCCCTAAAGTACATGCCCCACGCAGTCCTC AAACTCCTGGAGAACATGCCTATGCCTTGGGAGCAGATTCGGGATGTGCCTGTGCTGTAC CACATCACTGGAGCCATTTCCTTCGTCAATGAGATTCCCTGGGTCATTGAACCTGTCTAC ATCTCCCAGTGGGGGTCAATGTGGATTATGATGCGCCGAGAAAAAAGAGATAGGAGGCAT TTCAAGAGGATGCGTTTTCCCCCTTTTGATGATGAGGAGCCGCCCTTGGACTATGCTGAC AACATCCTAGATGTTGAGCCACTGGAGGCCATTCAGCTAGAGCTGGACCCTGAGGAGGAC GCCCCTGTGTTGGACTGGTTCTATGACCACCAGCCGTTGAGGGACAGCAGGAAGTATGTA AATGACTCCACTTACCAGCGCTGGCAGTTCACACTACCTATGATGTCGACTCTCTACCGC CTGGCTAATCAGCTCCTGACAGACTTGGTGGATGACAACTACTTCTACCTGTTTGATTTG AAGGCCTTCTTTACGTCCAAGGCACTCAATATGGCCATTCCTGGAGGCCCCAAATTTGAA CCTCTTGTTCGAGACATCAACCTACAGGATGAAGACTGGAATGAATTCAATGATATTAAC AAGATTATCATCCGGCAGCCTATCCGCACTGAGTACAAGATTGCTTTTCCTTACTTGTAC AACAATCTTCCACACCATGTCCACCTCACCTGGTACCATACTCCCAATGTTGTATTCATC AAAACTGAGGATCCTGACTTGCCAGCTTTCTACTTTGACCCTTTGATCAACCCAATCTCC CATAGGCACTCAGTCAAGAGCCAGGAACCATTGCCGGATGATGATGAGGAATTTGAGCTC CCGGAGTTTGTGGAGCCCTTCCTGAAGGACACACCCCTCTATACAGACAATACAGCCAAT GGCATTGCCCTGCTCTGGGCCCCGCGGCCCTTCAACCTACGCTCTGGTCGCACCCGTCGG GCCCTGGACATACCCCTTGTCAAGAACTGGTATCGGGAGCATTGTCCTGCCGGGCAGCCT GTGAAAGTGAGGGTCTCCTACCAGAAGCTGCTTAAGTACTATGTGCTGAATGCCCTGAAG CATCGGCCCCCTAAGGCTCAAAAGAAGAGGTATTTGTTCCGCTCCTTCAAAGCCACCAAA TTCTTTCAGTCCACAAAGCTGGACTGGGTGGAGGTTGGGCTCCAGGTTTGCCGCCAGGGC TACAACATGCTCAACCTTCTCATTCACCGCAAAAACCTCAACTACCTGCACCTGGACTAC AACTTCAACCTCAAGCCTGTGAAAACGCTCACCACCAAGGAAAGAAAGAAATCTCGTTTT GGGAATGCTTTCCACCTGTGTCGGGAAGTTCTGCGTTTGACTAAGCTGGTGGTGGATAGT CACGTGCAGTATCGGCTGGGCAATGTGGATGCCTTCCAGCTGGCAGATGGATTGCAGTAT ATATTTGCCCATGTTGGGCAGTTGACGGGCATGTATCGATACAAATACAAGCTGATGCGA CAGATTCGCATGTGCAAGGACCTGAAGCATCTCATCTATTATCGTTTCAACACGGGCCCT GTAGGGAAGGGTCCTGGCTGTGGCTTCTGGGCTGCCGGTTGGCGAGTCTGGCTCTTTTTC ATGCGTGGCATTACCCCTTTATTAGAGCGATGGCTTGGCAACCTCCTGGCCCGGCAGTTT GAAGGTCGACACTCAAAGGGGGTGGCAAAGACAGTAACAAAGCAGCGAGTGGAGTCACAT TTTGACCTTGAGCTGCGGGCAGCTGTGATGCATGATATTCTGGACATGATGCCTGAGGGG ATCAAGCAGAACAAGGCCCGGACAATCCTGCAGCACCTCAGTGAAGCCTGGCGCTGCTGG AAAGCCAACATTCCCTGGAAGGTCCCTGGGCTGCCGACGCCCATAGAGAATATGATCCTT CGATACGTGAAGGCCAAGGCTGACTGGTGGACCAACACTGCCCACTACAACCGAGAACGG ATCCGCCGAGGGGCCACTGTGGACAAGACTGTTTGTAAAAAGAATCTGGGCCGCCTCACC CGGCTCTATCTGAAGGCAGAACAGGAGCGGCAGCACAACTACCTGAAGGACGGGCCTTAC ATCACAGCGGAGGAAGCAGTGGCAGTATATACCACCACAGTGCATTGGTTGGAAAGCCGC AGGTTTTCACCCATCCCATTCCCCCCACTCTCCTATAAGCATGACACCAAGTTGCTCATC TTGGCATTGGAGCGGCTCAAGGAAGCTTATAGTGTGAAGTCTCGGTTGAACCAGTCTCAG AGGGAGGAGCTAGGTCTGATCGAGCAGGCCTACGATAACCCCCACGAGGCGCTGTCCCGC ATCAAGCGTCACCTCCTCACACAGAGAGCCTTCAAAGAGGTGGGCATTGAGTTCATGGAT CTGTATAGCCACCTCGTTCCAGTATATGATGTTGAGCCCCTGGAGAAGATAACTGATGCT TACCTGGACCAGTACCTGTGGTATGAAGCCGACAAGCGCCGCCTGTTCCCACCCTGGATT AAGCCTGCAGACACAGAACCACCTCCGCTGCTTGTTTACAAGTGGTGTCAAGGCATCAAT AACCTGCAGGACGTGTGGGAGACGAGTGAAGGCGAGTGCAATGTCATGCTGGAATCCCGC TTTGAGAAGATGTATGAGAAGATCGACTTGACTCTGCTCAACAGGCTGCTGCGCCTCATC GTGGACCACAACATAGCCGACTACATGACAGCCAAGAACAACGTCGTCATCAACTATAAG GACATGAACCATACGAATTCATATGGGATCATCAGAGGCCTGCAGTTTGCCTCATTCATC GTGCAGTATTATGGCCTGGTGATGGATTTGCTTGTATTGGGATTGCACCGGGCCAGTGAG ATGGCTGGGCCCCCTCAGATGCCAAATGACTTTCTCAGTTTCCAGGACATAGCCACTGAG GCTGCCCACCCCATCCGTCTCTTCTGCAGATACATTGATCGCATCCATATTTTTTTCAGG TTCACAGCAGATGAGGCTCGGGACCTGATTCAACGTTACCTGACAGAGCACCCTGACCCC AATAATGAAAACATCGTTGGCTATAATAACAAGAAGTGCTGGCCCCGAGATGCCCGCATG CGCCTCATGAAACATGATGTTAACTTAGGCCGGGCGGTATTCTGGGACATCAAGAACCGC TTGCCACGGTCAGTGACTACAGTTCAGTGGGAGAACAGCTTCGTGTCTGTGTACAGTAAG GACAACCCCAACCTGCTGTTCAACATGTGTGGCTTCGAGTGCCGCATCCTGCCTAAGTGC 
3601

3661

3721

3781

3841

3901

3961

4021

4081

4141

4201

4261

4321

4381

4441

4501

4561

4621

4681

4741

4801

4861

4921

4981

5041

5101

5161

5221

5281

5341

5401

5461

5521

5581

5641

5701

5761

5821

5881

5941

6001

6061

6121

6181

6241

6301

6361

6421

6481

6541

6601

6661

6721

6781

6841

6901

6961
CGCACCAGCTATGAGGAGTTCACCCACAAGGACGGGGTCTGGAACCTGCAGAATGAGGTT ACTAAGGAGCGCACAGCTCAGTGTTTCCTGCGTGTGGACGATGAGTCAATGCAGCGCTTC CACAACCGCGTGCGTCAGATTCTCATGGCCTCTGGGTCCACCACCTTCACCAAGATTGTG AATAAGTGGAATACAGCTCTCATTGGCCTTATGACATACTTTCGGGAGGCTGTGGTGAAC ACCCAAGAGCTCTTGGACTTACTGGTGAAGTGTGAGAACAAAATCCAGACACGTATCAAG ATTGGACTCAACTCCAAGATGCCAAGTCGGTTCCCCCCGGTTGTGTTCTACACCCCTAAG GAGTTGGGTGGACTCGGCATGCTCTCAATGGGCCATGTGCTCATCCCCCAATCCGACCTC AGGTGGTCCAAACAGACAGATGTAGGTATCACACACTTTCGTTCAGGAATGAGCCATGAA GAAGACCAGCTCATTCCCAACTTGTACCGCTACATACAGCCATGGGAGAGCGAGTTCATT GATTCTCAGCGGGTCTGGGCTGAGTACGCACTCAAGAGGCAAGAGGCCATTGCTCAGAAC AGACGCCTGACTTTAGAAGACCTAGAAGATTCATGGGATCGTGGCATTCCTCGAATCAAT ACCCTCTTCCAGAAGGACCGGCACACACTGGCTTATGATAAGGGCTGGCGTGTCAGAACT GACTTTAAGCAGTATCAGGTTTTGAAGCAGAATCCGTTCTGGTGGACACACCAGCGGCAT GATGGGAAGCTCTGGAACCTGAACAACTACCGTACAGACATGATCCAGGCCCTGGGCGGT GTGGAAGGCATTCTGGAACACACACTCTTTAAGGGCACTTACTTCCCTACCTGGGAGGGG CTTTTCTGGGAGAAGGCCAGTGGCTTTGAGGAATCTATGAAGTGGAAGAAGCTAACTAAT GCTCAGCGATCAGGACTGAACCAGATTCCCAATCGTAGATTCACCCTCTGGTGGTCCCCG ACCATTAATCGAGCCAATGTATATGTAGGCTTTCAGGTGCAGCTAGACCTGACGGGTATC TTCATGCACGGCAAGATCCCCACGCTGAAGATCTCTCTCATCCAGATCTTCCGAGCTCAC TTGTGGCAGAAGATCCATGAGAGCATTGTTATGGACTTATGTCAGGTGTTTGACCAGGAA CTTGATGCACTGGAAATTGAGACAGTACAAAAGGAGACAATCCATCCCCGAAAGTCATAT AAGATGAACTCTTCCTGTGCAGATATCCTGCTCTTTGCCTCCTATAAGTGGAATGTCTCC CGGCCCTCATTGCTGGCTGACTCCAAGGATGTGATGGACAGCACCACCACCCAGAAATAC TGGATTGACATCCAGTTGCGCTGGGGGGACTATGATTCCCACGACATTGAGCGCTACGCC CGGGCCAAGTTCCTGGACTACACCACCGACAACATGAGTATCTACCCTTCGCCCACAGGT GTACTCATCGCCATTGACCTGGCCTATAACTTGCACAGTGCCTATGGAAACTGGTTCCCA GGCAGCAAGCCTCTCATACAACAGGCCATGGCCAAGATCATGAAGGCAAACCCTGCCCTG TATGTGTTACGTGAACGGATCCGCAAGGGGCTACAGCTCTATTCATCTGAACCCACTGAG CCTTATTTGTCTTCTCAGAACTATGGTGAGCTCTTCTCCAACCAGATTATCTGGTTTGTG GATGACACCAACGTCTACAGAGTGACTATTCACAAGACCTTTGAAGGGAACTTGACAACC AAGCCCATCAACGGAGCCATCTTCATCTTCAACCCACGCACAGGGCAGCTGTTCCTCAAG ATAATCCACACGTCCGTGTGGGCGGGACAGAAGCGTTTGGGGCAGTTGGCTAAGTGGAAG ACAGCTGAGGAGGTGGCCGCCCTGATCCGATCTCTGCCTGTGGAGGAGCAGCCCAAGCAG ATCATTGTCACCAGGAAGGGCATGCTGGACCCACTGGAGGTGCACTTACTGGACTTCCCC AATATTGTCATCAAAGGATCGGAGCTCCAACTCCCTTTCCAGGCGTGTCTCAAGGTGGAA AAATTCGGGGATCTCATCCTTAAAGCCACTGAGCCCCAGATGGTTCTCTTCAACCTCTAT GACGACTGGCTCAAGACTATTTCATCTTACACGGCCTTCTCCCGTCTCATCCTGATTCTG CGTGCCCTACATGTGAACAACGATCGGGCAAAAGTGATCCTGAAGCCAGACAAGACTACT ATTACAGAACCACACCACATCTGGCCCACTCTGACTGACGAAGAATGGATCAAGGTCGAG GTGCAGCTCAAGGATCTGATCTTGGCTGACTACGGCAAGAAAAACAATGTGAACGTGGCA TCACTGACACAATCAGAAATTCGAGACATCATCCTGGGTATGGAGATCTCGGCACCGTCA CAGCAGCGGCAGCAGATCGCTGAGATCGAGAAGCAGACCAAGGAACAATCGCAGCTGACG GCAACACAGACTCGCACTGTCAACAAGCATGGCGATGAGATCATCACCTCCACCACCAGC AACTATGAGACCCAGACTTTCTCATCCAAGACTGAGTGGAGGGTCAGGGCCATCTCTGCT GCCAACCTGCACCTAAGGACCAATCACATCTATGTTTCATCTGACGACATCAAGGAGACT GGCTACACCTACATCCTTCCCAAGAATGTGCTTAAGAAGTTCATCTGCATATCTGACCTT CGGGCCCAAATTGCAGGATACCTATATGGGGTGAGCCCACCAGATAACCCCCAGGTGAAG GAGATCCGCTGCATTGTGATGGTGCCGCAGTGGGGCACTCACCAGACCGTGCACCTGCCT GGCCAGCTGCCCCAGCATGAGTACCTCAAGGAGATGGAACCCTTAGGTTGGATCCACACT CAGCCCAATGAGTCCCCGCAGTTATCACCCCAGGATGTCACCACCCATGCCAAGATCATG GCTGACAACCCATCTTGGGATGGCGAGAAGACCATTATCATCACATGCAGCTTCACGCCA GGCTCCTGTACACTGACGGCCTACAAGCTGACCCCCAGTGGCTACGAATGGGGCCGCCAG AACACAGACAAGGGCAACAACCCCAAGGGCTACCTGCCTTCACACTATGAGAGGGTGCAG ATGCTGCTGTCGGACCGTTTCCTTGGCTTCTTCATGGTCCCTGCCCAGTCCTCGTGGAAC TACAACTTCATGGGTGTTCGGCATGACCCCAACATGAAATATGAGCTACAGCTGGCGAAC CCCAAAGAGTTCTACCACGAGGTGCACAGGCCCTCTCACTTCCTCAACTTTGCTCTCCTG CAGGAGGGGGAGGTTTACTCTGCGGATCGGGAGGACCTGTATGCCTGA 


\subsection{Curriculum vitae}

\section{PERSONAL DATA}

First name

Family name

Date of birth

Nationality

Marital status

Address
Sunbin

Liu

20. 01.1963

Chinese

Married, with one child

Immanuel-Kant-Str. 34, 37083 Göttingen

\section{EDUCATION}

\begin{tabular}{|c|c|}
\hline $1969-1975$ & Long-Bei Primary School, Pingtan, Fujian \\
\hline $1975-1977$ & Long-Nan School, Pingtan, Fujian \\
\hline $1977-1980$ & Pingtan No. 1 High School, Fujian, graduated in July 1980 \\
\hline $980-1984$ & $\begin{array}{l}\text { Faculty of Biology at the University of Xiamen, Fujian } \\
\text { Received B.Sc. in July } 1984\end{array}$ \\
\hline $999-2005$ & $\begin{array}{l}\text { PhD work under the direction of Prof. Reinhard Lührmann } \\
\text { in the Institute of Molecular Biology and Tumor Research at } \\
\text { the University of Marburg (1999-2000) and } \\
\text { in the Department of Cellular Biochemistry in the Max-Planck- } \\
\text { Institute for Biophysical Chemistry in Göttingen }\end{array}$ \\
\hline
\end{tabular}

\section{WORKING EXPERIENCE}

04. 1997 - 03. 1999 Laboratory of Endocrinology, Clinic of Großhadern, University of München

Gene expression of the IGF-I receptor, IGF-II and

IGF-binding protein in human colon carcinomas

04. 1996 - 03. 1997 Department of Molecular Biology, Max-Planck-Institute for Biochemistry in Martinsried bei München.

Functional study of phosphatase

01.1996 - 03. 1996 Department of Endocrinology \& Reproduction,

Erasmus University Rotterdam in Holland 
(I received a fellowship from the World Health

Organization in Geneva)

Effect of FSH on the expression of leucine-rich primary response gene in primate testis

03. 1995 - 12. 1995 Institute for Reproductive Medicine at the University of Münster (I received a fellowship from the World Health Organization in Geneva) Gene expression of rat LHR and androgen receptor

08. 1984 - 03. 1995 Department of Human Genetics in the National Research Institute for Family Planning in Beijing (World Health Organization Collaborating Centre for Research in Human Reproduction) Environment and Genetics; Chromosome analysis; Male contraception; Spermatogenesis

\section{PUBLICATIONS DURING MY PHD WORK}

Makarova, O.V., Makarov, E.M., Liu, S., Vornlocher, H.P. and Lührmann, R. (2002) Protein 61K, encoded by a gene (PRPF31) linked to autosomal dominant retinitis pigmentosa, is required for U4/U6.U5 tri-snRNP formation and pre-mRNA splicing. EMBO J, 21, 1148-1157.

Medenbach, J., Schreiner, S., Liu, S., Lührmann, R. and Bindereif, A. (2004) Human U4/U6 snRNP recycling factor $\mathrm{p} 110$ : mutational analysis reveals the function of the tetratricopeptide repeat domain in recycling. Mol Cell Biol, 24, 7392-7401.

Laggerbauer, B., Liu, S., Makarov, E., Vornlocher, H.P., Makarova, O., Ingelfinger, D., Achsel, T. and Lührmann R. (2005) The human U5 snRNP 52K protein (CD2BP2) interacts with U5-102K (hPrp6), a U4/U6.U5 tri-snRNP bridging protein, but dissociates upon tri-snRNP formation. RNA, 11, 598-608. 
Nielsen, T.K., Liu, S., Lührmann, R. and Ficner, R. (2005) Structural basis of GYF-domain bifunctionality: the interaction between the proteins $15 \mathrm{~K}$ and $52 \mathrm{~K}$ of the spliceosomal U5 snRNP. In preparation.

Liu, S., Vornlocher, H.P., Rauhut, R. and Lührmann, R. (2005) A network of protein interactions in the human U4/U6.U5 tri-snRNP. In preparation. 